\title{
LOFT SYSTEM STRUCTURAL RESPONSE DURING SUBCOOLED BLOWDOWN
}

JOHN S. MARTINELL 


\section{DISCLAIMER}

This report was prepared as an account of work sponsored by an agency of the United States Government. Neither the United States Government nor any agency Thereof, nor any of their employees, makes any warranty, express or implied, or assumes any legal liability or responsibility for the accuracy, completeness, or usefulness of any information, apparatus, product, or process disclosed, or represents that its use would not infringe privately owned rights. Reference herein to any specific commercial product, process, or service by trade name, trademark, manufacturer, or otherwise does not necessarily constitute or imply its endorsement, recommendation, or favoring by the United States Government or any agency thereof. The views and opinions of authors expressed herein do not necessarily state or reflect those of the United States Government or any agency thereof. 


\section{DISCLAIMER}

Portions of this document may be illegible in electronic image products. Images are produced from the best available original document. 
Printed in the United States of America

$$
\text { Available from }
$$

National Technical Information Service

U.S. Department of Commerce

5285 Port Royal Road

Springfield, Virginia 22161

Price: Printed Copy \$6.50; Microfiche $\$ 3.00$

$$
\text { T. } 25
$$

"The NRC will make available data tapes and operational computer codes on research programs dealing with postulated loss-of-coolant accidents in light water reactors. Persons requesting this information must reimburse the NRC contractors for their expenses in preparing copies of the data tapes and the operational computer codes. Requests should be submitted to the Research Applications Branch, Office of Nuclear Regulatory Research, Nuclear Regulatory Commission, Washington, D.C. 20555."

NOTICE

This report was prepared as an account of work sponsored by the United States Government. Neither the the United States nor the Department of Energy, nor the Nuclear Regulatory Commission, nor any of their employees, nor any of their contractors, subcontractors, or their employees, makes any warranty, express or implied, or assumes any legal liability or responsibility for the accuracy, completeness or usefulness of any information, apparatus, product or process disclosed, or represents that its use would not infringe privately owned rights. 


\section{LOFT SYSTEM STRUCTURAL RESPONSE}

\section{DURING SUBCOOLED BLOWDOWN}

\section{Approved:}

L. P. Leach, Manager

LOFT Experimental Program Division

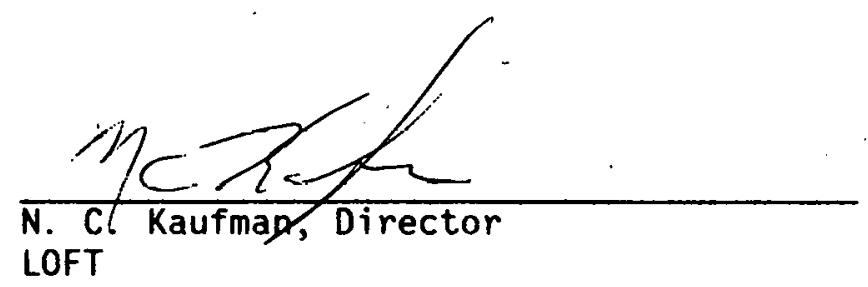

$$
\begin{aligned}
& \text { This report was prepared as an account of work } \\
& \text { sponsored by the United States Govemment. Neither the } \\
& \text { United Stotes nor the United States Department of } \\
& \text { Energy, not any of their employees, nor any of their } \\
& \text { contractors, subcontractors, or their employees, makes } \\
& \text { any warranty, express or implied, or assumes any legal } \\
& \text { llabulliy or responsbuthy for the accuracy, completeness } \\
& \text { or usefulness of any information, apparatus, product or } \\
& \text { process disclosed, or represents that its use would not } \\
& \text { infringe privately owned rights. }
\end{aligned}
$$




\title{
LOFT SYSTEM STRUCTURAL RESPONSE DURING SUBCOOLED BLOWDOWN
}

\author{
By \\ John S. Martine11
}

\begin{abstract}
EG\&G Idaho, Inc.
\end{abstract}
January 1978

\author{
PREPARED FOR THE \\ U.S. NUCLEAR REGULATORY COMMISSION \\ AND \\ DEPARTMENT OF ENERGY \\ IDAHO OPERATIONS OFFICE \\ - UNDER CONTRACT NO. EY-76-C-07-1570
}


Appreciation is expressed to R. C. Guenzler, I. K. Hall, Jr., R. G. Rahl, V. T. Berta, L. D. Goodrich, and the personnel of the Lossof-Fluid Test Data Systems Branch for their special help in preparing this document. 
ABSTRACT

The Loss-of-Fluid Test (LOFT) facility is a highly instrumented, pressurized water reactor test system designed to be representative of large pressurized water reactors. (LPWRs) for the simulation of loss-ofcoolant accidents (LOCAs). Detailed structural analysis and appropriate instrumentation (accelerometers and strain gages) on the LOFT system provided information for evaluation of the structural response of the LOFT facility for loss-of-coolant experiment (LOCE) induced loads. In general, the response of the system during subcooled blowdown was small with typical structural accelerations below $2.0 \mathrm{G}$ 's and dynamic strains less than $150 \times 10^{-6} \mathrm{~m} / \mathrm{m}$. The accelerations measured at the steam generator and simulated steam generator flange exceeded LOCE design values; however, integration of the accelerometer data at these locations yielded displacements which were less than one half of the design values associated with a safe shutdown earthquake (SSE), which assures structural integrity for LOCE loads.

Use of the LOFT structural response data for reactor safety and code qualification is not recommended due to the complexity of the LOFT system and to the problems associated with low amplitude data analysis. The existing measurement system was adequate for evaluation of the LOFT system response during the LOCEs. The conditions affecting blowdown loads during nuclear LOCEs will be nearly the same as those experienced during the nonnuclear LOCES, and the characteristics of the structural response data in both types of experiments are expected to be the same. The LOFT system is concluded to be adequately designed and further analysis of the LOFT system with structural codes is not required for future LOCE experiments. 
SUMMARY

The following subjects are addressed concerning the structural response of the LOFT system during subcooled blowdown.

(1) The LOFT system "structural response relative to (a) the experiment predictions and (b) the LOFT system design.

(2) The quality of the LOFT structural response data and applications for reactor safety, code qualification, and LOFT requalification.

(3) The existing measurement system and recommendations for repositioning and/or addition of new measurements.

(4) Projected changes in structural response data in nuclear LOCEs relative to nonnuclear LOCEs.

(5) The nced for additional analysis of the structural response data and/or LOFT system with structural codes.

The LOFT facility has boen designod to represent the major component and system thermal hydraulic responses of a LPWR during a LOCA. The test assembly includes five major subsystems which have been extensively instrumented. so that desirable system parameters can be measured and recorded during a LOCE. These subsystems were instrumented for structural response measurements for purposes of assurance of the adequacy of the LOFT structural design and requalification only. No attempt was made to instrument for purposes of structural cude verification. The major subsystems include: (a) the reactor vessel, (b) the primary coolant (intact) loop (c) the blowdown (broken) loop, (d) the blowdown suppression system, and (e) the emergency core coolant system. 


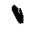

The $L l$ test series (nonnuclear blowdown tests) provided information concerning equipment and system performance, structural adequacy, test procedures, operator experience, and data for experimental verification of thermal-hydraulic system behavior prior to nuclear blowdowns. In particular, Experiments $L 1-2, L 1-3$, and $L 1-3 A$ were used in this analysis for addressing the subjects identified earlier. Structural response data (accelerometer and strain gage data) in the intact and broken loops and reactor vessel were reviewed and analyzed for comparison with predicted and design values to evaluate the system response in these areas. In general, the response of the system to LOCE loads was small -with typical structural accelerations below $2.0 \mathrm{G}$ and dynamic strains less than $150 \times 10^{-6} \mathrm{~m} / \mathrm{m}$. The measured accelerations from Experiment $L 1-3 A$ at the steam generator (AE-PC17-1 and $A E-P C 17-2)$ and the simulated steam generator flange (AE-BL2-1) exceeded the LOCE design values. Quantification of the accelerometer data is highly subjective since accuracy is poor due to the noise level in the measurements. A more detailed analysis of the data at these locations (integration of the acceleration plots) indicated that maximum deflections during subcooled blowdown were less than one half those associated with a safe shutdown earthquake, assuring structural integrity for LOCE loads since the system was designed for combined seismic and LOCA induced loads.

Due to the low magnitude of the LOFT structural response data, quantification for direct comparison with predicted values is of questionable value (strains only slightly larger than accuracy limits and high noise level). Use of the data for reactor safety and code qualification is not recommended due to the system complexity and the problems involved in data reduction and evaluation. The LOFT data are applicable for requalification purposes at LOFT but should not be relied upon solely, due to the problems associated with providing applicable measurements at all points in the system (tees, welds, junctions, etc). The requalification program will include a comprehensive inspection of welds and components on intervals recommended by fatigue analysis. The existing measurement system is deemed adequate for the purposes of evaluating LOFT system structural response, and no recommendations for repositioning or adding new measurements are made here. The data 
associated with nuclear LOCEs should have the same characteristics as the nonnuclear LOCE data since those conditions affecting blowdown loads are nearly the same in either case. Further analysis of the LOFT system with structural codes for LOCE loads is deemed unnecessary.

The horizontal accelerations measured at the top of steam generator (AE-PC17-1 and -2) for nonnuclear LOCEs are two to three times the values predicted by finite element analysis. This difference can, in part, be explained by two techniques used in modeling the structure in the area of the steam generator. First, the snubber supports as modeled are loaded with any incremental deflection, while, in the physical case, a finite amount of displacement at the top of the steam generator is required before the snubbers provide any restraint. Thus, low-amplitude vibration can occur at the top of the steam generator before lateral restraint occurs, for which the existing model can not account. However, as the amplitude of vibration increases, the modeled restraint is a better representation of the physical restraint giving rise to closer agreement between predicted and actual responses. Secondly, the predicted accelerations are for the center of gravity of the steam generator rather than at the top where the measurements were taken. Any rotational motion about a horizontal axis would give rise to higher acceleration at the top of the stealm generator than predicted.

The acceleration measured in the east-west direction at the simulated steam generator flange ( $A E-B L 2-1$ ) exceeds the predicted LOCE value by $17 \%$. This difference is felt to be within the allowable range of accuracy associated with quantifying and comparing the measured data with that predicted using finite element analysis.

Underprediction of the LOCL accelerations at the steam generator could give rise to questions concerning the predicted response for combined LOCA and seismic activity for which the LOFT system is designed. Review of the combined LOCA and seismic analysis of the mobile test assembly reveals that response to those loads is two to three times as severe as that measured during the nonnuclear. LOCEs. Inspection of predicted load data for combined LOCA and seismic activity indicates the 
elastic factor of safety of the steam generator support beams is greater than six. It is felt that this large factor of safety allows the existing structure sufficient margin to accomodate any additional load which may not have been predicted with the existing model. 


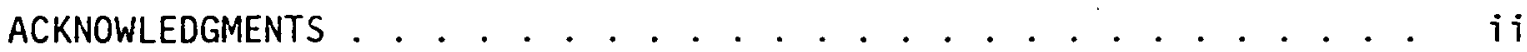

ABSTRACT ............................. . . . . . .

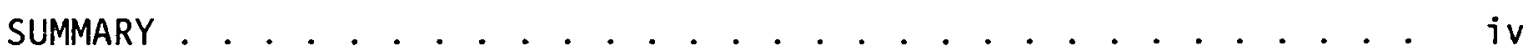

I. INTRODUCTION . . . . . . . . . . . . . . . . .... 1

II. SYSTEM CONFIGURATION . . . . . . . . . . . . 2

III. MEASUREMENTS AND INSTRUMENTATION . . . . . . . . . . 6

IV. EXPERIMENT CONDITIONS. . . . . . . . . . . . . . . . . 13

V. DATA PRESENTATION AND DISCUSSION . . . . . . . . . 15

VI. REFERENCES .................... 106

FIGURES

1. LOFT major components .............. 5

2. Acceleration at simulated steam generator flange, East-West $(A E-B L 2-1) \ldots . . . . . . . .21$

3. Acceleration at simulated steam generator flange, North-South (AE-BL2-2) ............. . . 21

4. Acceleration at simulated steam generator top, vertical $(A E-B[3-1) \ldots . \ldots 22$

5. Acceleration at QOBV, cold leg, North-South $(A E-B L 4-1) \ldots \ldots . \ldots 22$

6. Acceleration at QOBV, hot leg, North-South

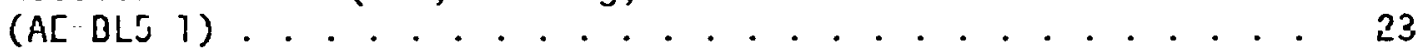

7. Acceleration at 90-degree-elbow downstream of primary coolant pumps, East-West (AE-PC3-1)

8. Acceleration at 90-degree-elbow downstream of primary coolant pumps, North-South (AE-PC3-2) . . . . . . 24

9. Acceleration at 90-degree-elbow downstream of primary coollant pumps, vertical (AE-PC3-3) . . . . . . . .

10. Acceleration at 45 -degree-elbow in intact loop hot

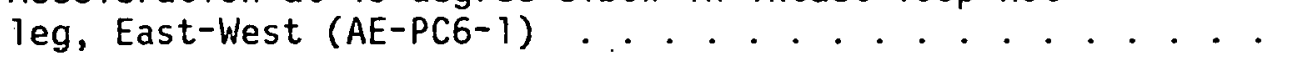


11. Acceleration at 45-degree-elbow in intact loop hot leg, North-South (AE-PC6-2)

12. Acceleration at 45 -degree-elbow in intact loop hot leg, vertical $(\mathrm{AE}-\mathrm{PC}-3)$. . . . . . . . . . . . . . 26

13. Acceleration at 90-degree-elbow in intact loop hot leg, East-West $(\mathrm{AE}-\mathrm{PC} \mathrm{C}-1)$. . . . . . . . . . . . . . 26

14. Acceleration at 90-degree-elbow in intact loop hot leg, North-South $(A E-P C 7-2)$. . . . . . . . . . . .

15. Acceleration at primary coolant pump inlet, East-West (AE-PC16-1)

16. Acceleration at primary coolant pump inlet, North-South (AE-PC16-2)

17. Acceleration at primary coolant pump inlet, vertical (AE-PC 16-3)

18. Acceleration at steam generator north side, East-West (AE-PC17-1)

19. Acceleration at steam generator north side, North-South (AE-PC17-2)

20. Acceleration at primary coolant pump 1 north side, East-West (AE-PC18-1)

21. Acceleration at primary coolant pump 1 north side, North-South (AE-PC18-2)

22. Acceleration at primary coolant pump 1 north side, vertical (AE-PC18-3).

23. Acceleration at primary coolant pump 2 north side, East-West (AE-PC19-1)

24. Acceleration at primary coolant pump 2 north side, North-South (AE-PC19-2)

25. Acceleration at primary coolant pump 2 north side, vertical (AE-PC19-3).

26. Acceleration at bottom of reactor vessel, west side, East-West (AE-RV1-1)

27. Acceleration at bottom of reactor vessel, west side, East-West (AE-RV1-2)

28. Acceleration at bottom of reactor vessel, west side, vertical (AE-RVI-3) 
29. Acceleration at bottom of reactor. vessel, north side, North-South (AE-RVI-4) . . . . . . . . . .

30. Acceleration at bottom of reactor vessel, north side, North-South (AE-RV1-5)

31. Acceleration at bottom of reactor vessel, north side, vertical (AE-RVI-6) . . . . . . . . . . .

32. Strain at reactor vessel broken loop cold leg nozzle (SE-BL8-1)

33. Strain at reactor vessel broken loop cold leg nozzle (SE-BL8-2)

34. Strain at reactor vessel broken loop cold leg nozzle (SE-BL8-3) . . . . . . . . . . . . . ...

35. Strain at reactor vessel broken loop cold leg nuzzle $(S E-B L 8-4)$. . . . . . . . . . . . . . . .

36. Strain at reactor vessel broken loop cold leg nozzle (SE-BL8-5)

37. Strain at reactor vessel broken loop cold leg nozzle (SE-BL8-6)

38. Strain at reactor vessel broken loop cold leg nozzle (SE-BL8-8). . . . . . . . . . . . . . . .

39. Strain at reactor vessel broken loop cold leg no>>le (SF-RL8-9)

40. Strain at reactor vessel broken loop cold leg nozzle (SE-BL8-11).

41. Strain at reactor vessel broken loop cold leg nozzle $(S E-B L 8-12)$. . . . . . . .......

42. Strain at reactor vessel broken loop hot leg nozzle (SE-BLG-1)

43. Strain at reactor vessel broken loop hot leg nozzle (SE-BL9-2)

44. Strain at reactor vessel:broken loop hot leg nozzle (SE-BL9-4)

45. Strain at reactor vessel broken loop höt leg nozzle (SE-BL9-4)

46. Strain at reactor vessel broken loop hot leg nozzle (SE-BL9-5) 
47. Strain at reactor vessel broken loop hot

leg nozzle (SE-BL9-6) . . . . . . . . . . . . . . . .

48. Strain between pump and steam generator

simulator (SE-BL27-2)

49. Strain between pump and steam generator simulator (SE-BL27-4)

50. Strain between pump and. steam generator simulator (SE-BL27-5)

51. Strain between pump and steam generator simulator (SE-BL27-6) . . . . . . . . . . . . . . .

52. Strain between pump and steam generator simulator (SE-BL27-8)

53. Strain at reactor vessel intact loop cold leg nozzle (SE-PC4-1)

54. Strain at reactor vessel intact loop cold leg nozzle (SE-PC4-2)

55. Strain at reactor vessel intact loop cold leg nozzle (SE-PC4-4) . . . . . . . . . ......

56. Strain at reactor vessel intact loop cold leg nozzle (SE-PC4-5)

57. Strain at reactor vessel intact loop cold leg nozzle (SE-PC4-7)

58. Strain at reactor vessel intact loop cold leg nozzle (SE-PC4-8)

59. Strain at reactor vessel intact loop hot leg nozzle (SE-PC5-1)

60. Strain at reactor vessel intact loop hot leg nozzle (SE-PC5-2).

61. Strain at reactor vessel intact loop hot leg nozzle (SE-PC5-3)

62. Strain at reactor vessel intact loop hot leg nozzle (SE-PC5-4)

63. Strain at reactor vessel intact loop hot leg nozzle (SE-PC5-5)

64. Strain at reactor vessel intact. loop hot. leg nozzle (SE-PC5-6) 
65. Strain at reactor vessel intact loop hot leg nozzle (SE-PC5-7) . . . . . . . . . . . . . . 52

66. Strain at reactor vessel intact loop hot leg nozzle (SE-PC5-8),............... 53

67. Strain at reactor vessel intact loop hot leg nozzle (SE-PC5-9) ................. 53

68. Strain at reactor vessel intact loop hot leg nozzle (SE-PC5-10)................ . 54

69. Strain at reactor vessel intact loop hot leg nozzle (SE-PC5-11) . . . . . . . . . . . . . 54

70. Strain at reactor vessel intact loop hot leg nozzle (SE-PC5-12). . . . . . . . . . . . . . . 55

71. Strain at steam generator inlet nozzle $(\mathrm{SE}-\mathrm{PC} 14-2)$. . . . . . . . . . . . . . . . . 55

72. Strain at steam generator inlet nozzle (SE-PC14-3) . ..... 56

73. Strain at steam generator inlet nozzle $(S E-P C 14-4) .$. . . . 56

74. Strain at steam generator inlet nozzle (SE-PC14-5). . . . . 57

75. Strain at steam generator inlet nozzle (SE-PC14-6) . . . . . 57

76. Strain at steam generator inlet nozzle (SE-PC14-7) . .... . 58

77. Strain at steam generator inlet nozzle (SE-PC14-8)..... . 58

78. Strain at steam generator inlet nozzle (SE-PC14-9) . . . . . 59

79. Strain at steam generator inlet nozzle (SE-PC14-10) . . . 59

80. Strain at steam generator inlet nozzle (SE-PC14-12) $\ldots .: \quad 60$

81. Strain at steam generator outlet nozzle (SE-PC15-1). . . . . 60

82. Strain at steam generator outlet nozzle (SE-PC15-2) . . . . 61

83. Strain at steam generator outlet nozzle $(S E-P C 15-3)$. . . . 61

84. Strain at steam generator outlet nozzle (SE-PC15-4) . . . . 62

85. Strain at steam generator outlet nozzle (SE-PC15-5) . . . . 62

86. Strain at steam generator outlet nozzle (SE-PC15-6) . . . . 63 
87. Strain at steam generator outlet nozzle $(S E-P C 15-8) \ldots 63$

88. Strain at steam generator outlet nozzle (SE-PC15-9). . . . 64

89. Strain at steam generator outlet nozzle $(S E-P C 15-10) \ldots 64$

90. Strain at steam generator outlet nozzle (SE-PC15-11).... 65

91. Strain at steam generator outlet nozzle (SE-PC15-12)..... 65

92. Strain at primary coolant pump outlet (SE-PC18-13) . . . . 66

93. Strain at primary coolant pump outlet (SE-PC18-14) .... 66

94. Strain at primary coolant pump outlet (SE-PC18-15) . . . 67

95. Strain at primary coolant pump outlet $($ SE-PC18-16) . . . . 67

96. Strain at primary coolant pump outlet (SE-PC18-17) ..... 68

97. Strain at primary coolant pump outlet (SE-PC18-18) . . . . 68

98. Strain at primary coolant pump outlet $(S E-P C 18-19) \ldots . . .69$

99. Strain at primary coolant pump outlet $(\mathrm{SE}-\mathrm{PC} 18-21) \ldots \ldots 9$

100. Strain at primary coolant pump outlet (SE-PC18-22) . . . 70

101. Strain at primary coolant pump outlet (SE-PC18-23) . . . . 70

102. Strain at primary coolant pump outlet (SE-PC18-24) ... . 71

103. Strain at reactor vessel broken loop cold leg nozzle

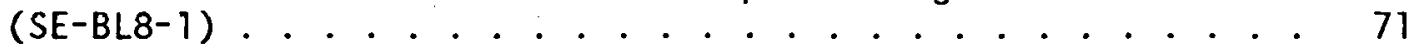

104. Strain at reactor vessel broken loop cold leg nozzle (SE-BL8-2) ..................... 72

105. Strain at reactor vessel broken loop cold leg nozzle (SE-BL8-3) ................. . . 72

106. Strain at reactor vessel broken loop cold leg nozzle (SE-BL8-4) .................... 73

107. Strain at reactor vessel broken loop cold leg nozzle $(\mathrm{SE}-\mathrm{BL8}-5) \ldots \ldots . \ldots 73$

108. Strain at reactor vessel broken loop cold leg nozzle $($ SE-BL8-6) . . . . . . . . . . . . . . . . . 74

109. Strain at reactor vessel broken loop cold leg nozzle (SE-BL8-8) . . . . . . . . . . . . . . 
110. Strain at reactor vessel broken loop cold leg nozzle $(\mathrm{SE}-\mathrm{BL} 8-9)$. . . . . . . . . . . . . . .

111. Strain at reactor vessel broken loop cold leg nozzle (SE-BL8-11)

112. Strain at reactor vessel broken loop cold leg nozzle (SE-BL8-12)

113. Strain at reactor vessel broken loop hot leg nozzle (SE-BL9-1)

114. Strain at reactor vessel broken loop hot leg nozzle (SE-BL9-2)

115. Strain at reactor vessel broken loop hot leg nozzle (SE-BL9-3)

116. Strain at reactor vessel broken loop hot leg nozzle (SE-BL9-4)

117. Strain at reactor vessel broken loop hot leg nozzle (SE-BL9-5)

118. Strain at reactor vessel broken loop hot leg nozzle (SE-BL9-6)

119. Strain between pump and steam generator simulator (SF-BI.27-2)

120. Strain between pump and steam generator simulator (SE-BL27-4)

121. Strain between pump and steam generator simulator (SE-BL27-5)

122. Strain between pump and steam generator simulator (SE-BL27-6)

123. Strain between pump and steam generator simulator (SE-BL27-8)

124. Strain at reactor vesse 7 intact loop cold leg liuzzle ( $\mathrm{jE}-\mathrm{PC} 4-\mathrm{i})$

125. Strain at reactor vessel intact loop cold leg nozzle (SE-PC4-2)

126. Strain at reactor vessel intact loop cold leg nozzle (SE-PC4-4)

127. Strain at reactor vessel intact loop cold leg nozzle (SE-PC4-5) 
128. Strain at reactor vessel intact loop cold leg nozzle (SE-PC4-7) ................

129. Strain at reactor vessel intact loop cold leg nozzle (SE-PC4-8)

130. Strain at reactor vessel intact loop hot leg nozzle (SE-PC5-1)

131. Strain at reactor vessel intact loop hot leg nozzle (SE-PC5-2)

132. Strain at reactor vessel intact loop hot leg nozzle (SE-PC5-3)

133. Strain at reactor vessel intact loop hot leg nozzle (SE-PC5-4)

134. Strain at reactor vessel intact loop hot leg nozzle (SE-PC5-5)

135. Strain at reactor vessel intact loop hot leg nozzle $(S E-P C 5-8)$. . . . . . . . . . . . . . 87

136. Strain at reactor vessel intact loop hot leg nozzle (SE-PC5-9)

137. Strain at reactor vessel intact loop hot leg nozzle $($ SE-PC5-10)............... 88

138. Strain at reactor vessel intact loop hot leg nozzle $($ SE-PC5-11) .............. 89

139. Strain at reactor vessel intact loop hot leg nozzle $($ SE-PC5-12) . . . . . . . . . . . . . . . 89

140. Strain at steam generator inlet nozzle (SE-PC14-2) . . . . 99 90

141. Strain at steam generator inlet nozzle $($ SE-PCl4-3) . . . . 90

142. Strain at steam generator inlet nozzle $($ SE-PC14-4) . . . . . 91

143. Strain at steam generator inlet nozzle (SE-PC14-5) . . . . 91

144. Strain at steam generator inlet nozzle $(S E-P C 14-6) \ldots . . .92$

145. Strain at steam generator inlet nozzle (SE-PC14-7) . . . . . 92

146. Strain at steam generator inlet nozzle (SE-PC14-8) . . . . . 93

147. Strain at steam generator inlet nozzle (S.E-PC14-9) . . . . 93 
148. Strain at steam generator inlet nozzle (SE-PC14-10) . . . . 94

149. Strain at steam generator inlet nozzle (SE-PC14-12) . . . . 94

150. Strain at steam generator cutlet nozzle (SE-PC15-1) . . . . 95

151. Strain at steam generator outlet nozzle (SE-PC15-2) . . . . 95

152. Strain at steam generator outlet nozzle (SE-PC15-3) . . . . . 96

153. Strain at steam generator outlet nozzle (SE-PC15-4) . . . . 96

154. Strain at steam generator outlet nozzle.$($ SE-PC15-5) $\quad \because \quad . . .97$

155. Strain at steam generator outlet nozzle (SE-PC15-6) .... . 97

156. Strain at steam generator outlet nozzle (SE-PC15-8) . . . . 98

157. Strain at steam generator outlet nozzle (SE-PC15-9) . . . . 98

158: Strain at steam generator outlet nozzle (SE-PC15-10) . . . 99

159. Strain at steam generator outlet nozzle (SE-PC15-11). . . . 99

160. Strain at steam generator outlet nozzle (SE-PC15-12) .... 100

161. Strain at primary coolant pump outlet (SE-PC18-13) . . . . . 100

162. Strain at primary coolant pump outlet (SE-PC18-14). . . . 101

163. Strain at primary coolant pump outlet (SE-PC18-15) . . . . . . .

164. Strain at primary coolant pump outlet (SE-PC18-16) . . . . 102

165. Strain at primary coolant pump outlet (SE-PC18-17) . . . . 102

166. Strain at primary coolant pump outlet (SE-PC18-18) . ... . 103

167. Strain at primary coolant pump outlet (SE-PC18-19) . ... 103

168. Strain at primary coolant pump outlet (SE-PC18-21) .... . 104

169. Strain at primary coolant pump outlet (SE-PC18-22) . . . . 104

170. Strain at primary coolant pump outlet (SE-PC18-23) . . . . 105

171. Strain at primary coolant pump outlet (SE-PC18-24) . . . . . 105 


\section{TABLES}

I. Accelerometer Locations. . . . . . . . . . . . . . . . . 7

II. Strain Gage Locations. . . . . . . . . . . . . . . . . . . . . 9

III. LOFT Ll-Series Experiment Conditions . . . . . . . . . . . . . 14

IV. Summary of Accelerometer Data for Experiment Ll-3A . . . . . 18 


\section{INTRODUCTION}

The presentation of the loss-of-fluid test (LOFT) system structural response during subcooled blowdown is addressed by the following:

(1) The response of the LOFT system relative to (a) experiment predictions and (b) system design.

(2) The quality and magnitude of LOFT accelerometer and strain gage data (structural response data).

(3) The applicability of LOFT structural response data for reactor safety and/or structural code qualification and LOFT requalification.

(4) The quality, quantity, and position of existing and/or proposed measurements.

(5) The differences in structural response data from nonnuclear to nuclear LOCEs.

(6) The need for further analysis of the existing structural response data and/or the LOFT system with structural codes.

This analysis concerns only the primary coolant system and blowdown loop to the quick-opening blowdown valves (QOBVs) of the LOFT facility as described in Section II of this report. Structural response data acquired with the instruments described in Section III for the nonnuclear series Experiments $L]-2, L I-3$, and $L 1-3 A^{[1,2,3,4,5]}$ were reviewed. A brief description of the experiment conditions is included in Section IV. A complete set of accelerometer and strain gage data from the $L I-3 A$ experiment is presented in Section $V$ with an evaluation and discussion. 


\section{SYSTEM CONFIGURATION}

The LOFT facility has been designed to simulate the major components and system thermal hydraulic responses of a large pressurized water reactor (LPWR) during a loss-of-coolant accident (LOCA). The test assembly is comprised of five major subsystems which have been instrumented such that desirable system parameters can be measured and recorded during a loss-of-coolant, experiment (LOCE). These subsystems were instrumented for structural response measurements for purposes of assurance of the adequacy of the LOFT structural design and for requalification only. No attempt was made to instrument for purposes of structural code verification. The subsystems include: (a) the reactor vessel, (b) the primary coolant (intact) loop, (c) the blowdown (broken) loop, (d) the blowdown suppression system, and (e) the emergency core cooling system (ECCS).

The LOFT reactor vessel simulates the reactor vessel of a LPWR. It has an annular downcomer, a lower plenum, lower core support plates, a core simulator, and an upper plenum. The downcomer connects with the cold leg of both the intact and broken loops and contains two experimental instrument stalks; the upper plenum connects the hot leg of both the intact and the broken loops. The core simulator contains an experimental instrument stalk and hydraulic orifice plate assembly to simulate the flow resistance of a nuclear core which will be installed for nonnuclear LOCE L1-5.

The 1ntact loup slmulales llie unduruken loujs of a LFWR. This loop contains a steam generator, two circulating coolant pumps connected in paralle1, a prossurizer, a venturi flowmeter, and connecting piping. For Experiment LI-3A, the primary side steam generator inlet and outlet plenums contained square-edged orifice plates sized for low resistance or core flow area scaling. Thus these orifices provided a similar pressure drop at scaled flow rates around the LOFT intact loop (excluding the reactor vessel) as exists in a LPWR operating loop. The secondary side of the steam generator was filled to a predetermined 
level and isolated from the remainder of the secondary coolant system. The intact loop circulating coolant pumps were used to bring the system to the initial test temperature of $282^{\circ} \mathrm{C}$.

The broken loop simulates the broken loop of a LPWR. It consists basically of hot and cold legs that are connected to the reactor vessel and the blowdown suppression tank header. Each leg consists of a break plane orifice which determines the break size to be simulated, a quickopening blowdown valve (QOBV) which simulates a pipe break, a recirculation line, an isolation valve, and connecting piping. The recirculation lines establish a small flow from the broken loop to the intact loop to maintain these loop temperatures approximately equal prior to the blowdown. These recirculation paths are secured just prior to blowdown initiation.

Experiments $L 1-2, L 1-3$, and $L 1-3 A$ simulated a $200 \%$ double-ended shear break in a cold leg of a LPWR operating loop. In this configuration, the broken loop hot leg contained, in addition to the above mentioned components, steam generator and pump simulators. These simulators have hydraulic orifice plate assemblies installed which have similar (passive) resistances to flow as a real pump and steam generator. The break flow area (break plane orifice area) in this configuration is $0.0084 \mathrm{~m}^{2}$; this is $100 \%$ of the possible break flow area in each line.

The blowdown suppression system simulates the containment back pressure of a LPWR. This system is comprised of the blowdown suppression tank header, the blowdown suppression tank (BDST), the nitrogen pressurization system, and the blowdown suppression tank spray system (BDSTSS). The blowdown header is connected to the suppression tank by four suppression tank downcomers that extend inside the tank and discharge below the water level established as a test initial condition. The nitrogen pressurization system is supplied by the LOFT inert gas system and utlizies a remote controlled pressure regulator to establish and maintain the specified BDST initial pressure. The spray system consists of a centrifugal pump which discharges through a heatup heat 
exchanger and either three spray headers or a pump recirculation line that contains a cooldown heat exchanger. The spray pump suction can be aligned to either the BDST or the borated water storage tank (BWST). The three spray headers have $0.0013-, 0.0038-$, and $0.0139 \mathrm{~m}^{3} / \mathrm{s}$ flow rate capacities and are located in the BDST along the upper centerline: To model the containment back pressure of a LPWR, predetermined initial conditions are established in the BDST.

The LOFT ECCS simulates the ECCS of a LPWR. The accumulator, the high-pressure injection system (HPIS), and the low-pressure injection system (LPIS) were used during the L1-3A experiment. Each system was configured to inject scaled volumetric flow rates of ECC directly into the lower plenum of the reactor vesse1. To provide these scaled flow rates, accumulator ACC-A, HPIS pump A, and LPIS pump A were utilized. Accumulator ACC-A was preset to inject ECC at a system pressure of 4.22 MPa. HPIS pump A was preset to inject at $0.001 \mathrm{~m}^{3} / \mathrm{s}$ and to initiate by LOCE control at $22 \mathrm{~s}$ after the initiation of blowdown; LPIS pump $A$ was adjusted to initiate by LOCE control at $35.5 \mathrm{~s}$ after the initiation of blowdown.

A detailed description of the LOFT facility can be found in Reference 6. Oniy the first three subsystems mentioned above are discussed and a pictorial view is included in Figure 1 . 


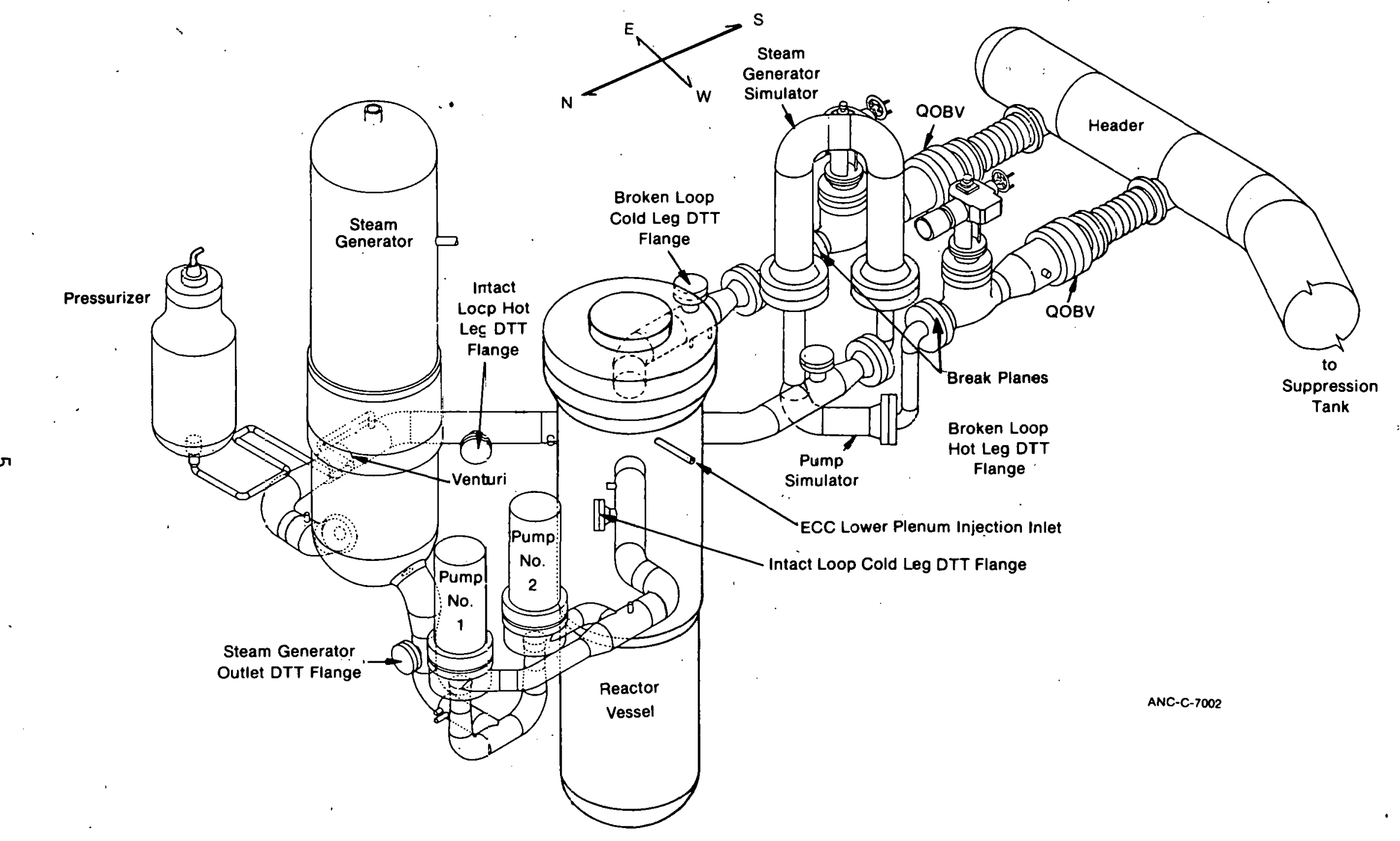

Fig. 1 LOFT major components. 


\section{MEASUREMENTS AND INSTRUMENTATION}

The LOFT instrumentation system was designed to measure and record the important parameters that occur during a LOCE. The accelerometer and strain gage data from the locations summarized in Tables I and II are considered sufficient for use in the analysis presented herein. Information on the calibration factors, accuracy, and response of specific instruments is given in Reference 7. Reference 5 should be consulted for detaits of instrument design and locations. 
TABLE I

ACCELEROMETER LOCATIONS

Device Number

$A E-B L 2-1$

$A E-B L 2-2$

$A E-B L 3-1$

$A E-B L 4-1$

$A E-B L 5-1$

$A E-P C 3-1$

$A E-P C 3-2$

$A E-P C 3-3$

AE-PC6-1

$A E-P C 6-2$

AE-PC6-3

ẢE-PC7- 1

$A E-P C 7-2$

$A E-P C 7-3$
Direction

East-West

North-South

Vertical

North-South

North-South

East-West

North-South

Vertical

East-West

North-South

Vertical

East-West

North-South

Vertical
Location

Simulated steam generator flange

Simulated steam generator flange

Simulated steam generator top

Quick-opening blowdown valve, cold leg

Quick-opening blowdown valve, hot leg

90-degree-elbow downstream of primary coolant pumps

90-degree-elbow downstream of primary coolant pumps

90-degree-elbow downstream of priamry coolant pumps

45-degree-elbow between reactor vessel and steam generator

45-degree-elbow between reactor vessel and steam generator

45-degree-elbow between reactor vessel and steam generator

90-degree-elbow between reactor vessel and steam generator

90-degree-elbow between reactor vessel ard steam generator

90-degree-elbow between reactor vessel steam generator 
TABLE I (continued)

Device Number

AE-PC16- 1

AE-PC 16-2

AE-PC16-3

AE-PC 17-1

$A E-P C 17-2$

$A E-P C 18-1$

$A E-P C 18-2$

AE-PC 18-3

AE-PC 19-1

AE-PC19-2

AE-PC 19-3

AE-RVI-T

$A E-R V 1-2$

$A[\cdot R V] \cdot 3$

AE-RV1-4

$A E-R V T-5$

$A E-R V 1-6$
Direction

East-West

North-South

Vertical

East-West

North-South

tast-West

North-South

Vertical

East-West

North-South

Vertical

East-West

East-West

Vertical

North-South

North-South

Vertical

\section{Location}

Primary coolant pump inlet

Primary coolant pump inlet

Primary coolant pump inlet

Steam generator, north side

Steam generator, north side

Primary coolanl pump 1 , north side

Primary coolant pump 1 , north side

Primary cooliant pump 1, north side

Primary coolant pump 2, north side

Primary coolant pump 2, north side

Primary coolant pump 2, north side

Reactor vessel bottom, west side

Reactor vessel bottom, wast side

Reactor vessel bottom, west. side

Reactor vesse] bottom, north side

Reactor vessel bottom, north side

Reactor vessel bottom, north side 
TABLE II

STRAIN GAGE LOCATIONS

\begin{tabular}{|c|c|c|}
\hline Device Number & Position & Location \\
\hline SE-BL8-1 & Top-longitudinal & Broken loop, cold leg nozzle \\
\hline SE-BL8-2 & Top -45 degrees & Broken loop, cold leg nozzle \\
\hline$S E-B L 8-3$ & Top-circumferentiàl & Broken loop, cold leg nozzle \\
\hline$S E-B L 8-4$ & Right-longitudinal & Broken loop, cold leg nozzle \\
\hline$S E-B L 8-5$ & Right-45 degrees & Broken loop, cold leg nozzle \\
\hline$S E-B L 8-6$ & Right-circumferential & Broken loop, cold leg nozzle \\
\hline$S E-B L 8-7^{[a]}$ & Bottom-longitudinal & Broken loop, cold leg nozzle \\
\hline SE-BL8-8 & Bottom- 45 degrees & Broken loop, cold leg nozzle \\
\hline$S E-B L 8-9$ & Bottom-circumferential & Broken loop, cold leg nozzle \\
\hline$S E-B L 8-10^{[a]}$ & Left-longitudinal & Broken loop, cold leg nozzle \\
\hline SE-BL8- 11 & Left -45 degrees & Broken loop, cold leg nozzle \\
\hline SE-BL8-12 & Left-circumferential & Broken loop, cold leg nozzle \\
\hline SE-BL9-1 & Top-longitudinal & Broken loop, hot leg nozzle \\
\hline$S E-B L 9-2$ & Right-longitudinal & Broken loop, hot leg nozzle \\
\hline$S E-B L 9-3$ & Right-45 degrees & Broken loop, hot leg nozzle \\
\hline$S E-B L 9-4$ & Right-circumferential & Broken loop, hot leg nozzle \\
\hline SE-BL9-5 & Bottom-longitudinal & Broken loop, hot leg nozzle \\
\hline$S E-B L 9-6$ & Left-longitudinal. & Broken loop, hot leg nozzle \\
\hline$S E-B L 9-7^{[a]}$ & Left- 45 degrees & Broken loop, hot leg nozzle \\
\hline$S E-B L 9-8^{[a]}$ & Left-circumferential & Broken loop, hot leg nozzle \\
\hline$S E-B L 27-1[a]$ & South-longitudinal & $\begin{array}{l}\text { Between pump and steam } \\
\text { generator simulator }\end{array}$ \\
\hline$S E-B L 27-2$ & South-1ongitudinal & $\begin{array}{l}\text { Between pump and steam } \\
\text { generator simulator }\end{array}$ \\
\hline$S E-B L 27-3^{[a]}$ & South-circumferential & $\begin{array}{l}\text { Between pump and'steam } \\
\text { generator simulator }\end{array}$ \\
\hline SE-BL27-4 & East-longitudinal & $\begin{array}{l}\text { Between pump and steam } \\
\text { generator simulator }\end{array}$ \\
\hline$S E \rightarrow B L 27-5$ & North-longitudinal & $\begin{array}{l}\text { Between pump and steam } \\
\text { generator simulator }\end{array}$ \\
\hline
\end{tabular}


TABLE II (continued)

\begin{tabular}{|c|c|c|}
\hline evice Number & Position & Location \\
\hline SE-BL27-6 & North-45 degrees & $\begin{array}{l}\text { Between pump and steam } \\
\text { generator simulator }\end{array}$ \\
\hline$S E-B L 27-7^{[a]}$ & North-circumferential & $\begin{array}{l}\text { Between pump and steam } \\
\text { generator simulator }\end{array}$ \\
\hline SE-BL27-8 & West-longitudinal & $\begin{array}{l}\text { Between pump and steam } \\
\text { generator simulator }\end{array}$ \\
\hline SE-PC4- 1 & Top-longitudinal & Intact loop, cold leg nozzle \\
\hline$S E-P C 4-2$ & Right-1ongitudinal & Intact loop, cold leg nozzle \\
\hline$S E-P C 4-3^{[a]}$ & Right-45 degrees & Intact loop, cold leg nozzle \\
\hline$S E-P C 4-4$ & Right-circumferential & Intact loop, cold leg nozzle \\
\hline SE-PC4-5 & Bottom-longitudinal & Intact loop, cold leg nozzle \\
\hline$S E-P C 4-6^{[a]}$ & Left-longitudinal & Intact loop, cold leg nozzle \\
\hline SE-PC4-7 & Left-45 degrees & Intact loop, cold leg nozzle \\
\hline SE-PC4-8 & Left-circumferential & Intact loop, cold leg nozzle \\
\hline$S E-P C 5-1$ & Top-longitudinal & Intact loop, cold leg nozzle \\
\hline$S E-P C 5-2$ & Top-45 degrees & Intact loop, hot leg nozzle \\
\hline$S E-P C 5-3$ & Top-circumferential & Intact loop, hot leg nozzle \\
\hline$S E-P C 5-4$ & Right-longitudinal & Intact loop, hot leg nozzle \\
\hline $\bar{S} E-P C 5-5$ & Right-45 degrees & Intact loop, not leg nozzle \\
\hline$S E-P C 5-6^{\lfloor b\rfloor}$ & Right-circumferential & Intact loop, hot leg nozzle \\
\hline$S E-P C 5-7^{[b]}$ & Bottom-longitudinal & Intact loop, hot leg nozzle \\
\hline$S E-P C 5-8$ & Bottom-45 degrees & Intact loop, hot leg nozzle. \\
\hline$S E-P C 5-9$ & Bottom-circumferential & Intact loop, hot leg nozzle \\
\hline$S E-P C 5-10$ & Left-longitudinal & Intact loop, hot leg nozzle \\
\hline SE-PC5-11 & Left -45 degrees & Intact loop, hot leg nozzle \\
\hline$S E-P C 5-12$ & Left-circumferential & Intact loop, hot leg nozzle \\
\hline SE-PC14-1 ${ }^{[a]}$ & Right-longitudinal & Steam generator inlet nozzle \\
\hline$S E-P C 14-2$ & Right-45 degrees & Steam generator inlet nozzle \\
\hline$S E-P C 14-3$ & Right-circumferential & Steam generator inlet nozzle \\
\hline SE-PC14-4 & Top-longitudinal & Steam generator inlet nozzle \\
\hline SE-PC14-5 & Top-45 degrees & Steam generator inlet nozzle \\
\hline
\end{tabular}


TABLE II (continued)

\begin{tabular}{|c|c|c|}
\hline Device Number & Position & Location \\
\hline SE-PC14-6 & Top-circumferential & Steam generator inlet nozzle \\
\hline SE-PC14-7 & Left-longitudinal & Steam generator inlet nozzle \\
\hline SE-PC14-8 & Left -45 degrees & Steam generator inlet nozzle \\
\hline SE-PC14-9 & Left-circumferential & Steam generator inlet nozzle \\
\hline$S E-P C 14-10$ & Bottom-longitudinal & Steam generator inlet nozzle \\
\hline SE-PC14-11 [a & ]$_{\text {Bottom-45 degrees }}$ & Steam generator inlet nozzle \\
\hline$S E-P C 14-12$ & Bottom-circumferential & Steam generator inlet nozzle \\
\hline SE-PC15-1 & North-longitudinal & Steam generator outlet nozzle \\
\hline SE-PC15-2 & North-45 degrees & Steam generator outlet nozzle \\
\hline$S E-P C 15-3$ & North-circumferential & Steam generator outlet nozzle \\
\hline SE-PC15-4 & East-longitudinal & Steam generator outlet nozzle \\
\hline SE-PC 15-5 & East -45 degrees & Steam generator outlet nozzle \\
\hline$S E-P C i 5-6$ & East-circumferential & Steam generator outlet nozzle \\
\hline SE-PC15-7 & South-longitudinal & Steam generator outlet nozzle \\
\hline$S E-P C 15-8$ & South & Steam generator outlet nozzle \\
\hline SE-PC15-9 & South-circumferential & Steam geneprator outlet nozzle \\
\hline SE-PC15-10 & longitu & Steam generator outlet nozzle \\
\hline SE-PC15-11 & West -45 degrees & Steam generator outlet nozzle \\
\hline SE-PC15-12 & West-circumferential & Steam generator outlet nozzle \\
\hline$S E-P C 18-13$ & Bottom-longitudinal & Primary coolant pump outlet \\
\hline SE-PC18- 14 & Bottom-45 degrees & Primary coolant pump outlet \\
\hline$S E-P C 18-15$ & Bottom-circumferential & Primary coolant pump outlet \\
\hline$S E-P C 18-16$ & Left-longitudinal & Primary coolant pump outlet \\
\hline SE-PC18-17 & Left- 45 degrees & Primary coolant pump outlet \\
\hline$S E-P C 18-18$ & Left-circumferential & Primary coolant pump outlet \\
\hline SE-PC18-19 & Top-langitudinal & Priamry coolant pump outlet \\
\hline$S E-P C 18-20^{[}$ & ]$_{\text {Top }-45 \text { degrees }}$ & Primary coolant pump outlet \\
\hline$S E-P C 18-21$ & Top-circumferential & Primary coolant pump outlet \\
\hline$S E-P C 18-22$ & Right-longitud & Primary coolant pump outlet \\
\hline$S E-P C 18-23$ & Right-45 degrees & Primary coolant pump outlet \\
\hline
\end{tabular}


TABLE II (continued):

Device Number $\frac{\text { Position }}{\text { SE-PC18-24 }} \frac{\text { Right-circumferential }}{\text { Primary coolant pump outlet }}$

[a] Plots not included due to signal failure.

[b] Plots to 1.0 second not included due to calibration problem.

[c] Plots not included due to calibration problem. 


\section{EXPERIMENT CONDITIONS}

The parameters affecting blowdown loads for Experiments $L l-2, L]-3$, and L1-3A are summarized in Table III. For a detailed description of the experiment configuration, operation, and conditions for each of the above mentioned experiments, the reader is directed to References 1 and 2. The conditions affecting blowdown loads in the intact and broken loops remain the same for the nuclear experiments as seen in the above mentioned $L I$ series experiments. 
TABLE III

LOFT LI-SERIES EXPERIMENT CONDITIONS

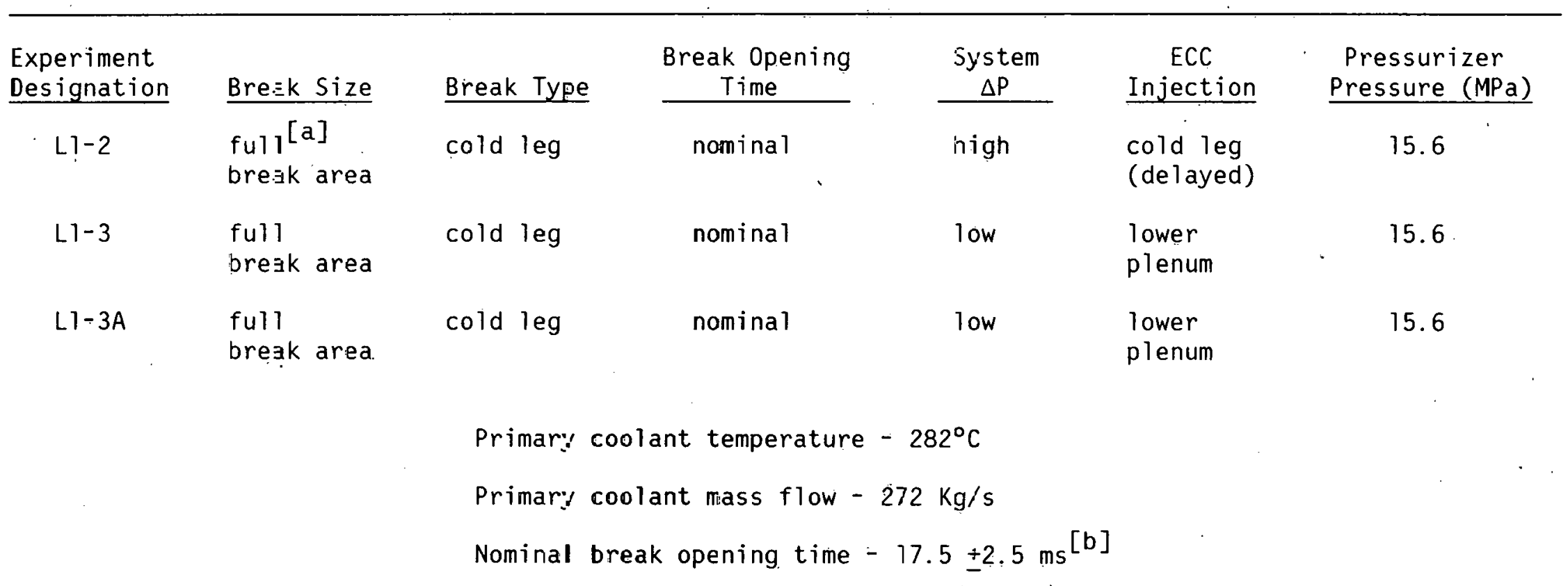

[a] Full break area corresponds to sinulation of a non-comminicative double-ended break of an LPWR main primary coclant pipe.

[b] Nominal break ofening time is the expected time interval for propagation of a full circumferential break in the main coolant pipe of an -PWR. 


\section{DATA PRESENTATION AND DISCUSSION}

Accelerometer and strain gage data from Experiment L1-3A are included in Figures 2 through 172 which are included in total at the end of this section. The characteristics of this set of data are similar to those from Experiments $L 1-2$ and $L 1-3$, except in the case of accelerometer data from Experiment $\mathrm{LI}-2$ which was considered to be unusable due to nonzero average traces and spurious noise. Review of L1-3 acceleration data to 0.2 s revealed amplitude of acceleration and frequency content similar to the included L7-3A acceleration data. The strain gage data for all three experiments were reviewed to $0.2 \mathrm{~s}$, and it was concluded that the $L 1-3 A$ strain gage data were representative of the strain gage data from all three experiments. Strain gage data to 1.0 s were reviewed since, in a few cases, the maximum dynamic strain did not occur in the time during which subcooled conditions existed.

Review and comparison of accelerometer data from Experiment LI]-3A with predicted and design accelerations, as summarized in Table IV, indicates the following:

(1) In general the data are characterized by a high degree of noise in the form of preblowdown system vibration and/or high frequency localized accelerations which are amplified due to resonance in the accelerometers (Figures $5,11,15,17,20$, $21,22,23,24$, and 25). These characteristics make quantification of the recorded accelerations difficult and highly subjective.

(2) In many cases the low frequency (less than $110 \mathrm{~Hz}$ ) amplitude of the recorded signal is estimated to be less than the accuracy 1 imits of the accelerometer which is on the order of $\pm 0.20 \mathrm{G}$ (Figures $7,13,17,21,23,26,27,28,29,30$, and 31 ). 
(3) Some of the data are characterized by a shift in the average value of the signal and/or are highly nonsymmetric which, upon integration, would indicate unbounded displacements in the system (Figures 6 and 14).

(4) With the problems in 1 through 3 above in mind, the data review and comparison indicate in most cases that accelerations in the frequency range less than $300 \mathrm{~Hz}$ are below the predicted and design values. Accelerations at frequencies greater than $300 \mathrm{~Hz}$ are believed to be local rather than gross structural response and/or noise and give rise to deflections less than $0.025 \mathrm{~mm}$ (Figures $2,3,10,11,12,15,16,18,19$, $20,21,22,23,24$, and 25 ).

(5) The measured accelerations at $A E-P C 17-1$ and $A E-P C-17-2$ (on the steam generator, north side) exceed the LOCE design values by nearly a factor of two. However, integration of the data yielded deflections which were less than half those associated with seismic loads. Since the system is designed for combined seismic and LOCA loads, the LOCE loads will not present a structural problem.

(6) The accelerometer data at AE-BL2-1 (simulated steam generator flange) indicate that the measured accelerations are slightly higher than predicted and design. values. Integration of data at this location yielded deflections less than half those for seismic loads assuring structural adequacy for LOCE loads.

Review of the strain gage data indicates that the dynamic strains at all measurement locations are less than $150 \times 10^{-6} \mathrm{~m} / \mathrm{m}$. The strain data are characterized by a gradual build up of the signals corresponding to response to pressure relaxation during blowdown. Dynamic fluctuations about the gradual build up. correspond to response to dynamic excitations, and the half range magnitudes are much lower than those associated with pressure relaxation. The accuracy level of the strain gage data is on the order of $10 \times 10^{-6} \mathrm{~m} / \mathrm{m}$ which is 25 to $50 \%$ of 
the half range magnitudes of the dynamic fluctuations. Since the dynamic fluctuations are small (giving rise to stresses less than $1.12 \times 10^{7} \mathrm{~N} / \mathrm{m}^{2}$ ) and not much larger than the accuracy level of the signal, reduction of the strain gage data to component loads for comparison with predicted data is deemed unnecessary.

In general, the magnitude and noise level of the structural response data make quantification for direct comparison with predicted and design values highly subjective. It is felt that the data are applicable only to the LOFT facility due to the complexity of the system and are not applicable to LPWRs in general. Use of the data for structural code qualification is not recommended due to the problems involved in quantifying the recorded signals (low amplitudes, high noise leve1). It is felt that the data can be used but should not be relied upon solely for LOFT requalification due to the problems associated with obtaining meaningful measurements at all critical structural points in. the system (welds, joints, tees, etc.). A comprehensive inspection program for welds and components at intervals based on fatigue analysis will be included for requalification of the system. The present measurement system is deemed adequate for the purposes of LOFT structural response determination and evaluation, and additional insturments or repositioning of measurements is felt to be unnecessary.

Hydraulic loads associated with nuclear LOCEs should be no more severe than those arising from nonnuclear LOCEs since the system flow rates for each case (assuming equal break areas) are the same. Decompression loads for nuclear LOCEs should be somewhat smaller than those for nonnuclear LOCEs, because the saturation pressure in the upper plenum is higher for nuclear experiments (11.44 MPa nuclear LOCE, $6.62 \mathrm{MPa}$ nonnuclear $(\mathrm{OCE})$. It is concluded that no major differences in structural response data are expected in the data from nuclear tests.

Results of this analysis indicate the subject system is adequate for LOCE loads and further analysis with structural codes is deemed unnecessary. 
TABLE IV

SUMMARY OF ACCELEROMETER DATA

FOR EXPERIMENT LI-3A

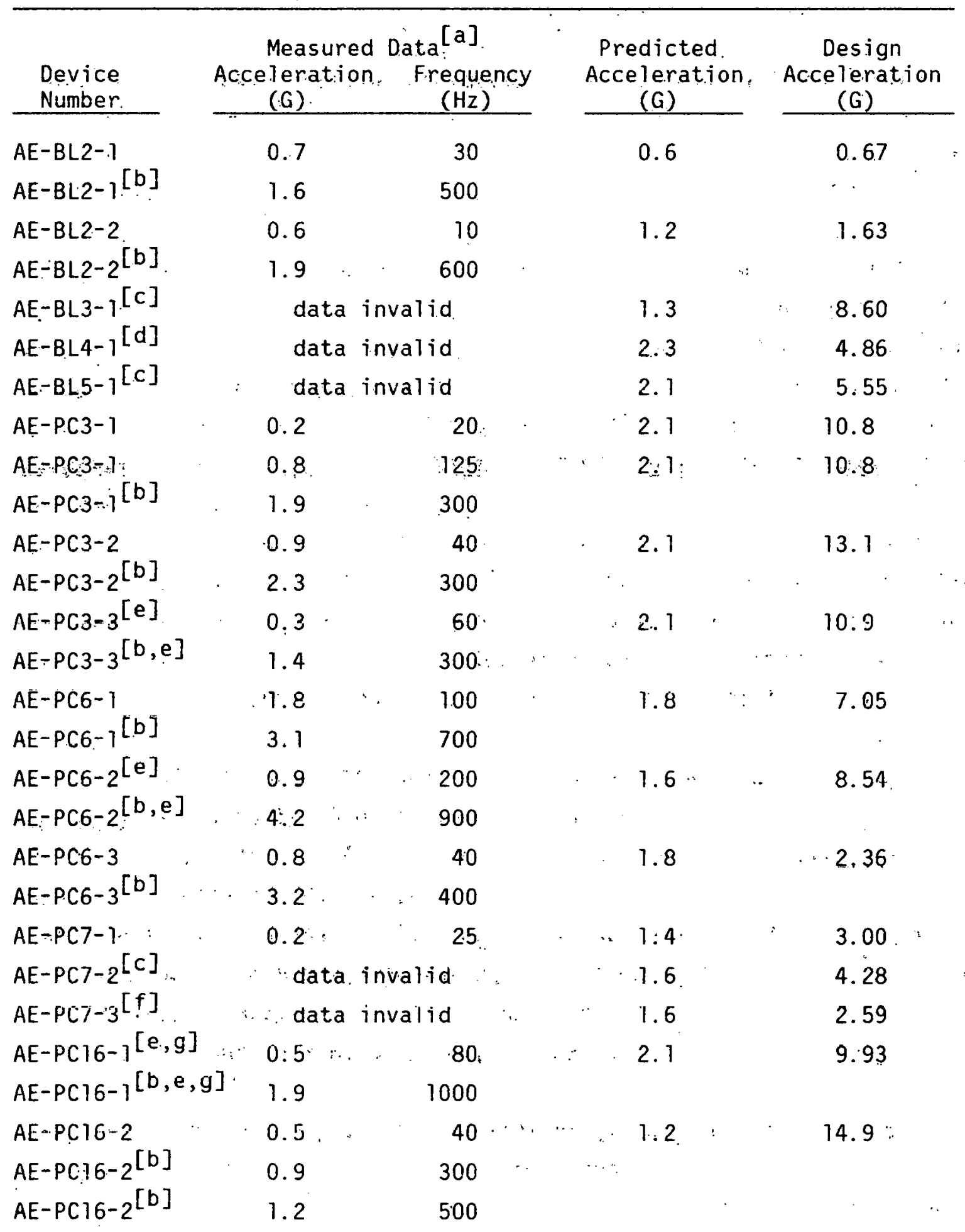


TABLE IV (continued)

\begin{tabular}{|c|c|c|c|c|}
\hline $\begin{array}{l}\text { Device } \\
\text { Number }\end{array}$ & $\begin{array}{r}\text { Measured } \\
\text { Acceleration } \\
\text { (G) } \\
\end{array}$ & $\begin{array}{l}\text { Data }{ }^{[a]} \\
\text { Frequency } \\
(\mathrm{Hz}) \\
\end{array}$ & $\begin{array}{l}\text { Predicted } \\
\text { Acceleration } \\
(\mathrm{G}) \\
\end{array}$ & $\begin{array}{c}\text { Design } \\
\text { Acceleration } \\
(G) \\
\end{array}$ \\
\hline$A E-P C 16-3^{[e, g]}$ & 0.3 & 30 & 1.0 & 11.3 \\
\hline$A E-P C 16-3^{[b, e, g]}$ & 2.0 & 400 & & \\
\hline$A E-P C 17-1$ & 0.3 & 15 & 0.1 & 0.18 \\
\hline AE-PC17-1 & 0.1 & 100 & 0.1 & 0.18 \\
\hline$A E-P C 17-1^{[b]}$ & 2.8 & 700 & & \\
\hline$A E-P C 17-2$ & 0.6 & 25 & 0.3 & 0.34 \\
\hline$A E-P C 17-2^{[b]}$ & 7.8 & 1000 & & \\
\hline$A E-P C 18-1^{[g]}$ & 0.2 & 30 & 0.6 & 1.79 \\
\hline$A E-P C 18-1[b, g]$ & 1.6 & 800 & & \\
\hline$A E-P C 18-2^{[g]}$ & 0.4 & 60 & 0.7 & 2.75 \\
\hline$A E-P C] 8-2^{[b, g]}$ & 2.0 & 1000 & & \\
\hline$A E-P C 18-3^{[g]}$ & 0.3 & 25 & 0.4 & 3.57 \\
\hline$A E-P C] 8-3^{[b, g]}$ & 1.2 & 600 & & \\
\hline$A E-P C 19-1[g]$ & 0.2 & 100 & 0.6 & 2.08 \\
\hline$A E-P C 19-1[b, g]$ & 0.6 & 400 & & \\
\hline$A E-P C 19-1[b, g]$ & 1.1 & 7.00 & & \\
\hline$A E-P C 19-2^{[g]}$ & 0.4 & 50 & 0.8 & 2.49 \\
\hline$A E-P C 19-2^{[b, g]}$ & 2.5 & 800 & & \\
\hline$A E-P C 19-3^{[g]}$ & 0.4 & 30 & 0.4 & 5.77 \\
\hline$A E-P C 19-3^{[h, 0]}$ & 1.3 & 400 & & \\
\hline$A E-R V I-1$ & 0.2 & 20 & 0.1 & 0.21 \\
\hline$A E-R V 1-1^{[b]}$ & 1.6 & 350 & & \\
\hline$A E-R V 1-2^{[h]}$ & 0.3 & 13 & 0.1 & 0.21 \\
\hline$A E-R V T-2^{[b]}$ & 1.8 & 350 & & \\
\hline$A E-R V I-3$ & 0.1 & 15 & 0.3 & 0.42 \\
\hline$A E-R V 1-3^{[b]}$ & 2.0 & 350 & & \\
\hline$A E-R V I-4$ & 0.1 & 30 & 0.4 & 0.42 \\
\hline$A E-R V 1-4^{[b]}$ & 1.6 & 300 & & \\
\hline$A E-R V I-5$ & 0.1 & 13 & 0.4 & 0.42 \\
\hline
\end{tabular}




\begin{tabular}{|c|c|c|c|c|}
\hline $\begin{array}{l}\text { Device } \\
\text { Number }\end{array}$ & $\begin{array}{l}\text { Measured } \\
\text { Acceleration } \\
(\mathrm{G}) \\
\end{array}$ & $\begin{array}{l}\text { Data }[\mathrm{a}] \\
\text { Frequency } \\
\quad(\mathrm{Hz}) \\
\end{array}$ & $\begin{array}{l}\text { Predicted } \\
\text { Acceleration } \\
\text { (G) } \\
\end{array}$ & $\begin{array}{c}\text { Design } \\
\text { Acceleration } \\
\text { (G) }\end{array}$ \\
\hline$A E-R V 1-5^{[b]}$ & 1.5 & 300. & & . \\
\hline$A E-R V I-6$ & 0.3 & 100 & 0.3 & 0.42 \\
\hline$A E-R V 1-6^{[b]}$ & 2.1 & 350 & & . \\
\hline
\end{tabular}

ra] Accuracy of tabulated data is poor due to its low magnitude relative to noise level.

[b] Acceleration believed to be local and/or high level noise, not structural as displacements are less than $0.25 \mu \mathrm{m}$.

[c] Data have a bias zero shift and/or the signal is highly nonsymmetric (indicating unbounded displacements.).

[d] Signal appears to be $60-\mathrm{Hz}$ noise.

[e] Data are highty questionable due to nonsymmetric characteristics.

[f] Signal failed.

[g] High degree.. of noise prior to time zero has definite effect on signal after time zero, making resulits of data reduction. questinnable:

[h] Integration of the data yields deflections which increase: in magnitude throughout the: subcooled blowdown state indicating the data: are invalid: 


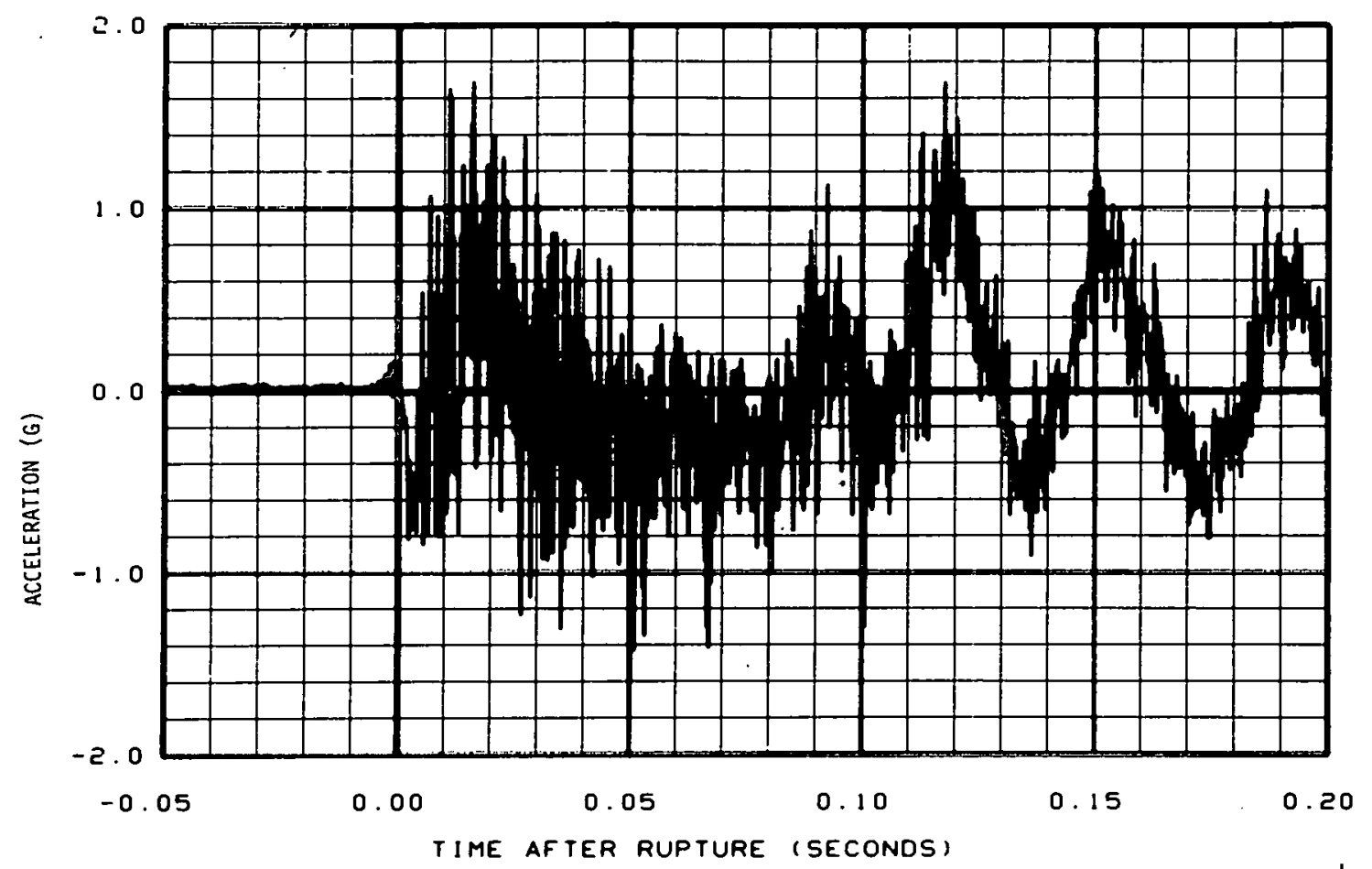

Fig. 2 Acceleration at simulated steam generator flange, East-West (AE-BL2-1).

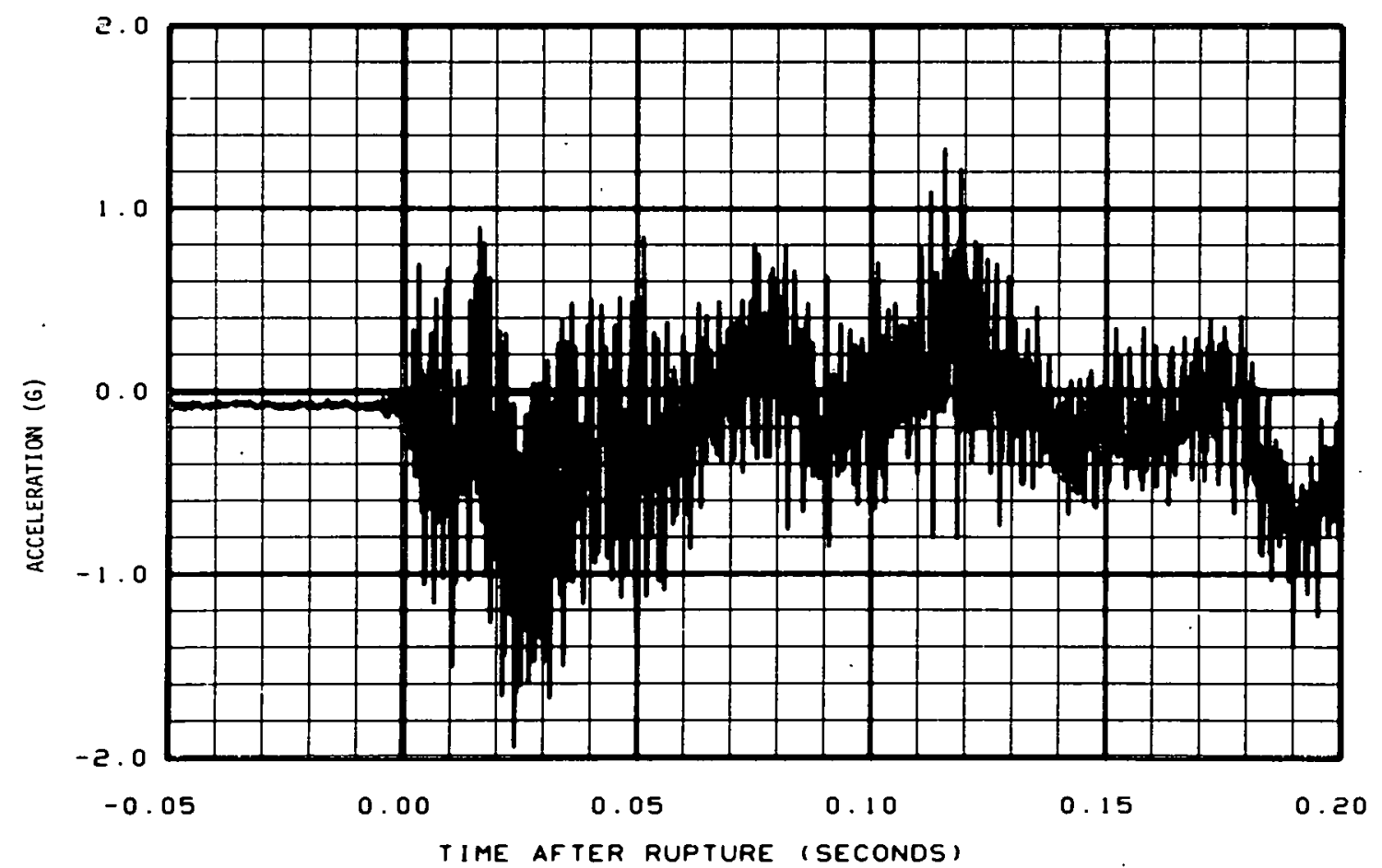

Fig. 3 Acceleration at simulated steam generator flange, North-South $(A E-B L 2-2)$. 


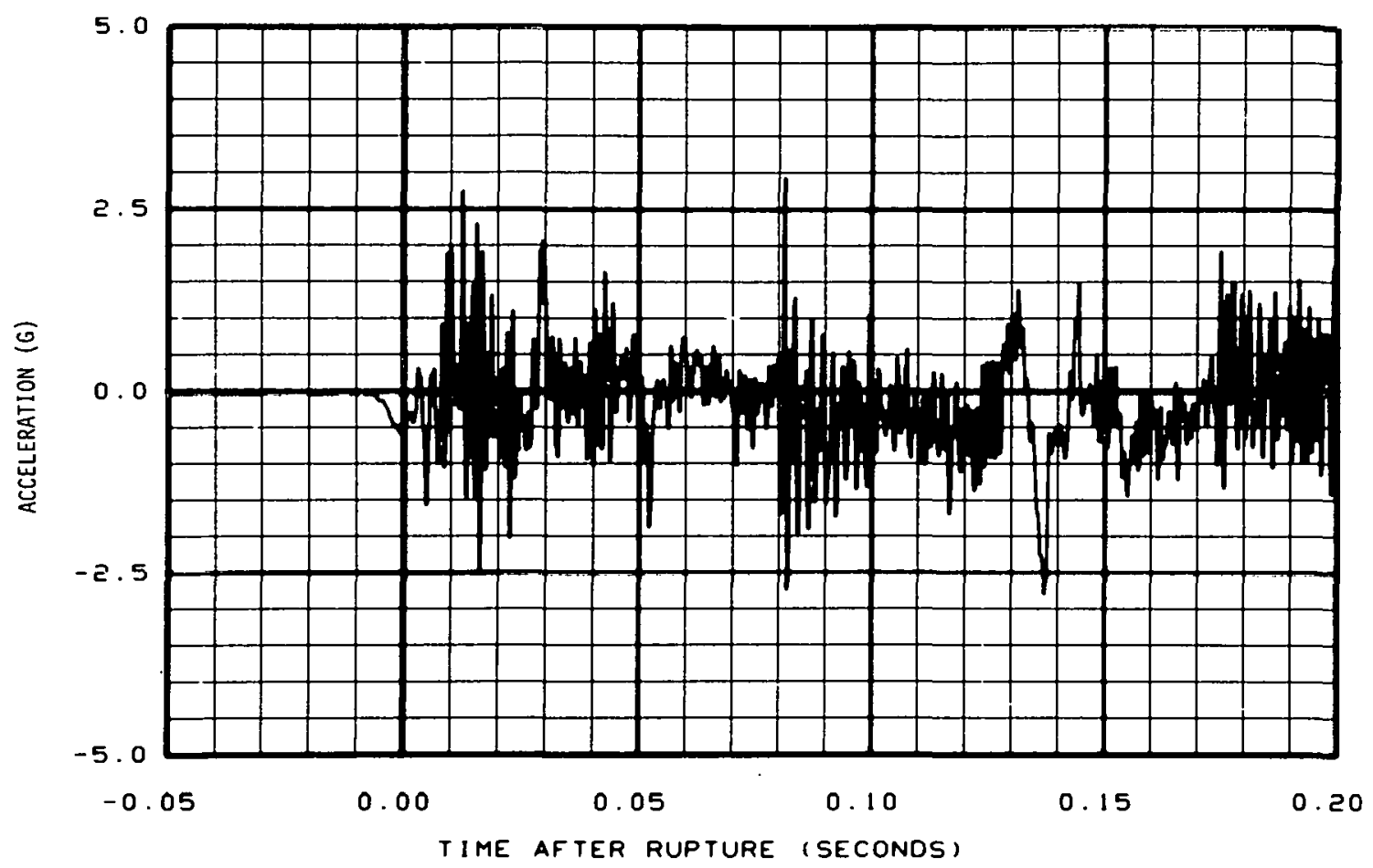

Fig. 4 Acceleration at simulated steam generator top, vertical (AE-BL-3-1).

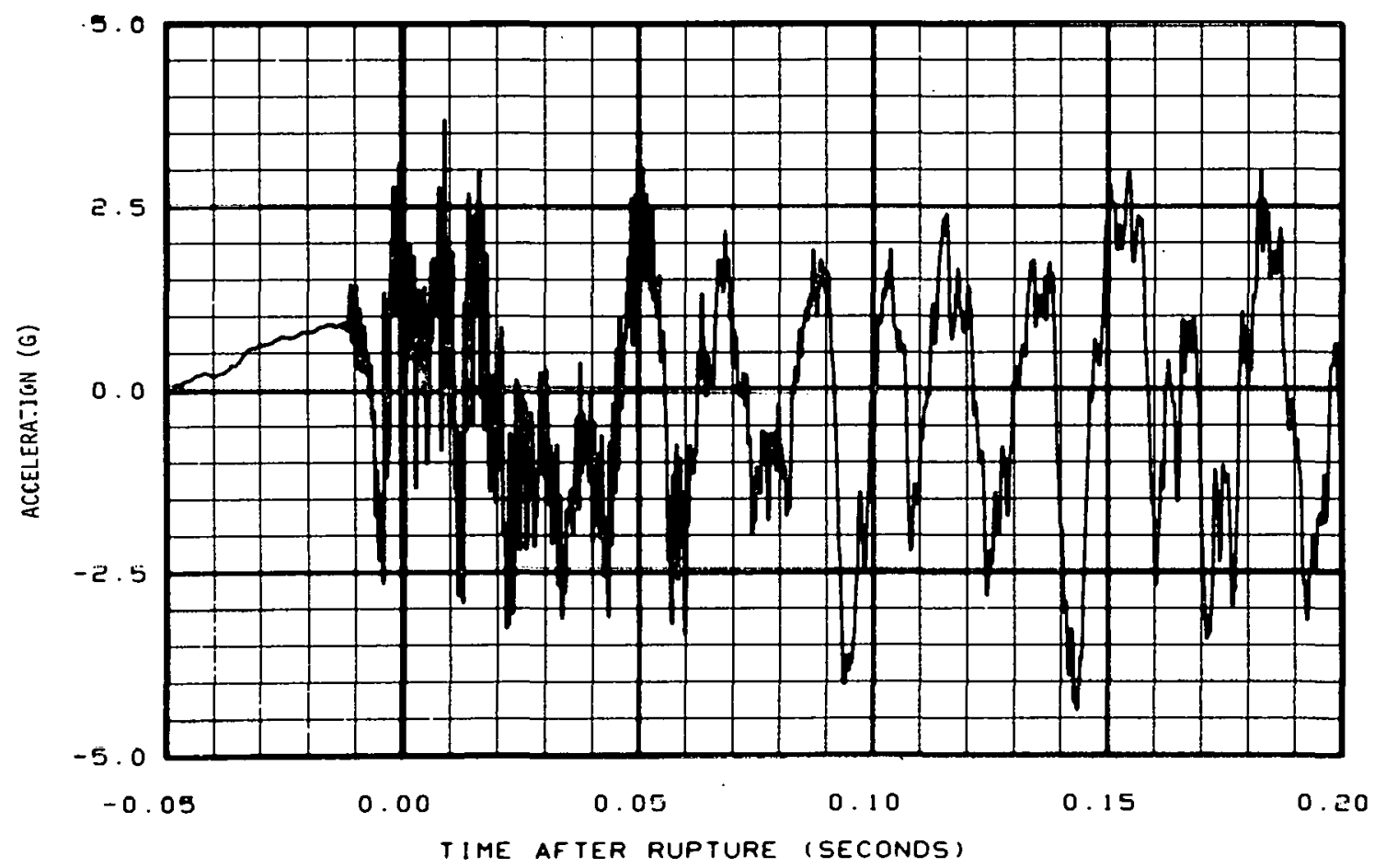

Fig. 5 Acceleration at QOBV, cold leg, North-South (AE-BL4-1). 


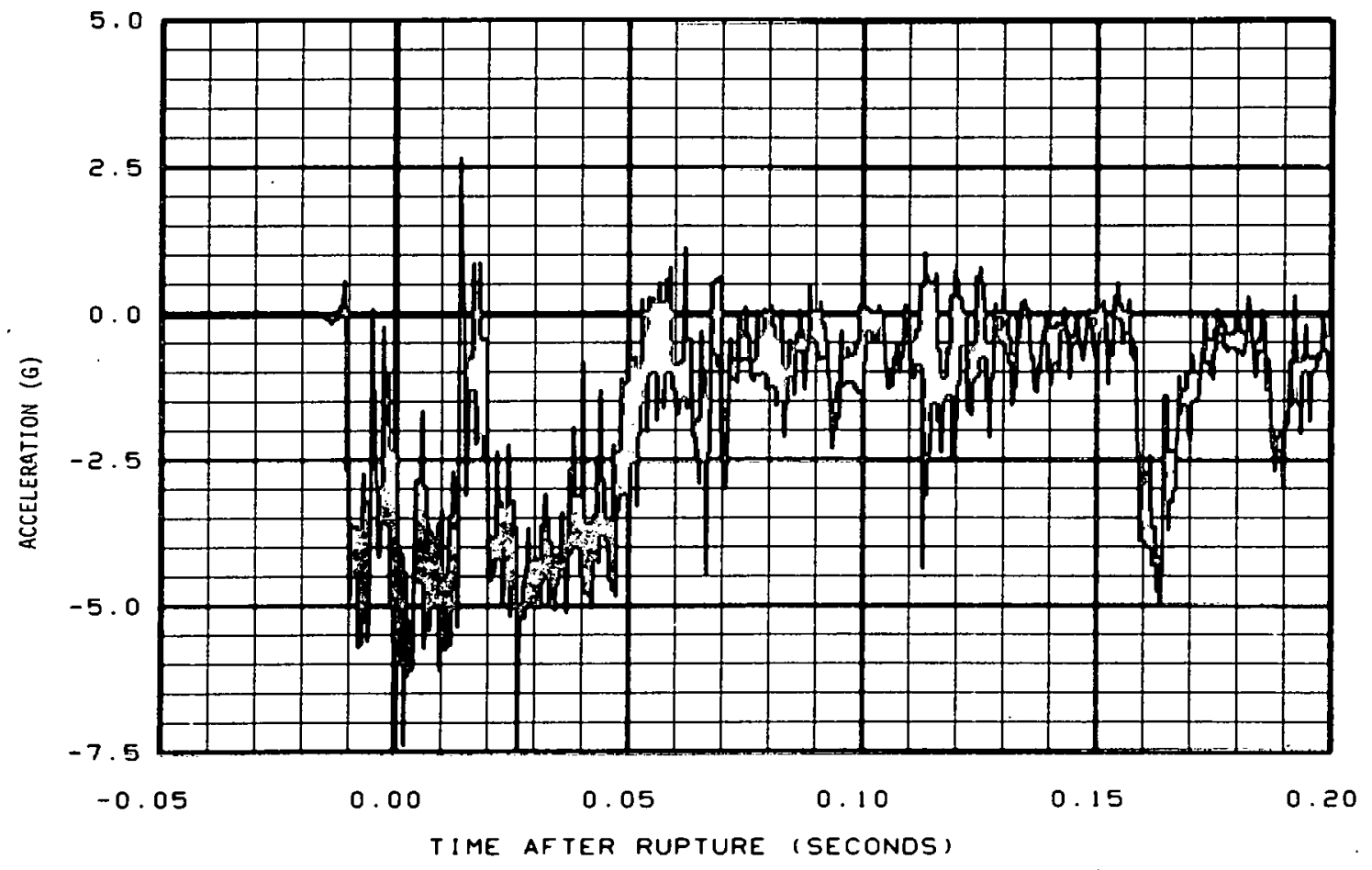

Fig. 6 Acceleration at QOBV, hot leg, North-South (AE-BL5-1).

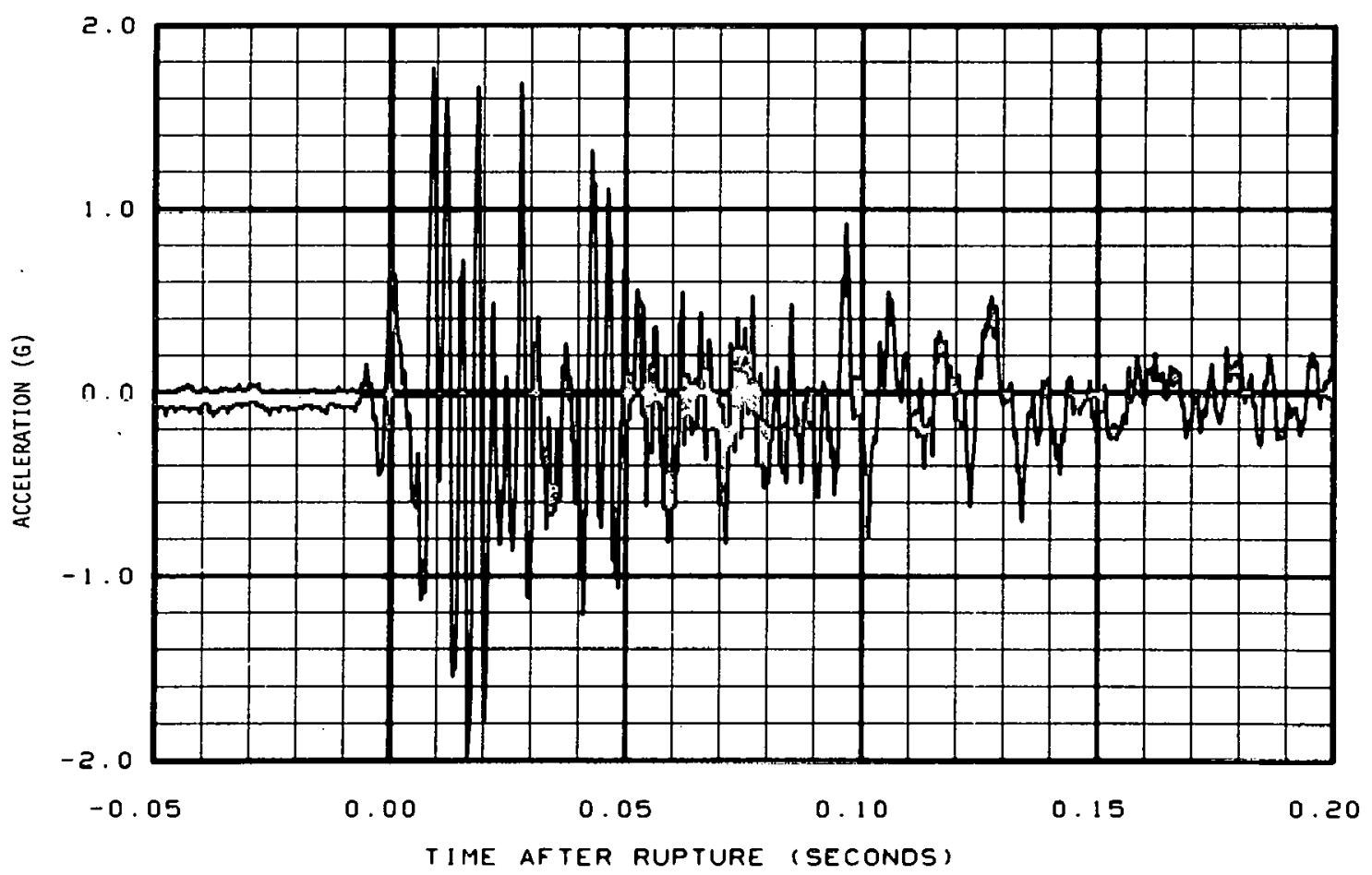

Fig. 7 Acceleration at 90-degree-elbow downstream of primary coolant pumps, East-West (AE-PC3-1). 


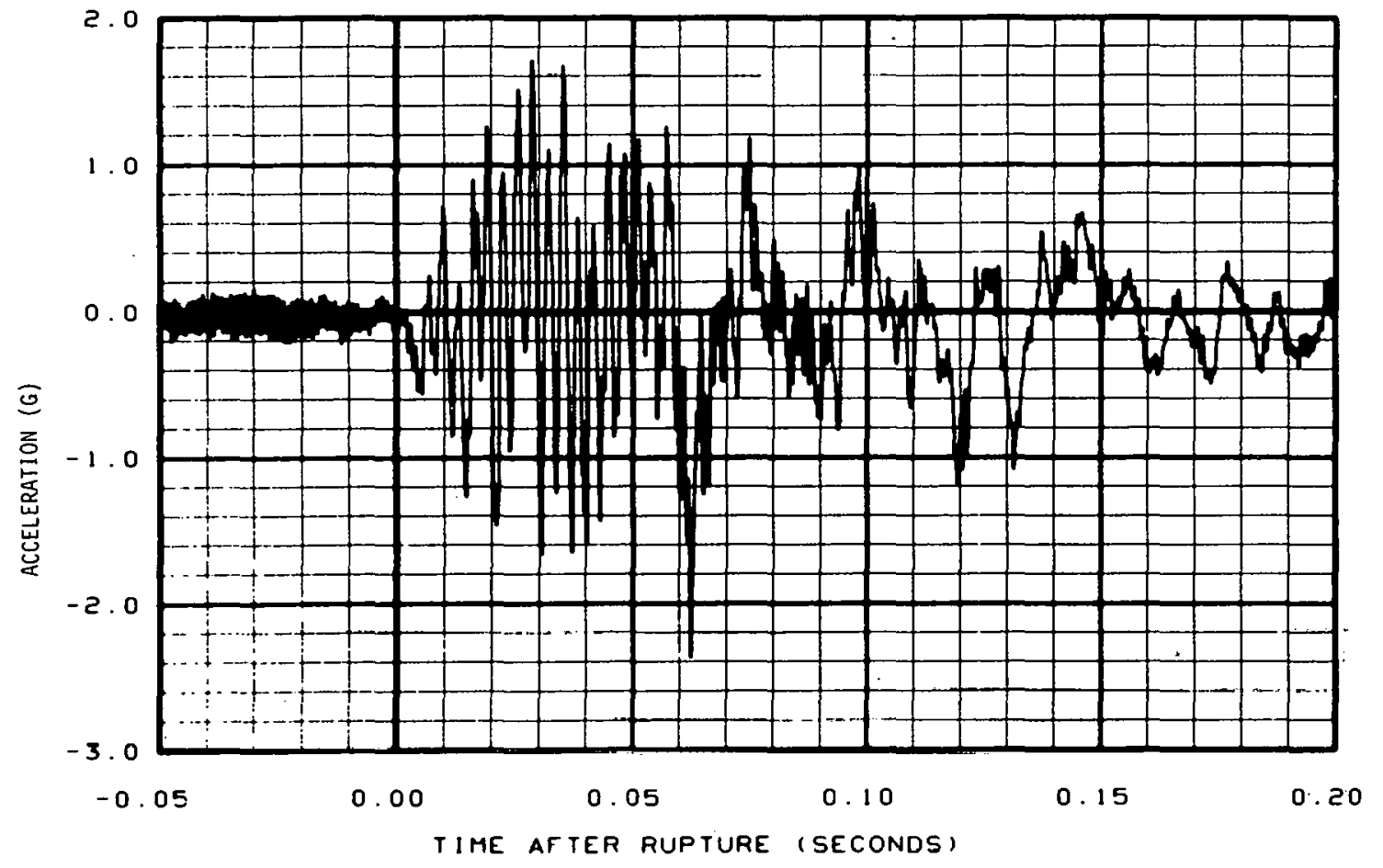

Fig. 8 Acceleration at 90-degree-elbow downstream of primary coolant pumps, North-South (AE-PC3-2).

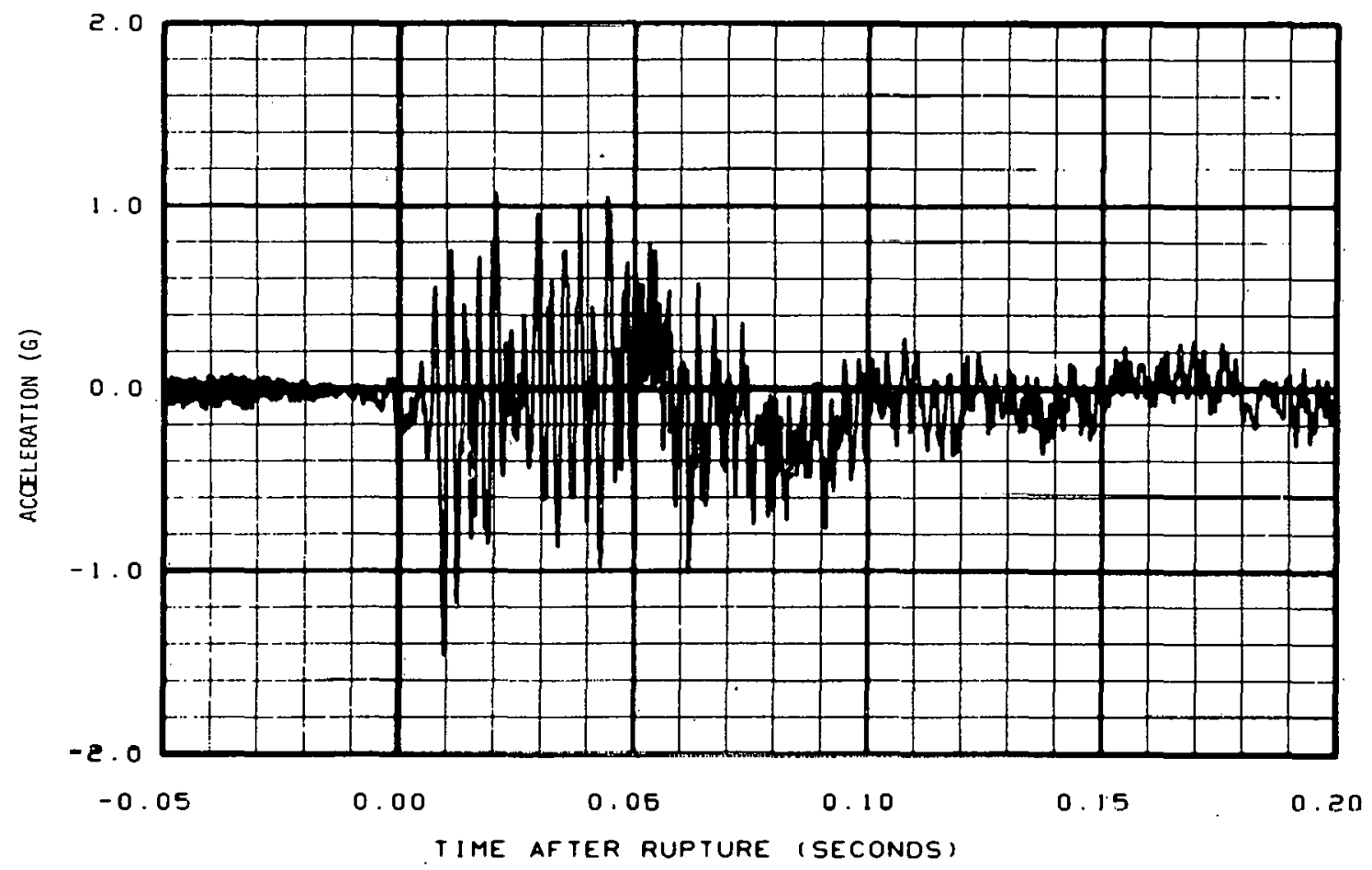

Fig. 9 Acceleration at 90 -degree-el bow downstream of primary coolant pumps, vertical (AE-PC 3-3). 


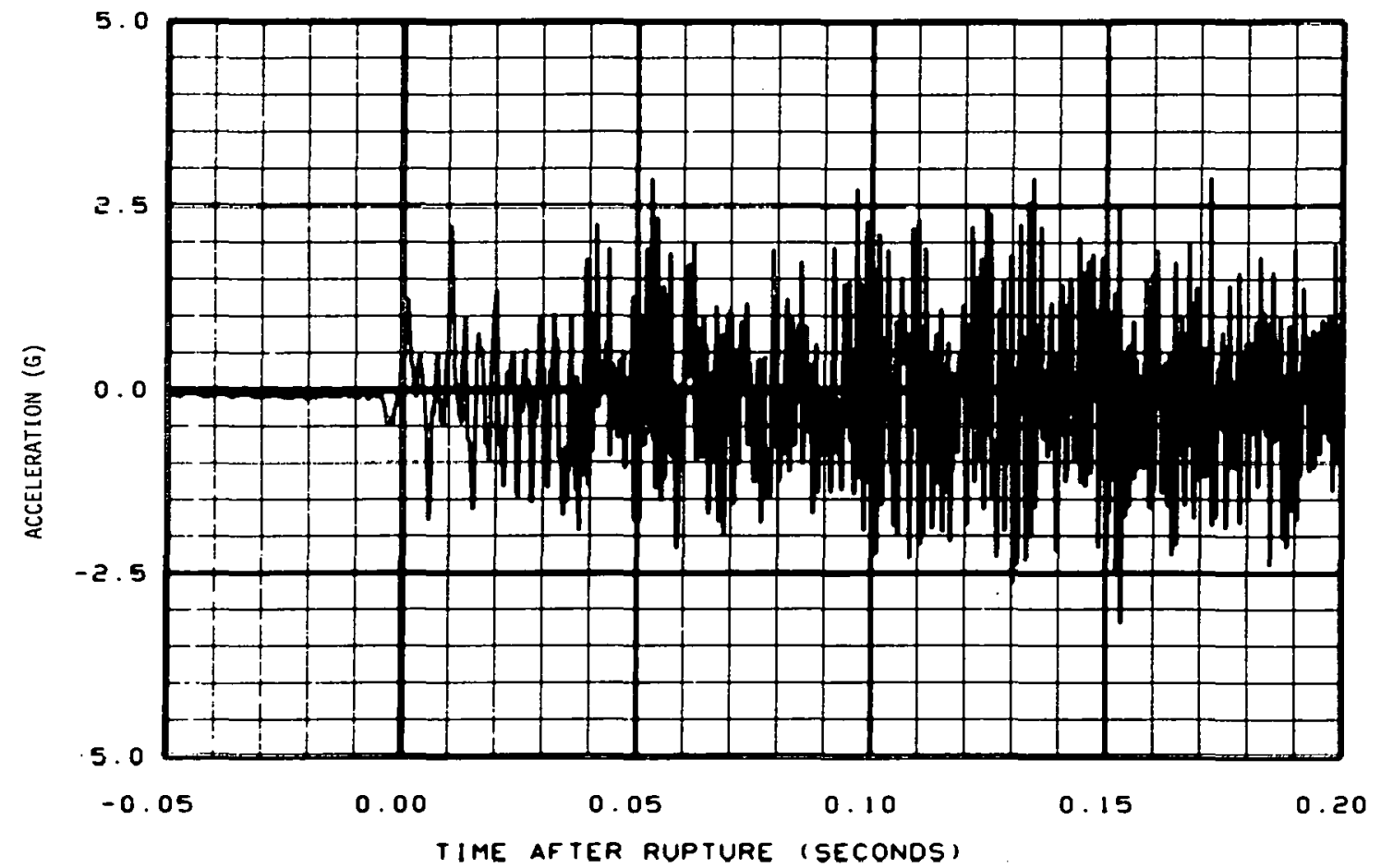

Fig. 10 Acceleration at 45-degree-elbow in intact loop hot leg, East-: West $(A E-P C 6-1)$.

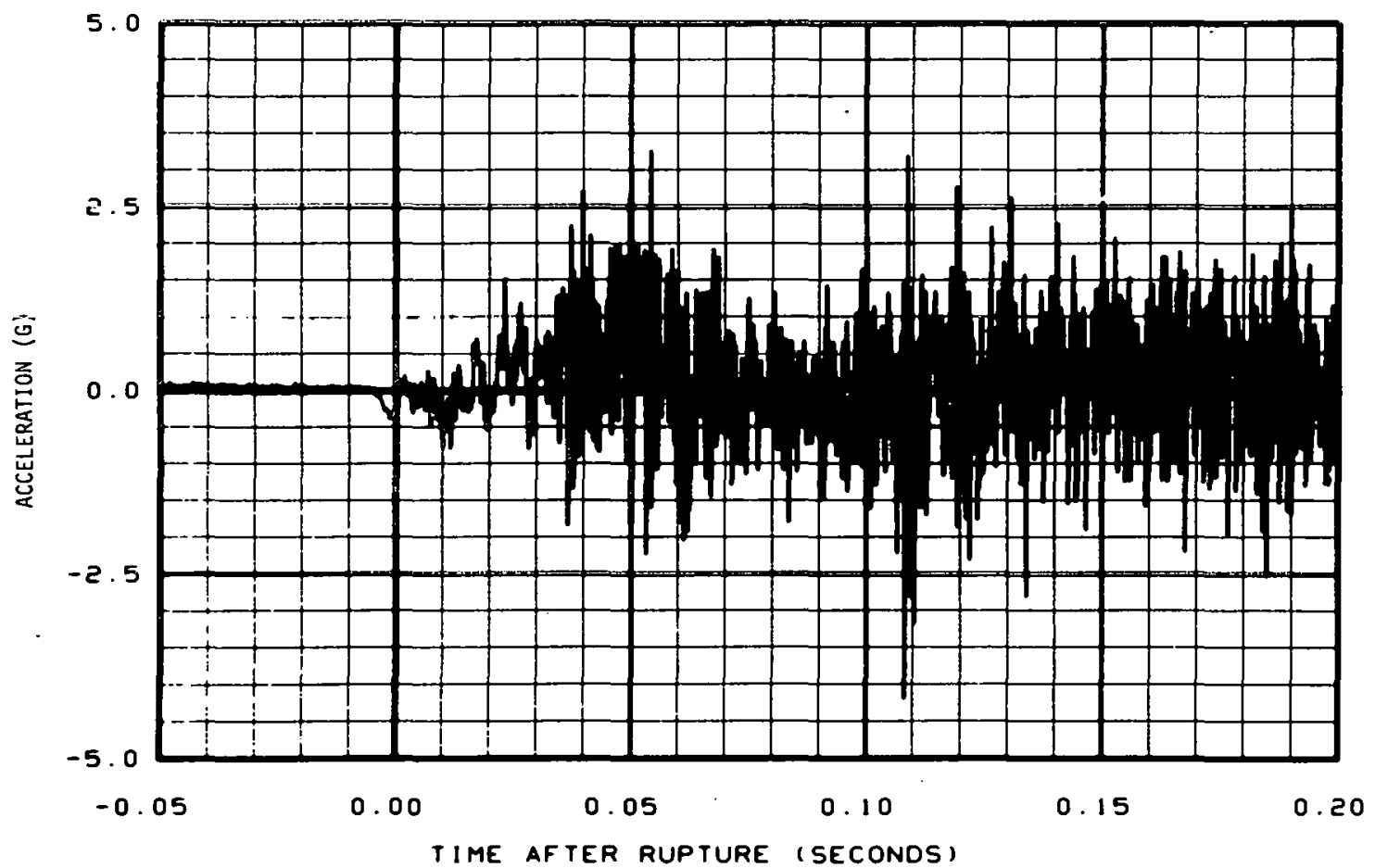

Fig. 11 Acceleration at 45-degree-elbow in intact loop hot leg, NorthSouth (AE-PC6-2). 


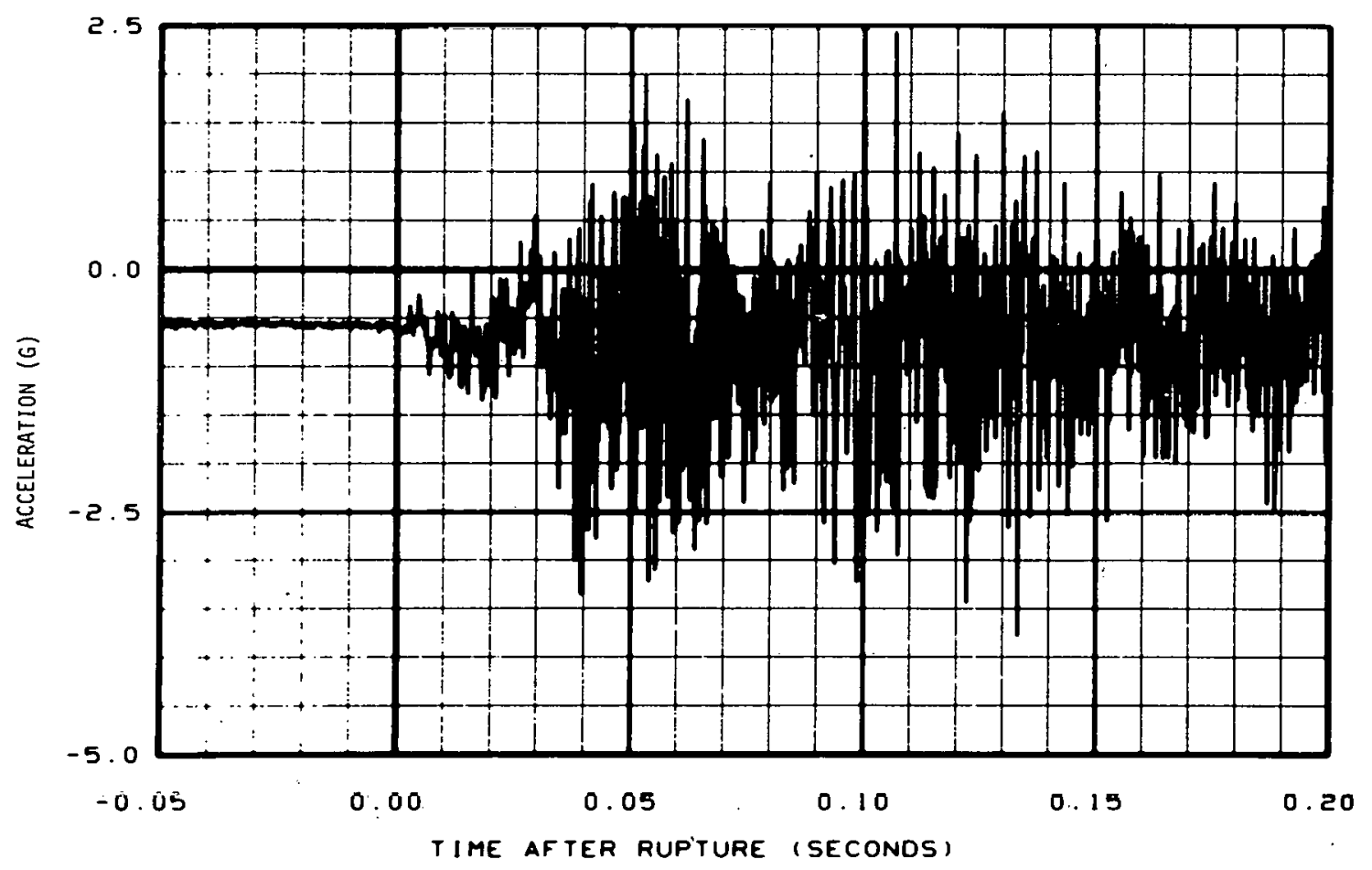

Fig. T2 Acceleration at: 45-degree-elbow in intact loop hot leq. vertical (AE-PC6-3) .

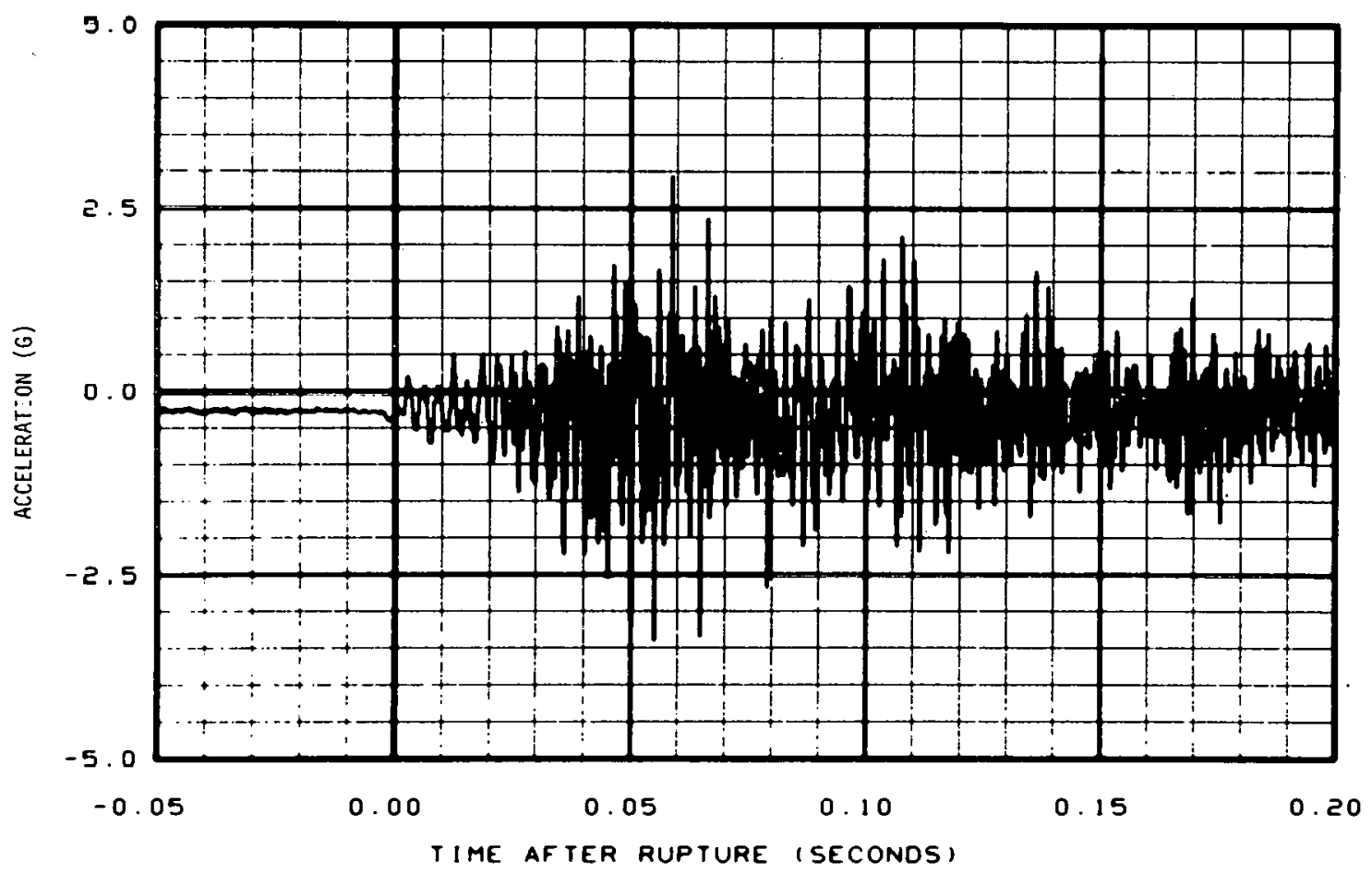

Fig. 13 Acceleration at 90-degree-elbow in intact loop hot 1eg, EastWest (AE-PC7-1). 


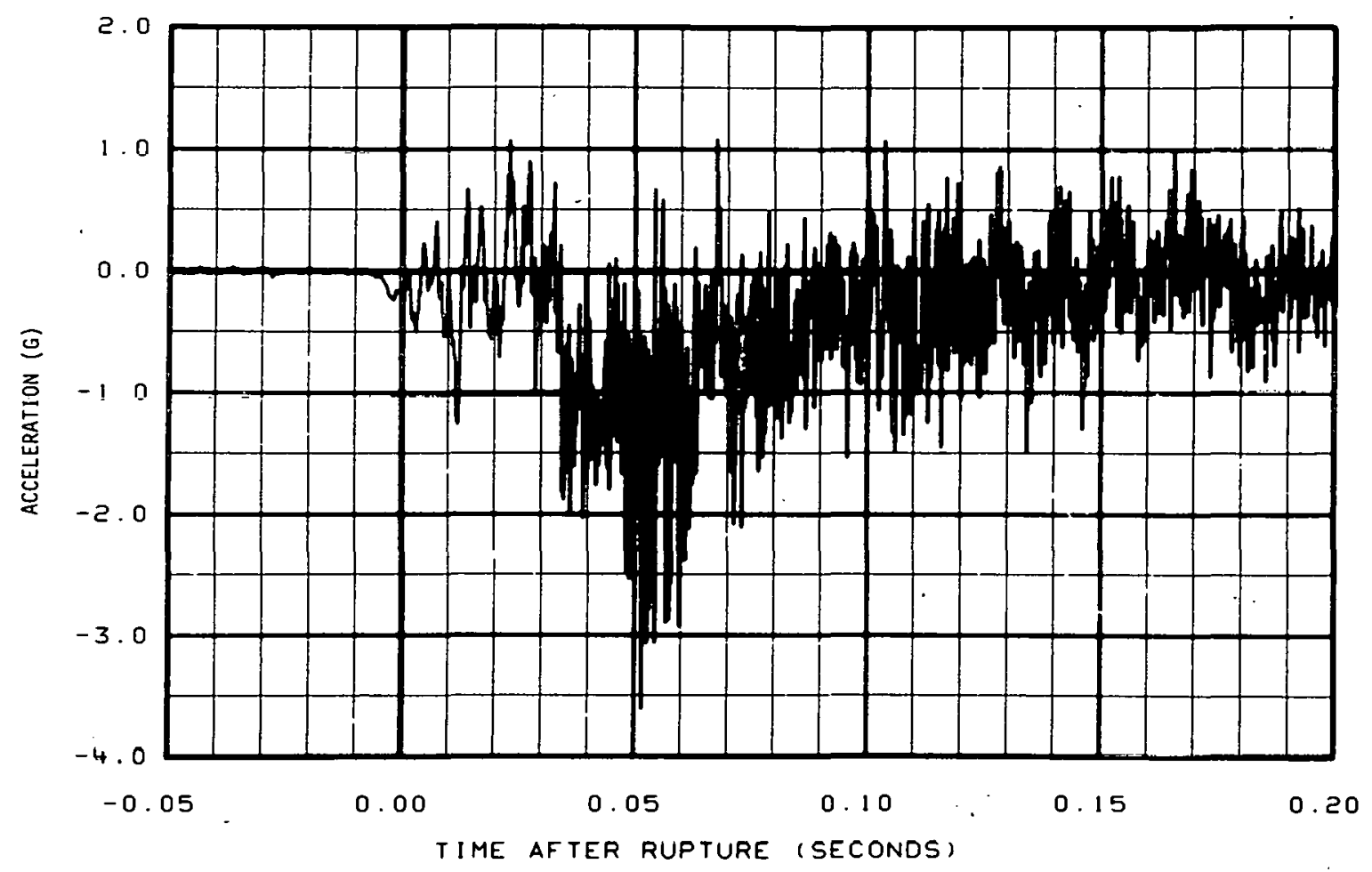

Fig. 14 Acceleration at 90-degree-elbow in intact loop hot leg, NorthSouth (AE-PC7-2).

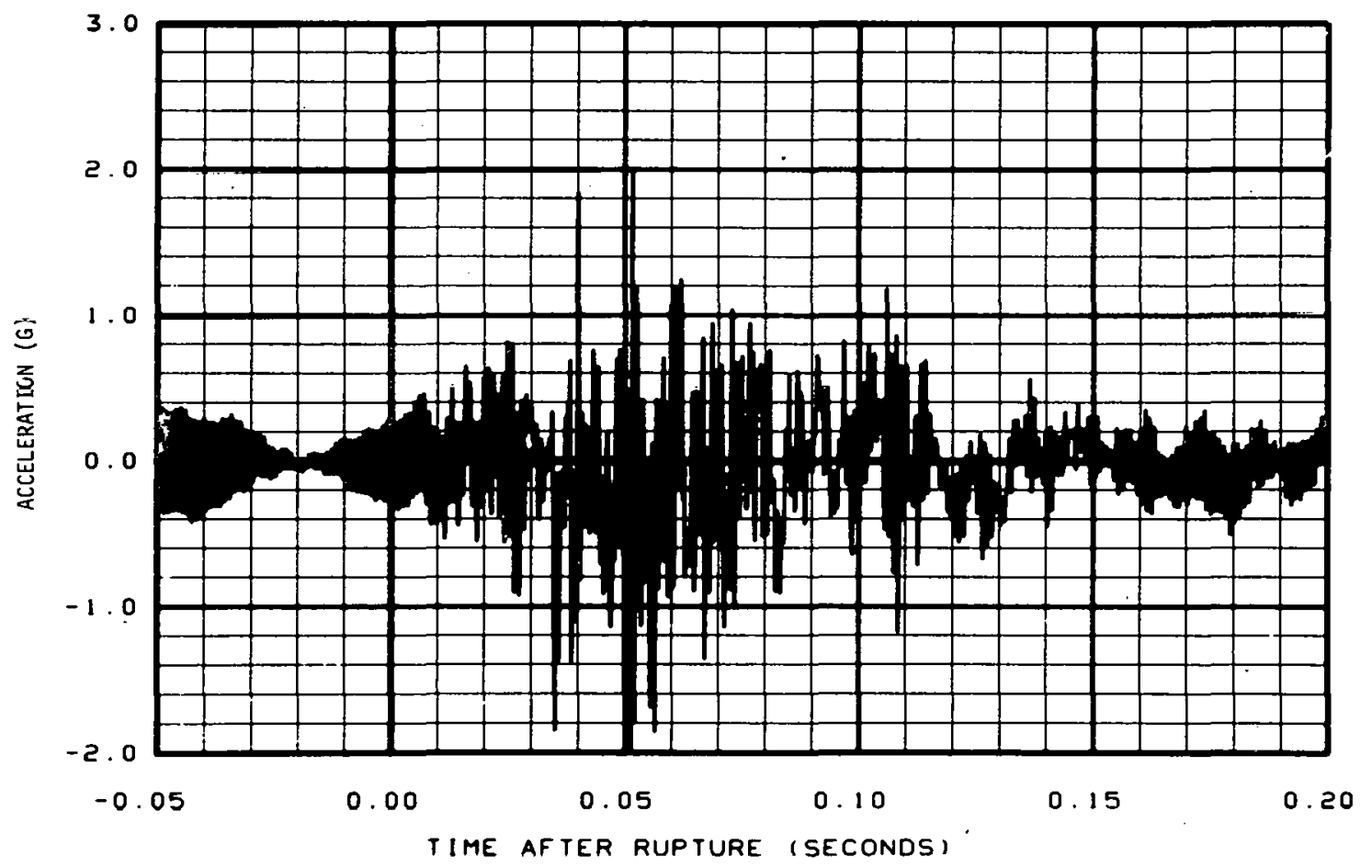

Fig. 15 Acceleration at primary coolant pump inlet, East-West (AE-PC16-1). 


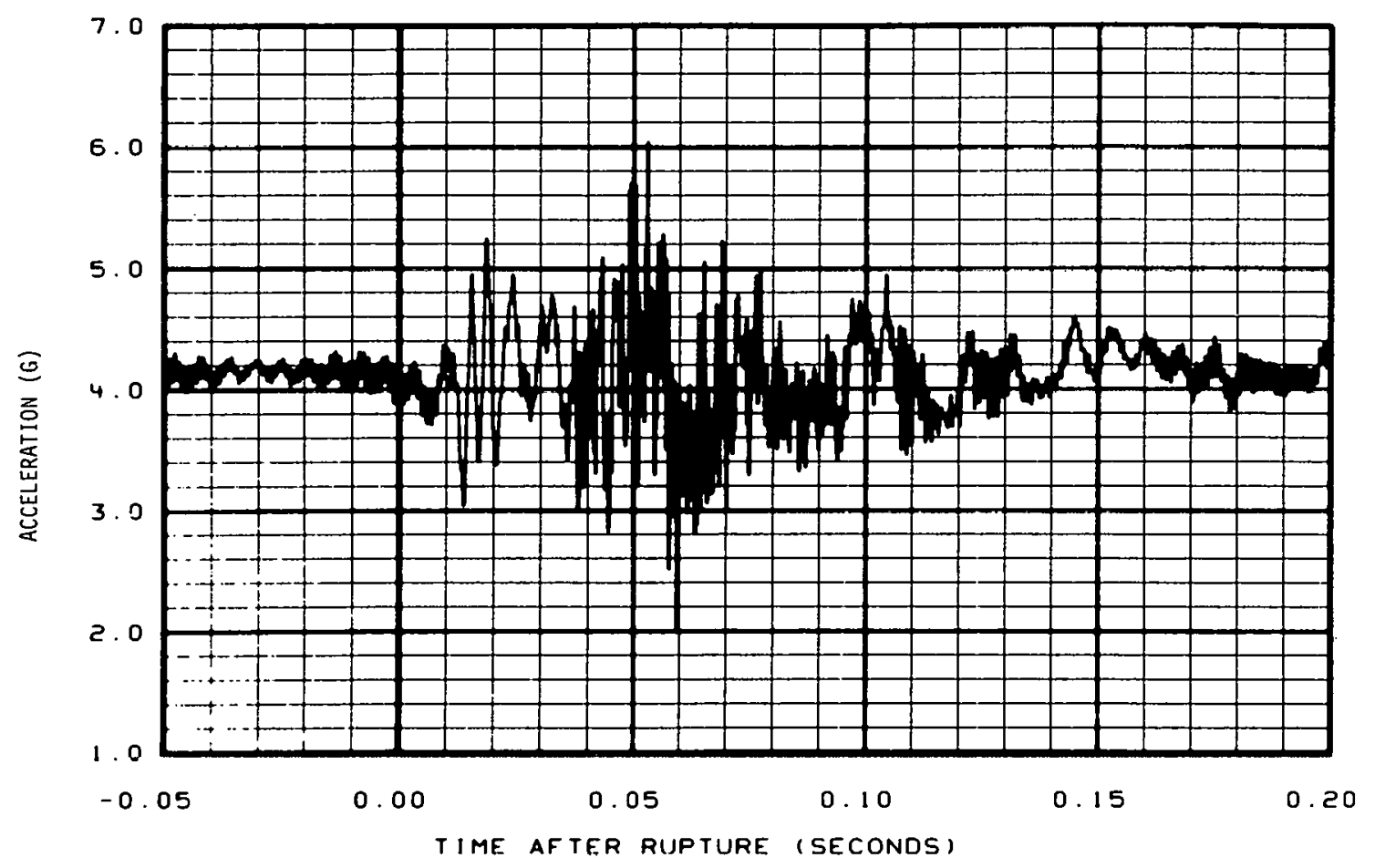

Fig. 16 Acceleration at primary coolant pump inlet, North-South (AE-PC16-2).

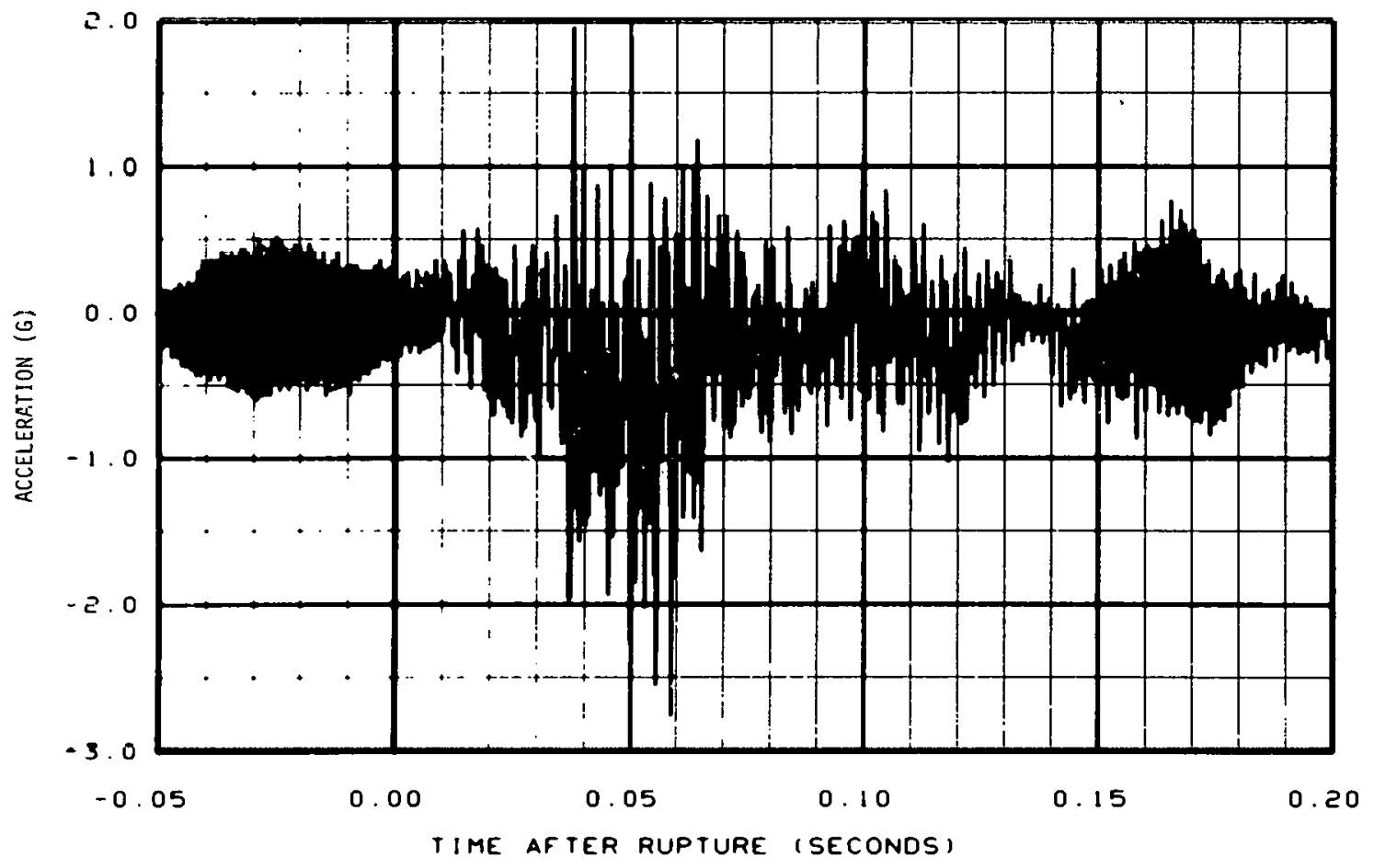

Fig. 17 Acceleration at primary coolant pump inlet, vertical (AE-PC16-3). 


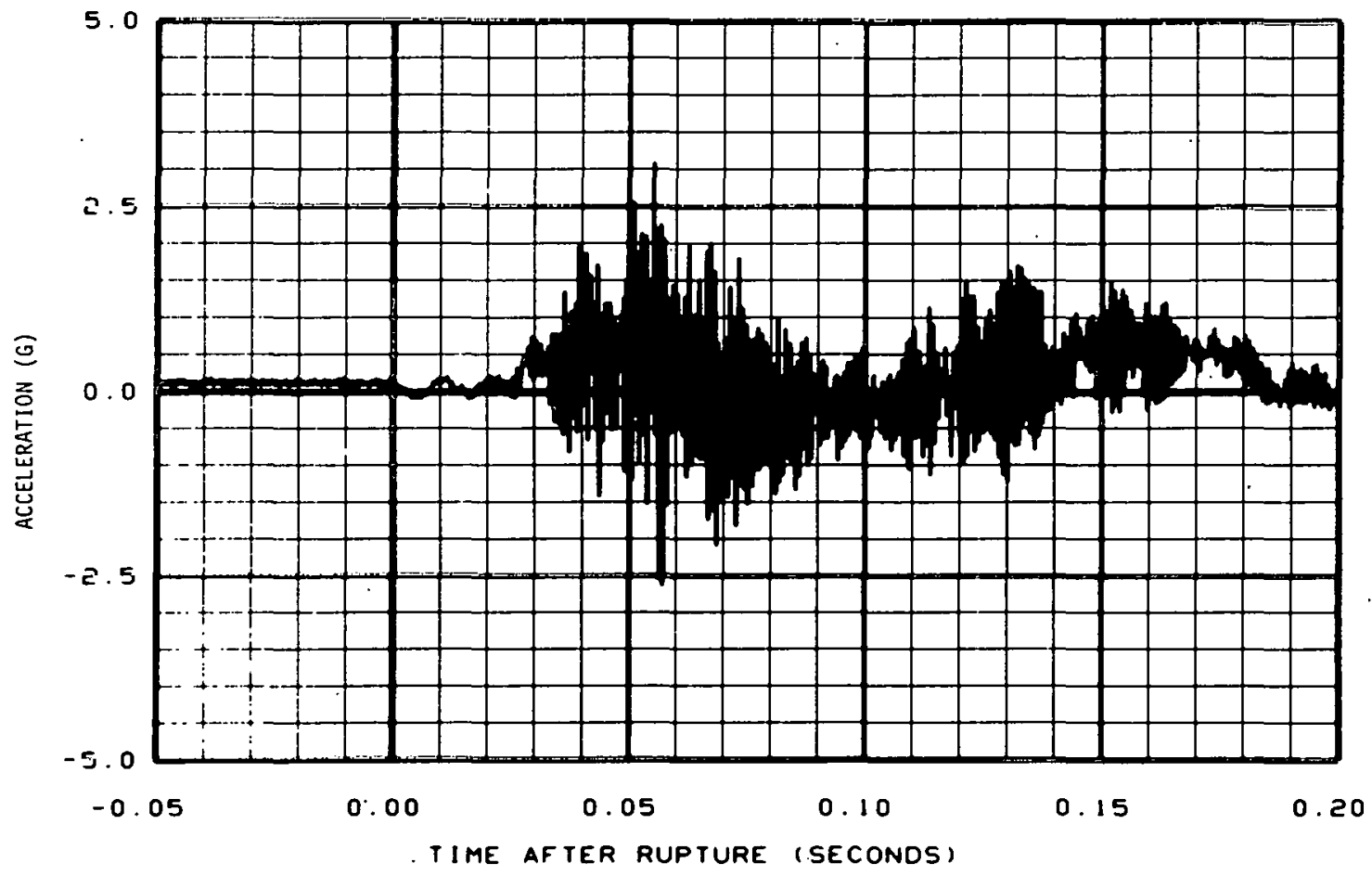

Fig. 18 Acceleration at steam generator north side, East-West (AE-PC17-1).

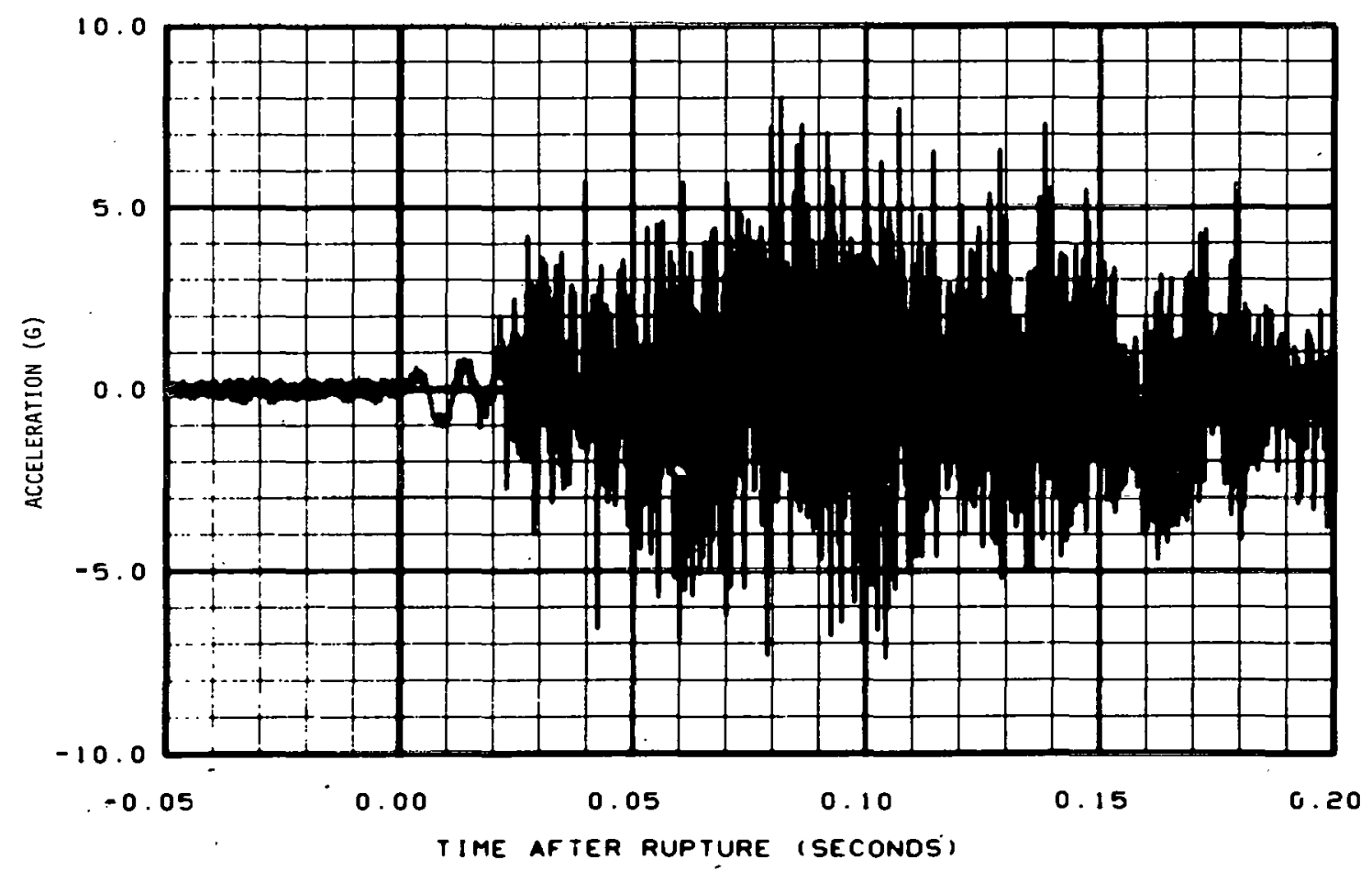

Fig. 19 Acceleration at steam generator north side, North-South (AE-PC17-2). 


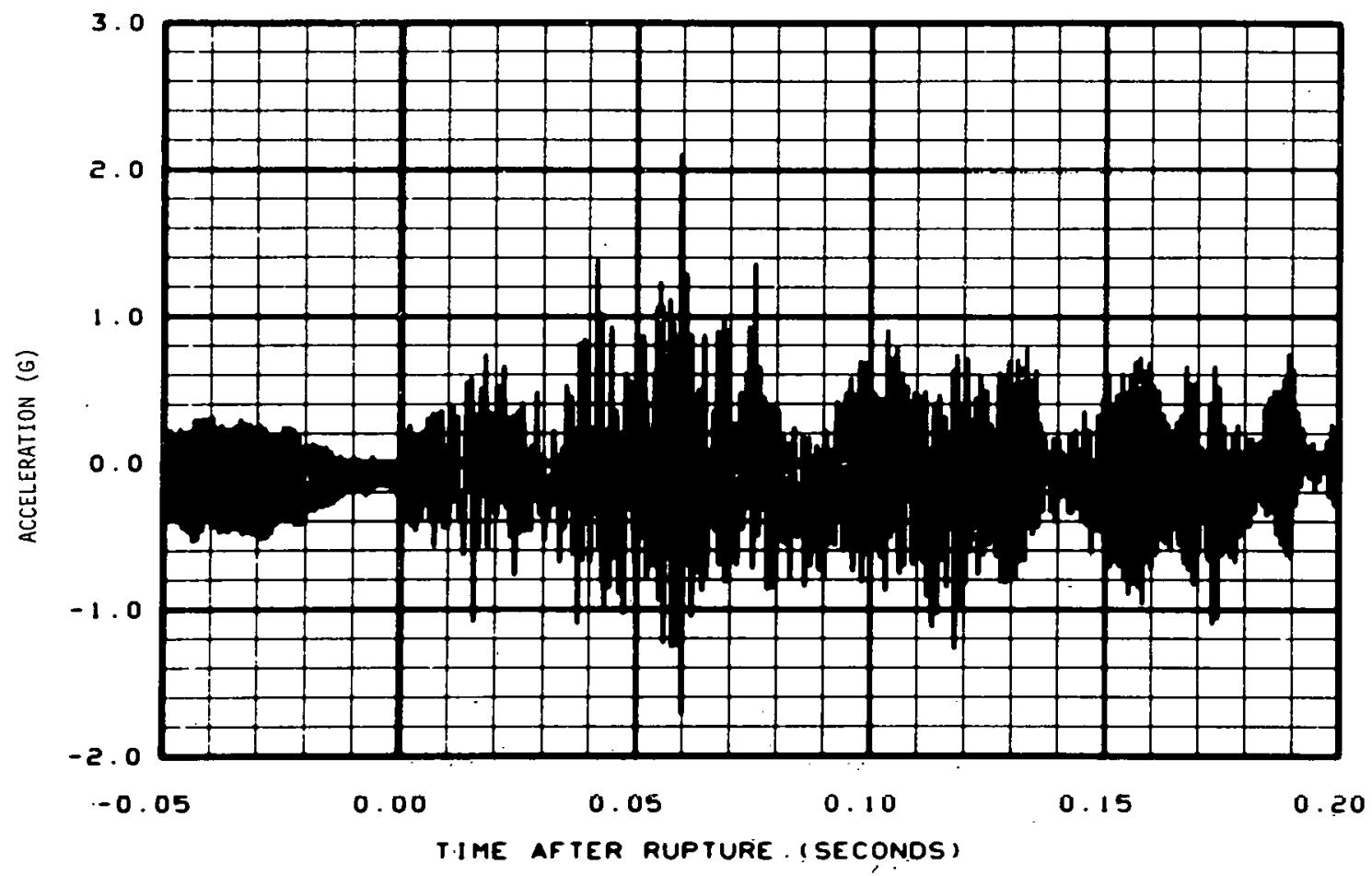

Fig. 20 Acceleration at primary coolant pump 1 north side, East-West (AE-PC18-1).

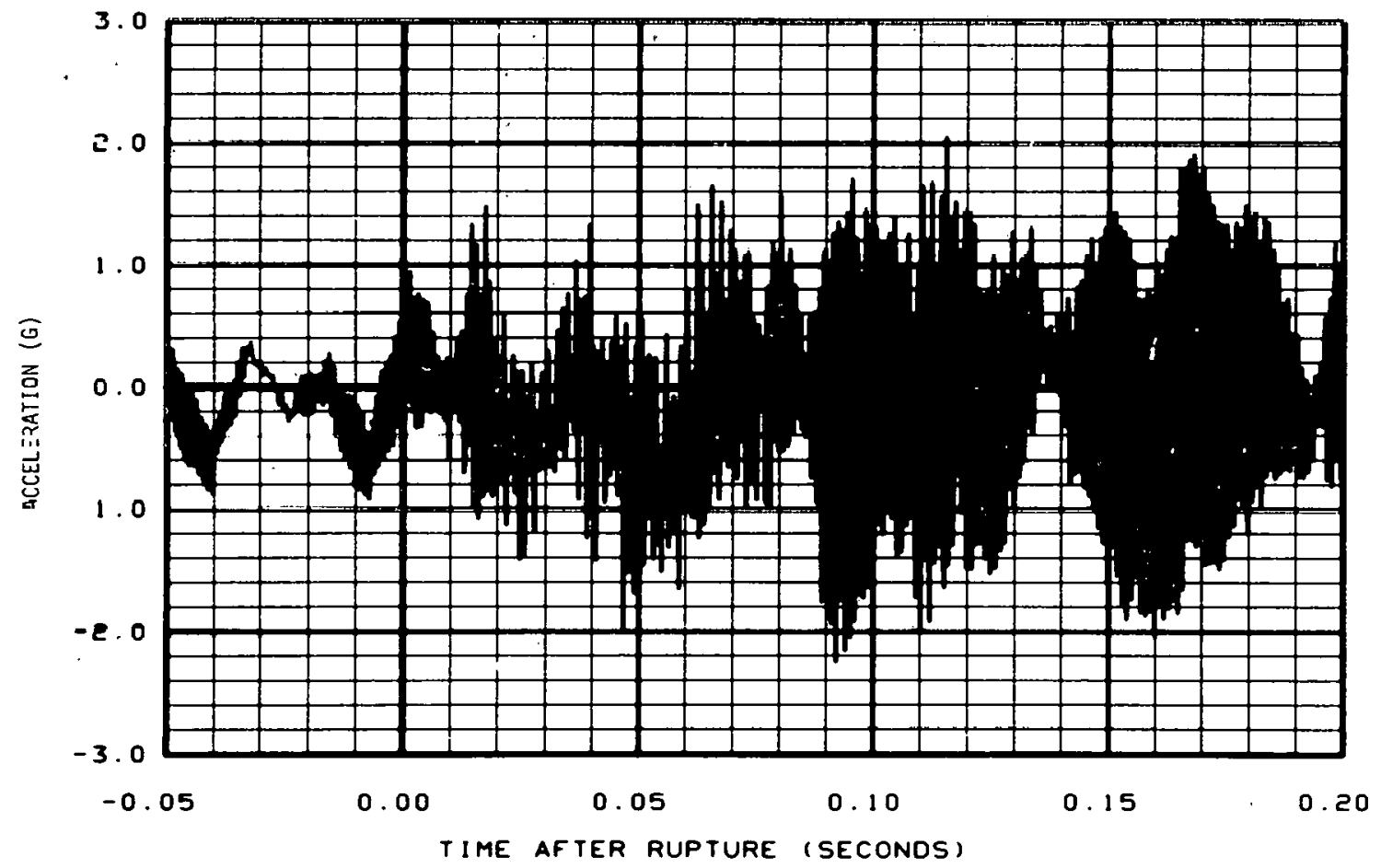

Fig. 21 Acceleration at primary coolant pump 1 north side, North-South (AE-PC18-2). 


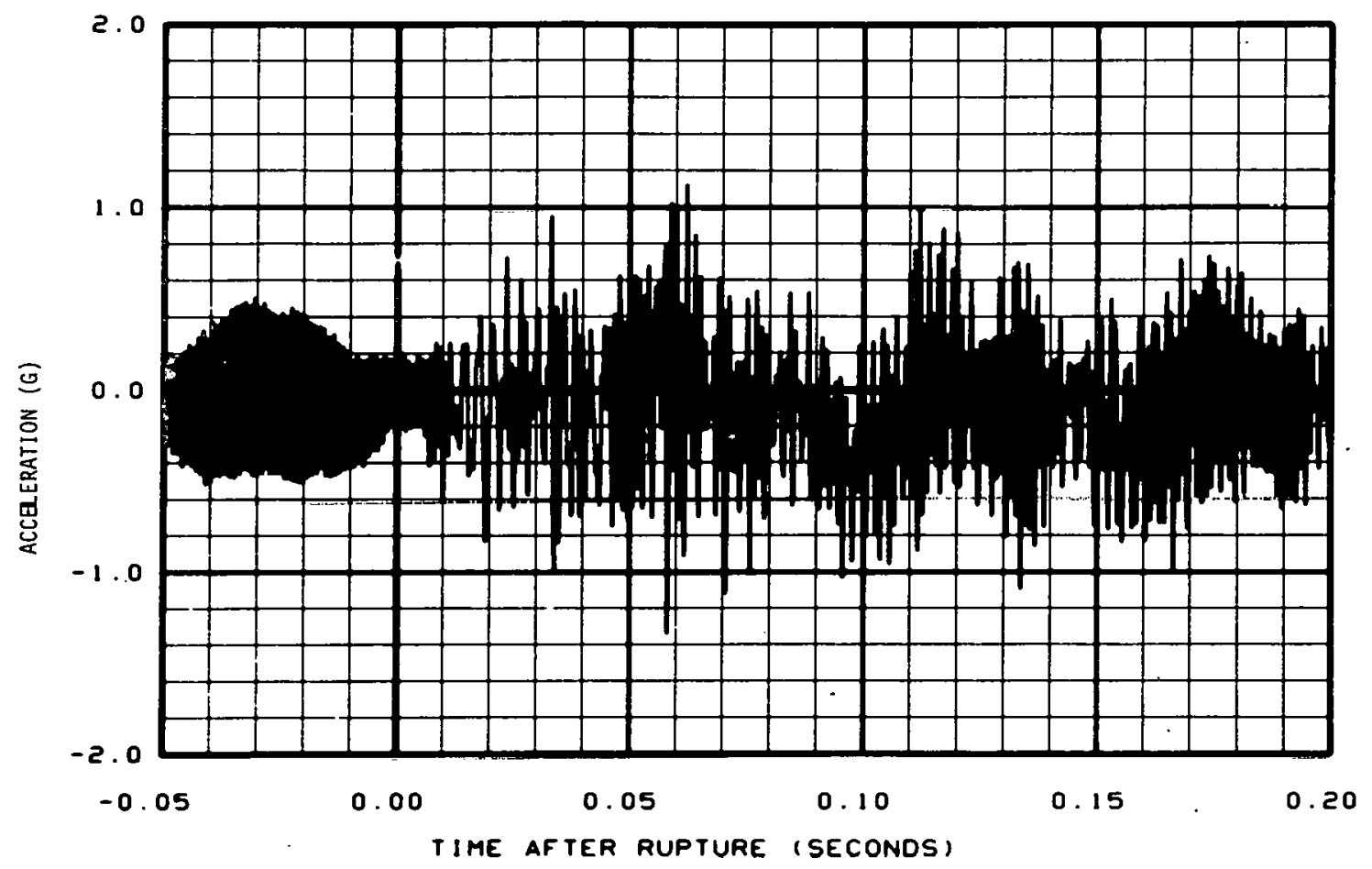

Fig. 22 Acceleration at primary coolant pump 1 north side, vertical (AE-PC18-3).

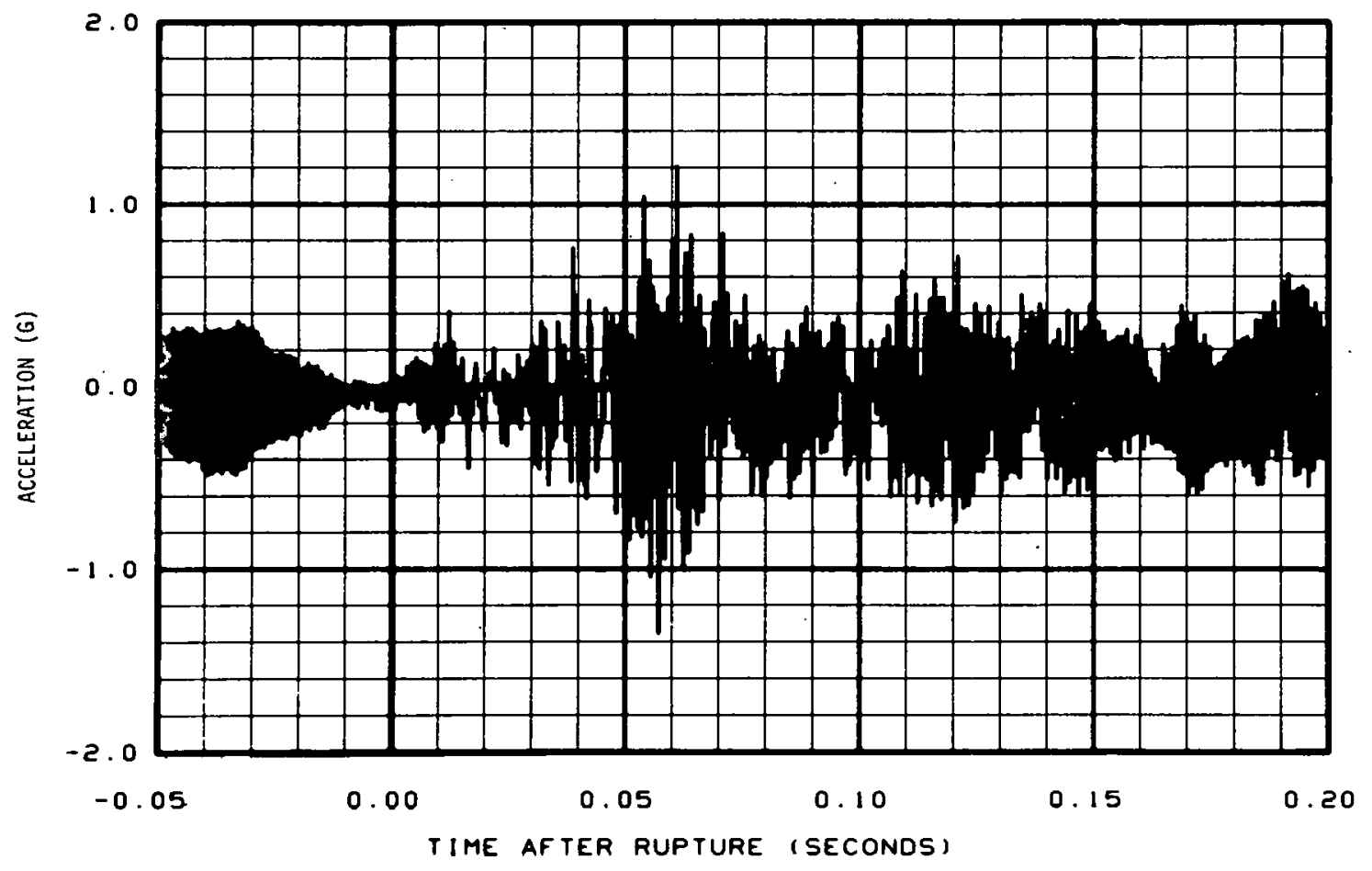

Fig. 23 Acceleration at primary coolant pump 2 north side, East-West (AE-PC19-1). 


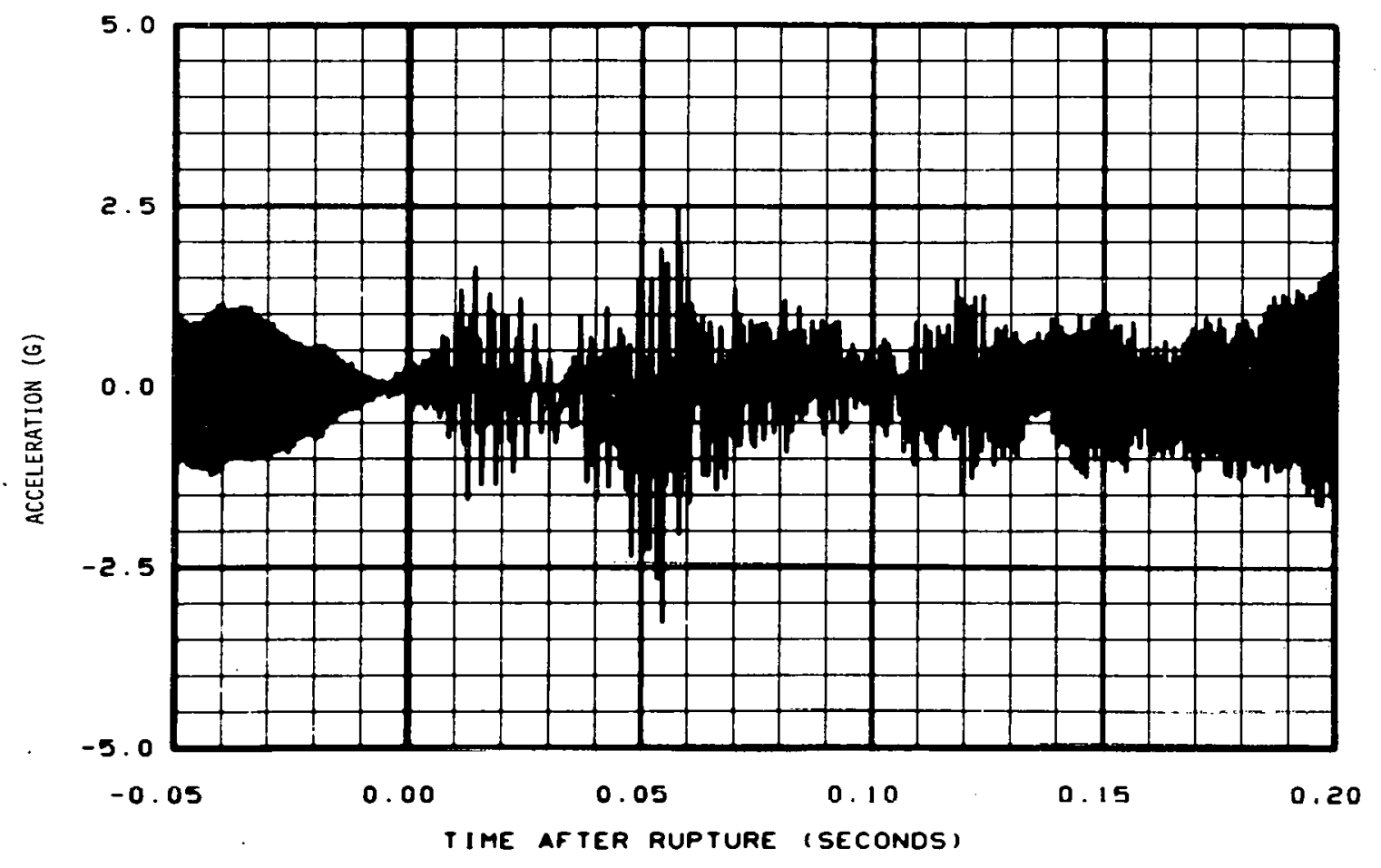

Fig. 24 Acceleration at primary coolant pump 2 north side, North-South (AE-PC19-2).

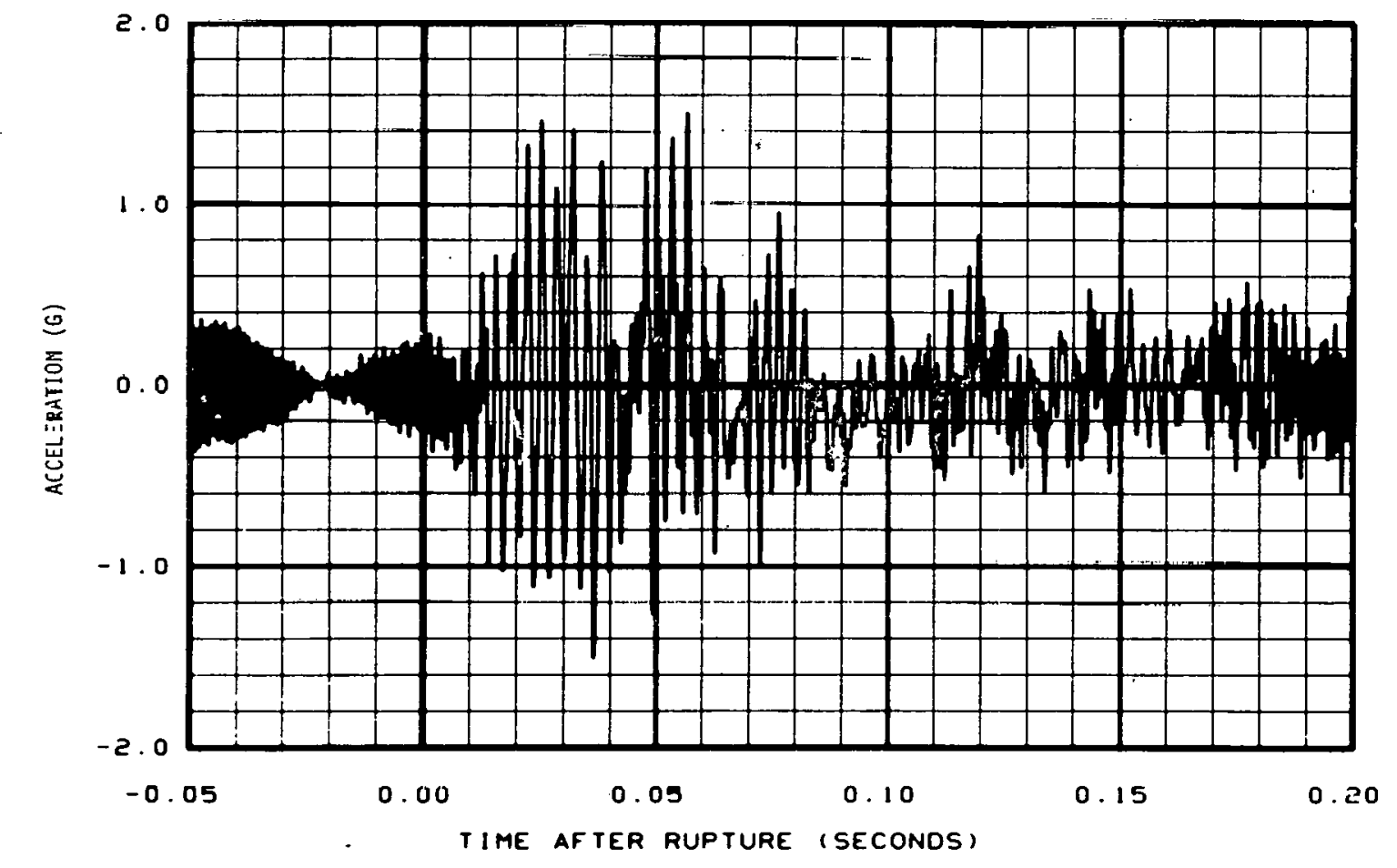

Fig. 25 Acceleration at primary coolant pump 2 north side, vertical (AE-PC19-3). 


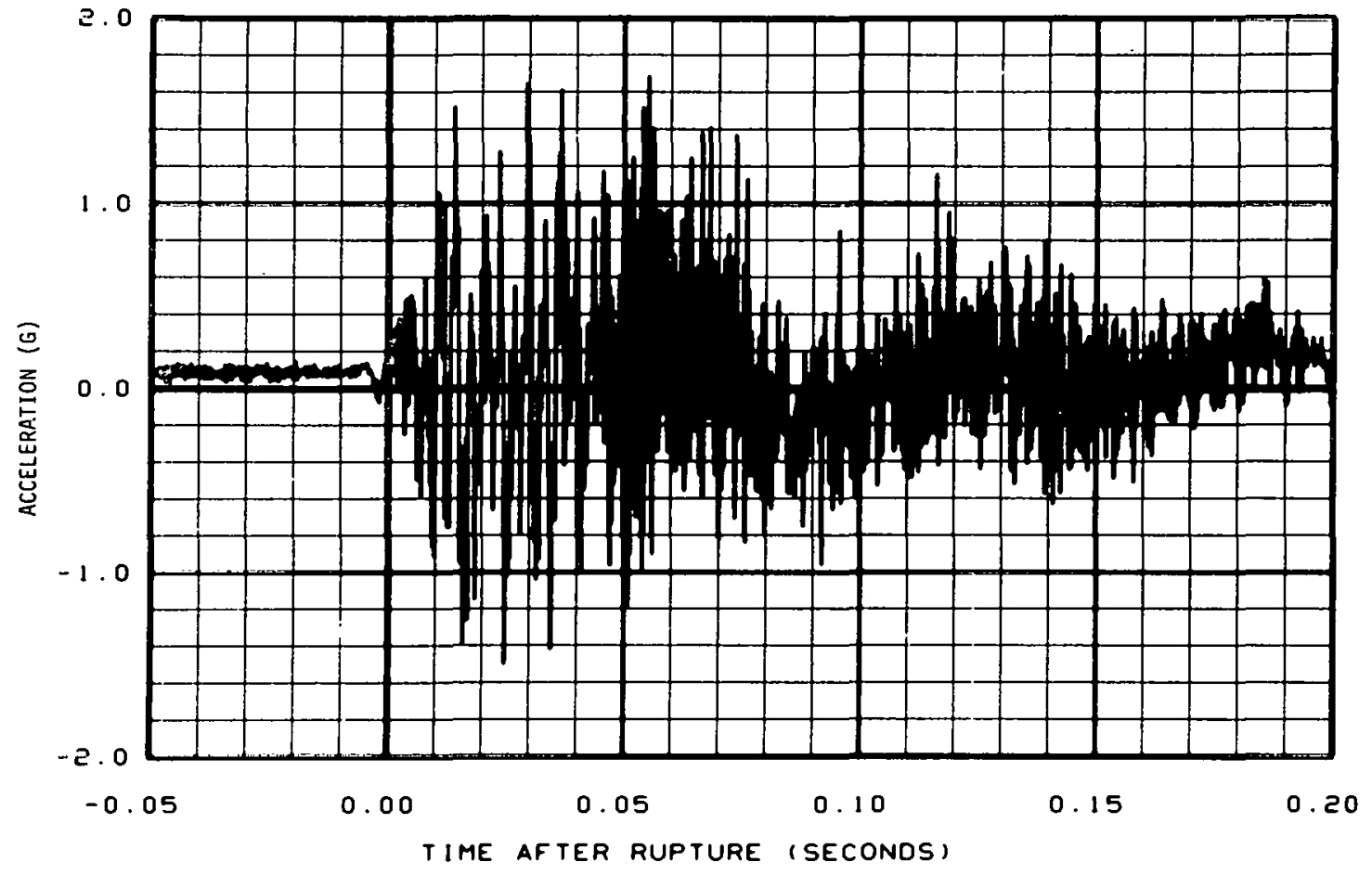

Fig. 26 Acceleration at bottom of reactor vessel, west side, East-West $(A E-R V 1-1)$.

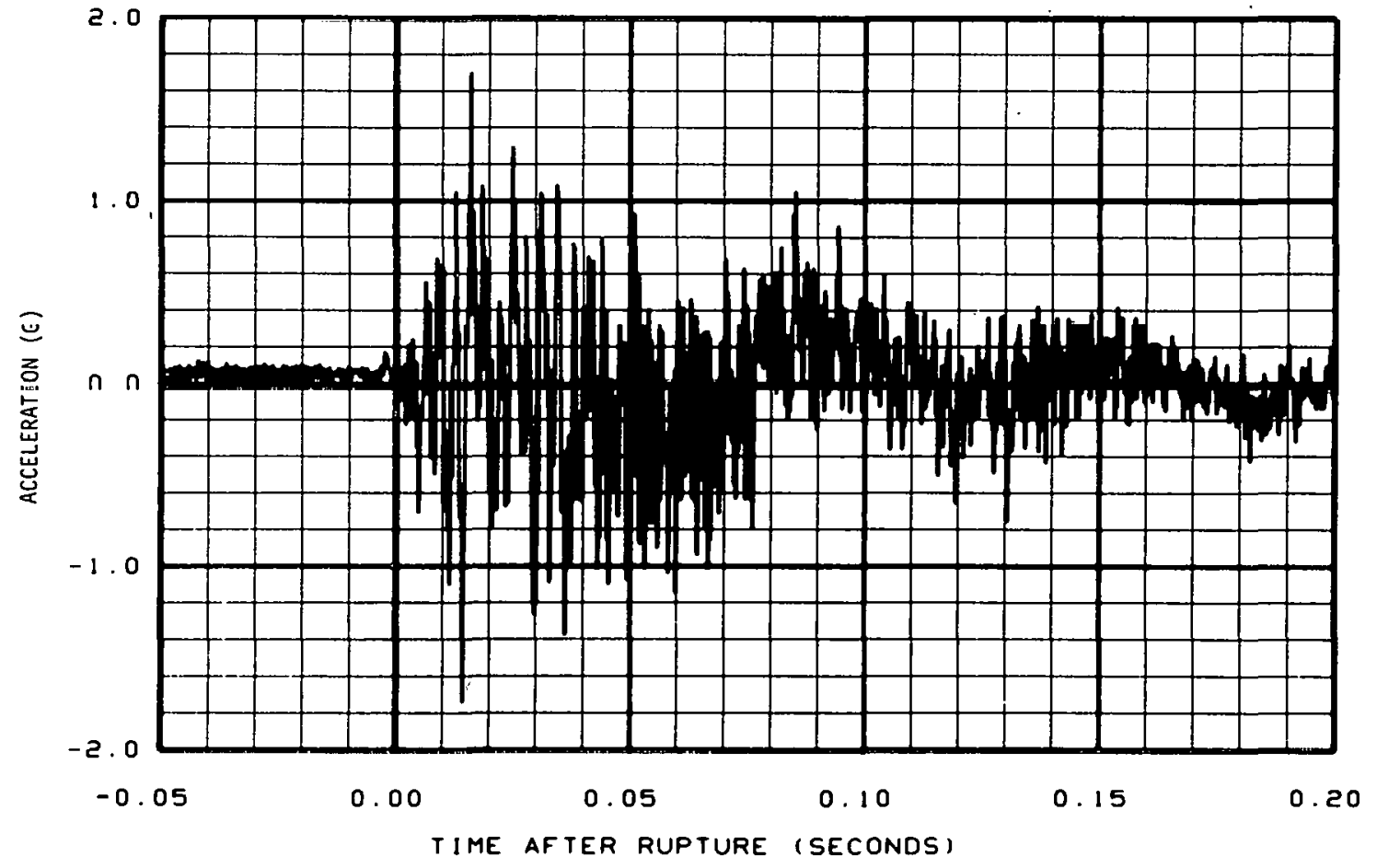

Fig. 27 Acceleration at bottom of reactor vessel, west side, East-West (AE-RV1-2). 


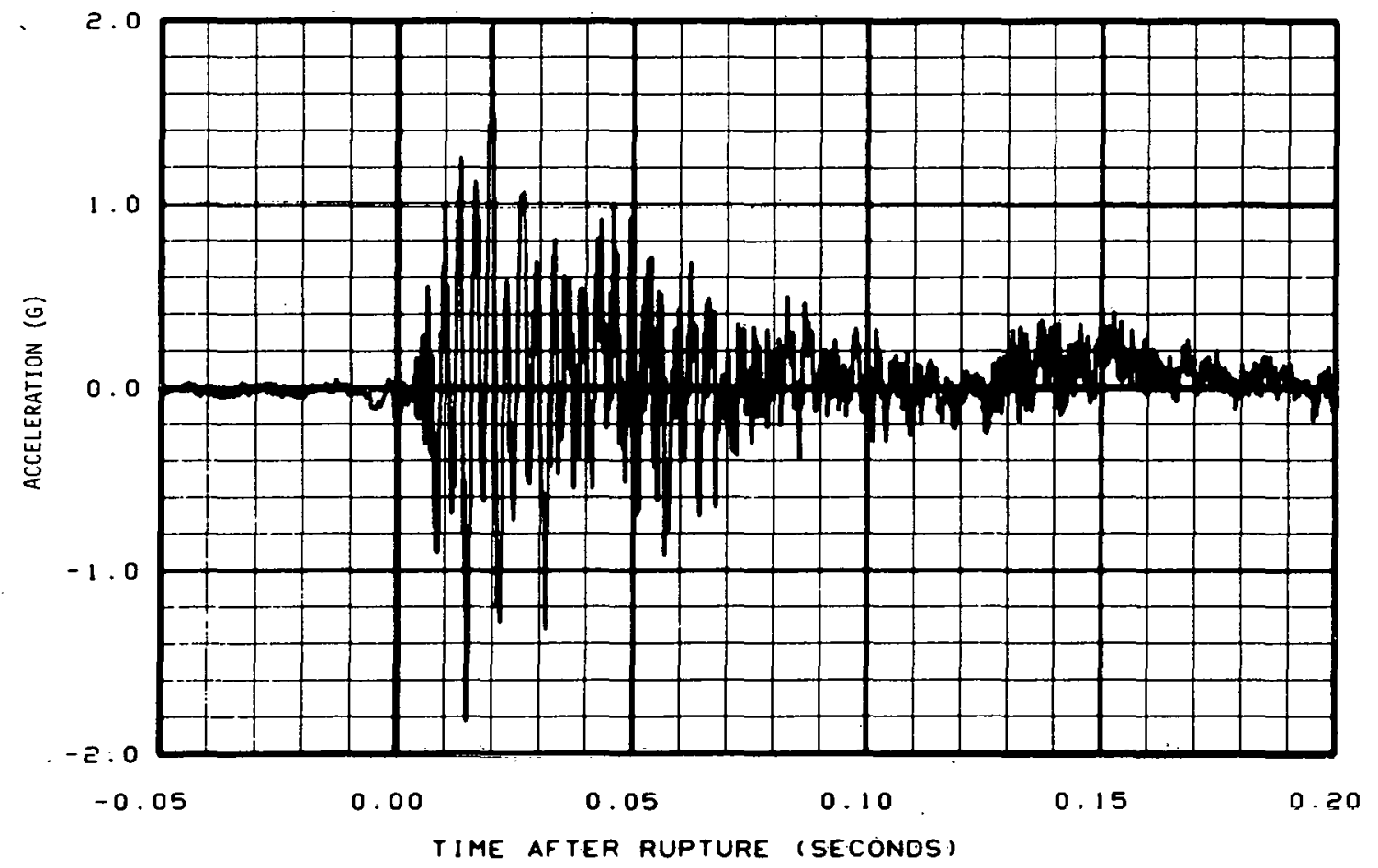

Fig. 28 Acceleration at bottom of reactor vessel, west side, vertical $(A E-R V 1-3)$.

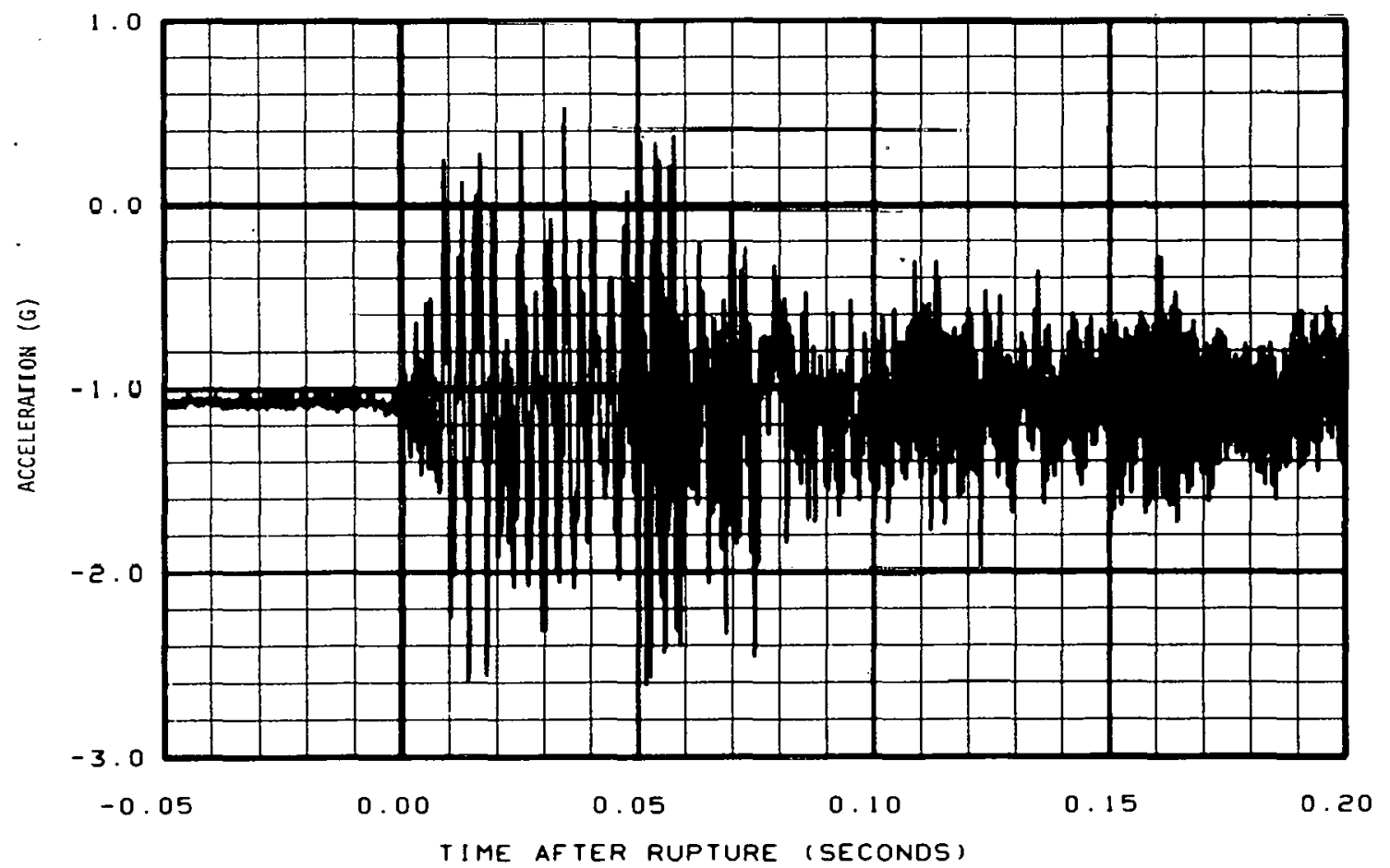

Fig. 29 Acceleration at bottom of reactor vesse], north side, NorthSouth (AE-RVI-4). 


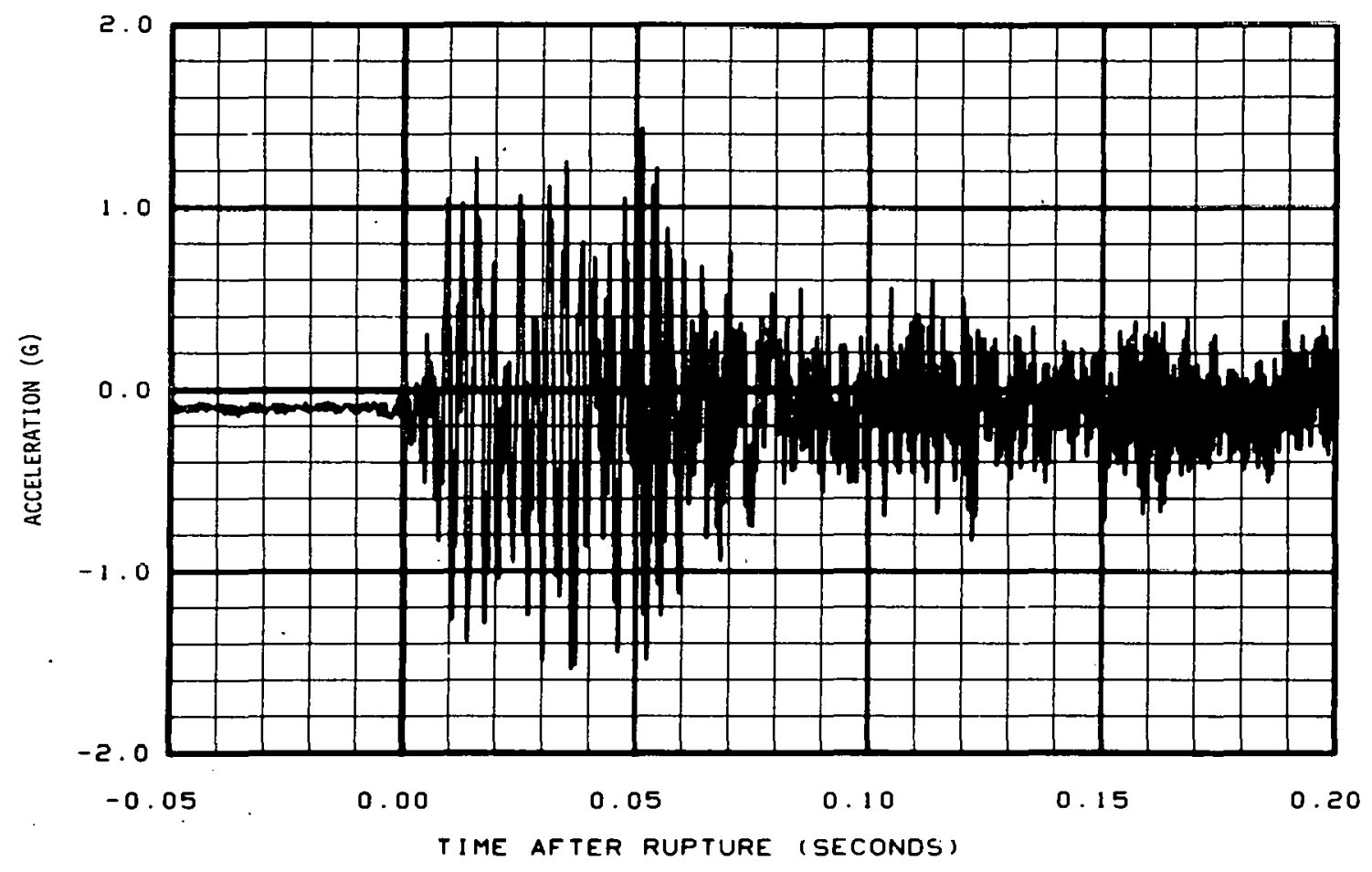

Fig. 30 Acceleration at bottom of reactor vessel, north side, NorthSouth (AE-RVI-5).

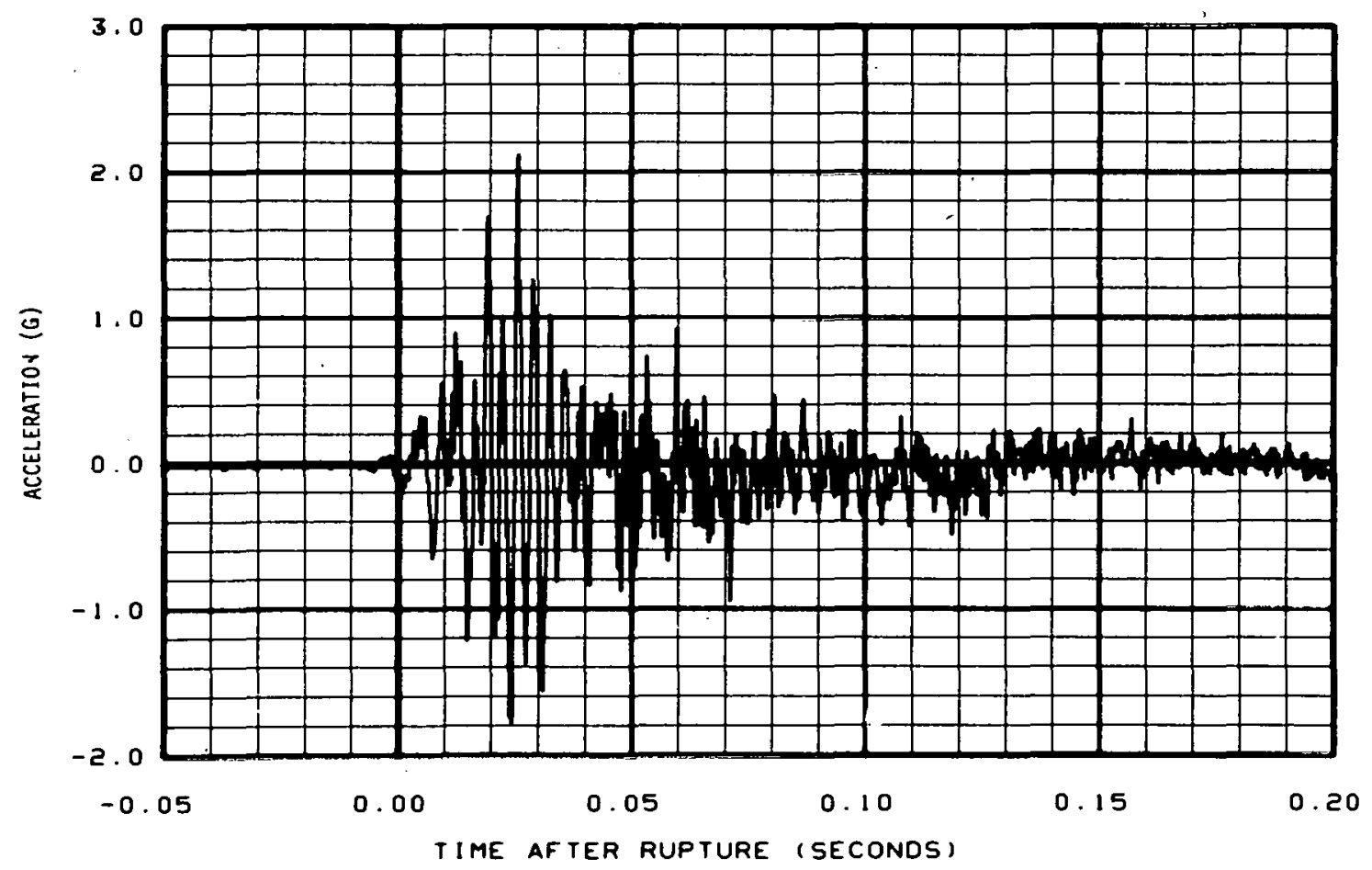

Fig. 31 Acceleration at bottom of reactor vessel, north side, vertical $(A E-R V 1-6)$. 


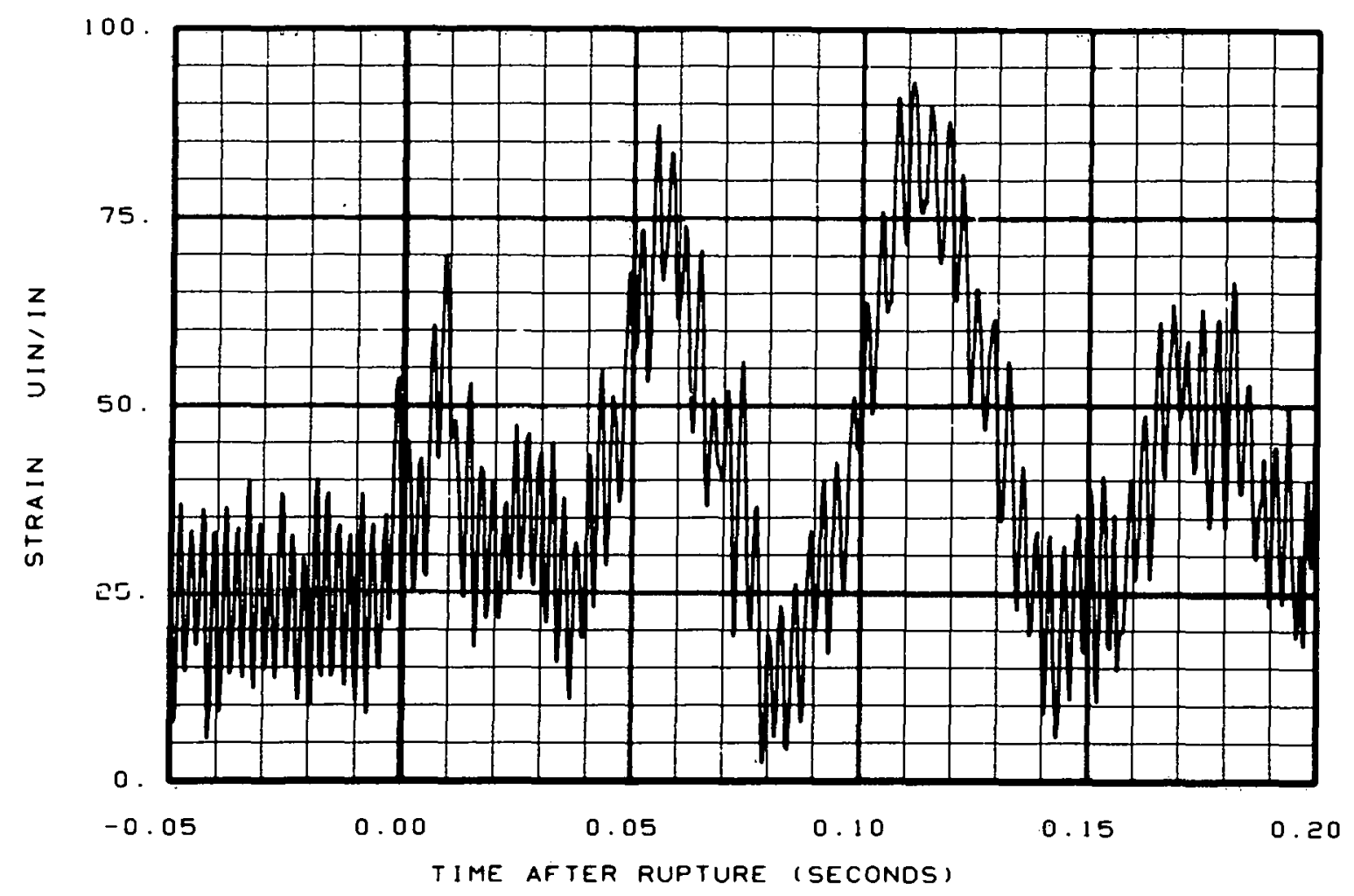

Fig. 32 Strain at reactor vessel broken loop cold leg nozzle (SE-BL8-1).

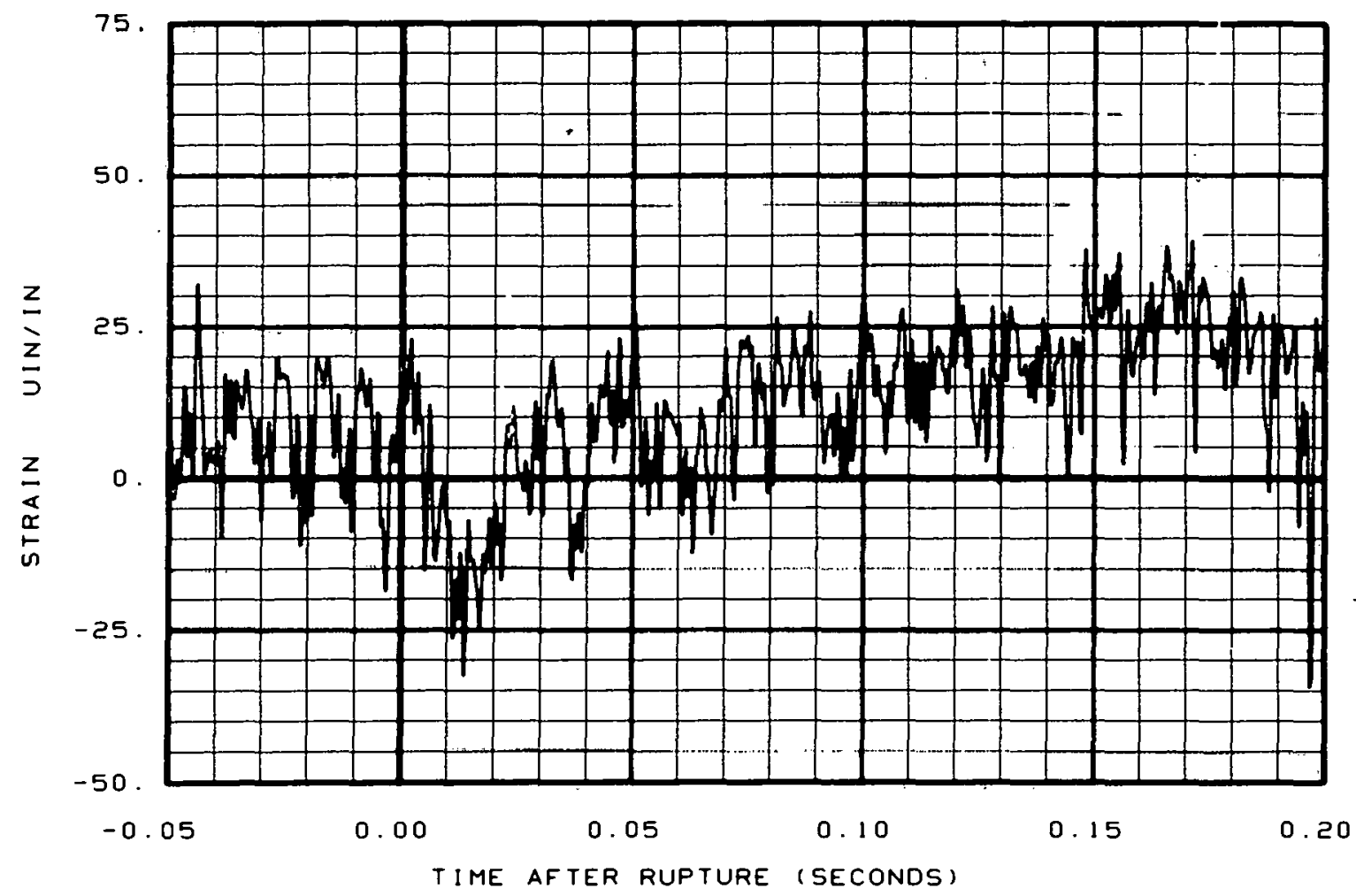

Fig. 33 Strain at reactor vessel broken loop cold leg nozzle (SE-BL8-2). 


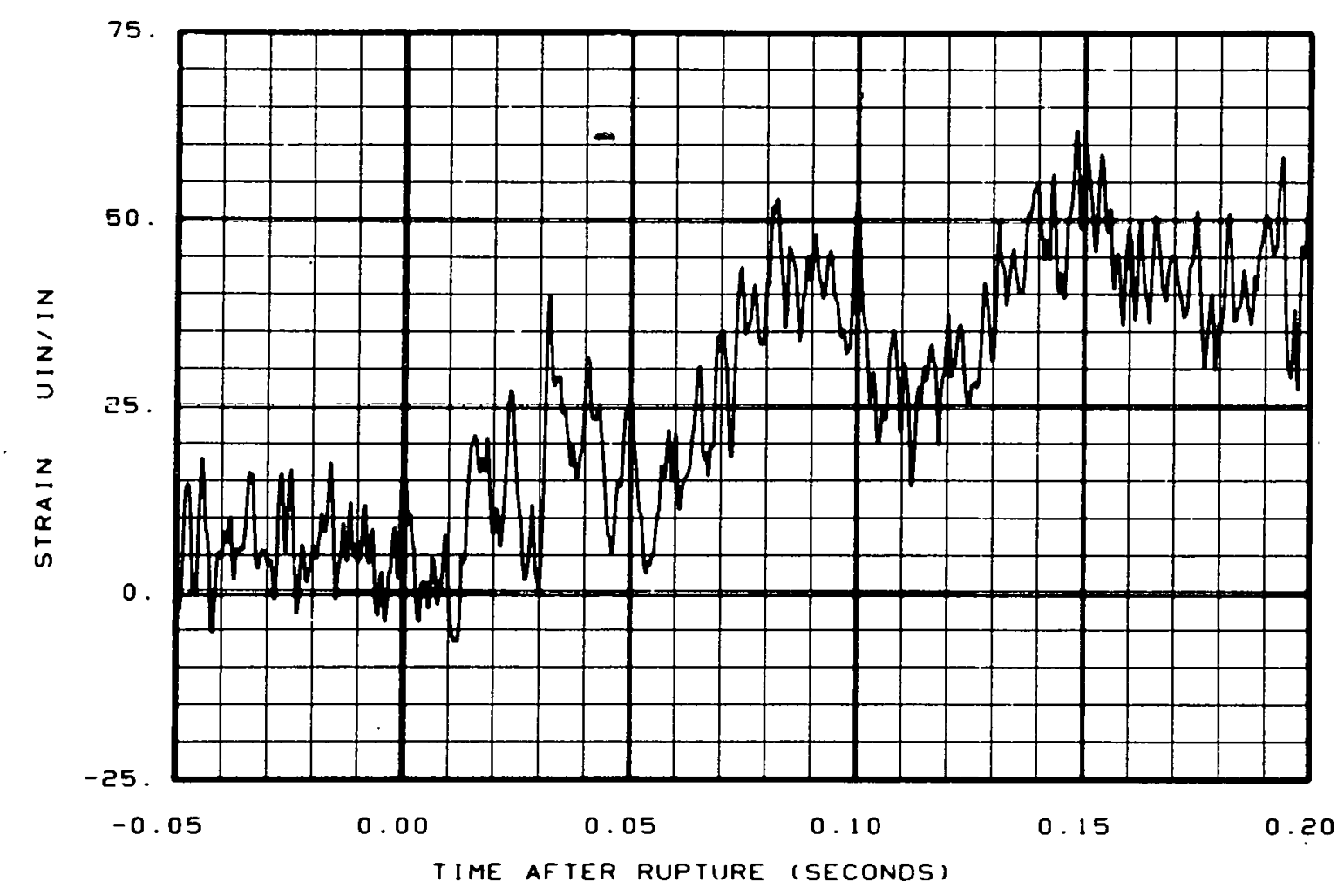

Fig. 34 Strain at reactor vessel broken loop cold leg nozzle (SE-BL8-3).

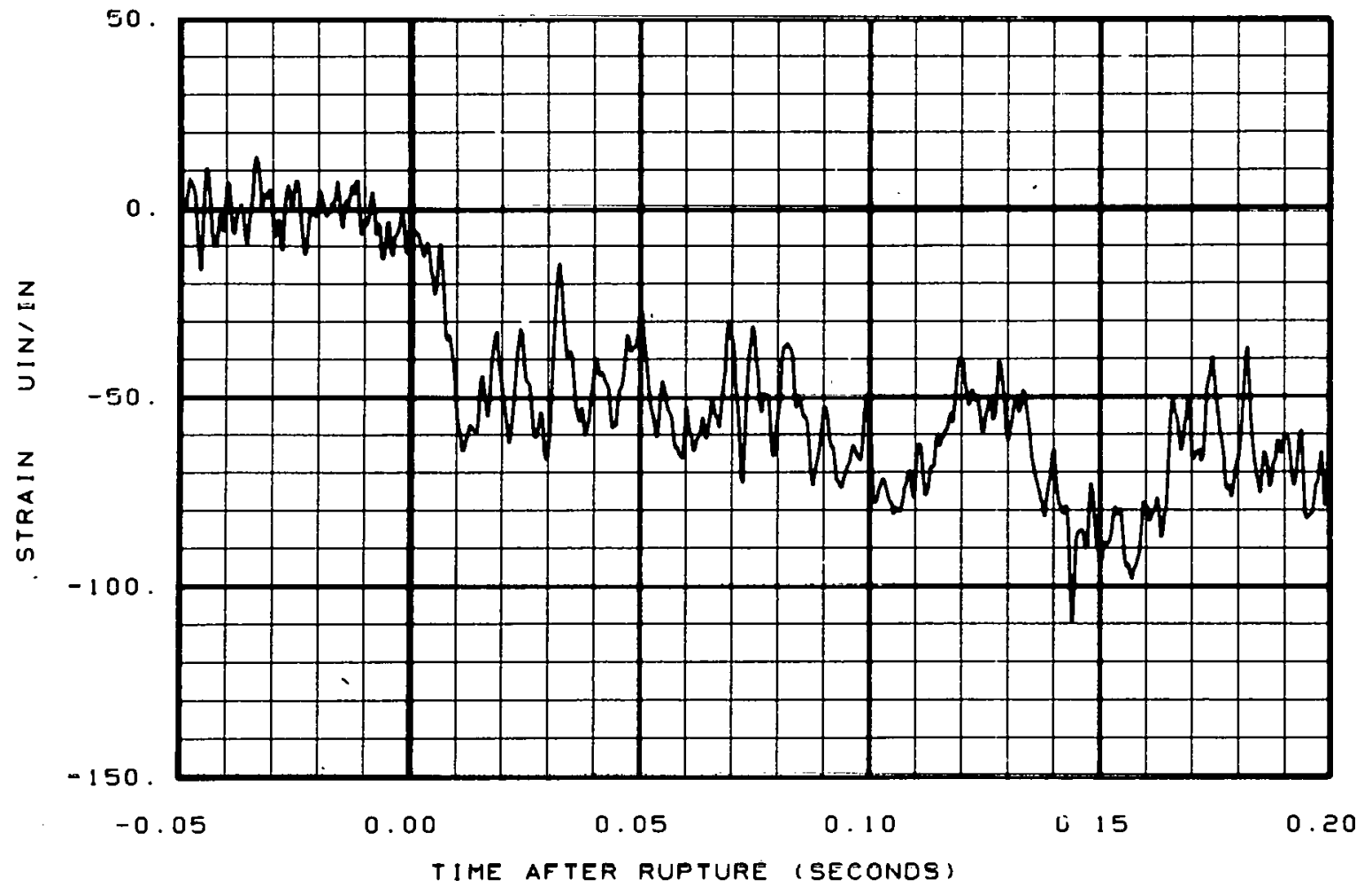

Fig. 35 Strain at reactor vessel broken loop cold leg nozzle (SE-BL8-4). 


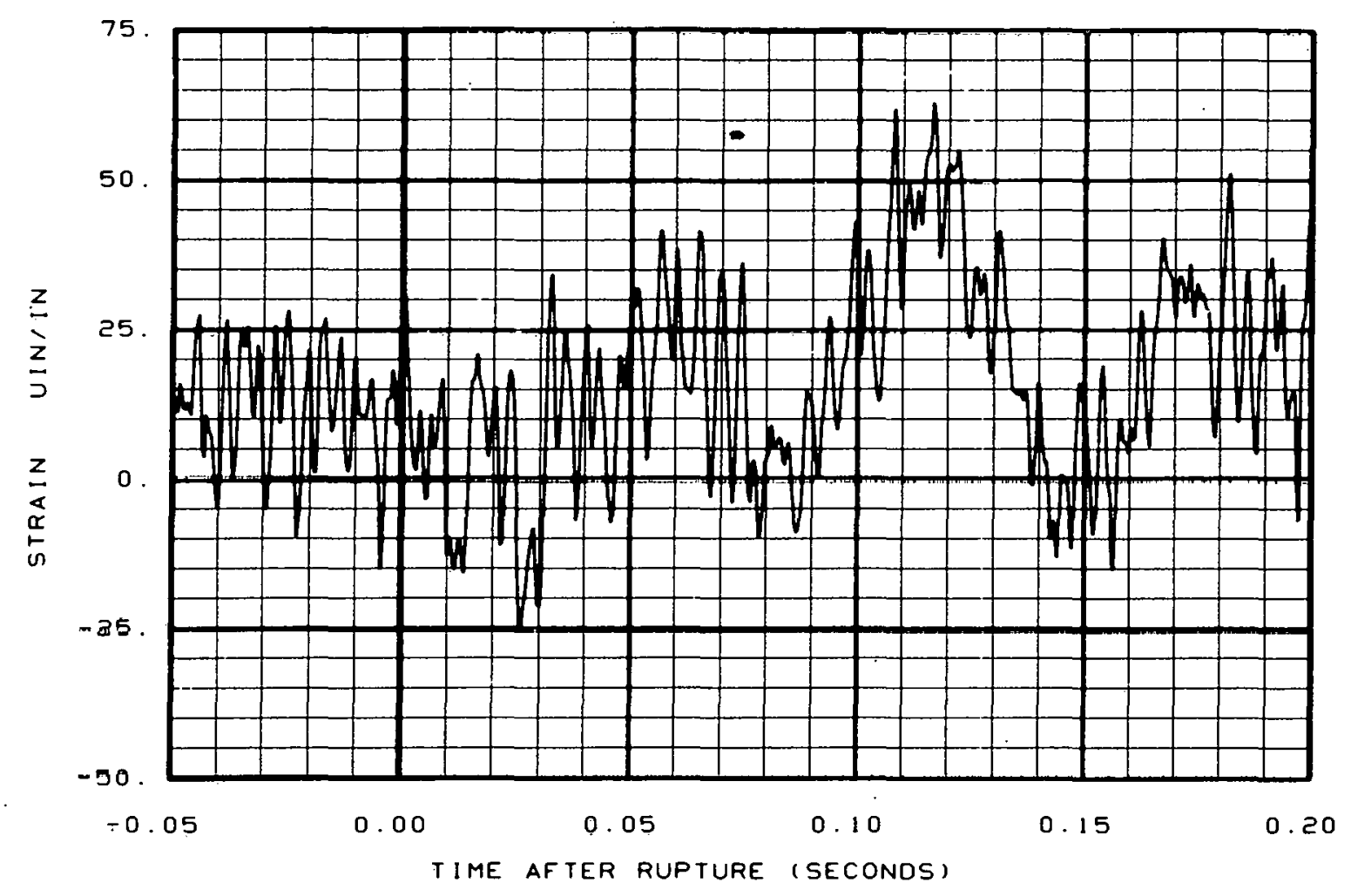

Fig. 36 Strain at reactor vessel broken loop cold leg nozzle (SE-BL8-5).

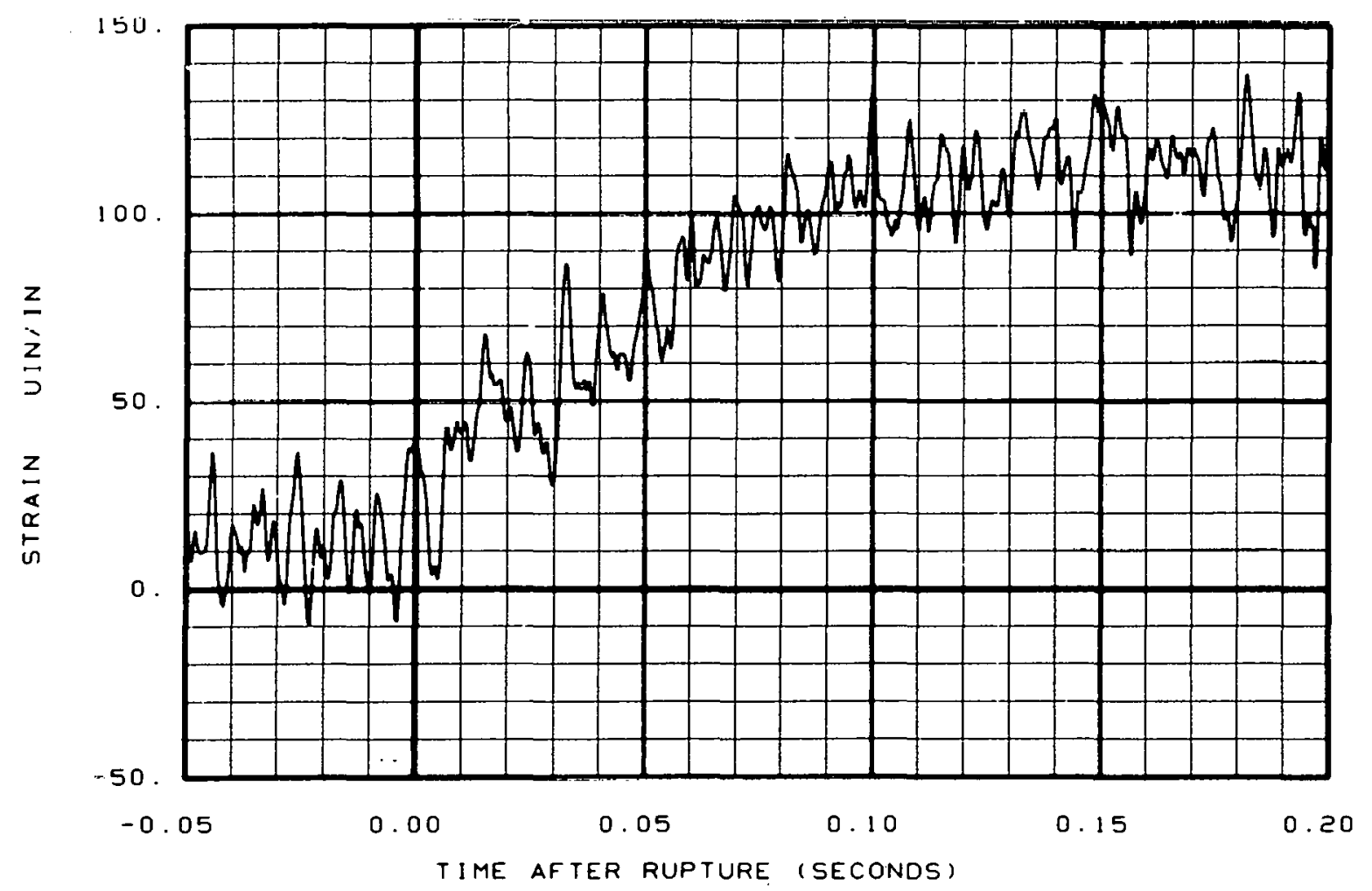

Fig. 37 Strain at reactor vessel broken loop cold leg nozzle (SE-BL8-6). 


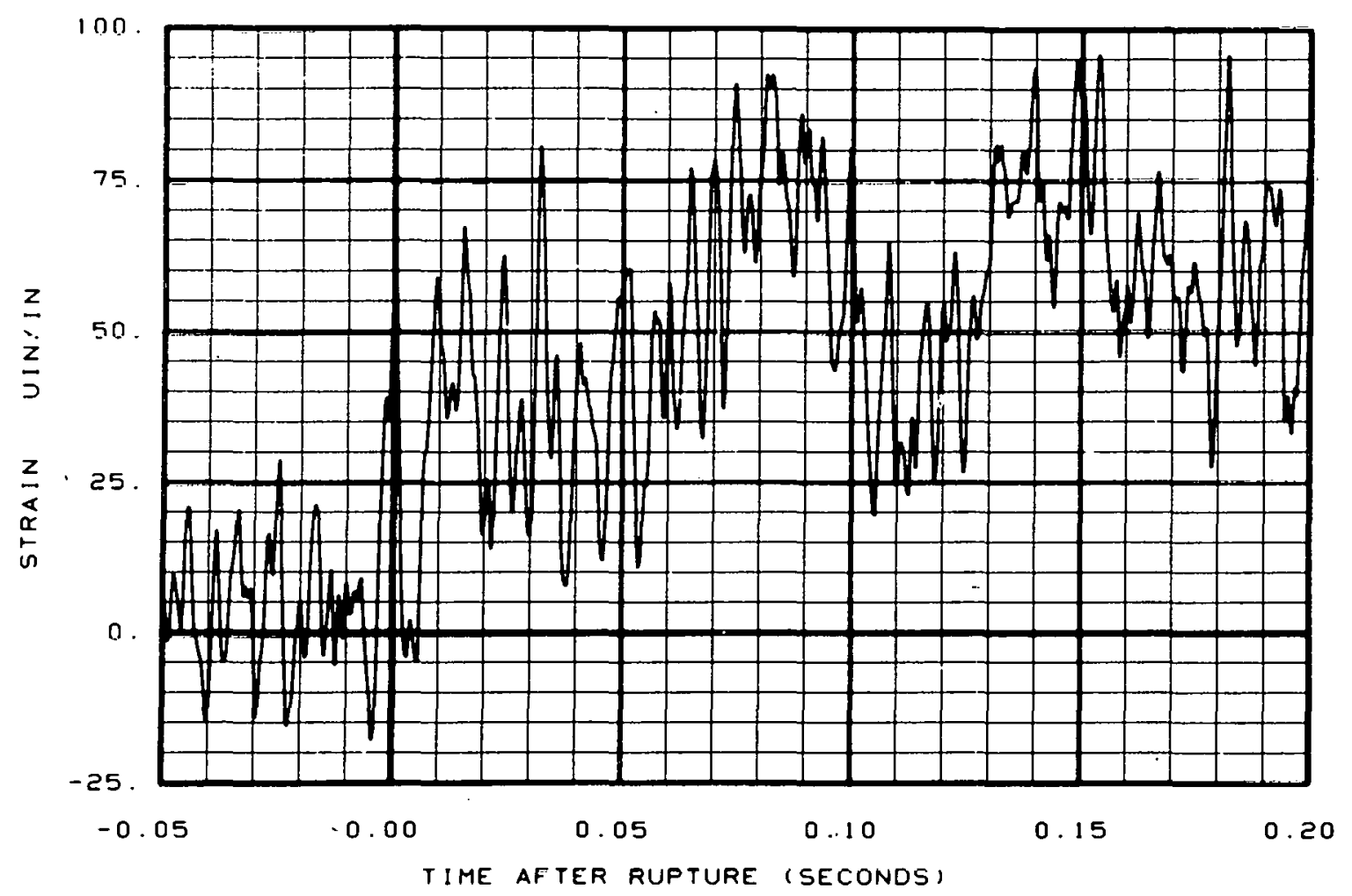

Fig. 38 Strain at reactor vessel broken loop cold leg nozzle (SE-BL8-8).

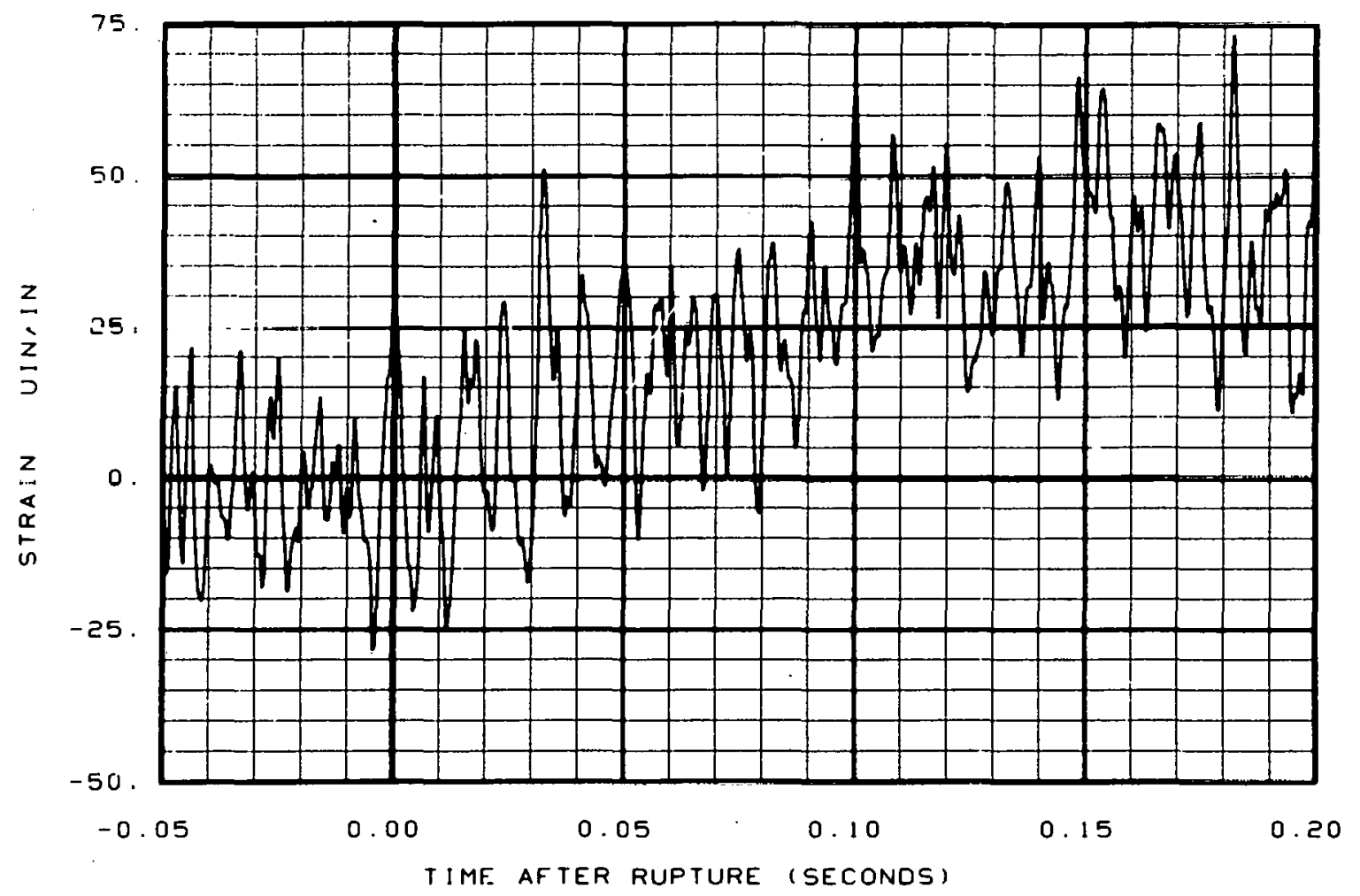

Fig. 39 Strain at reactor vessei broken loop cold leg nozzle (SE-BL8-9). 


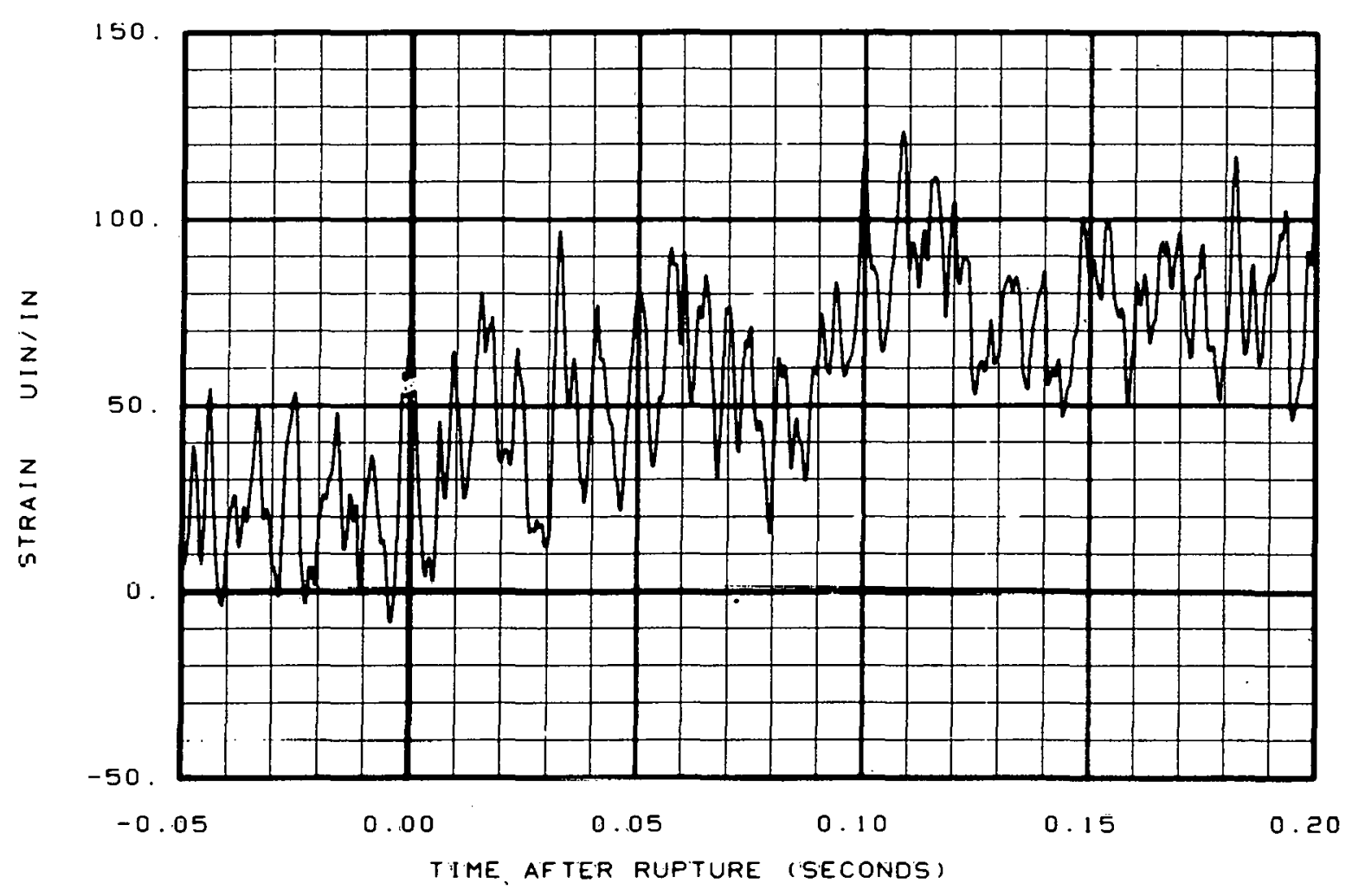

Fig. 40 Strain at reactor vessel broken loop cold leg nozzle (SE-BL8-11).

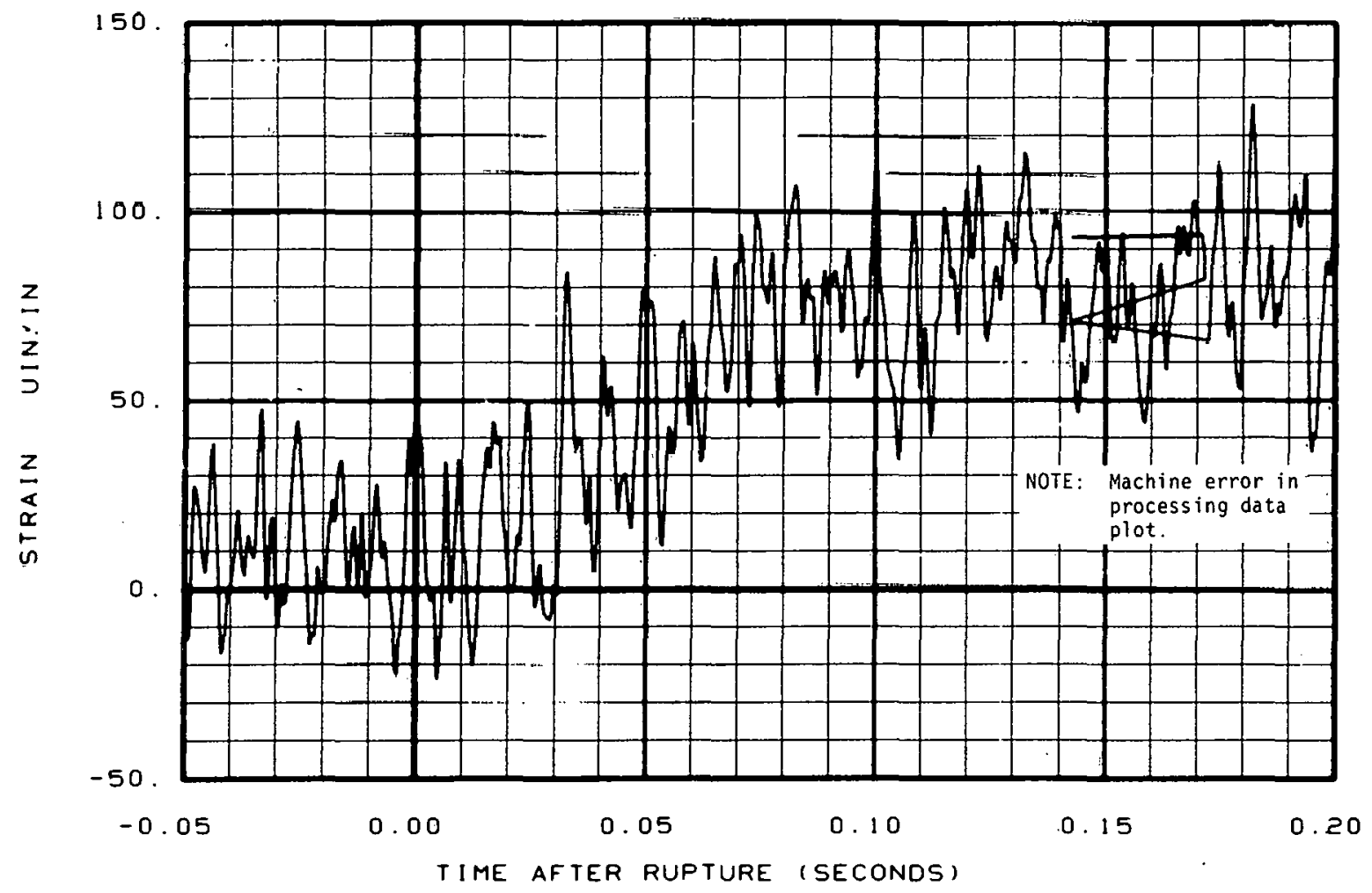

Fig. 41 Strain at reactor vessel broken loop cold leg nozzle (SE-BL8-12). 


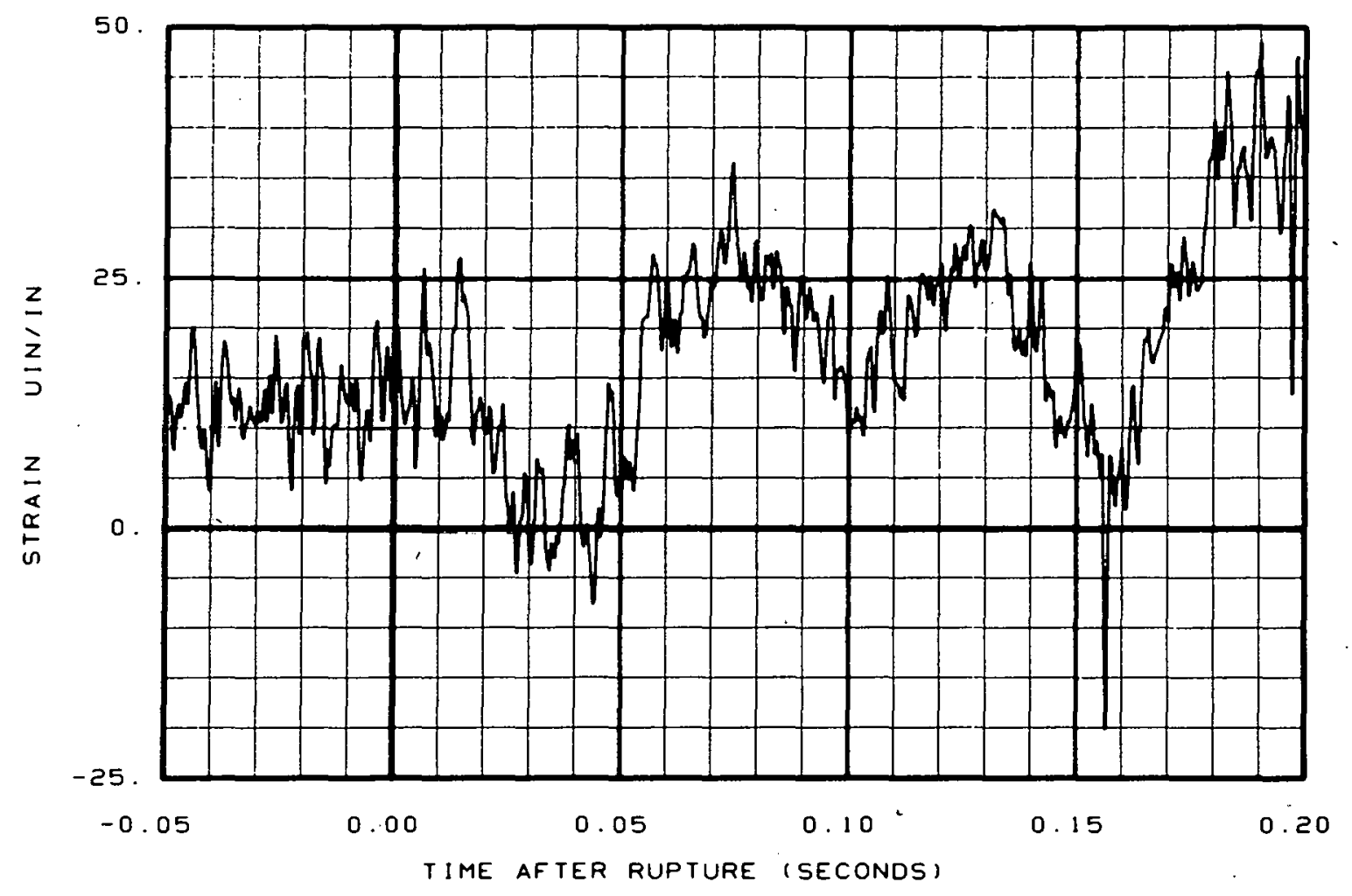

Fig. 42 Strain at reactor vessel broken loop hot leg nozzle (SE-BL9-1).

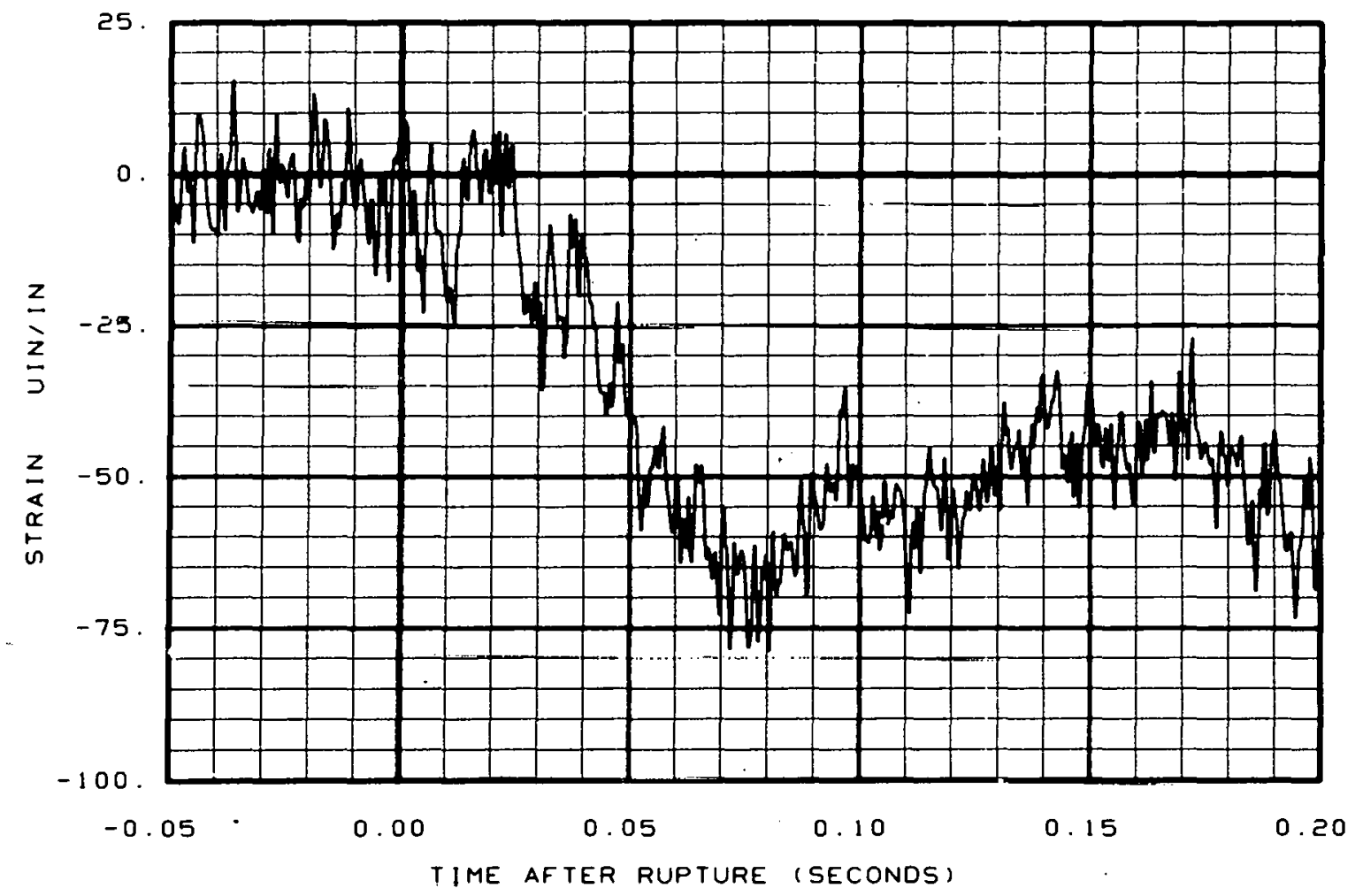

Fig. 43 Strain at reactor vessel broken loop hot leg nozzle (SE-BL9-2). 


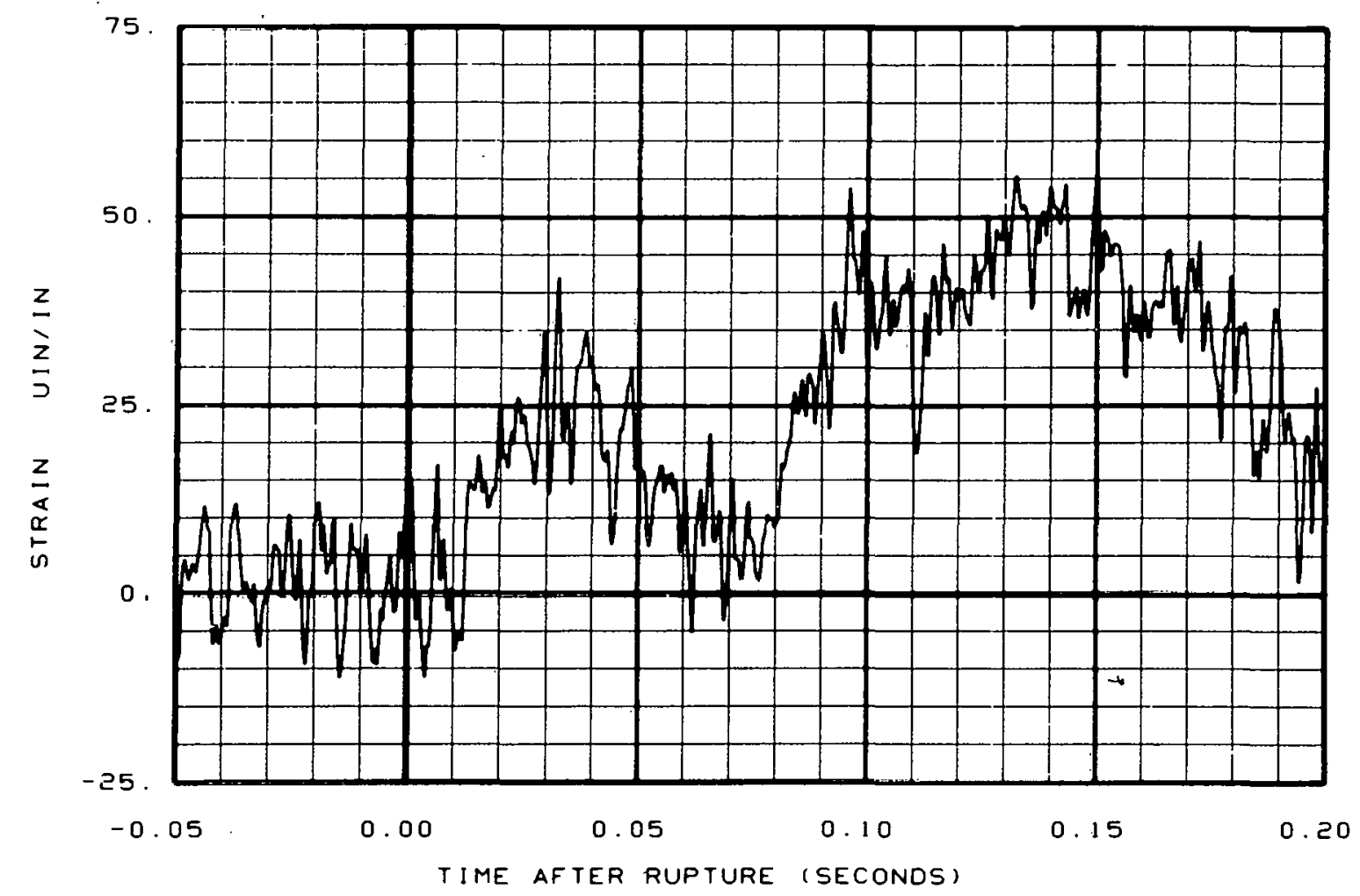

Fig. 44 Strain at reactor vessel broken loop hot leg nozzle (SE-BL.9-4).

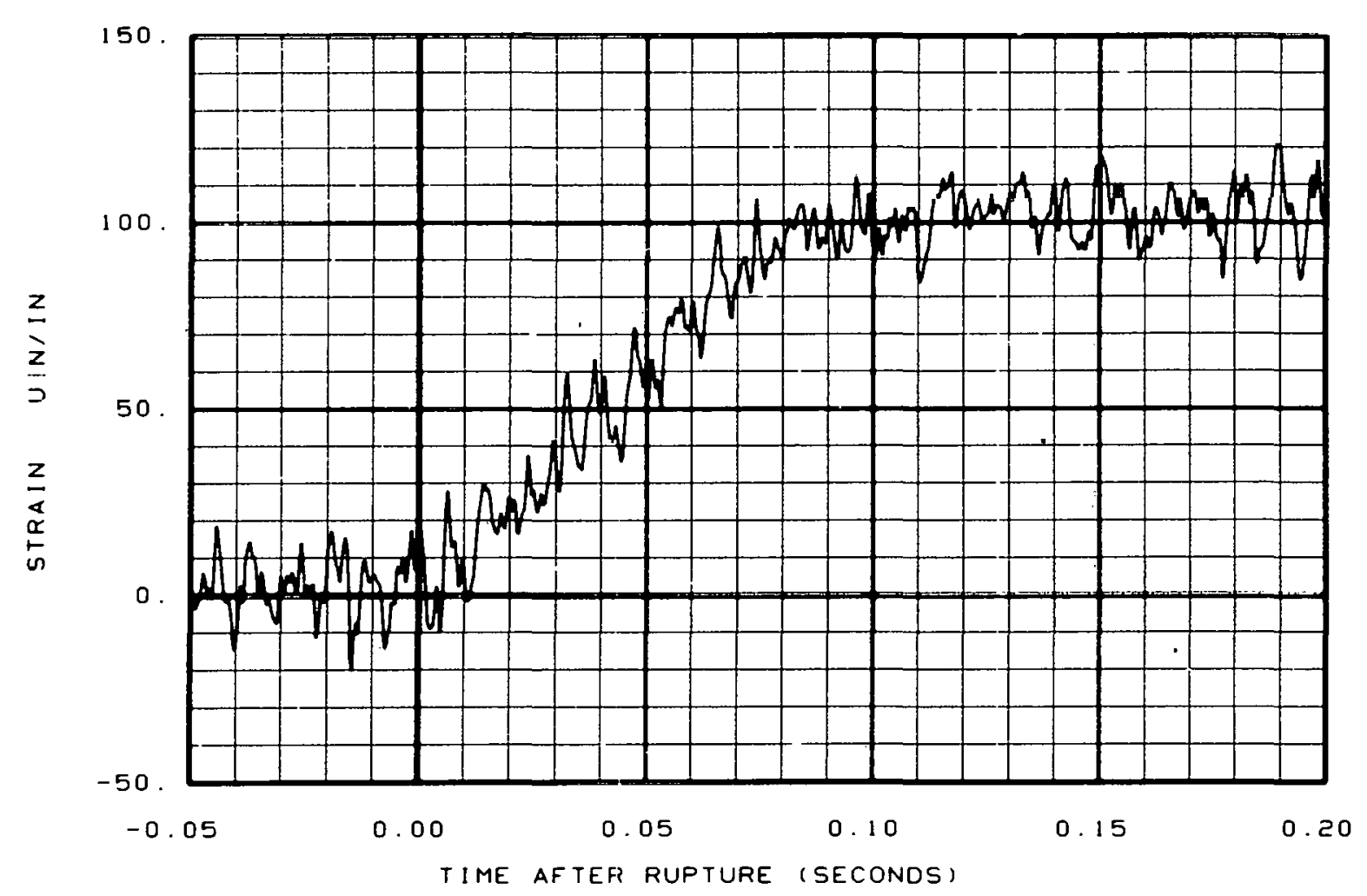

Fig. 45 Strain at reactor vessel broken loop hot leg nozzle (SE-BL9-4). 


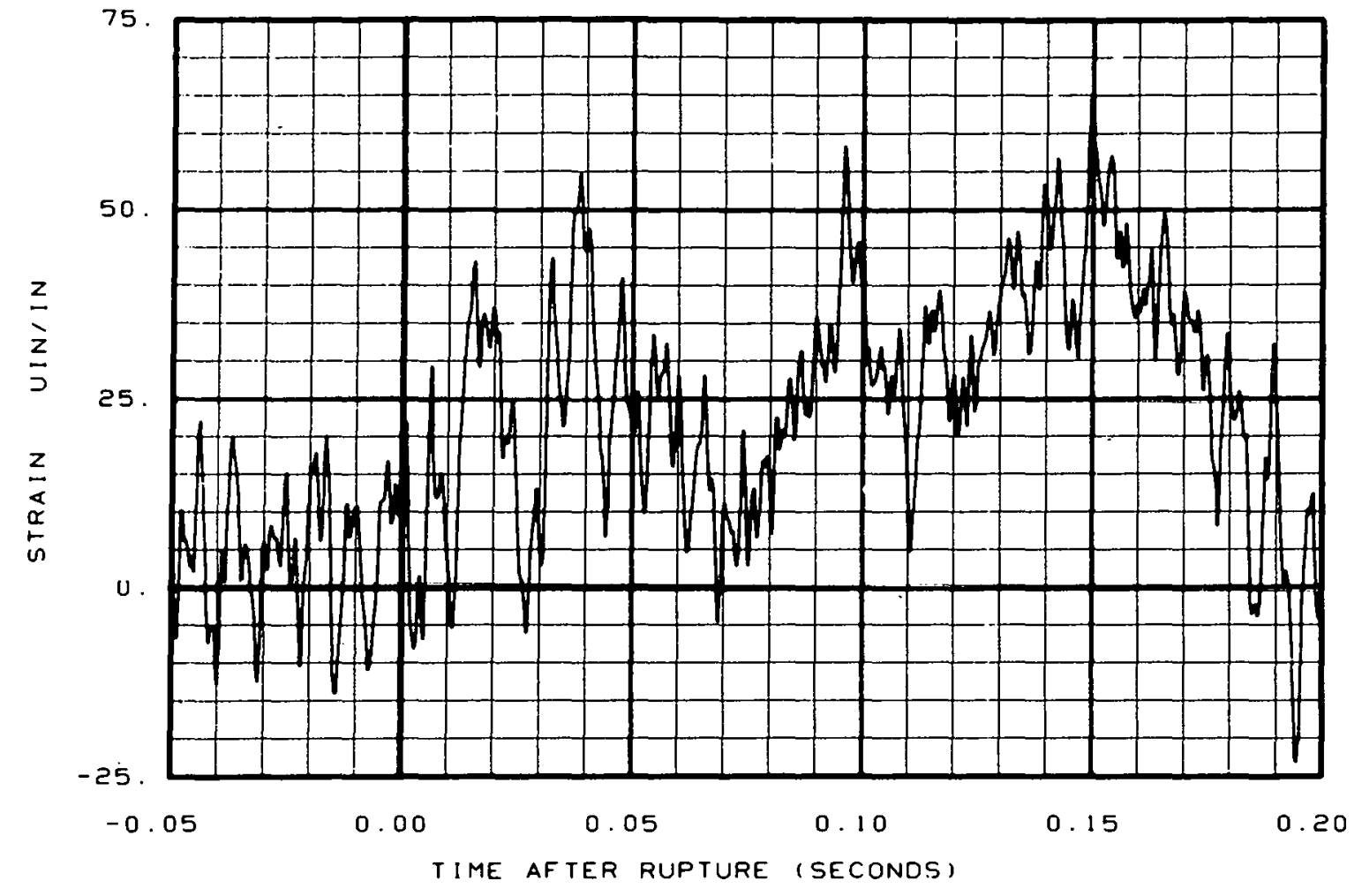

Fig. 46 Strain at reactor vessel broken loop hot leg nozzle (SE-BL9-5).

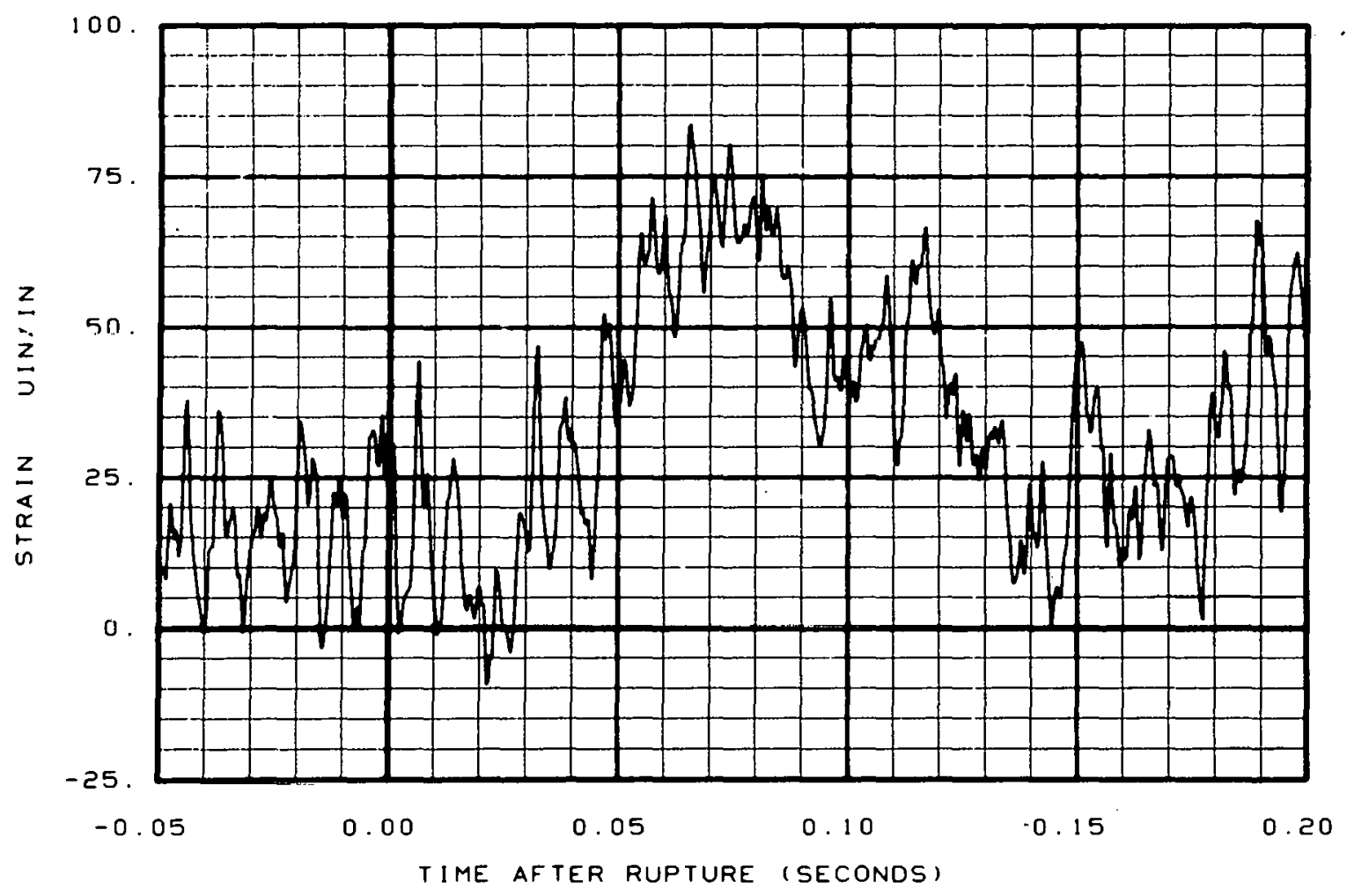

Fig. 47 Strain at reactor vessel broken loop hot leg nozzle (SE-BL9-6). 


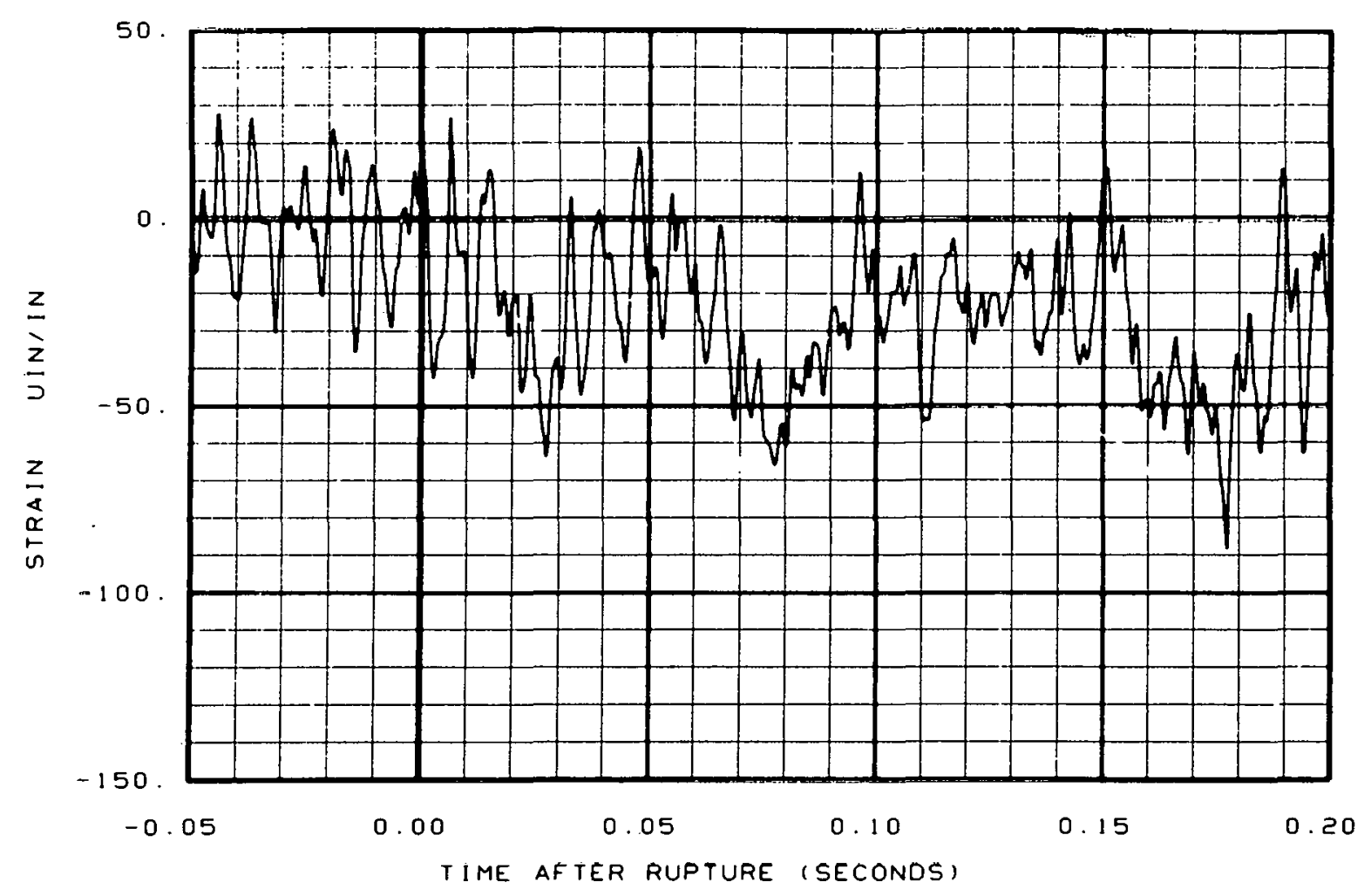

Fig. 48 Strain between pump and steam generator simulator (SE-BL27-2).

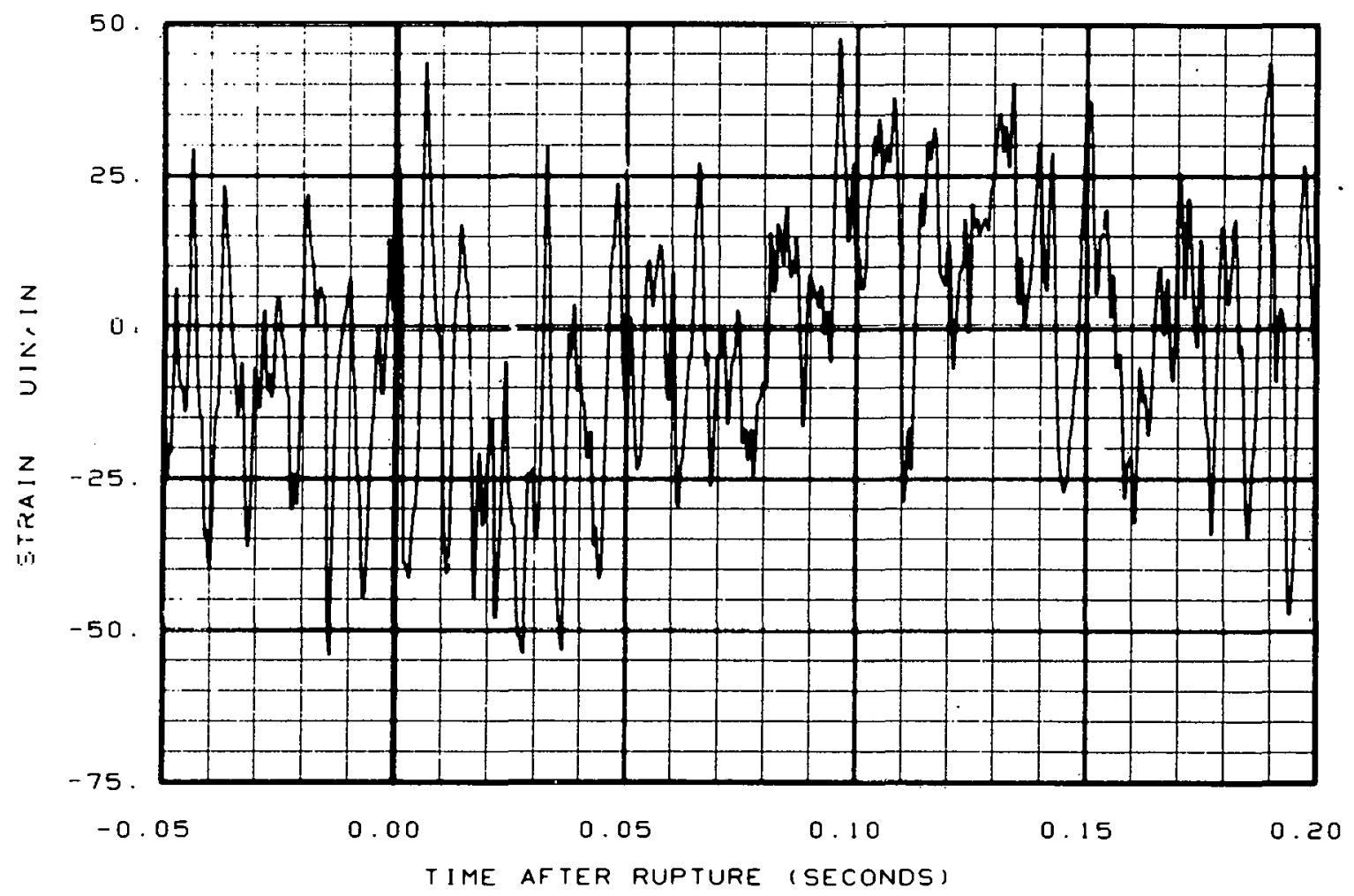

Fig. 49 Strain between pump and steam generator simulator (SE-BL27-4). 


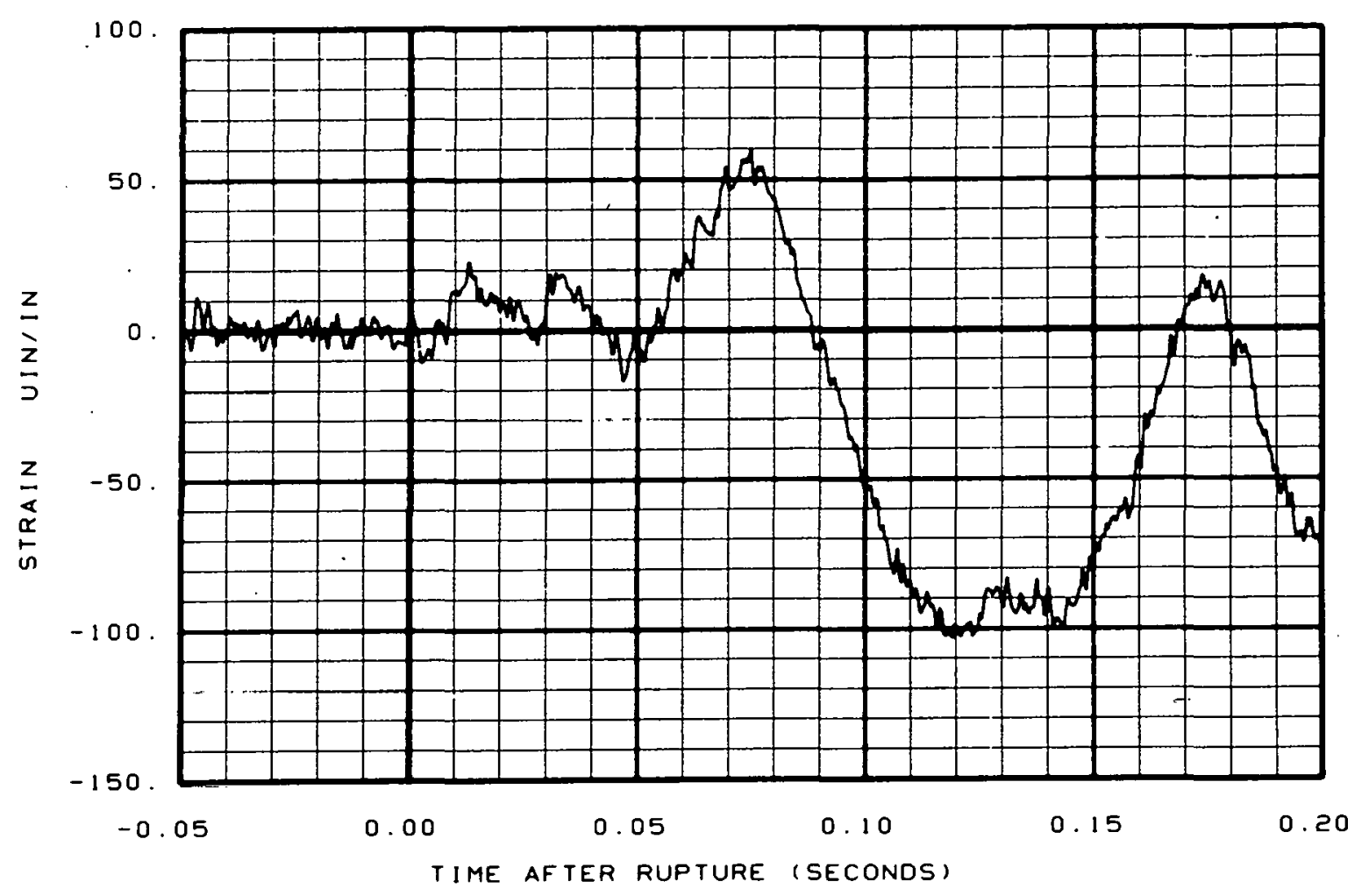

Fig. 50 Strain between pump and steam generator simulator (SE-BL27-5).

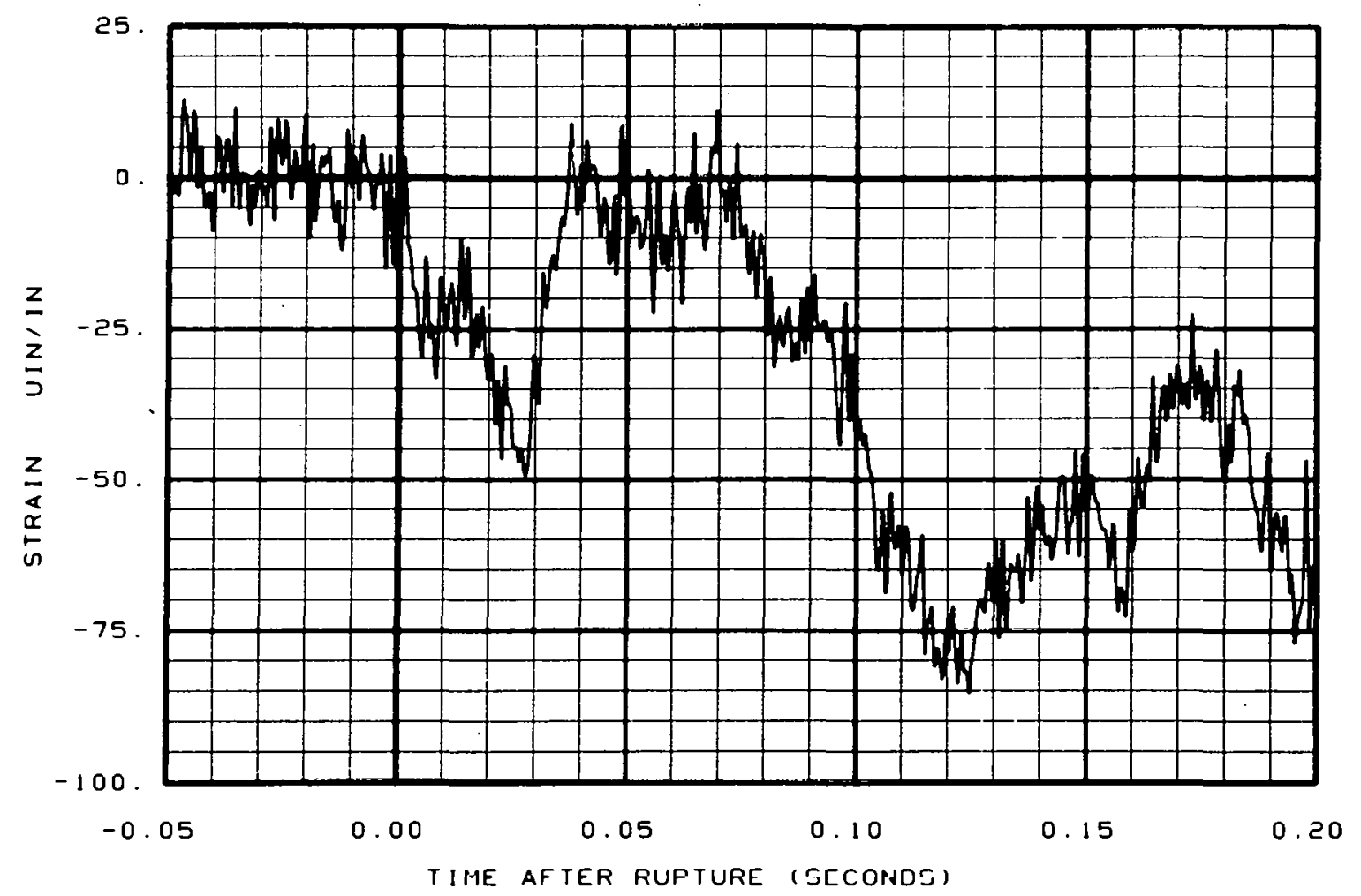

Fig. 51 Strain between pump and steam generator simulator (SE-BL27-6). 


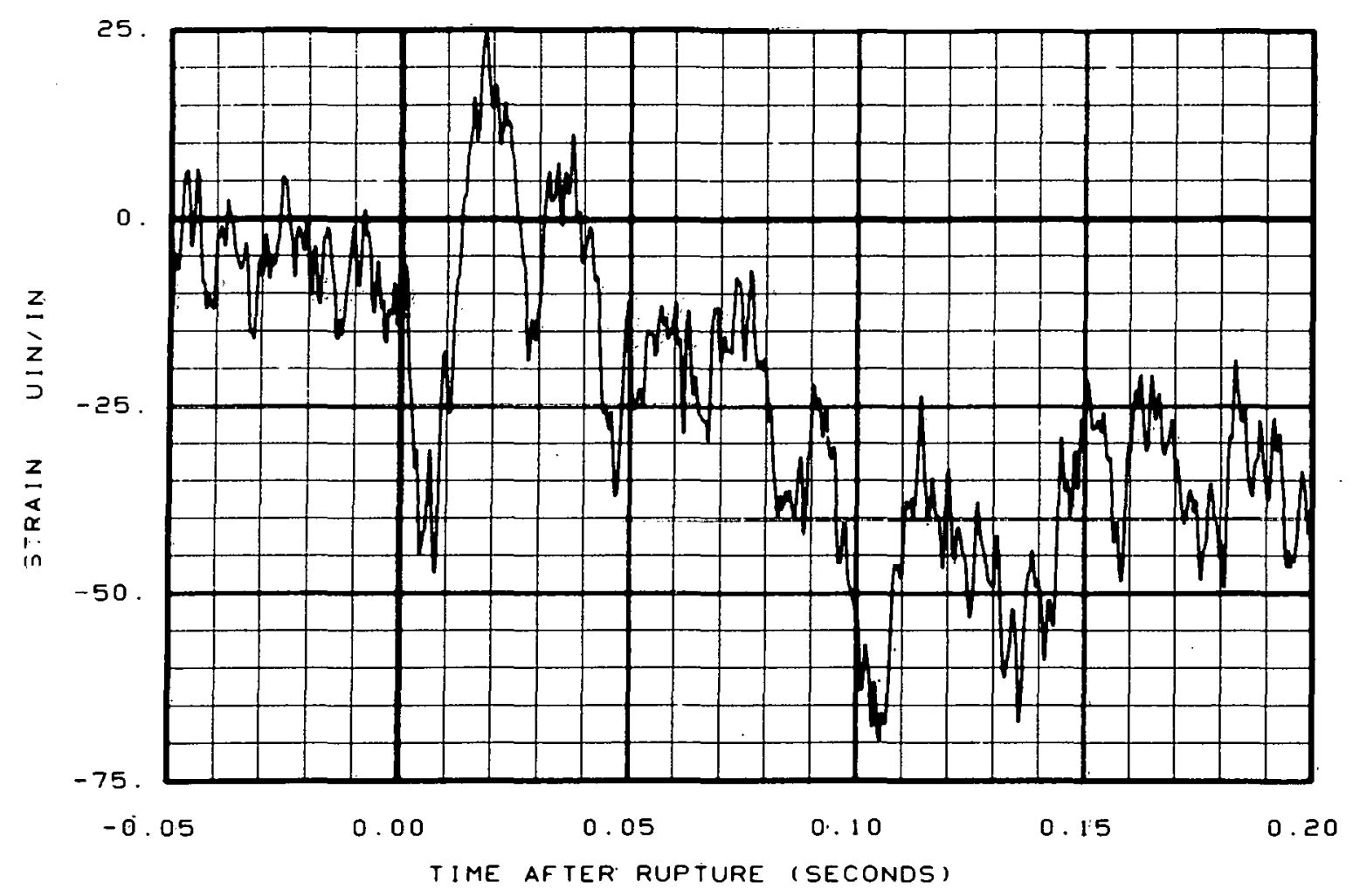

Fig. 52 Strain between pump and steam generator simulator (SE-BL27-8).

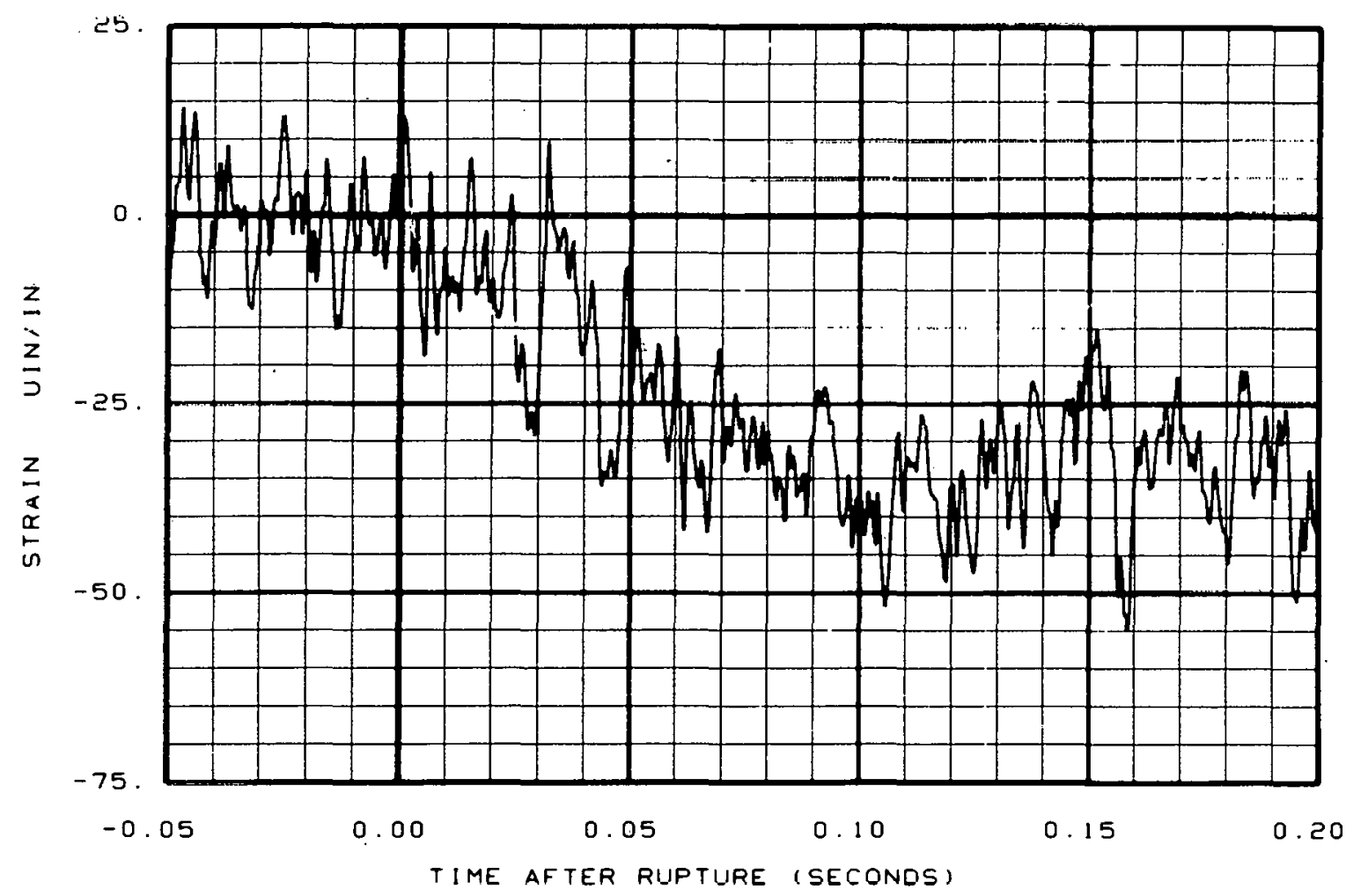

Fig. 53 Strain at reactor vessel intact loop cold leg nozzle (SE-PC4-1). 


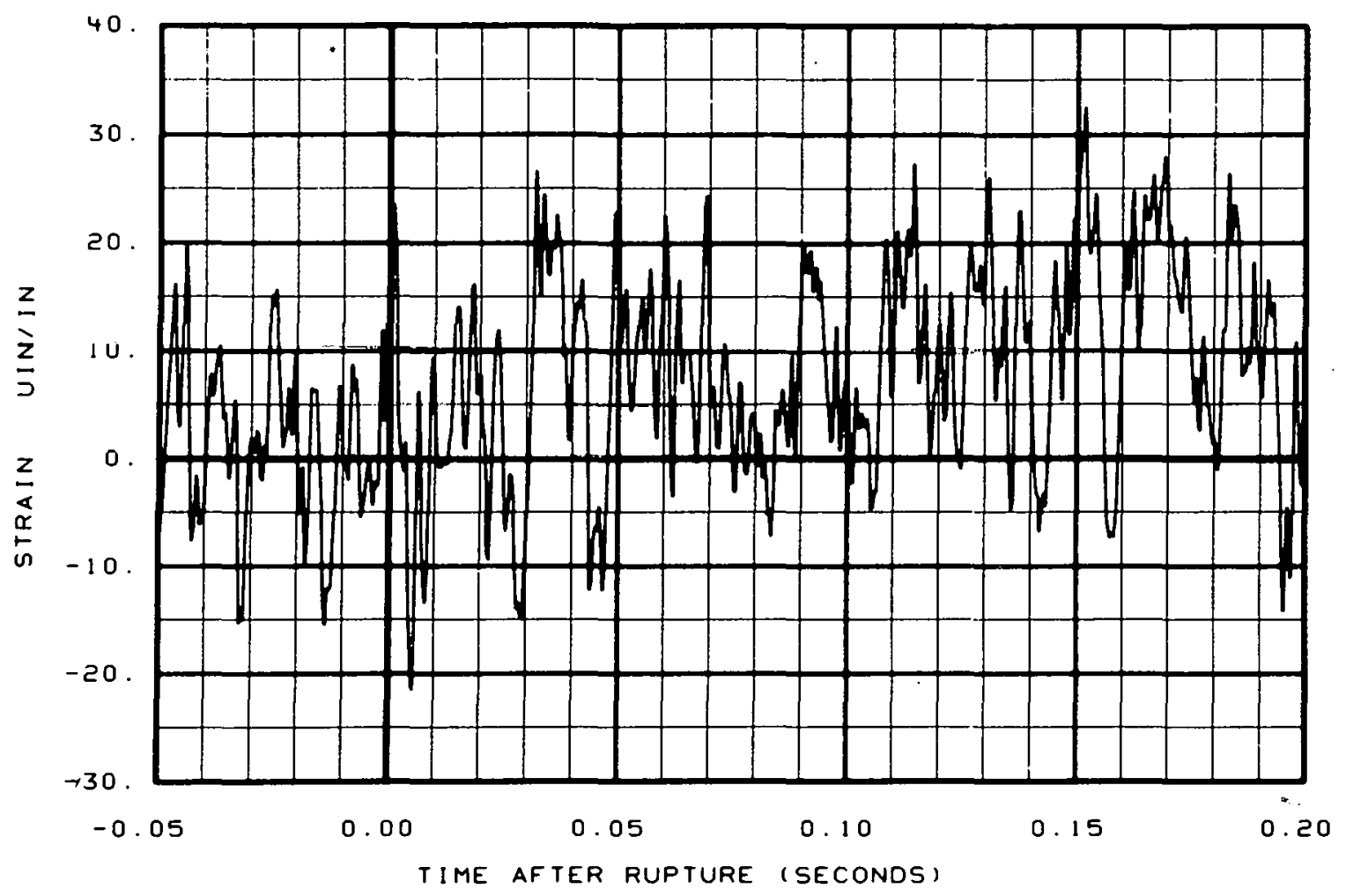

Fig. 54 Strain at reactor vessel intact loop cold leg nozzle (SE-PC4-2).

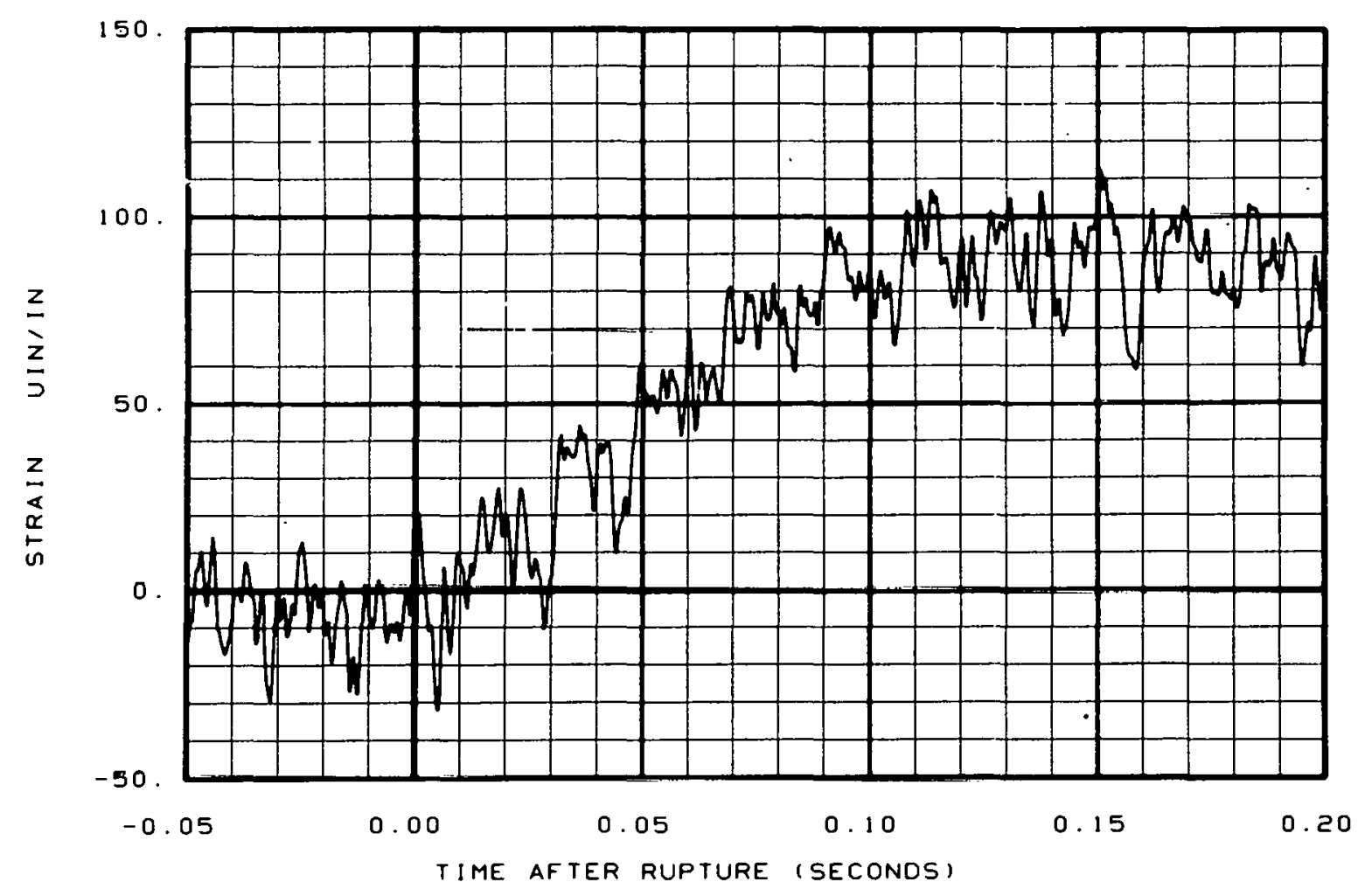

Fig. 55 Strain at reactor vessel intact loop cold leg nozzle (SE-PC4-4). 


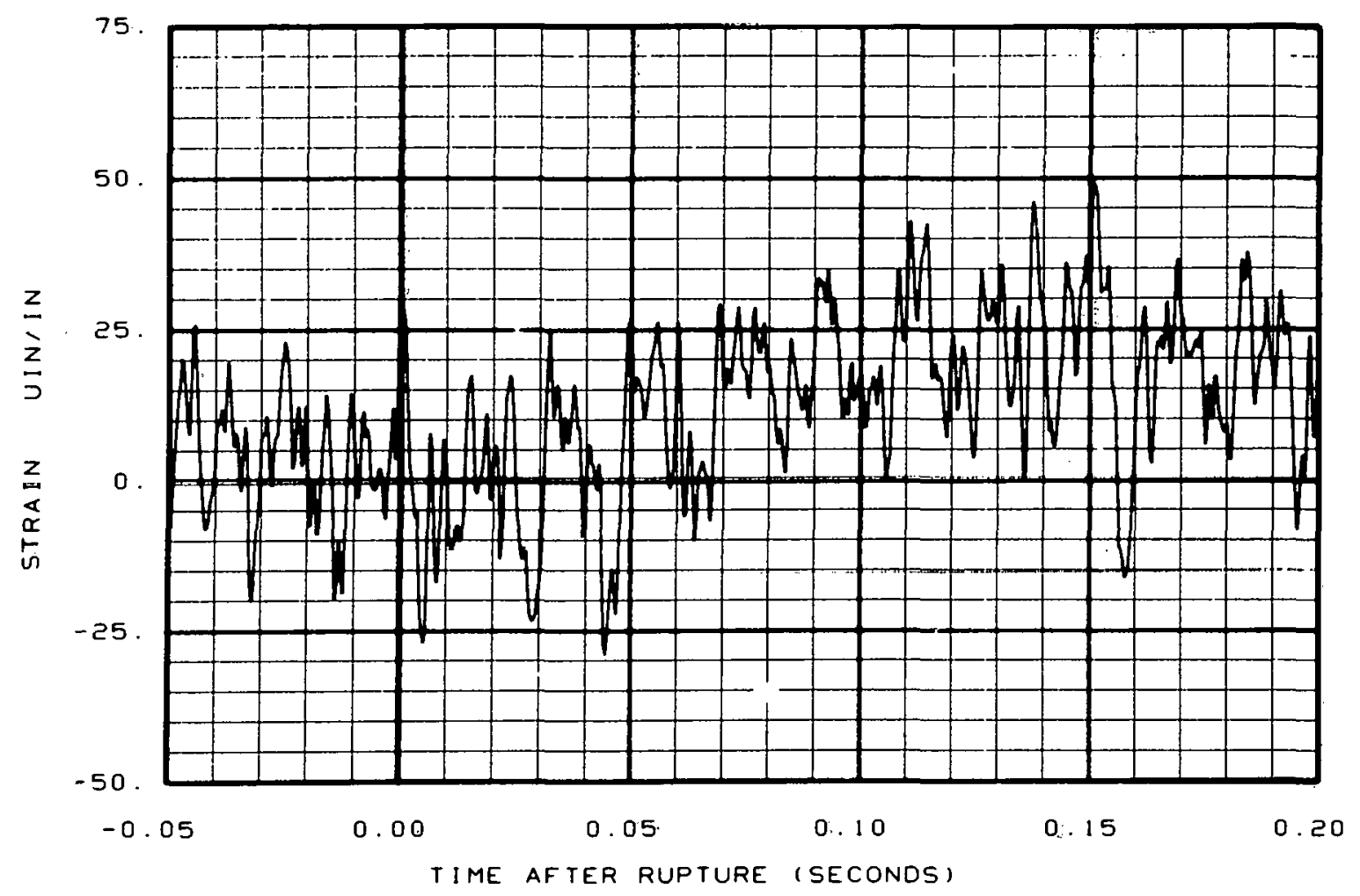

Fig. 56 Strain at reactor vessel intact loop cold leg nozzle (SE-PC4-5).

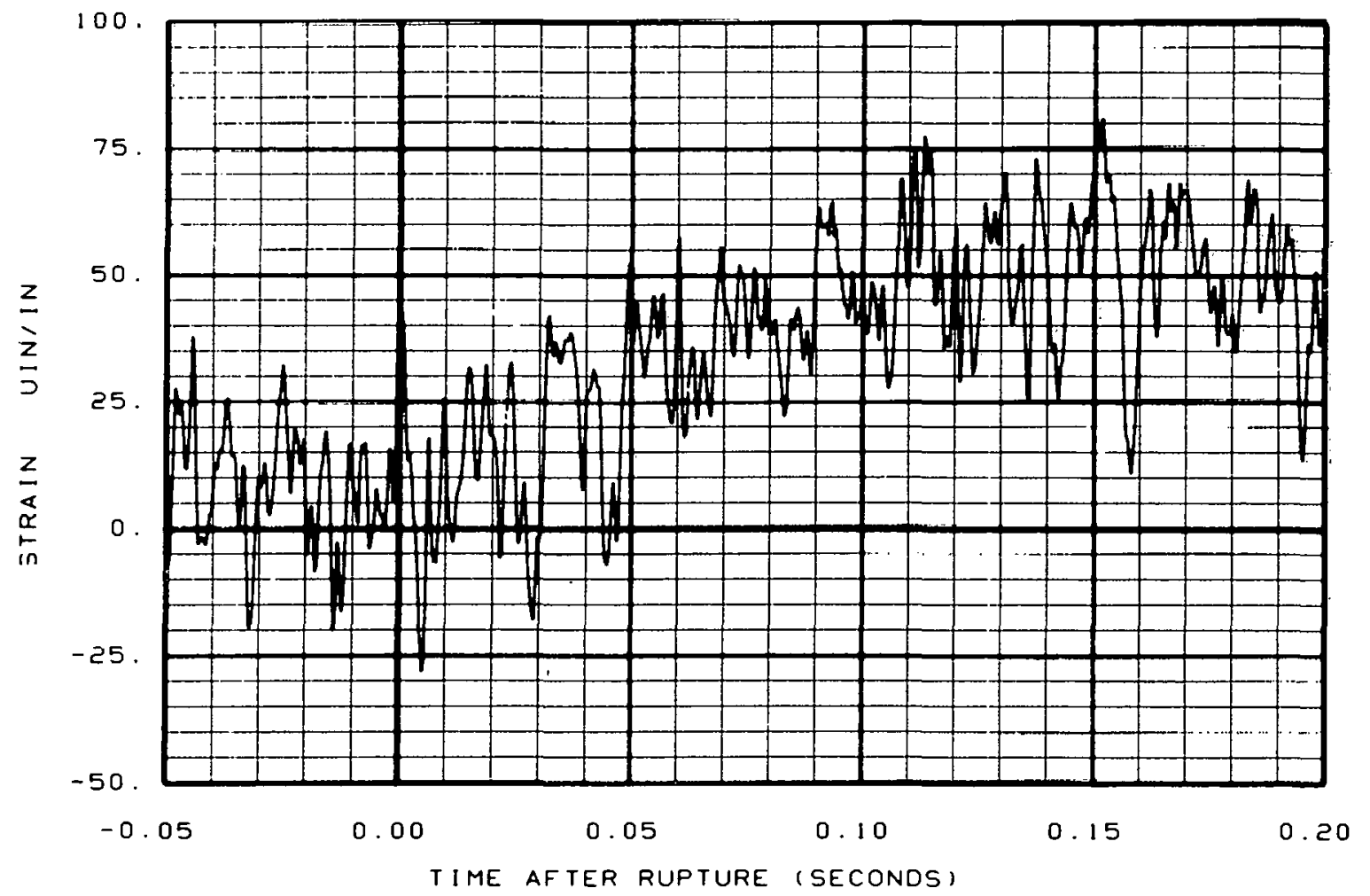

Fig. 57 Strain at reactor vessel intact loop cold leg nozzle (SE-PC4-7). 


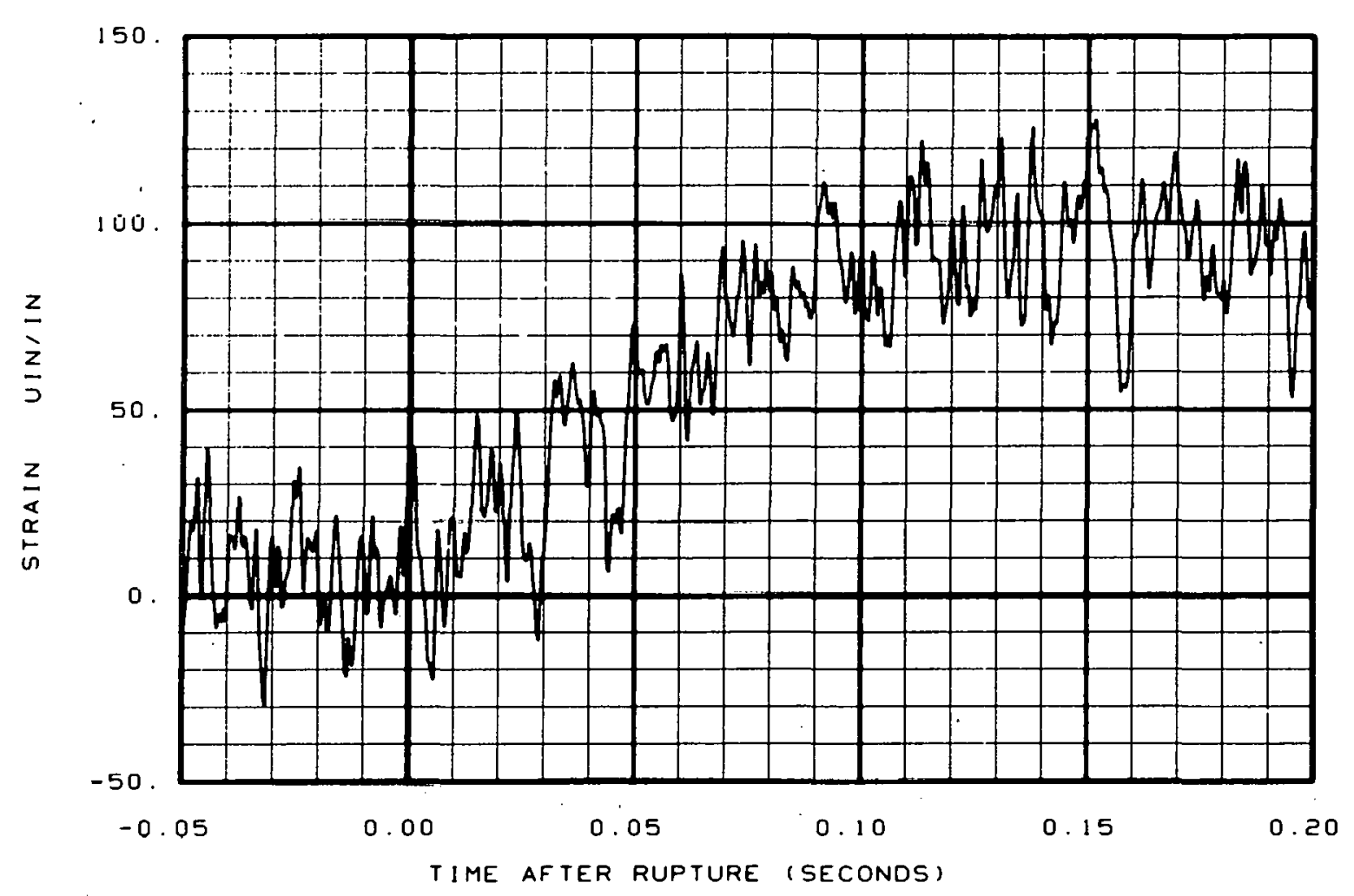

Fig. 58 Strain at reactor vessel intact loop cold leg nozzle (SE-PC4-8).

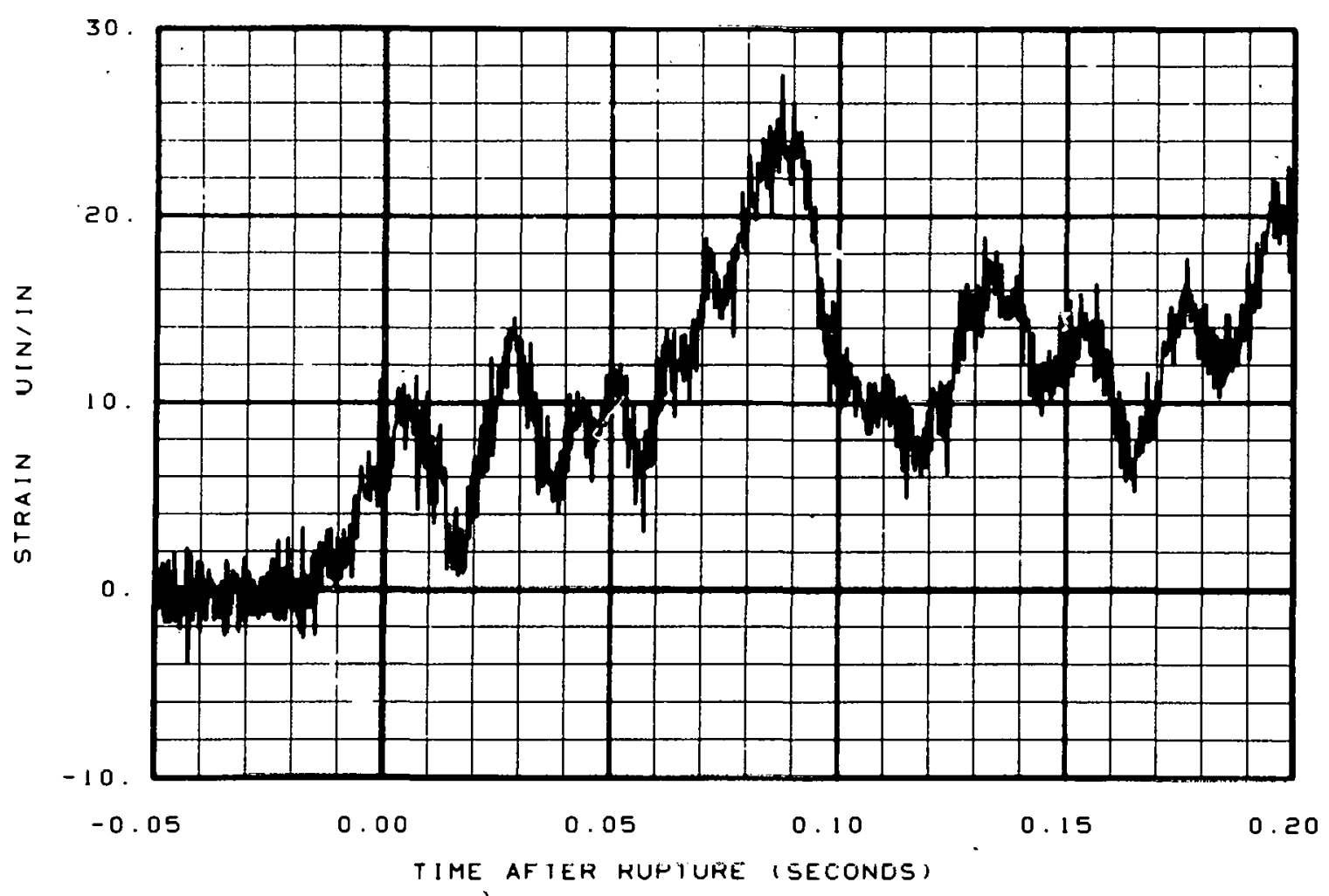

Fig. 59 Strain at reactor vessel intact loop hot leg nozzle (SE-PC5-1). 


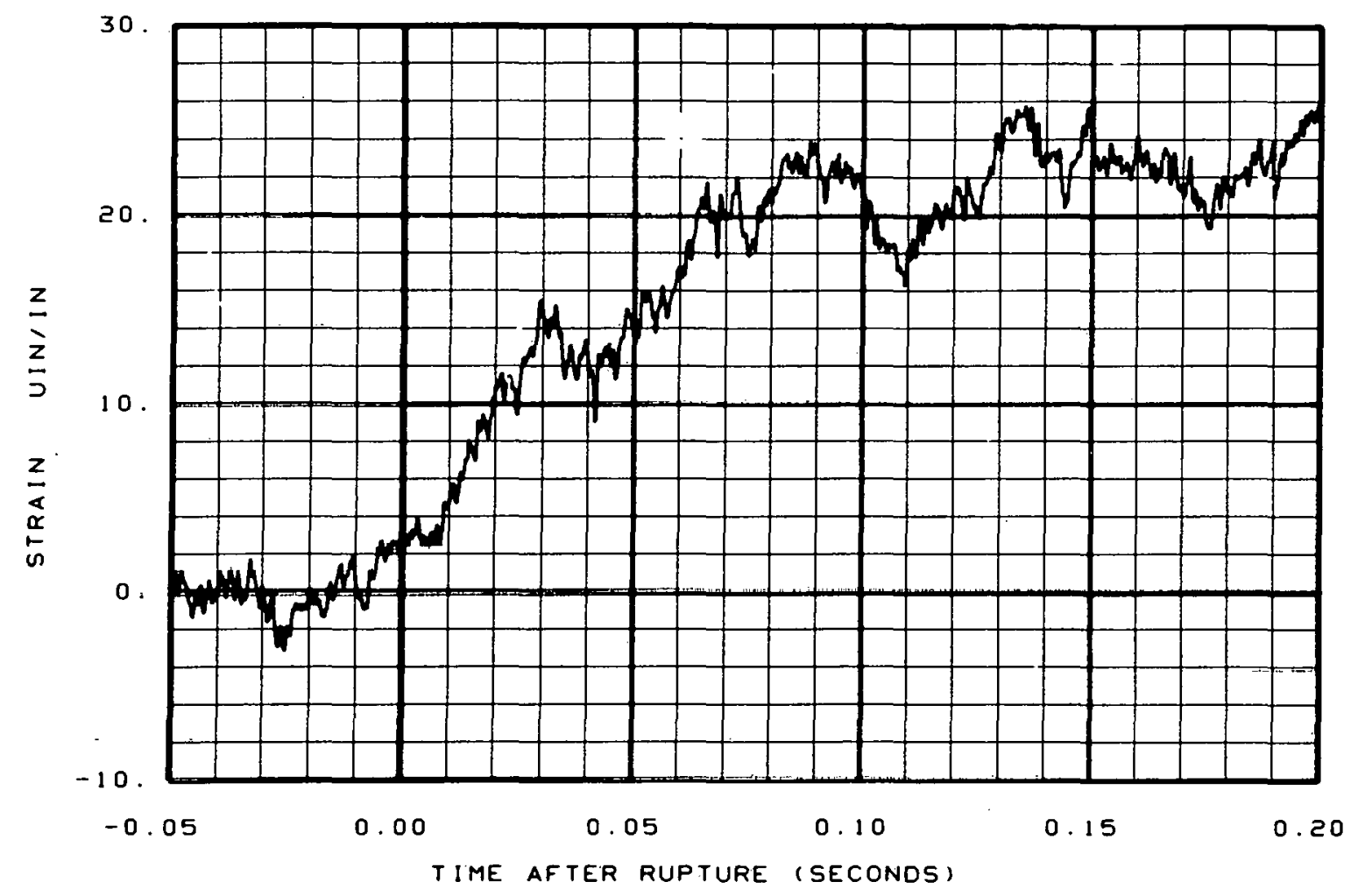

Fig. 60 Strain at reactor vessel intact loop hot leg nozzle (SE-PC5-2).

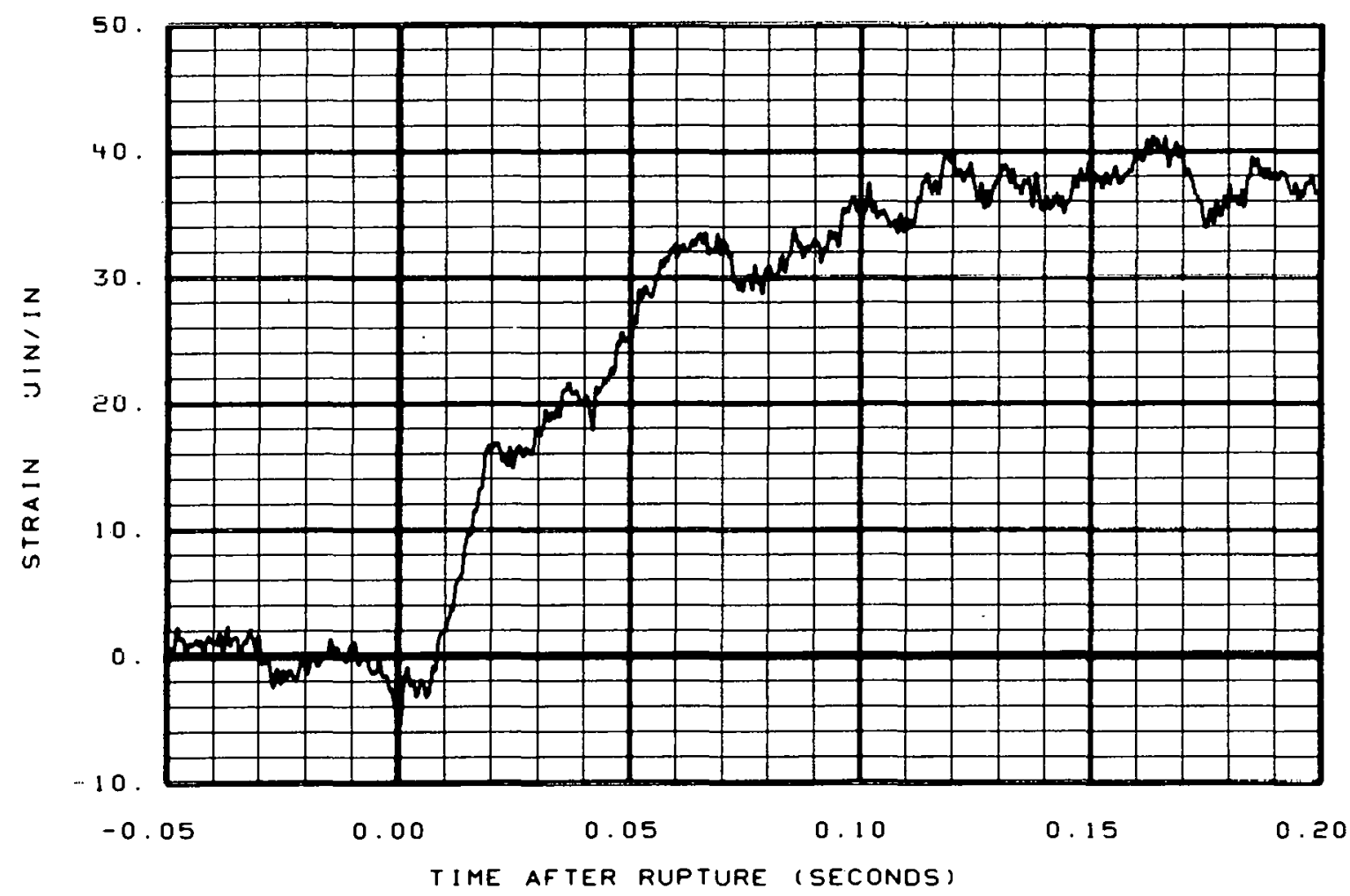

Fig. 61 Strain at reactor vessel intact loop hot leg nozzle (SE-PC5-3). 


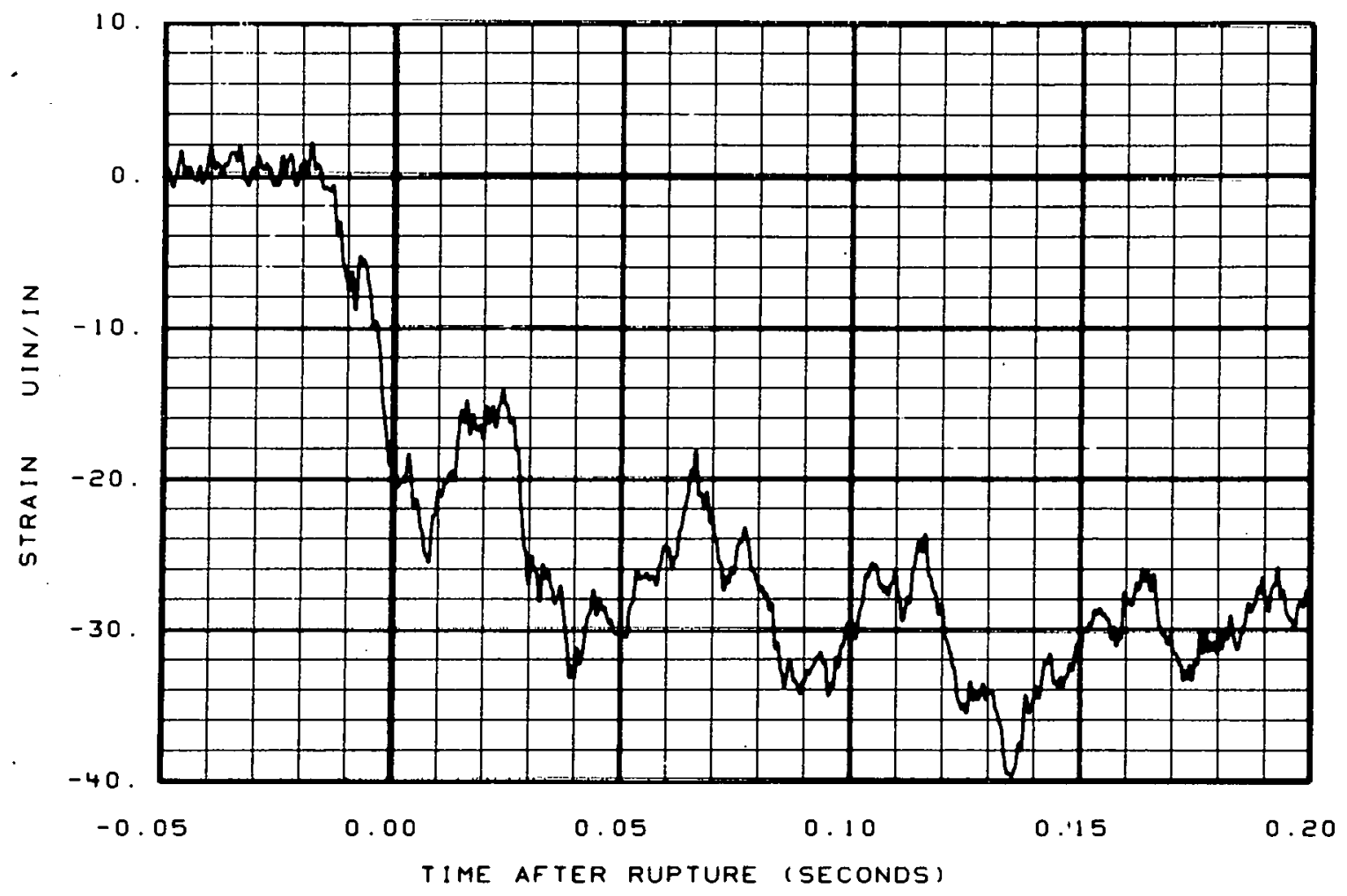

Fig. 62 Strain at reactor vessel intact loop hot leg nozzle (SE-PC5-4).

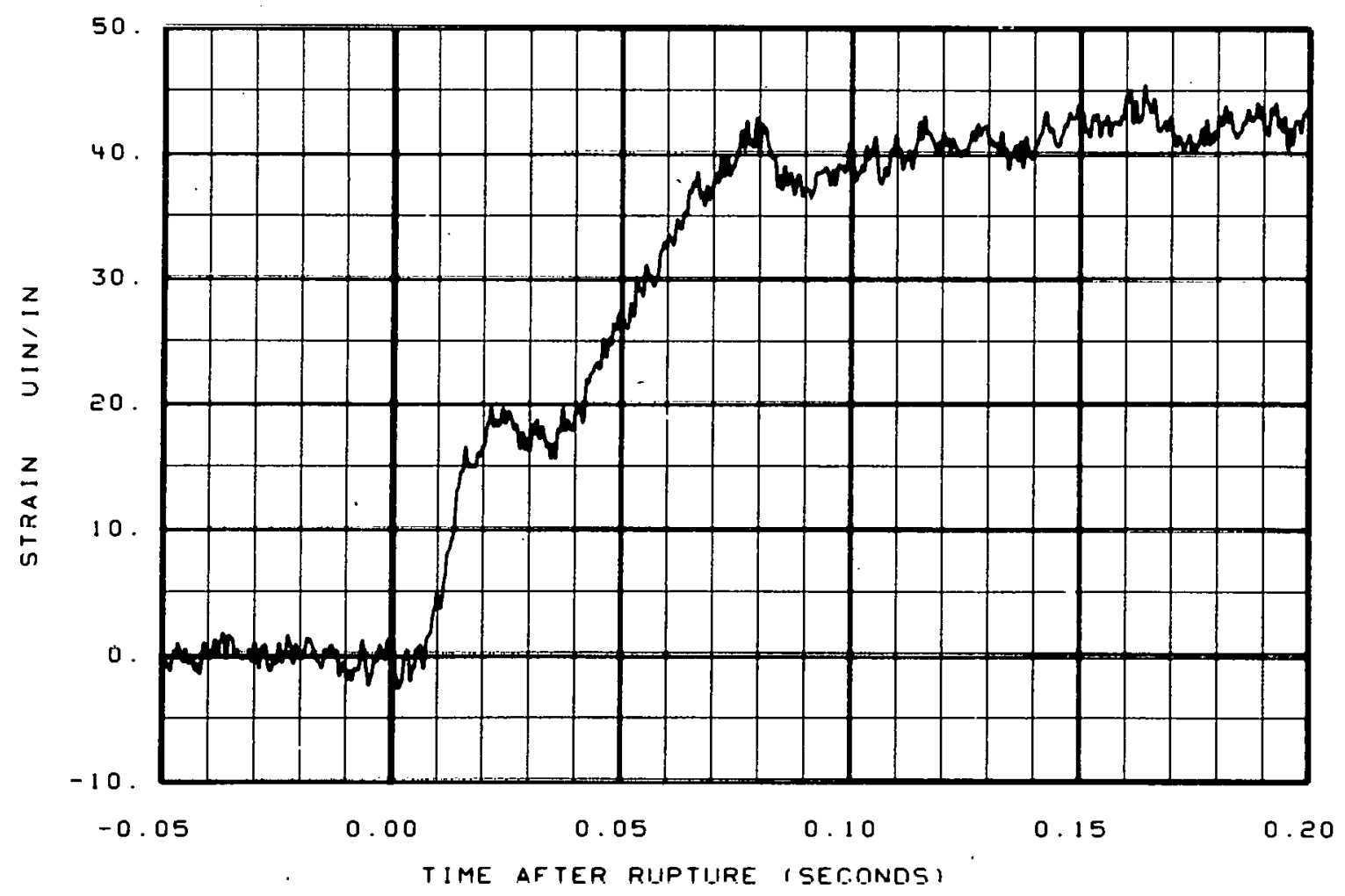

Fig. 63 Strain at reactor vessel intact loop hot leg nozzle (SE-PC5-5). 


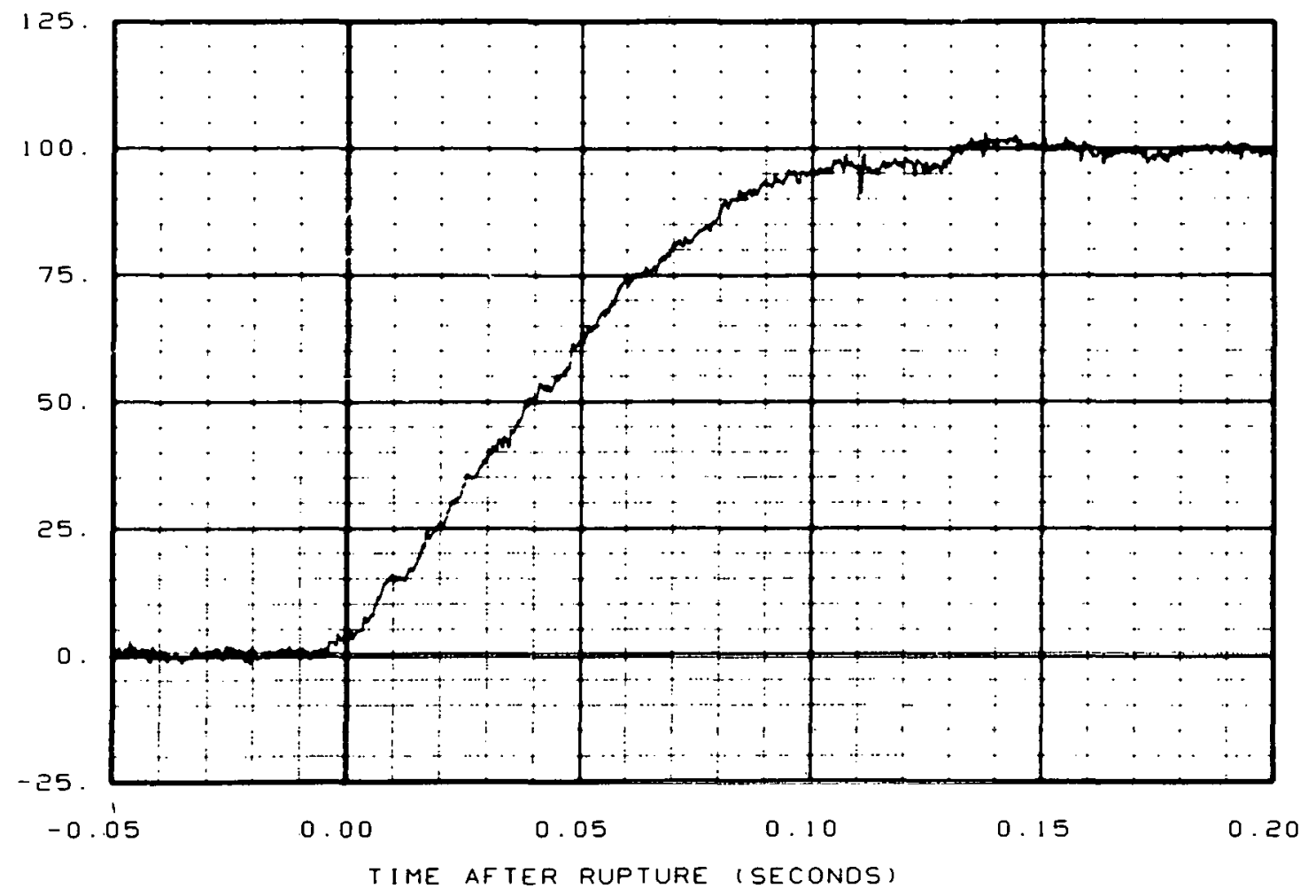

Fig. 64 Strain at reactor vessel intact loop hot leg nozzle (SE-PC5-6).

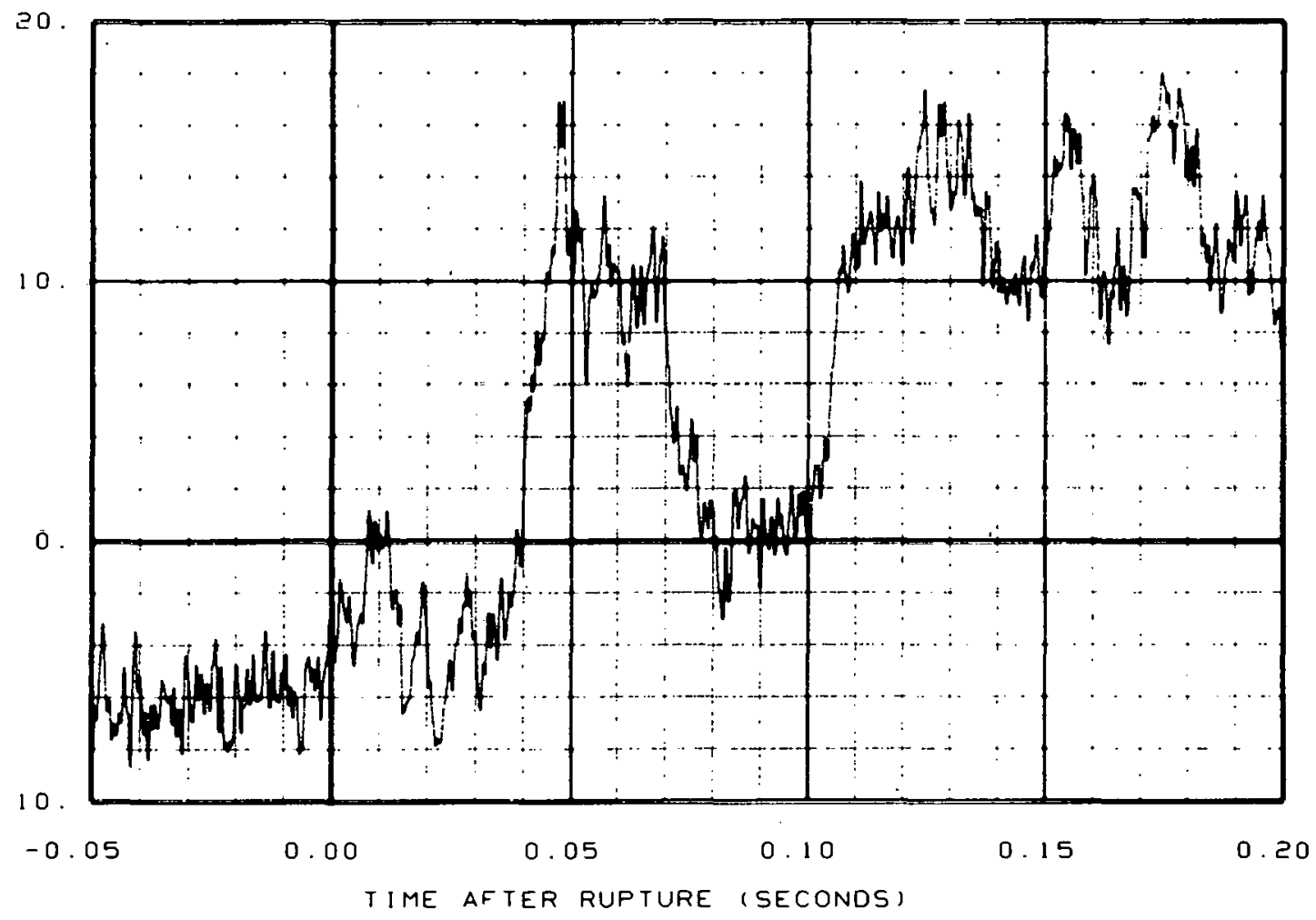

Fig. 65 Strain at reactor vessel intact loop hot leg nozzle (SE-PC5-7). 


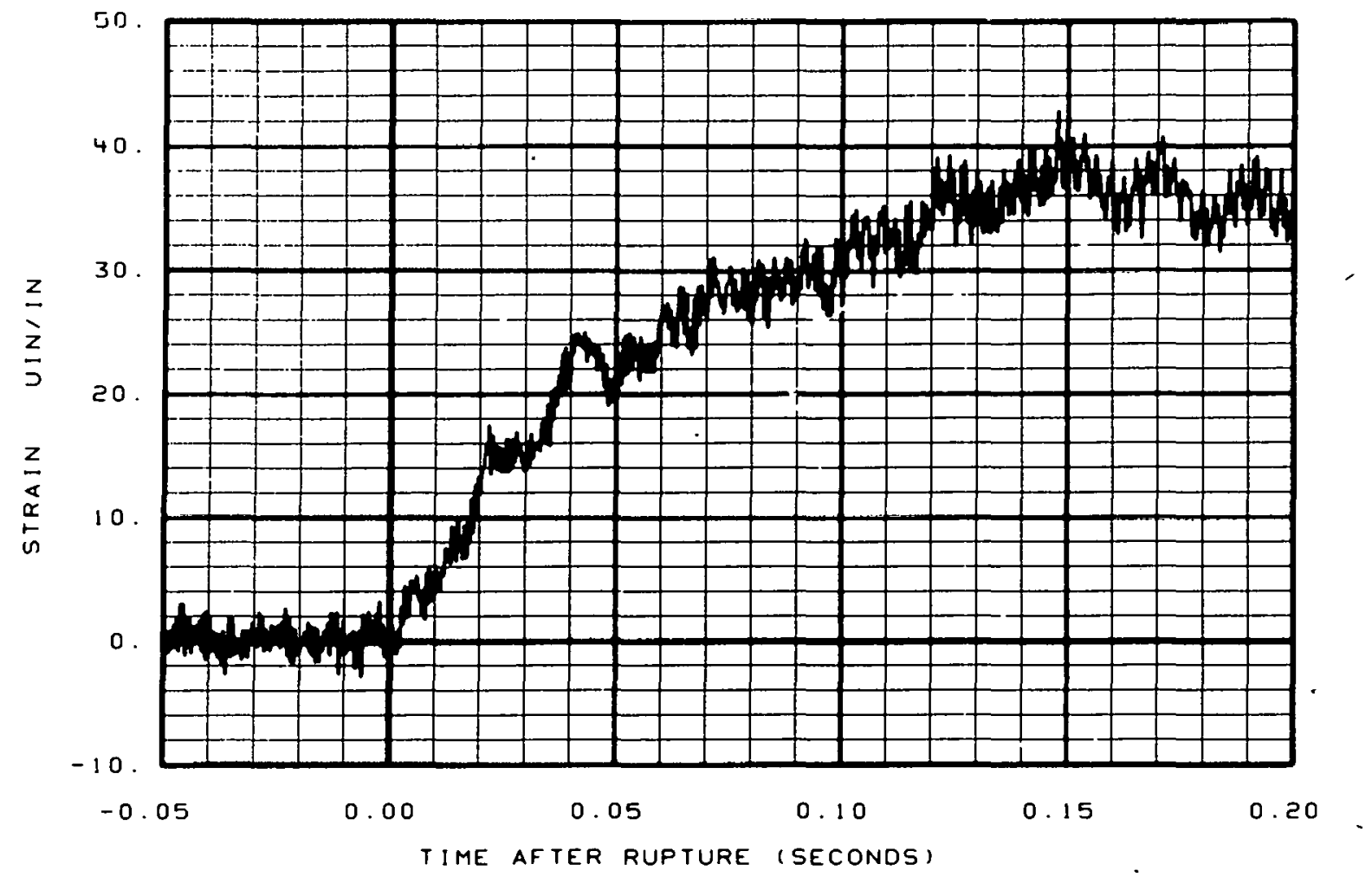

Fig. 66 Strain at reactor vessel intact loop hot leg nozzle (SE-PC5-8).

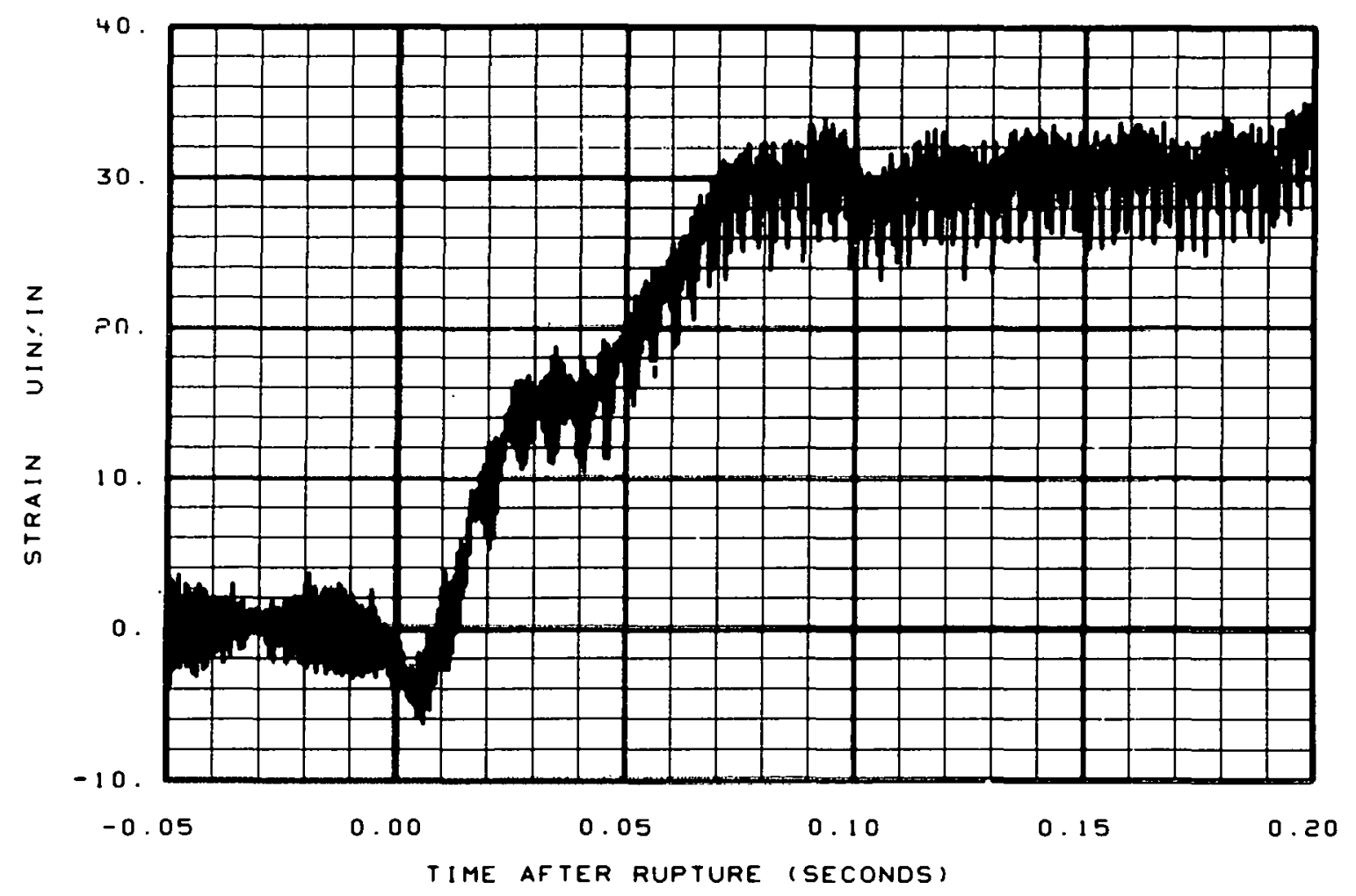

Fig. 67 Strain at reactor vessel intact loop hot leg nozzle (SE-PC5-9). 


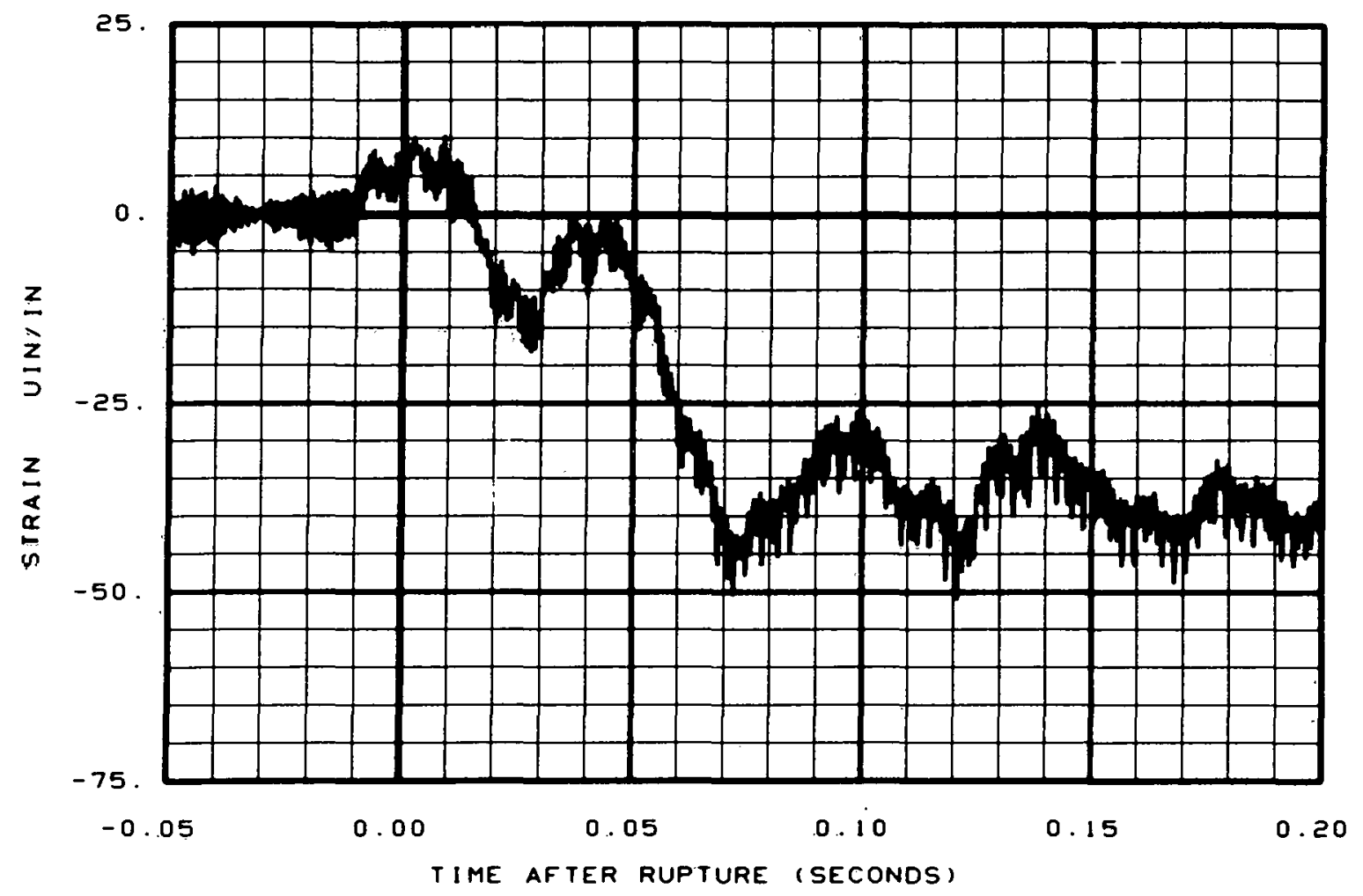

Fig. 68 Strain at reactor vessel intact loop hot leg nozzle (SE-PC5-10).

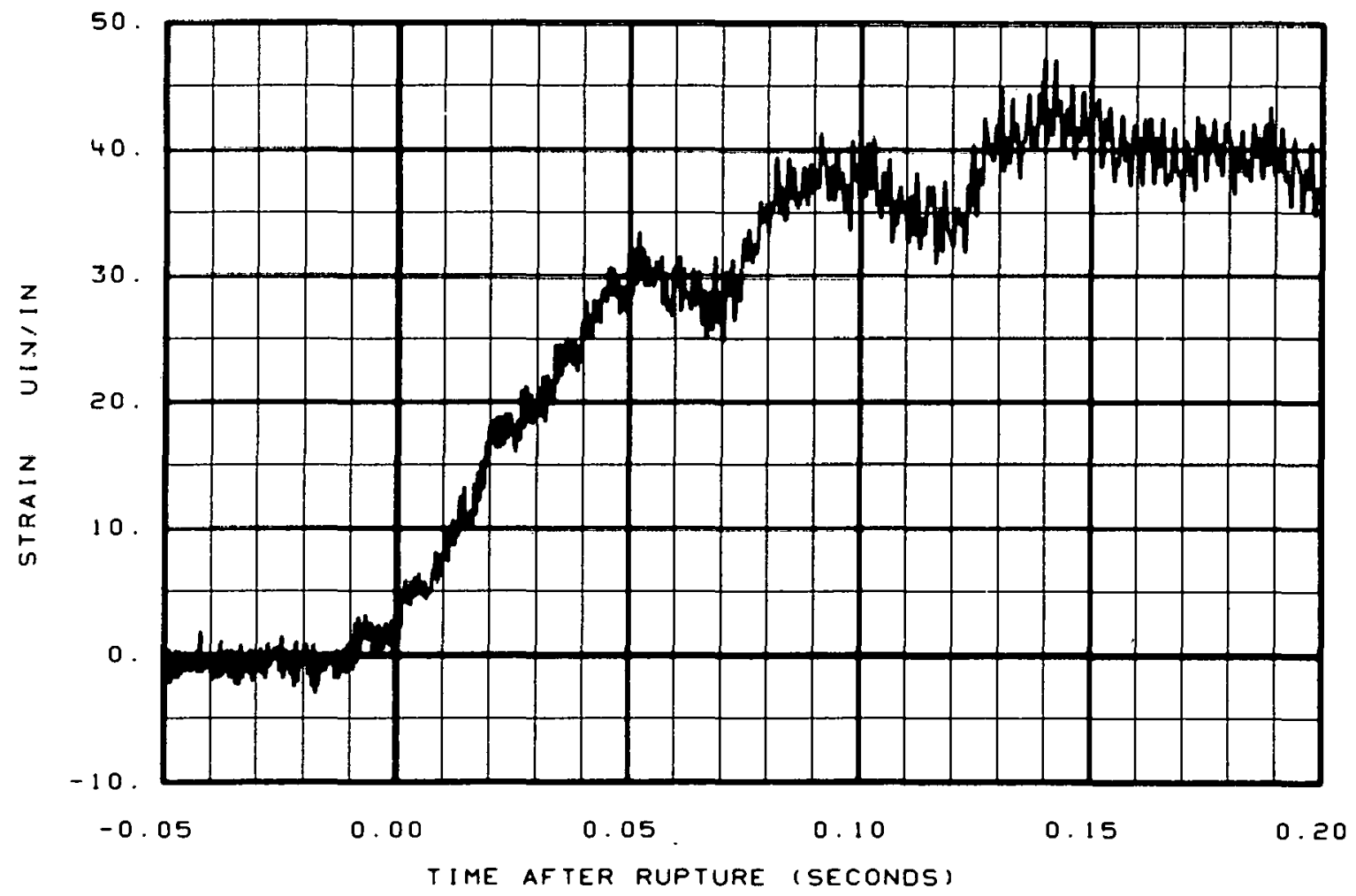

Fig. 69 Strain at reactor vessel intact loop hot leg nozzle (SE-PC5-11). 


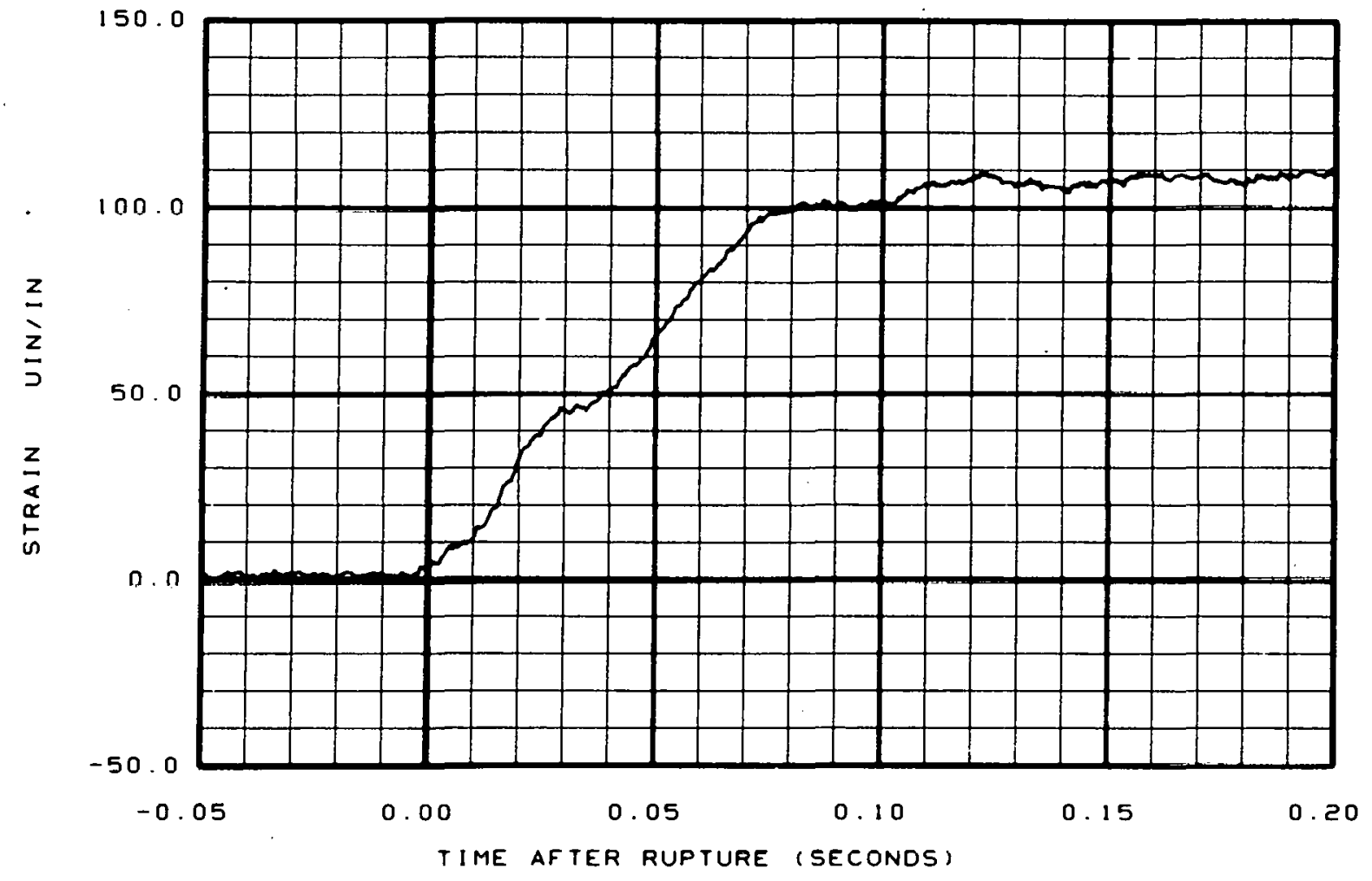

Fig. 70 Strain at reactor vessel intact loop hot leg nozzle (SE-PC5-12).

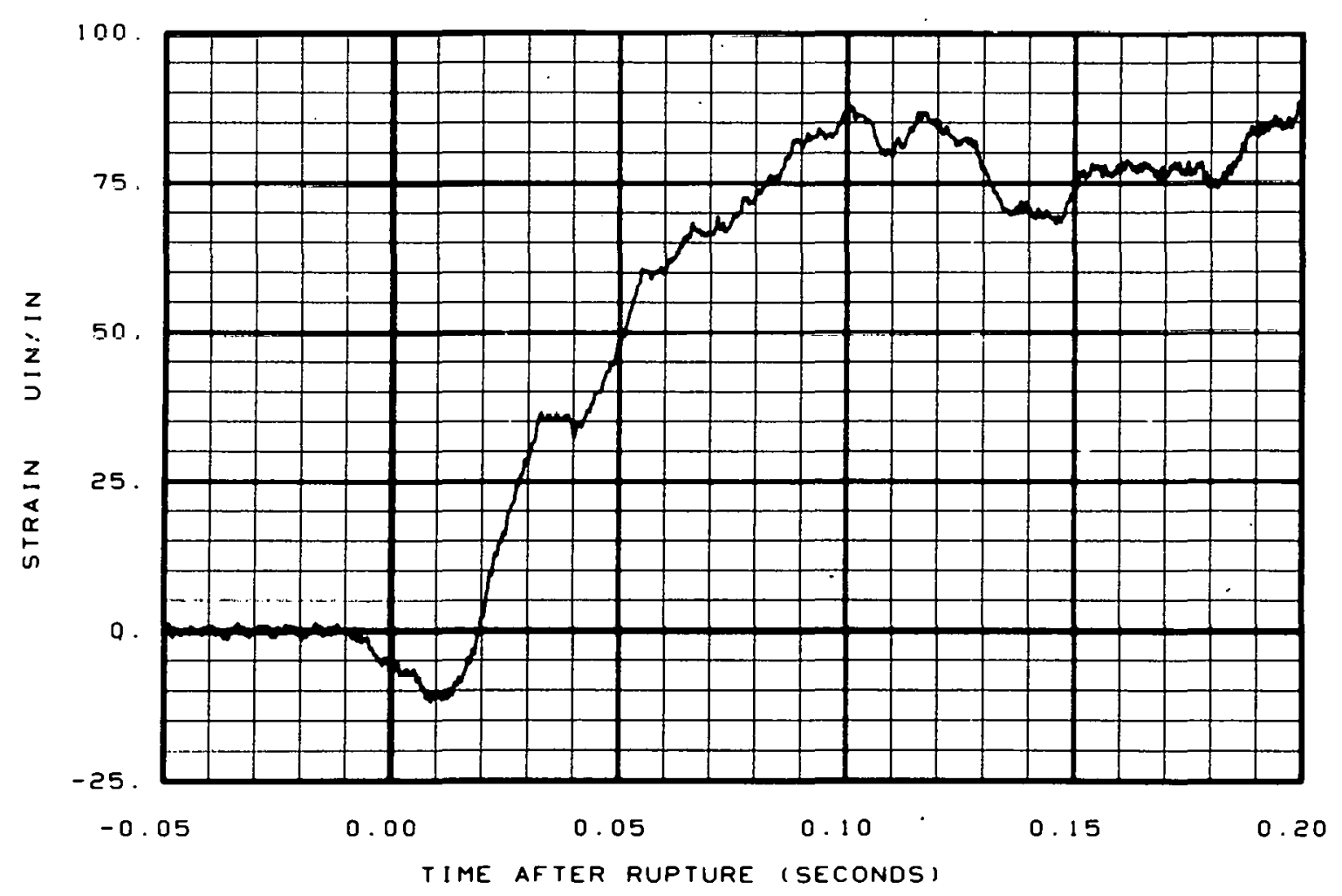

Fig. 71 Strain at steam generator inlet nozzle (SE-PC14-2). 


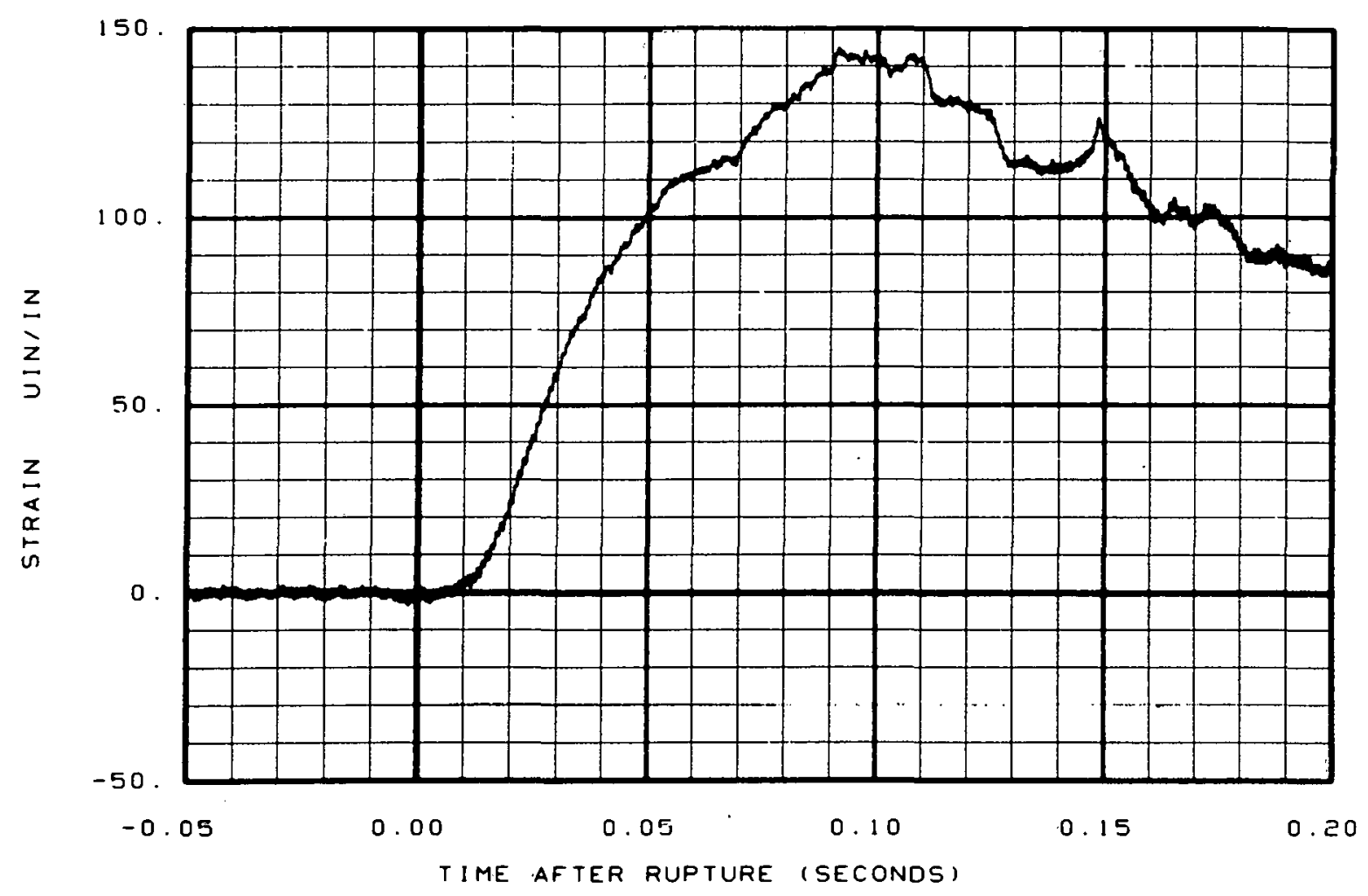

Fig. 72 Strain at steam generator inlet nozzle (SE-PCI4-3).

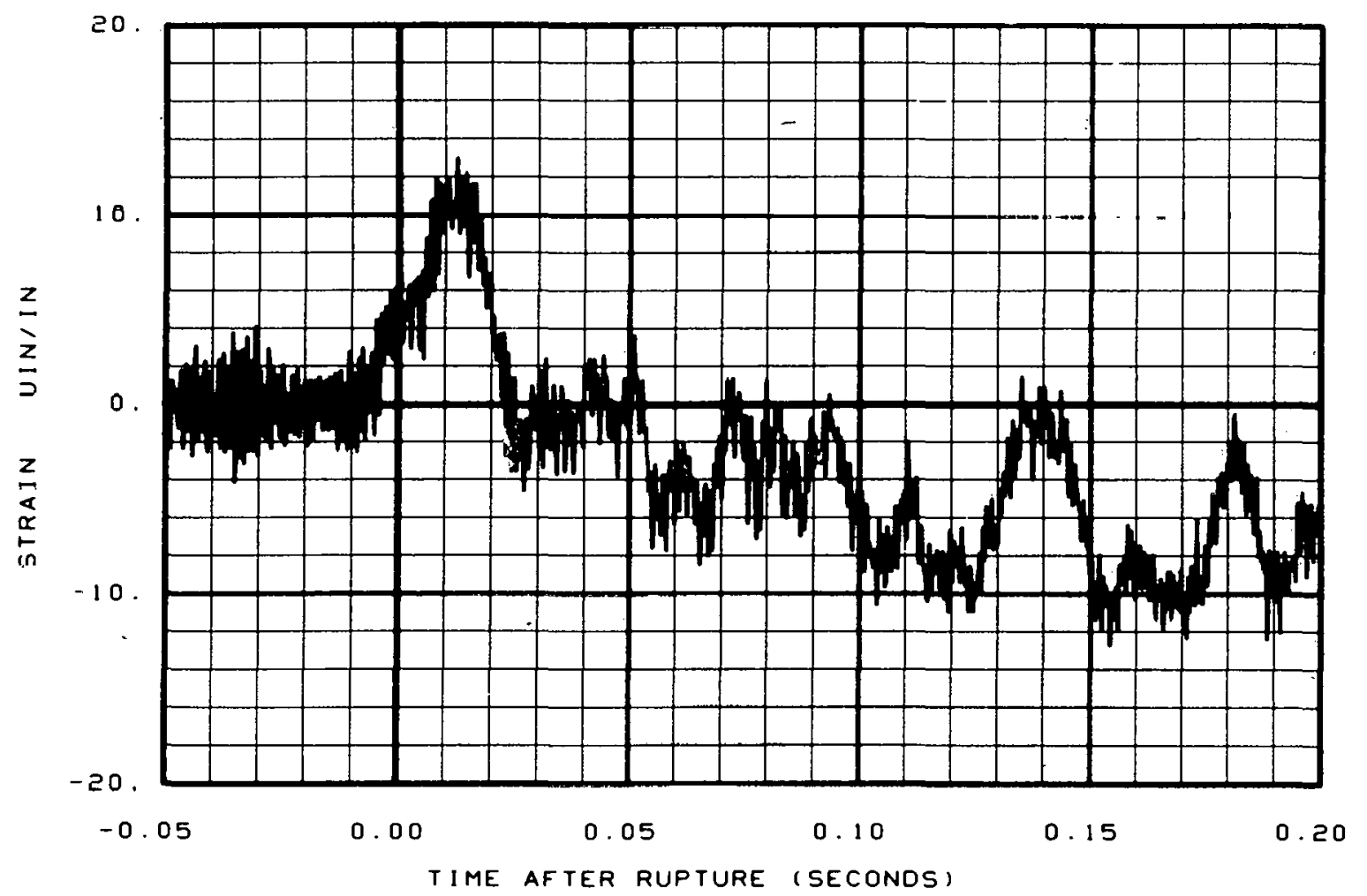

Fig. 73 Strain at steam generator inlet nozzle (SE-PC14-4). 


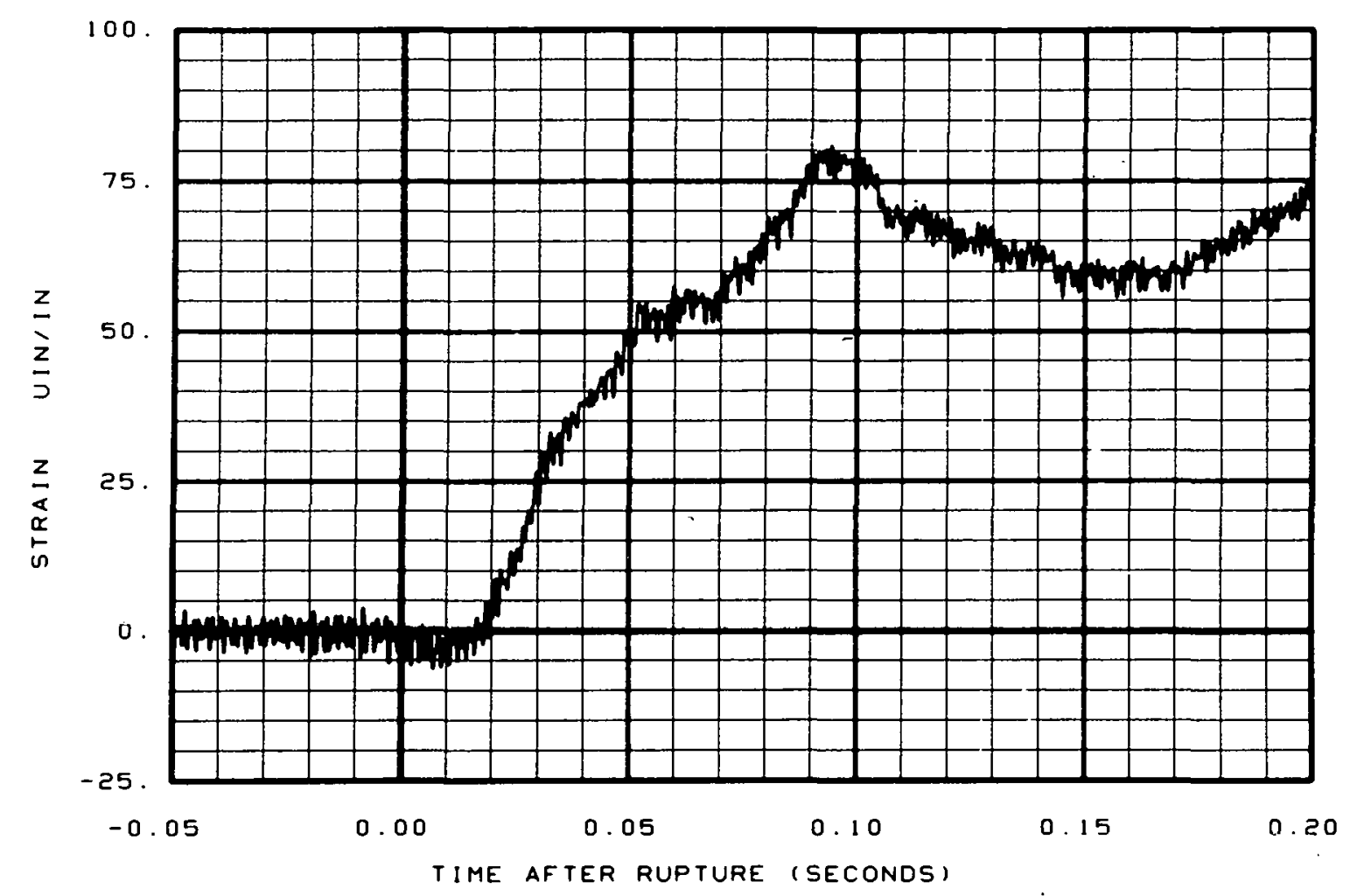

Fig. 74 Strain at steam generator inlet nozzle (SE-PC14-5).

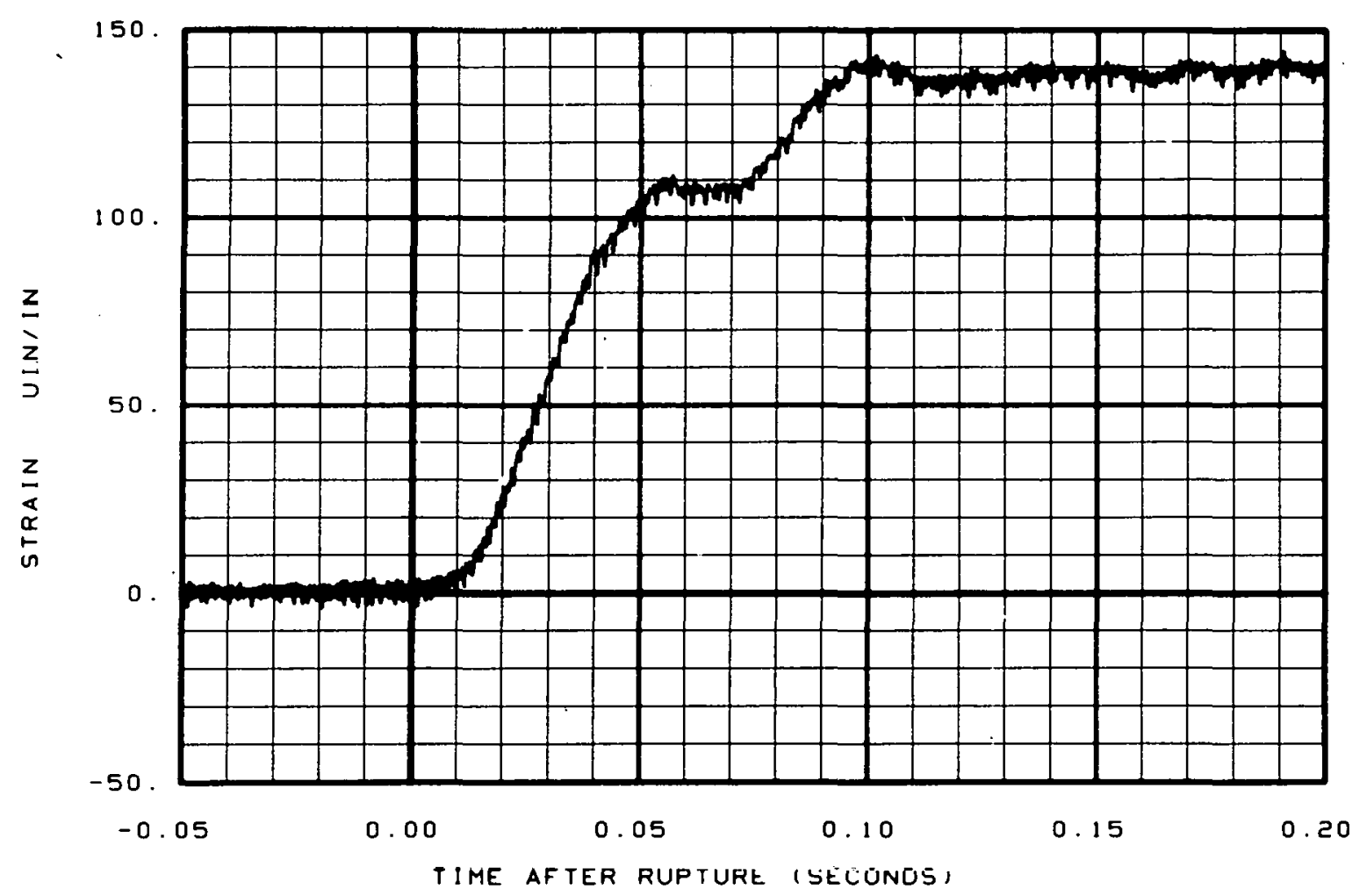

Fig. 75 Strain at steam generator inlet nozzle (SE-PC14-6). 


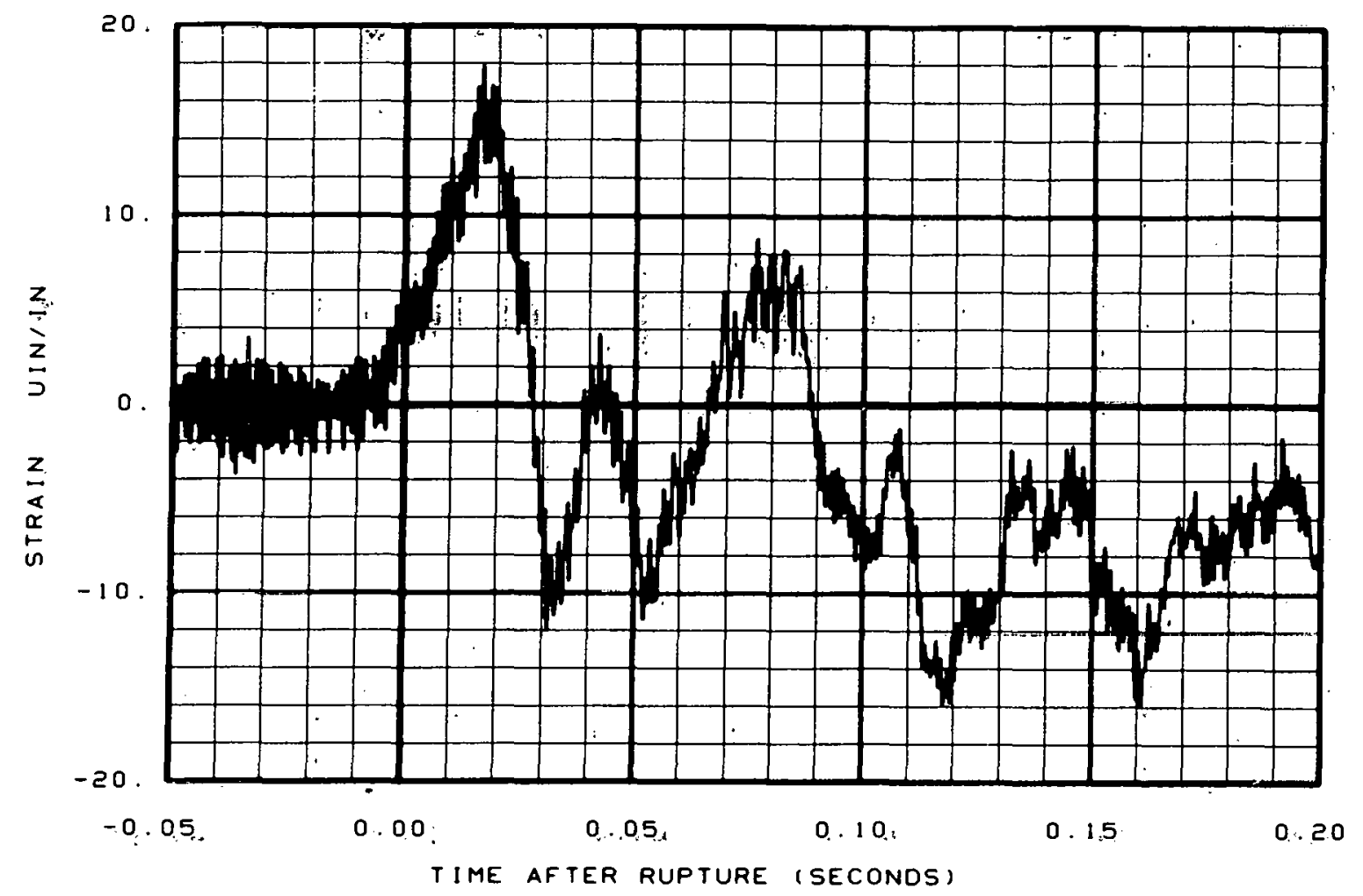

Fig. 76 Strain at steam generator inlet nozzle (SE-PC14-7).

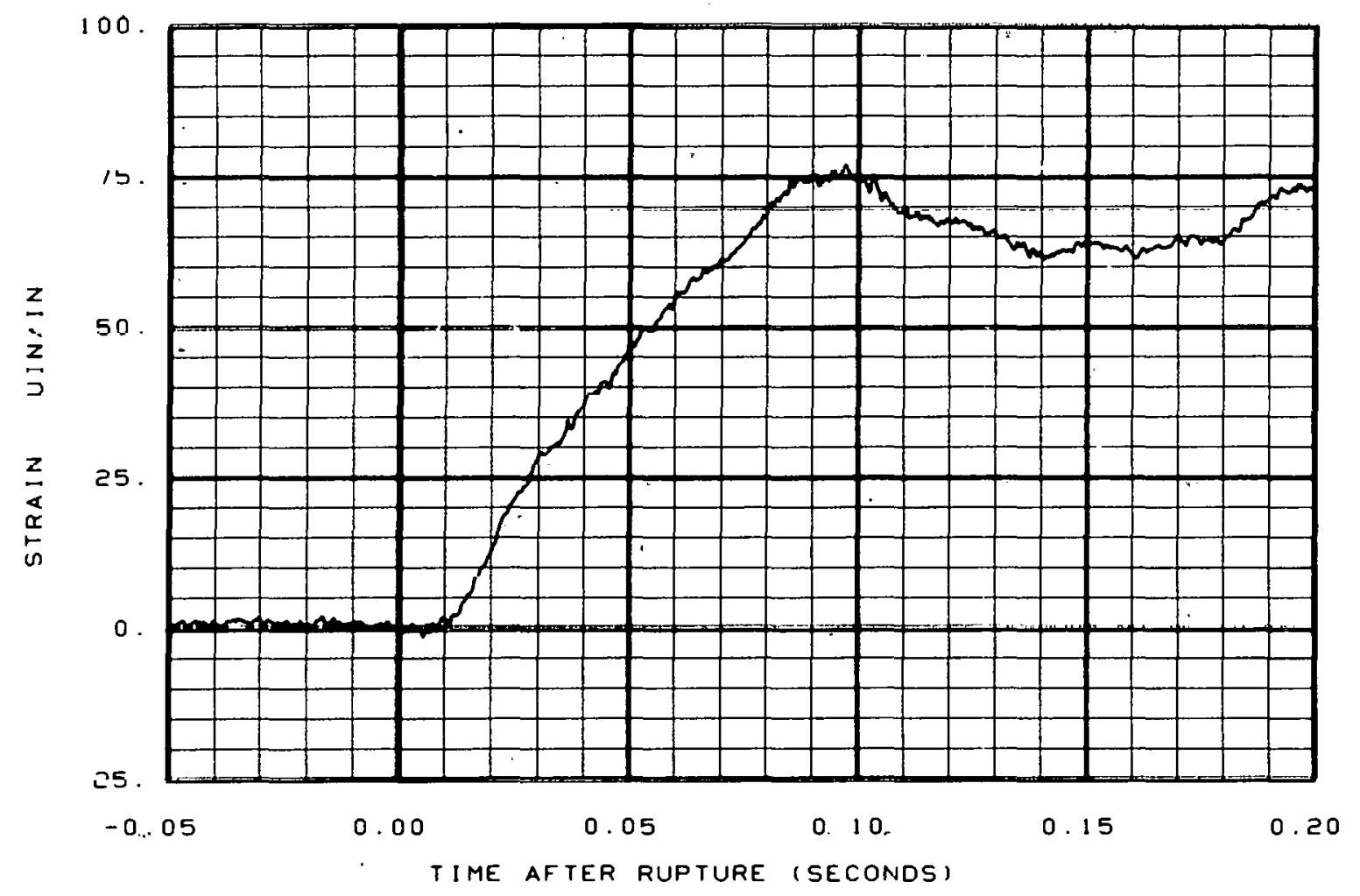

Fig. 77 Strain at steam generator inlet nozzle (SE-PC14-8). 


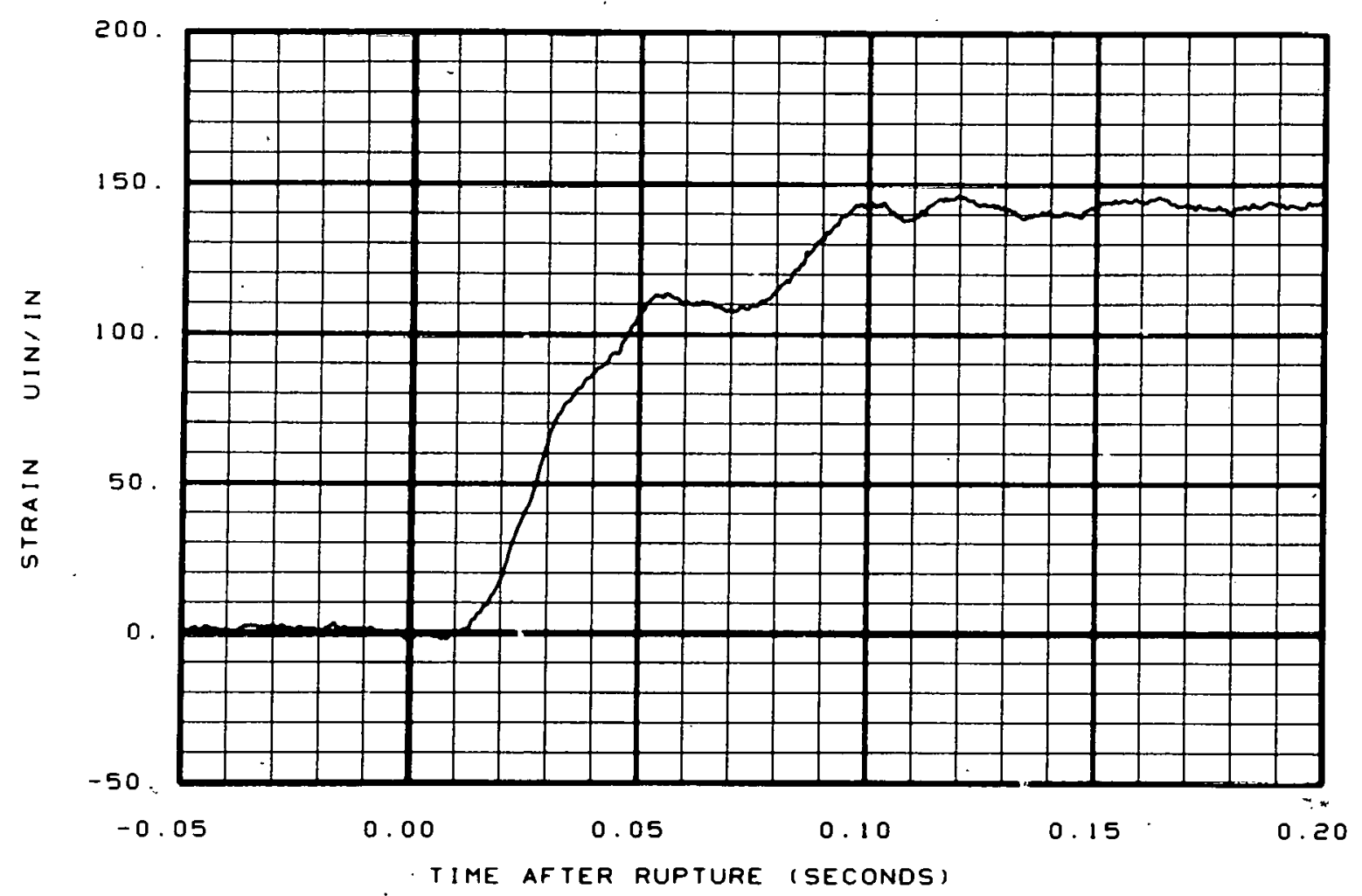

Fig. 78 Strain at steam generator inlet nozzle (SE-PCl4-9).

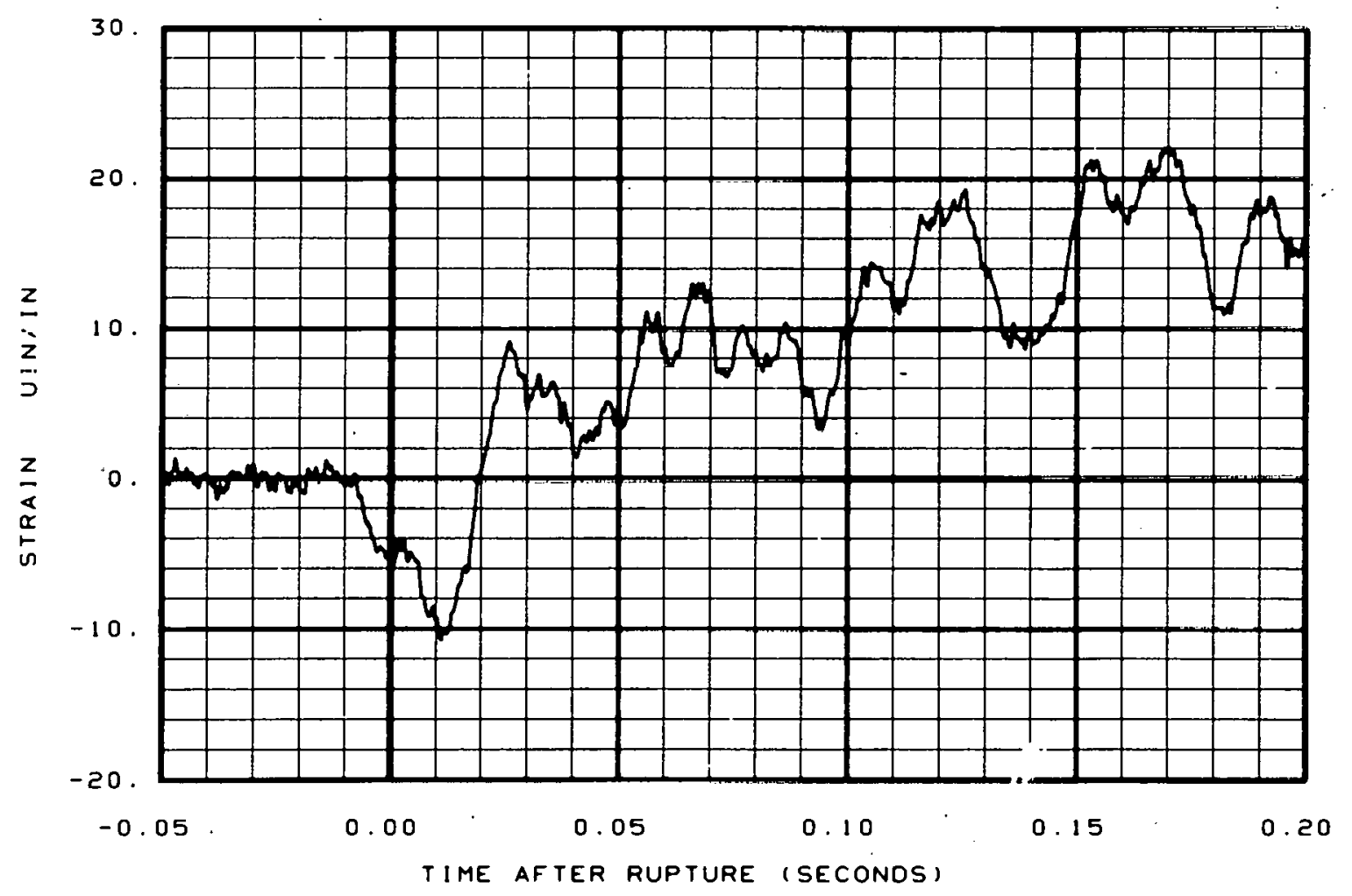

Fiy. 79 Strain at steam generator inlet nozzle (SE-PC14-10). 


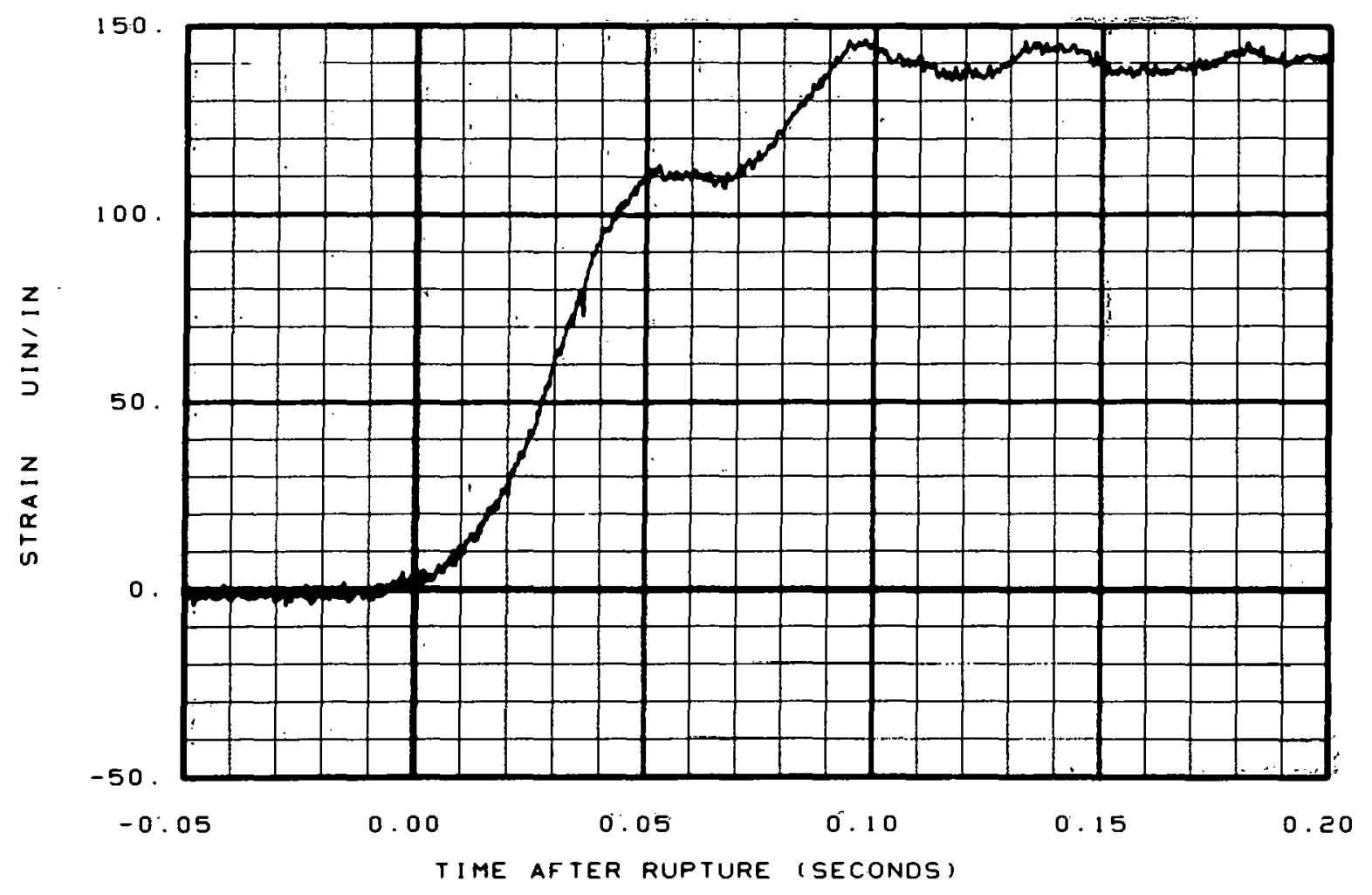

Fig. 80 Strain at steam generator inlet nozzle (SE-PC14-12).

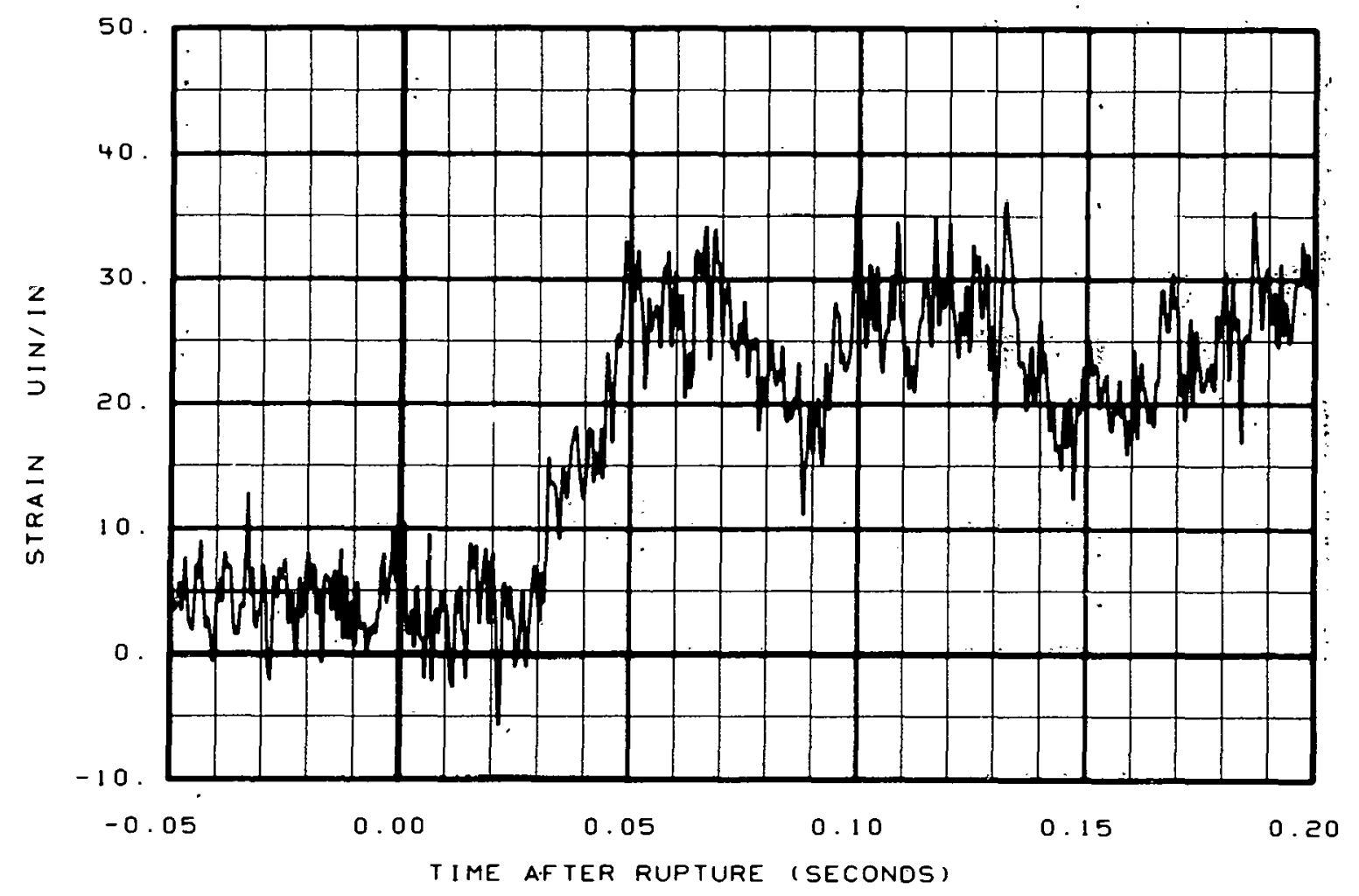

Fig. 81 Strain at steam generator outlet nozzle (SE-PC15-1). 


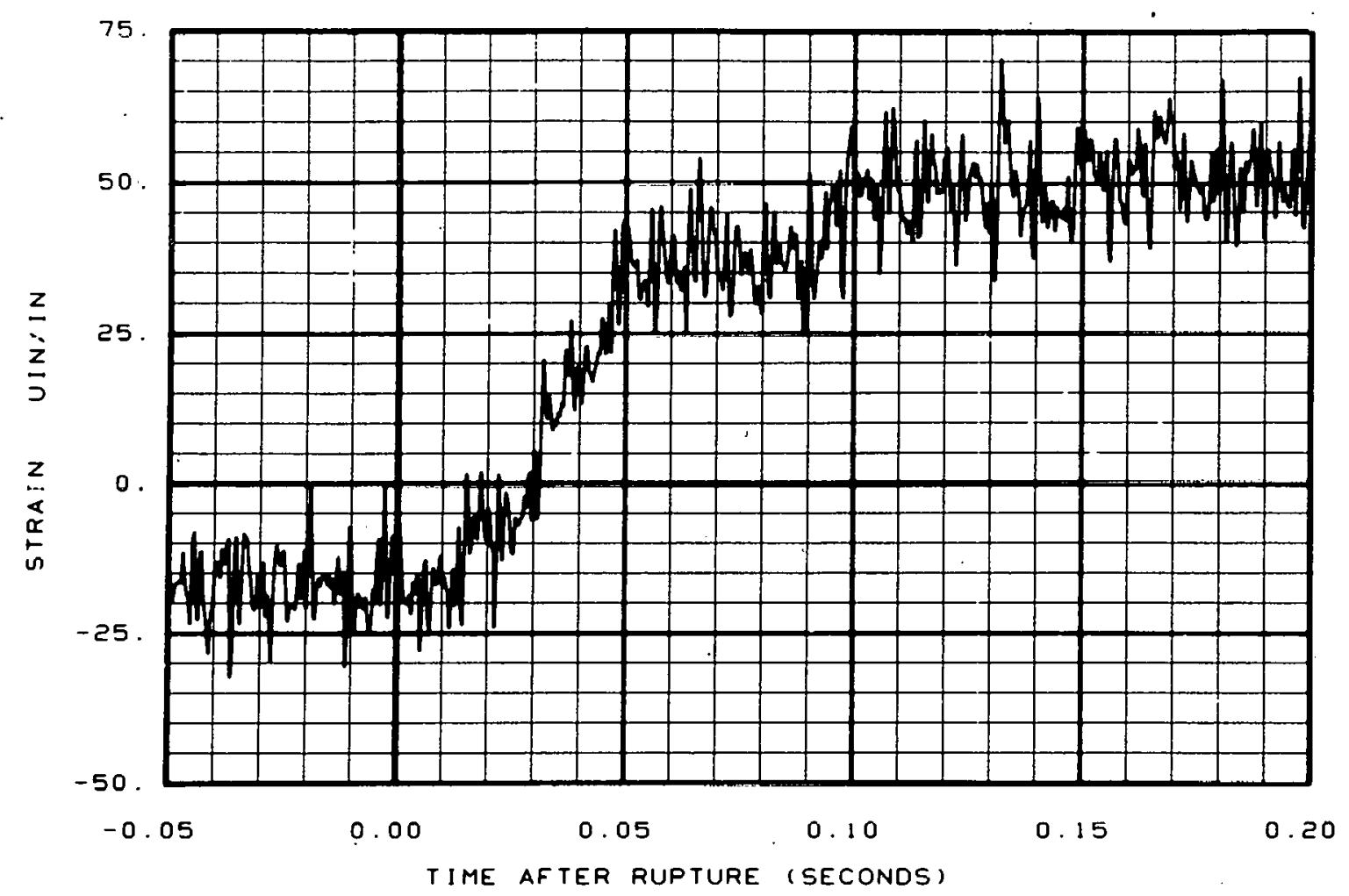

Fig. 82 Strain at steam generator outlet nozzle (SE-PC15-2).

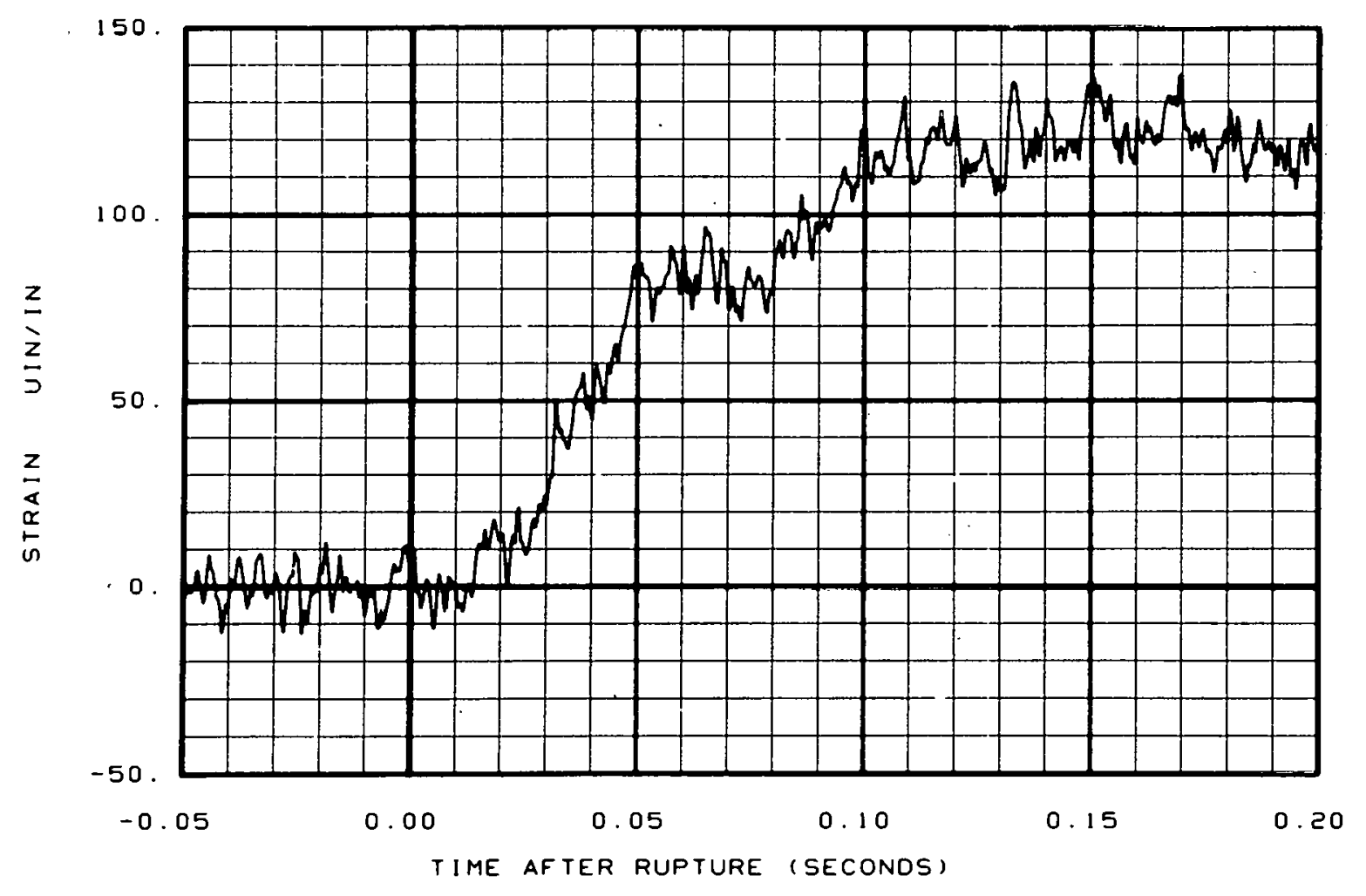

F1g. 83 Strain at steam generator outlet nozzle (SE-PC15-3). 


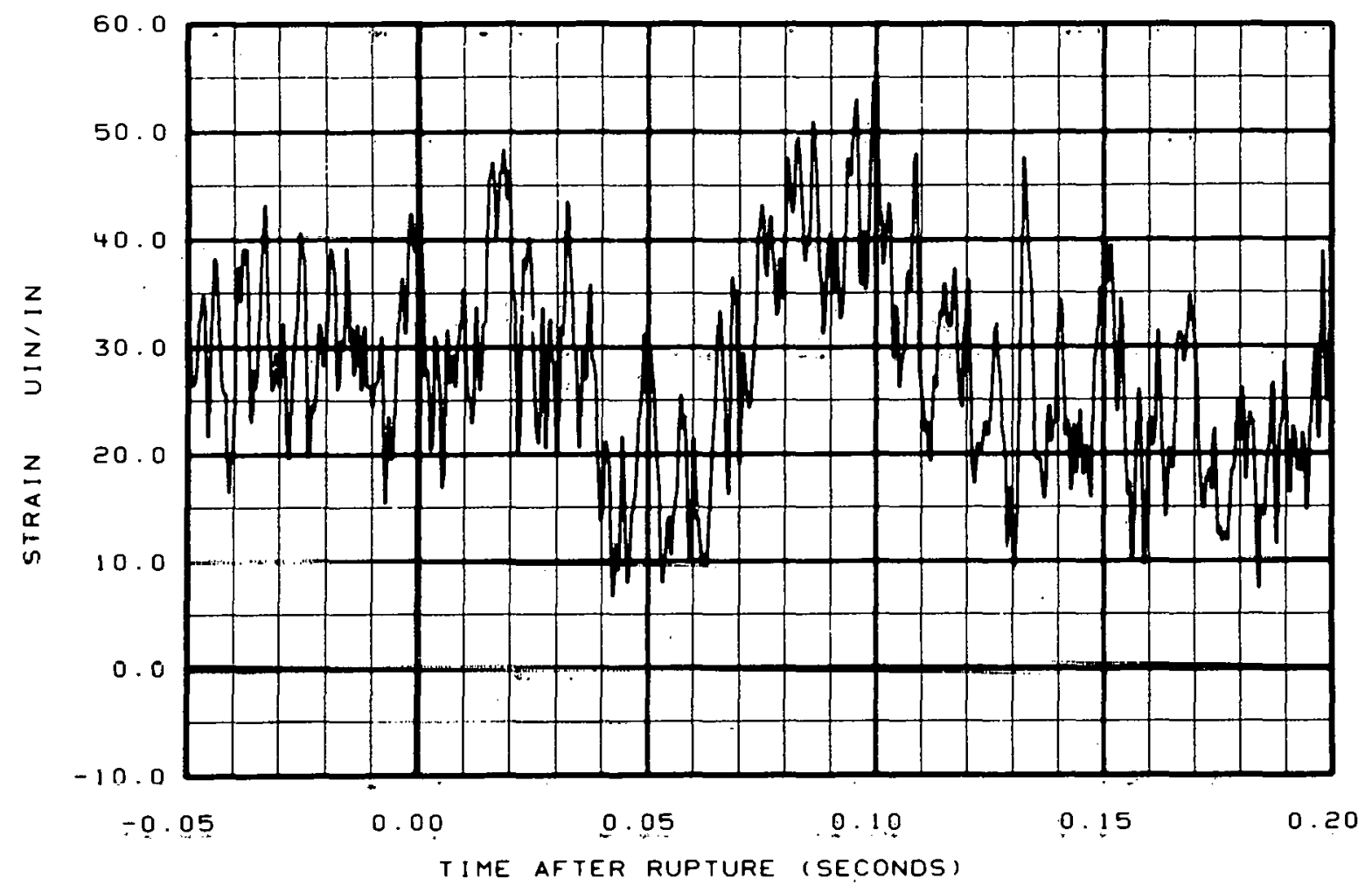

Fig. 84 Strain at steam generator outlet nozzle (SE-PC15-4).

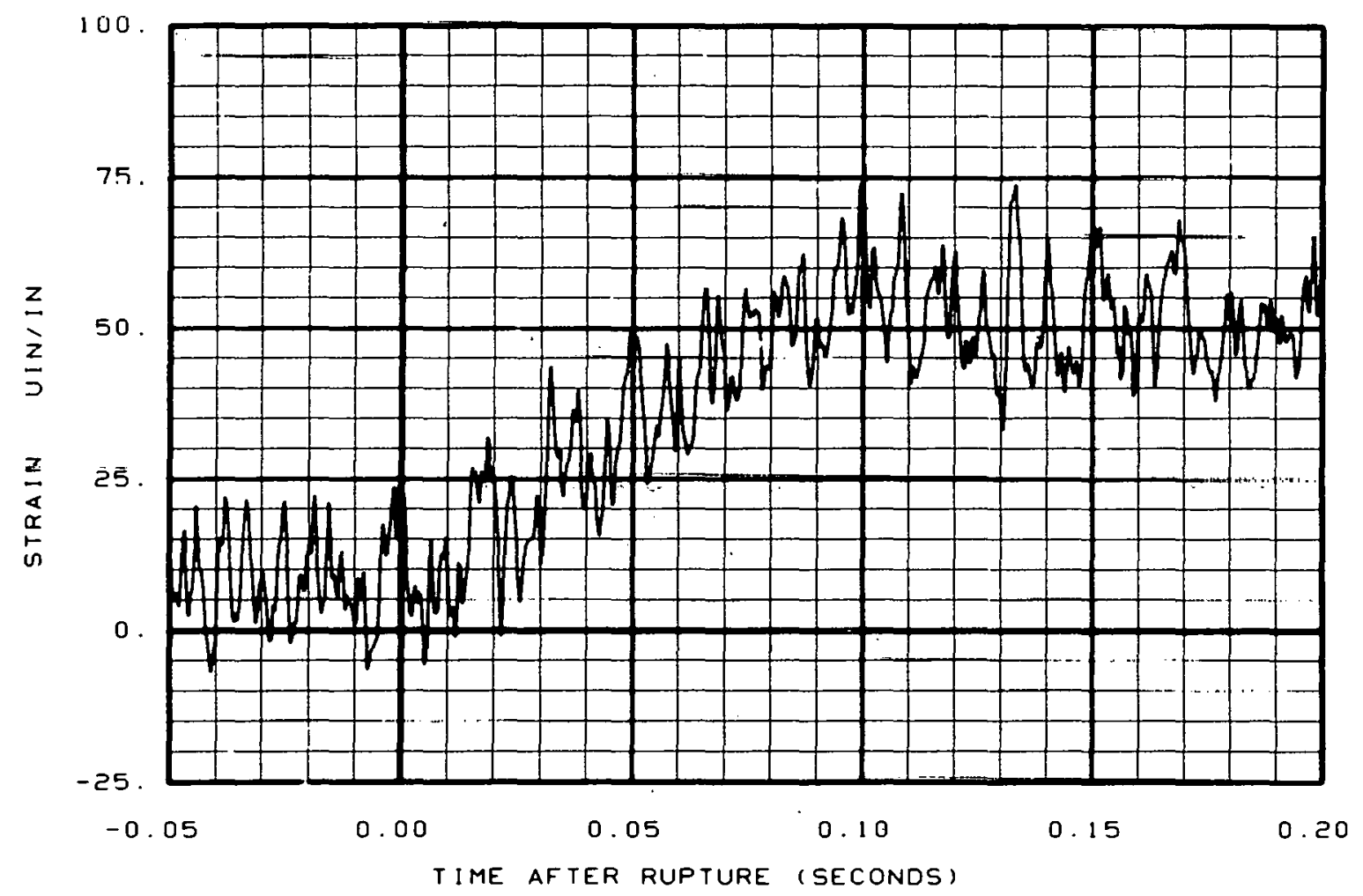

Fig. 85 Strain at steam generator outlet nozzle (SE-PC15-5). 


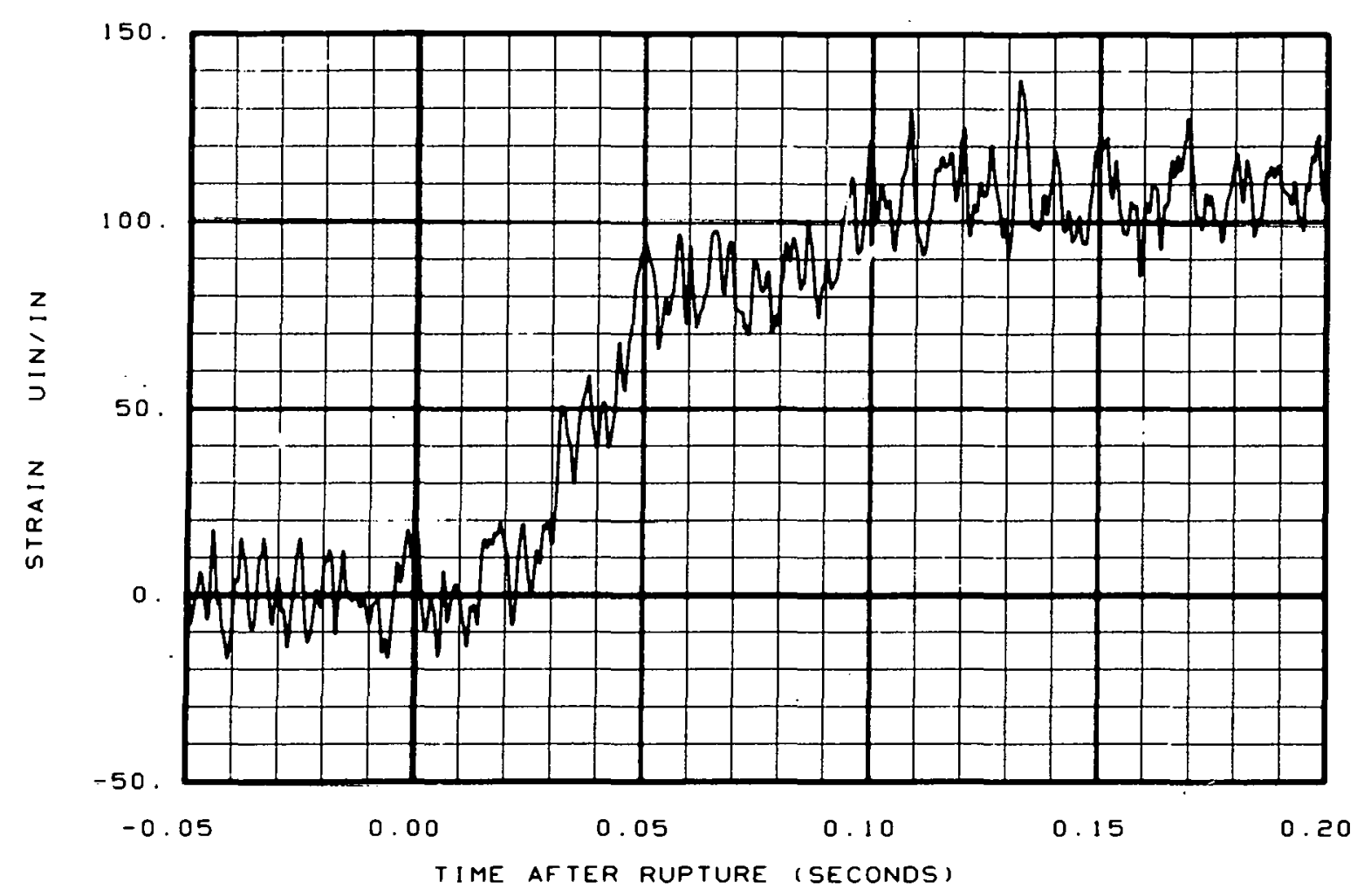

Fig. 86 Strain at steam generator outlet nozzle (SE-PC15-6).

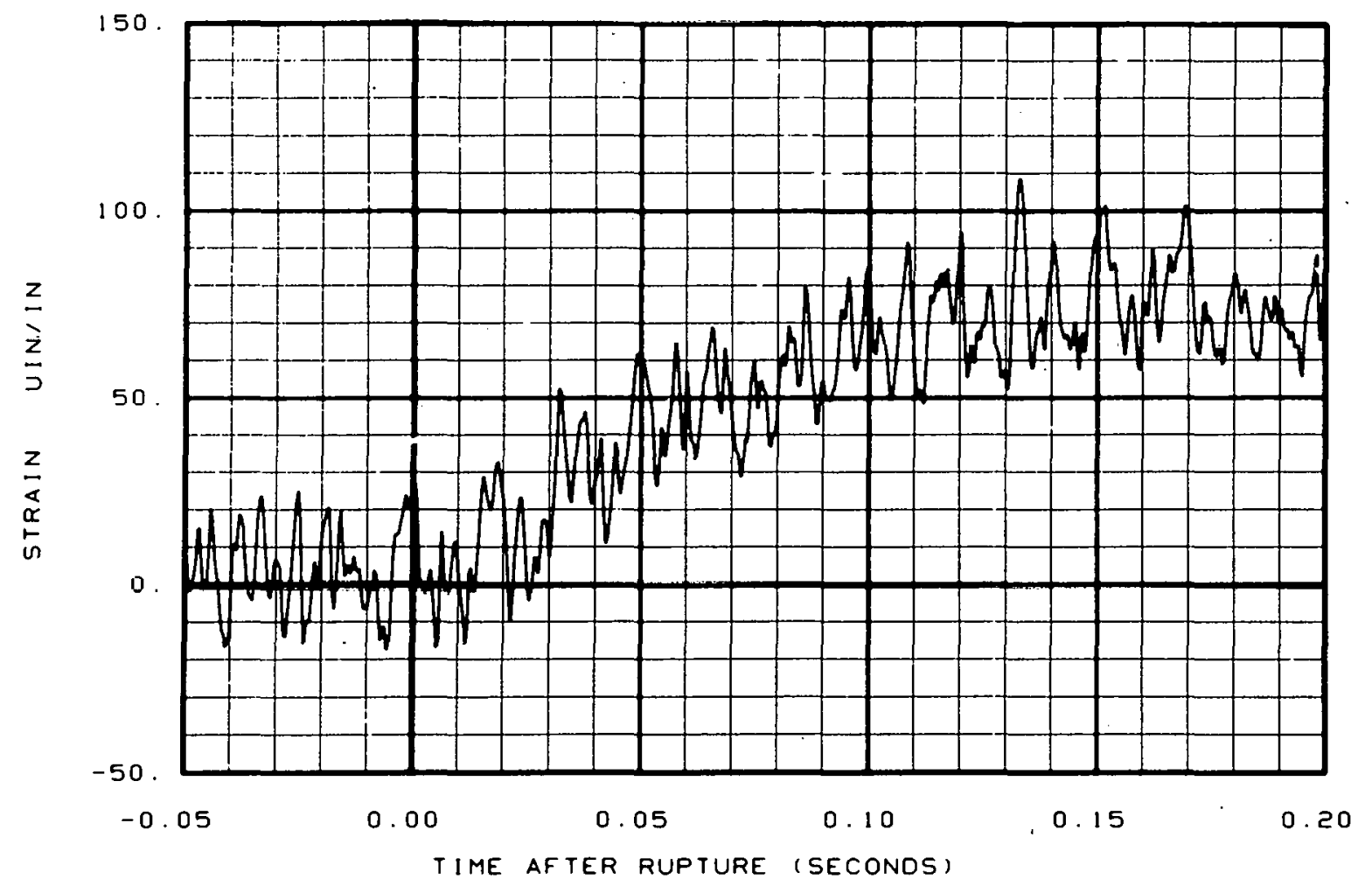

Fig. 87 Strain at steam generator outlet nozzle (SE-PC15-8). 


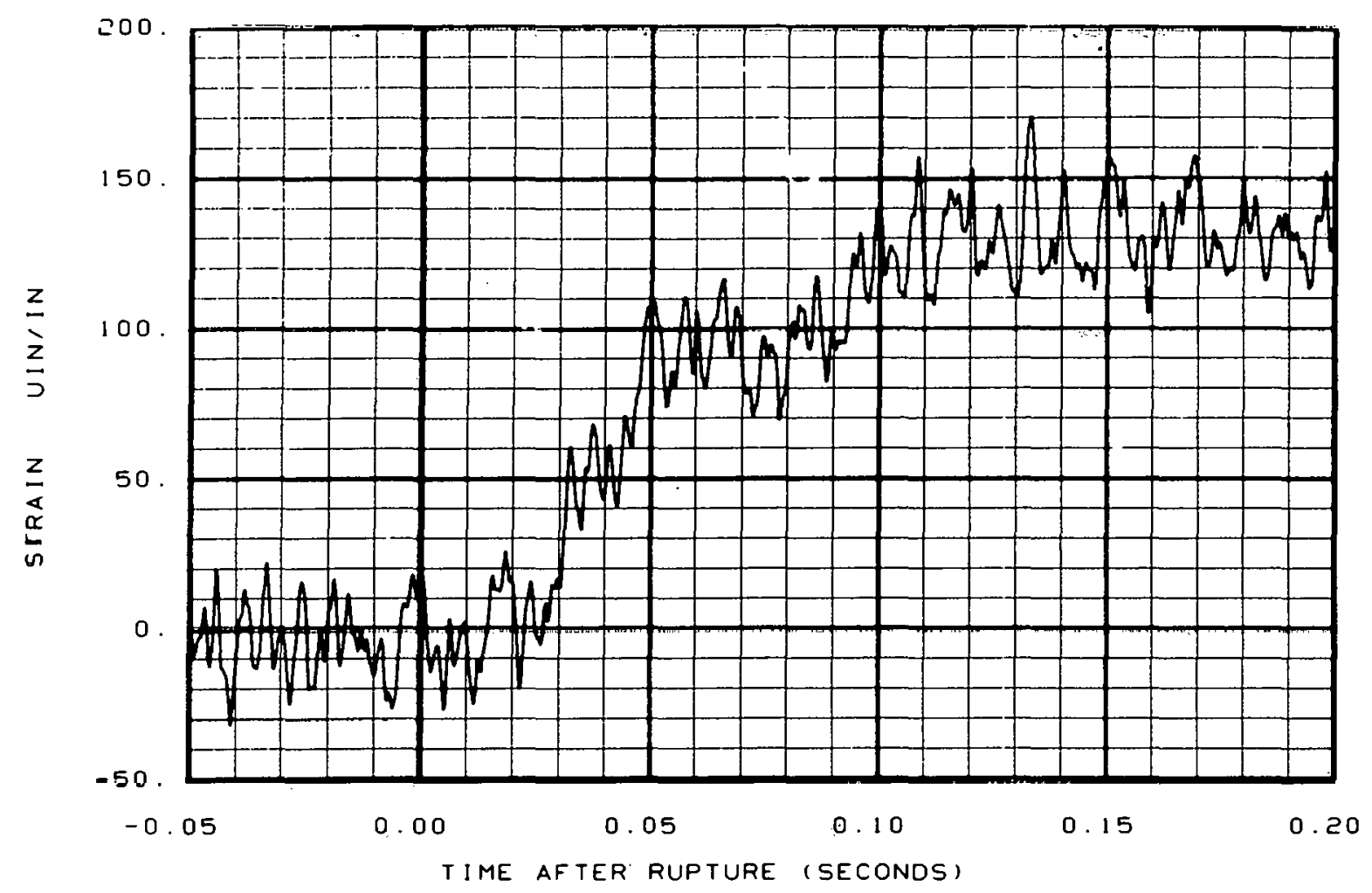

Fig. 88 Strain at steam generator outlet nozzle (SE-PC15-9).

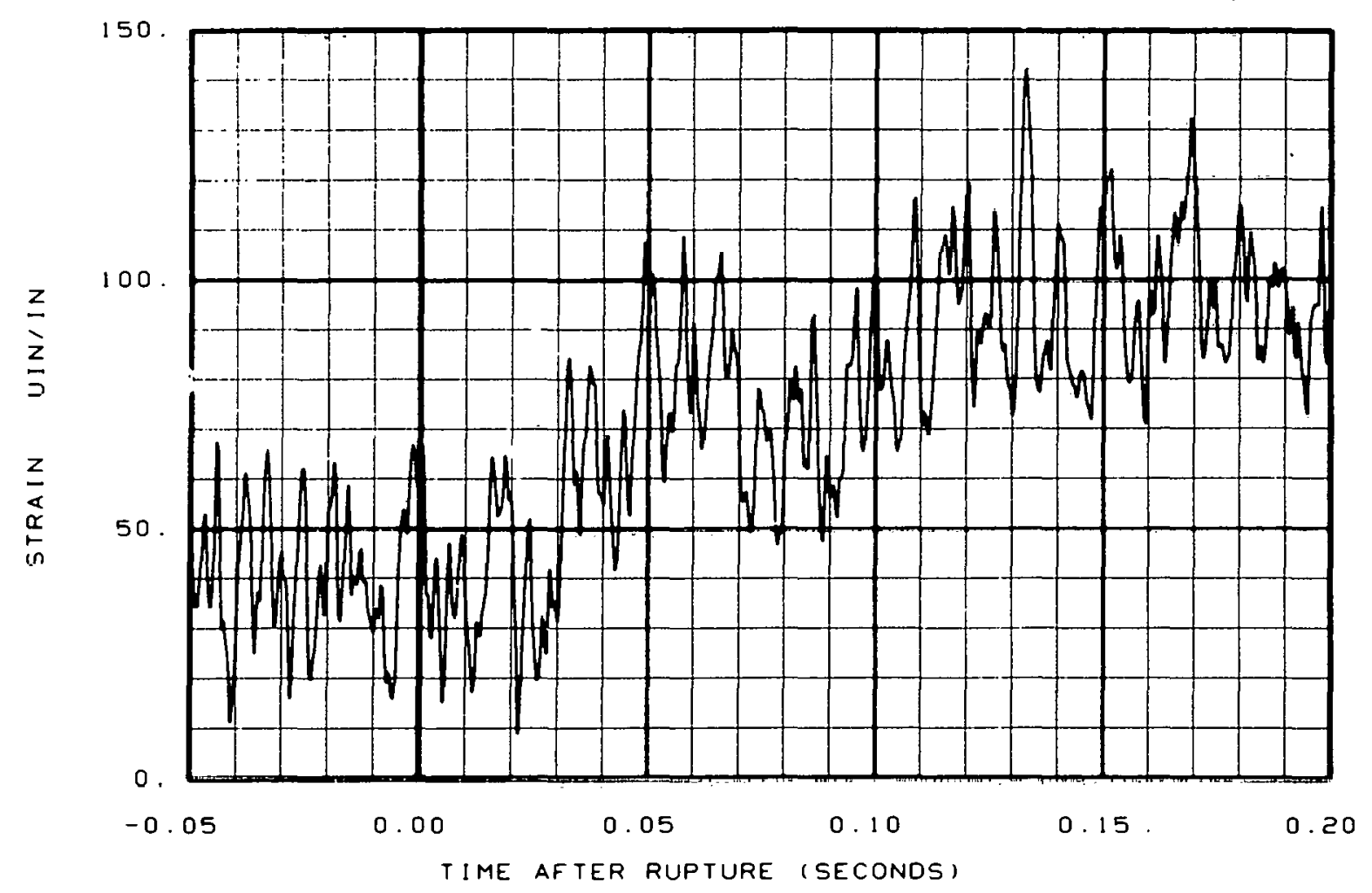

Fig. 89 Strain at steam generator outlet nozzle (SE-PC15-10). 


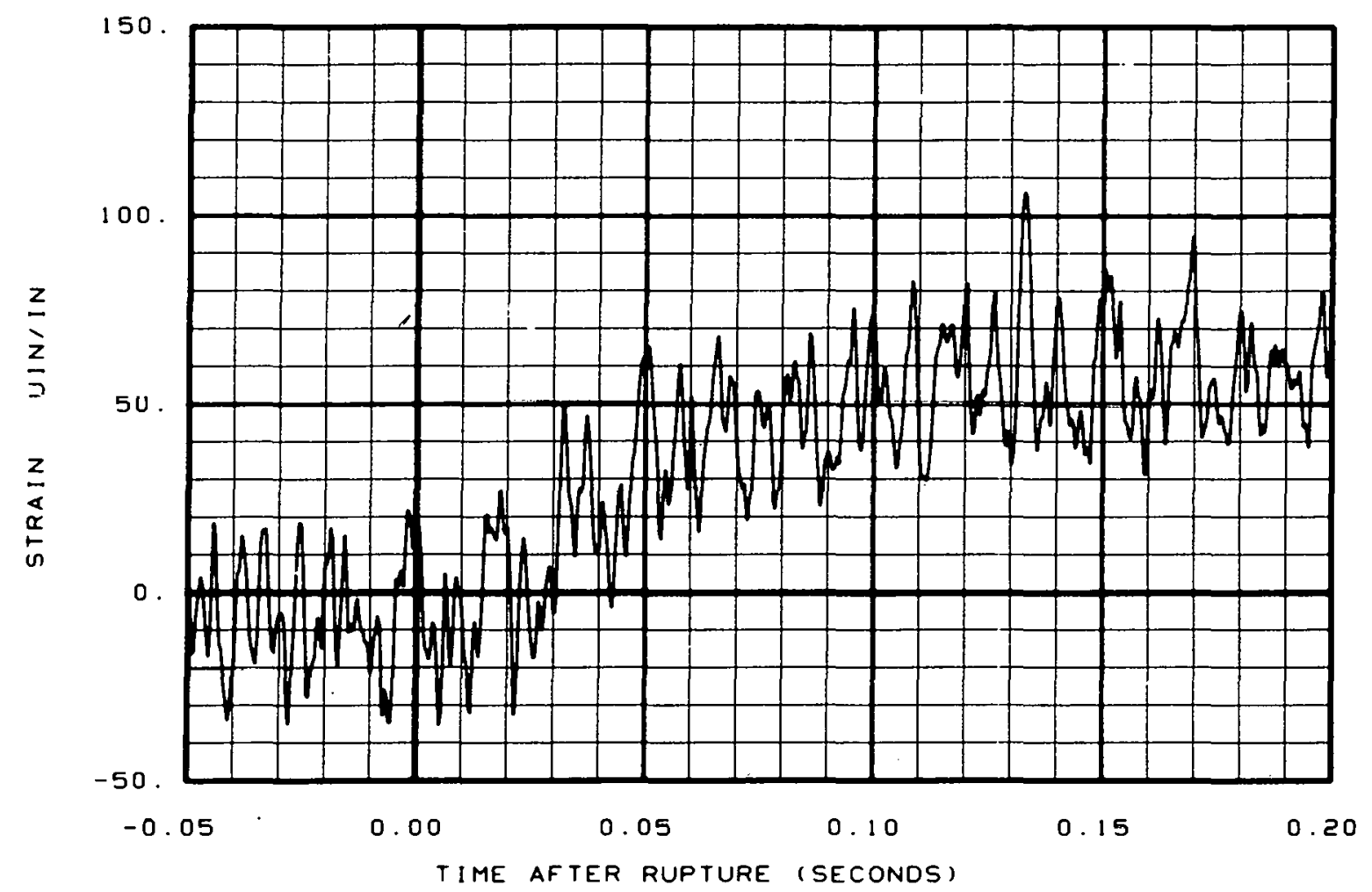

Fig. 90 Strain at steam generator outlet nozzle (SE-PC15-11).

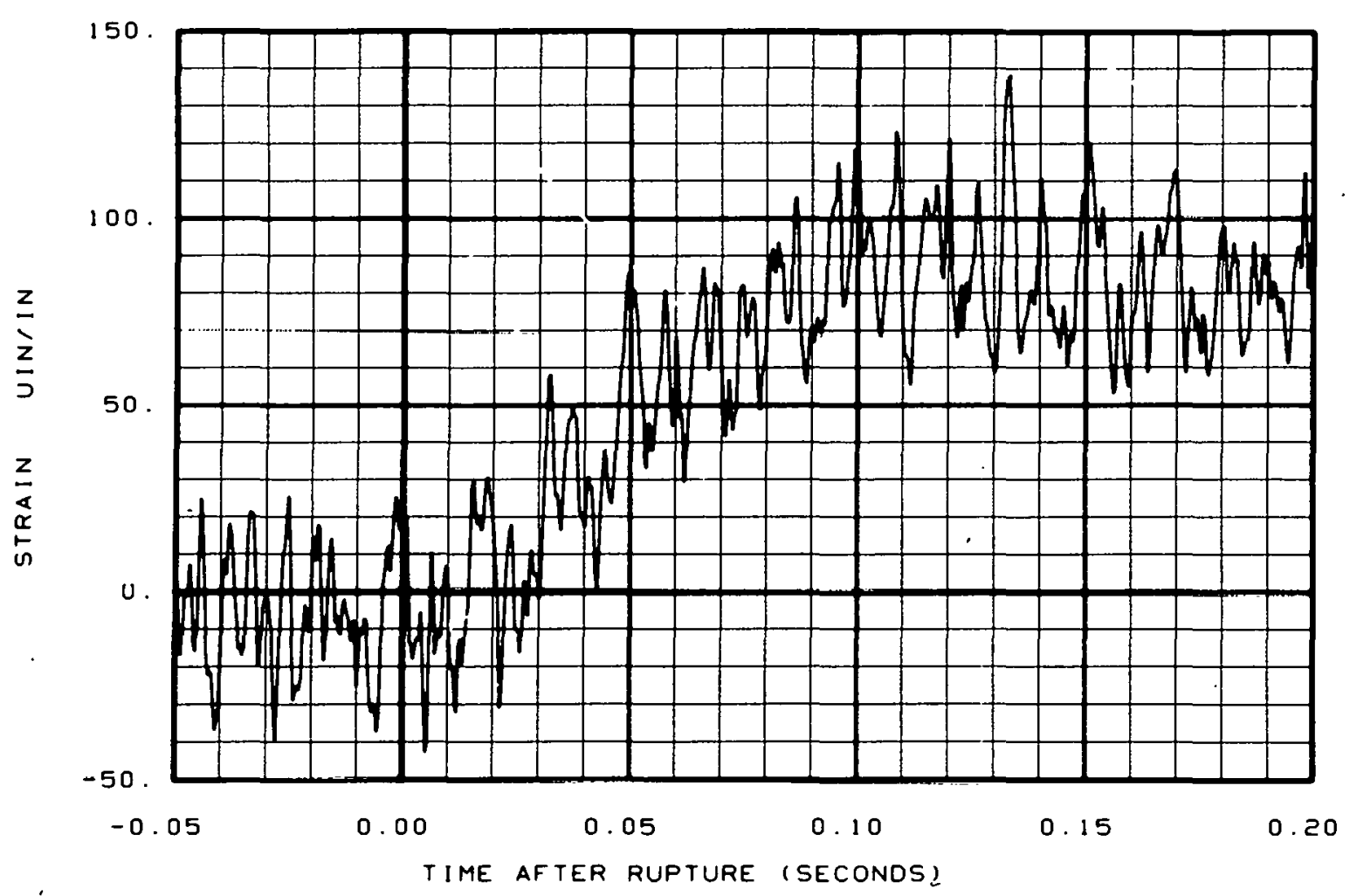

Fig. 91 Strain at steam generator outlet nozzle (SE-PC15-12). 


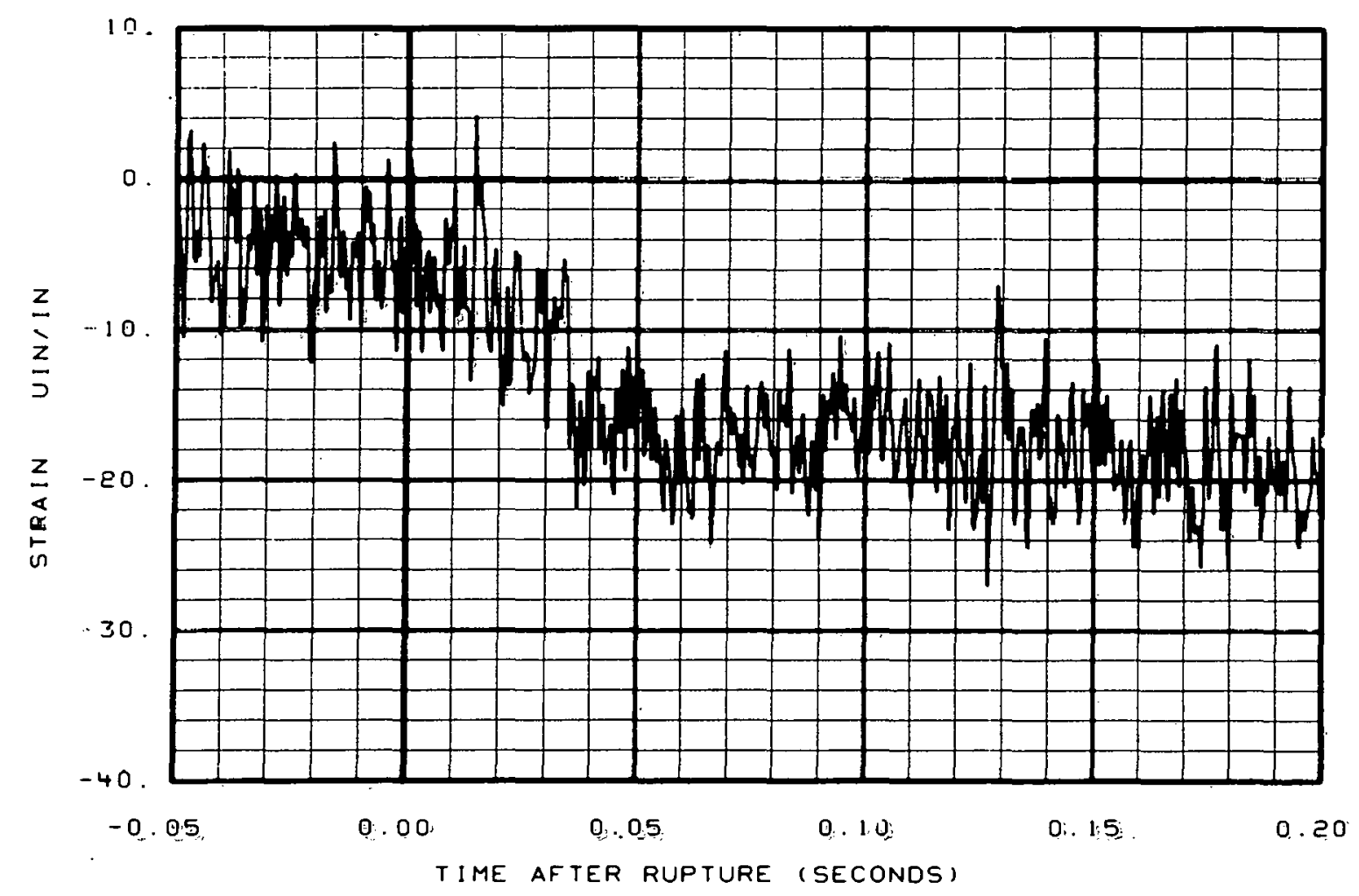

Fig. 92 Strain at primary coolant pump outlet (SE-PC18-13).

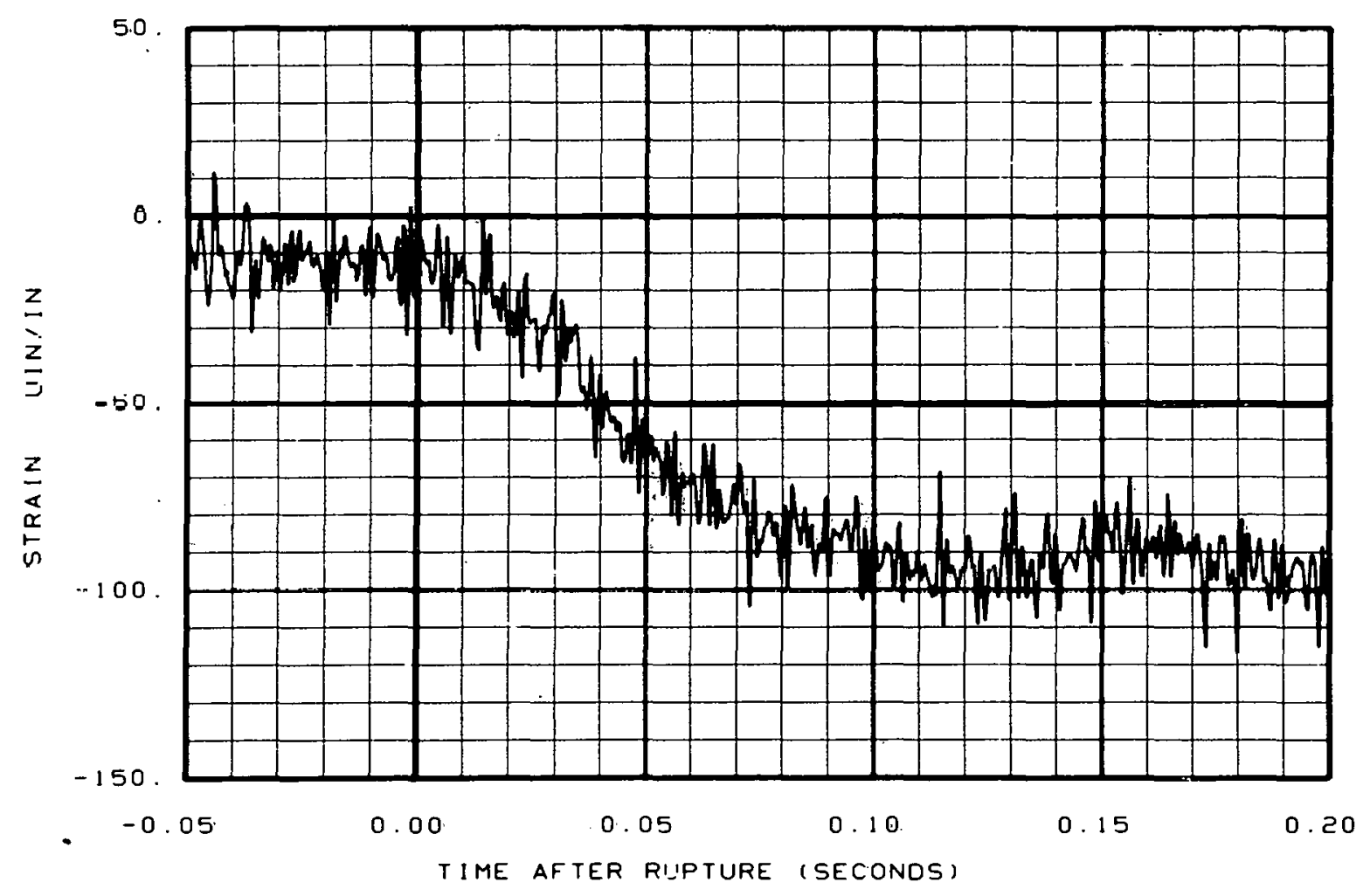

Fig. 93 Strain at primary coolant pump outlet (SE-PC18-14). 


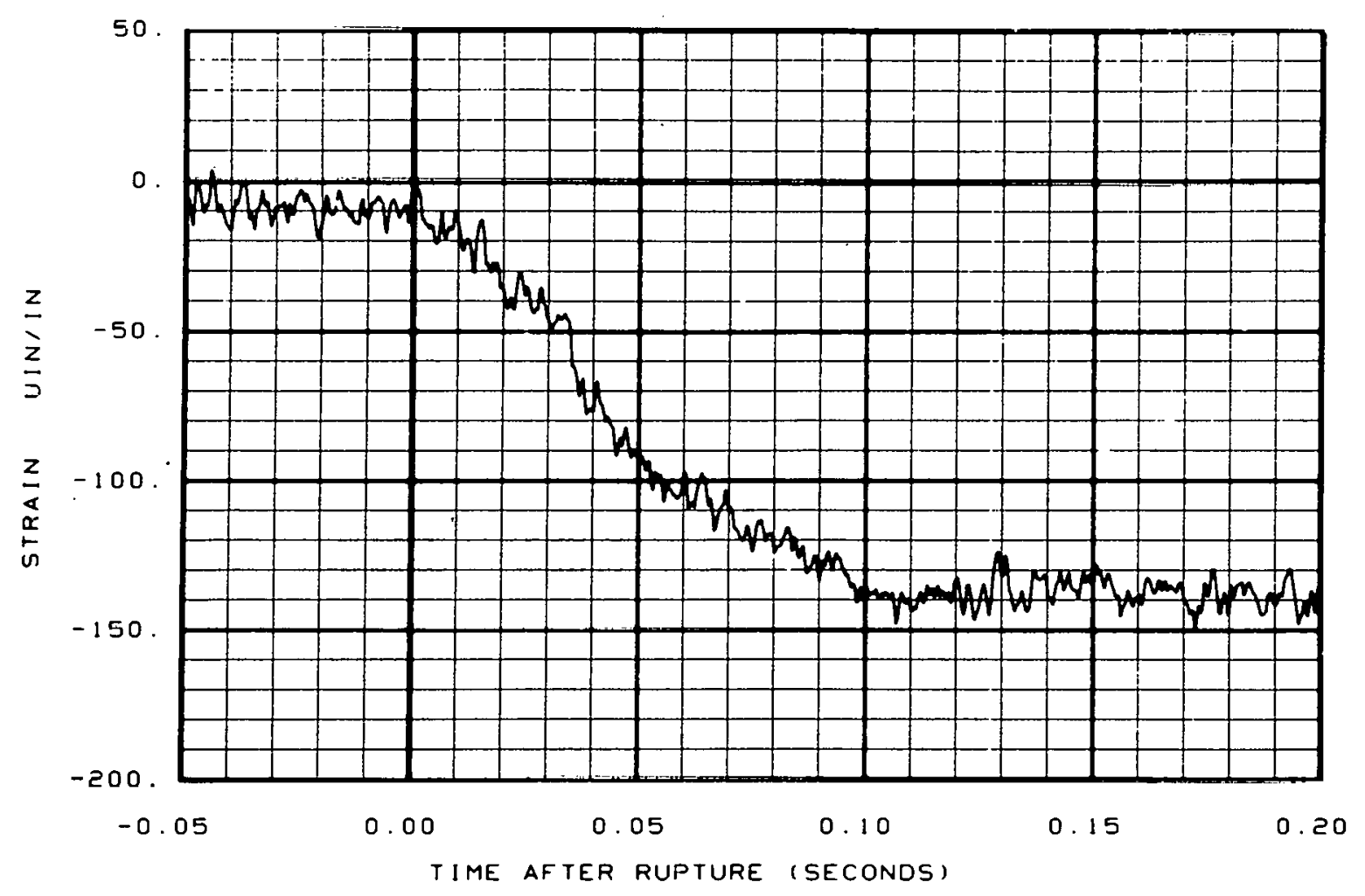

Fig. 94 Strain at primary coolant pump outlet (SE-PC18-15).

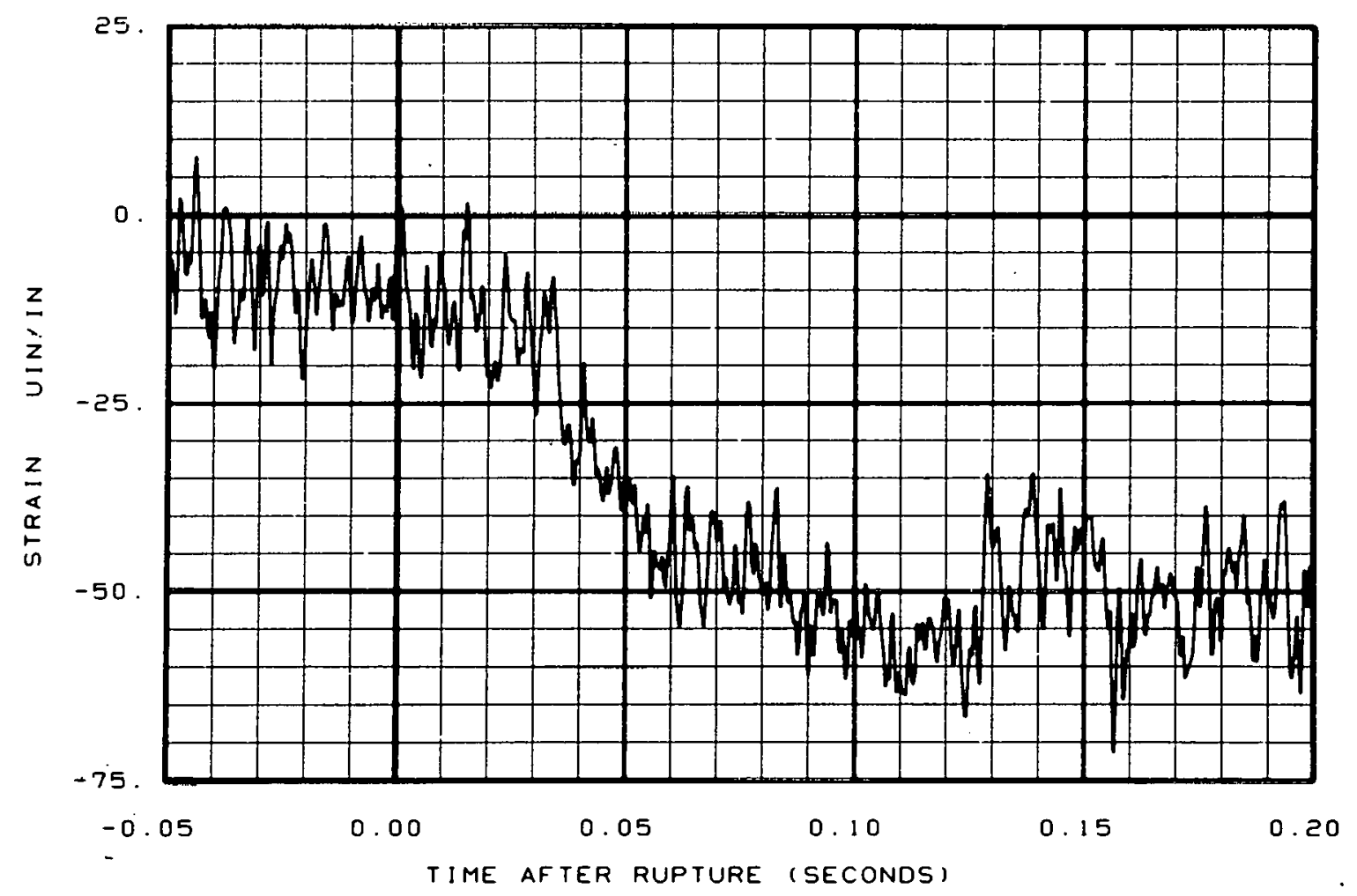

Fig. 95 Strain at primary coolant pump outlet (SE-PC18-16). 


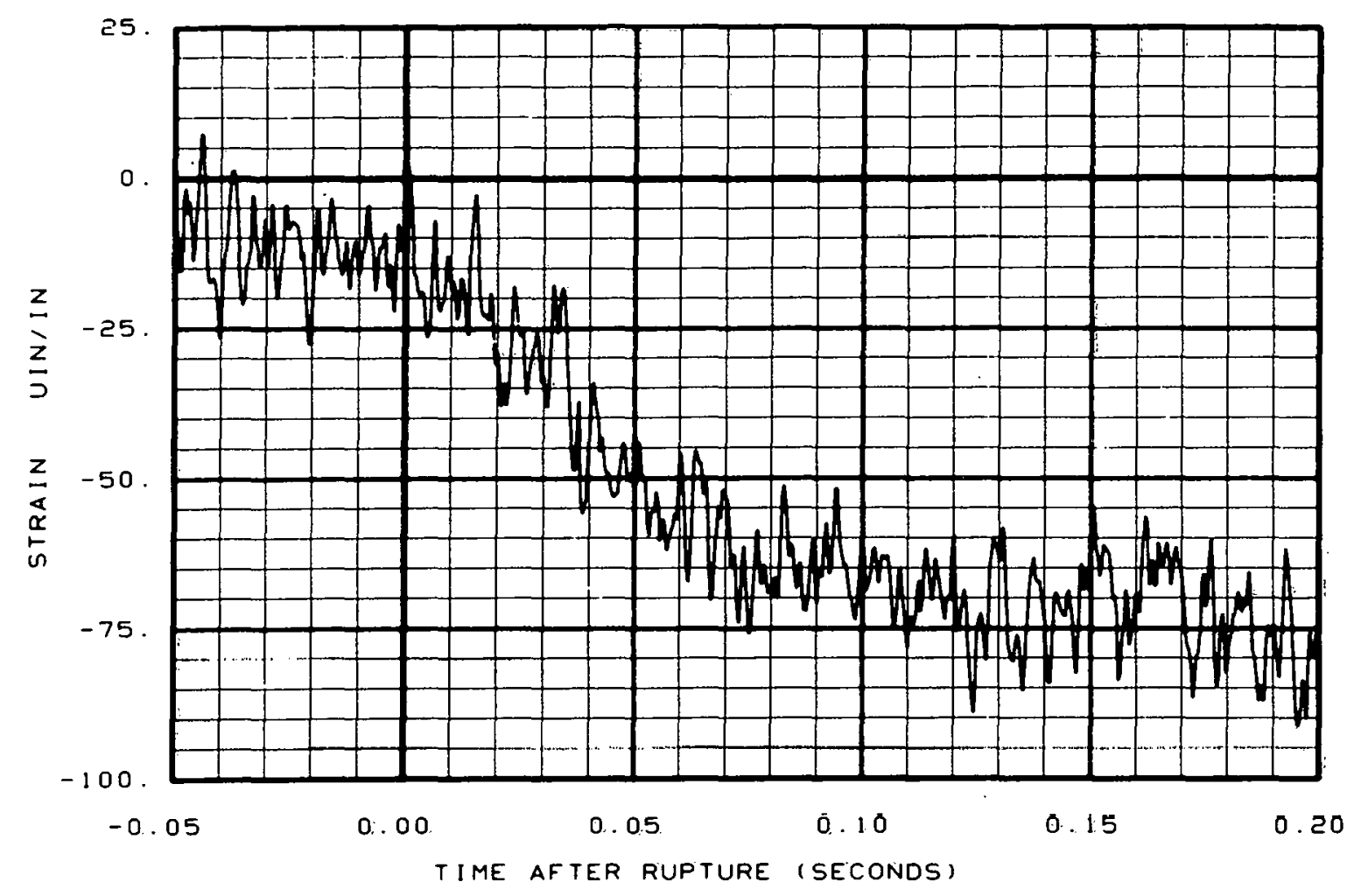

Fig. 96 Strain at primary coolant pump outlet (SE-PC18-17).

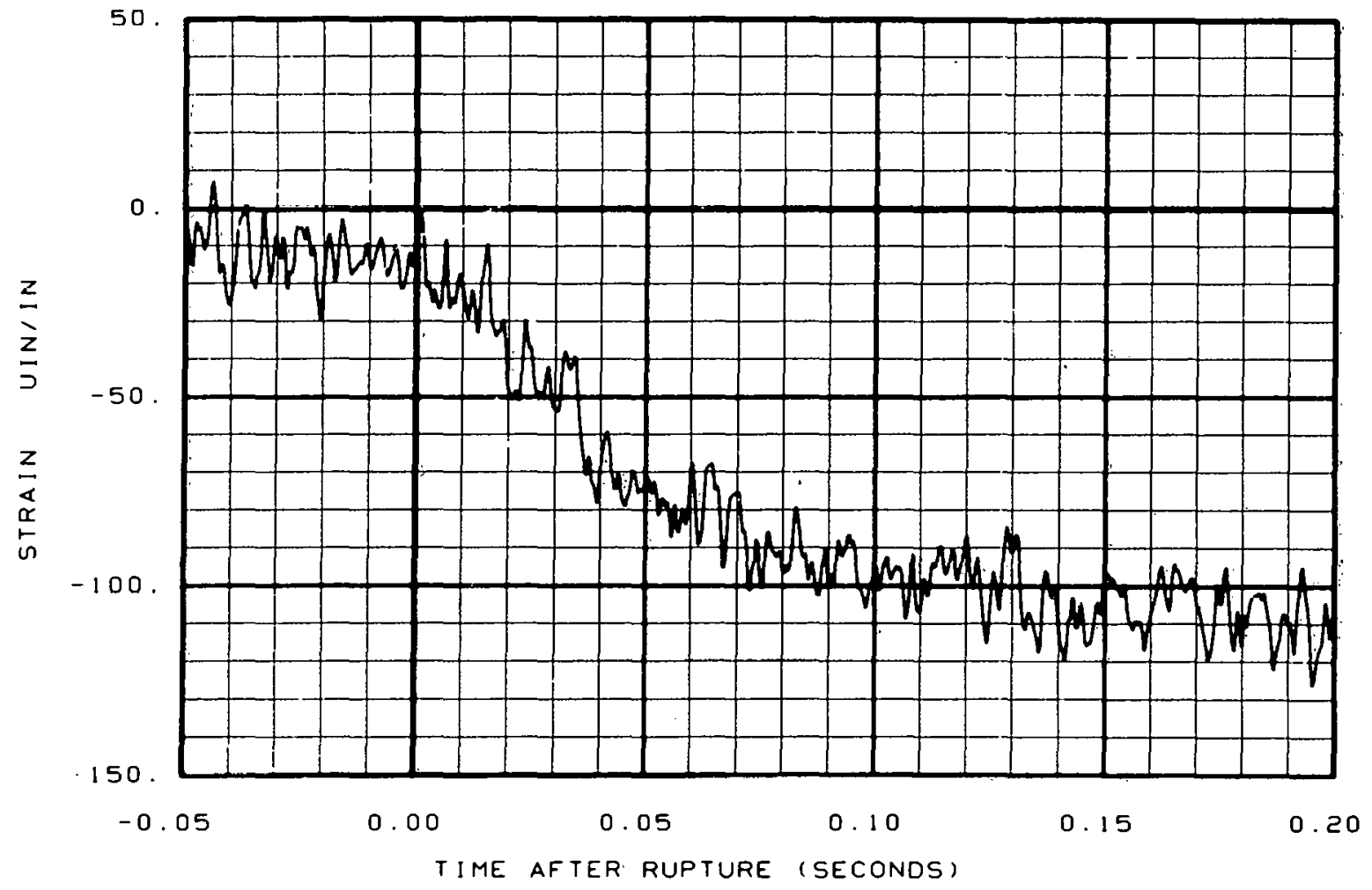

Fig. 97 Strain at primary coolant pump outlet (SE-PC18-18). 


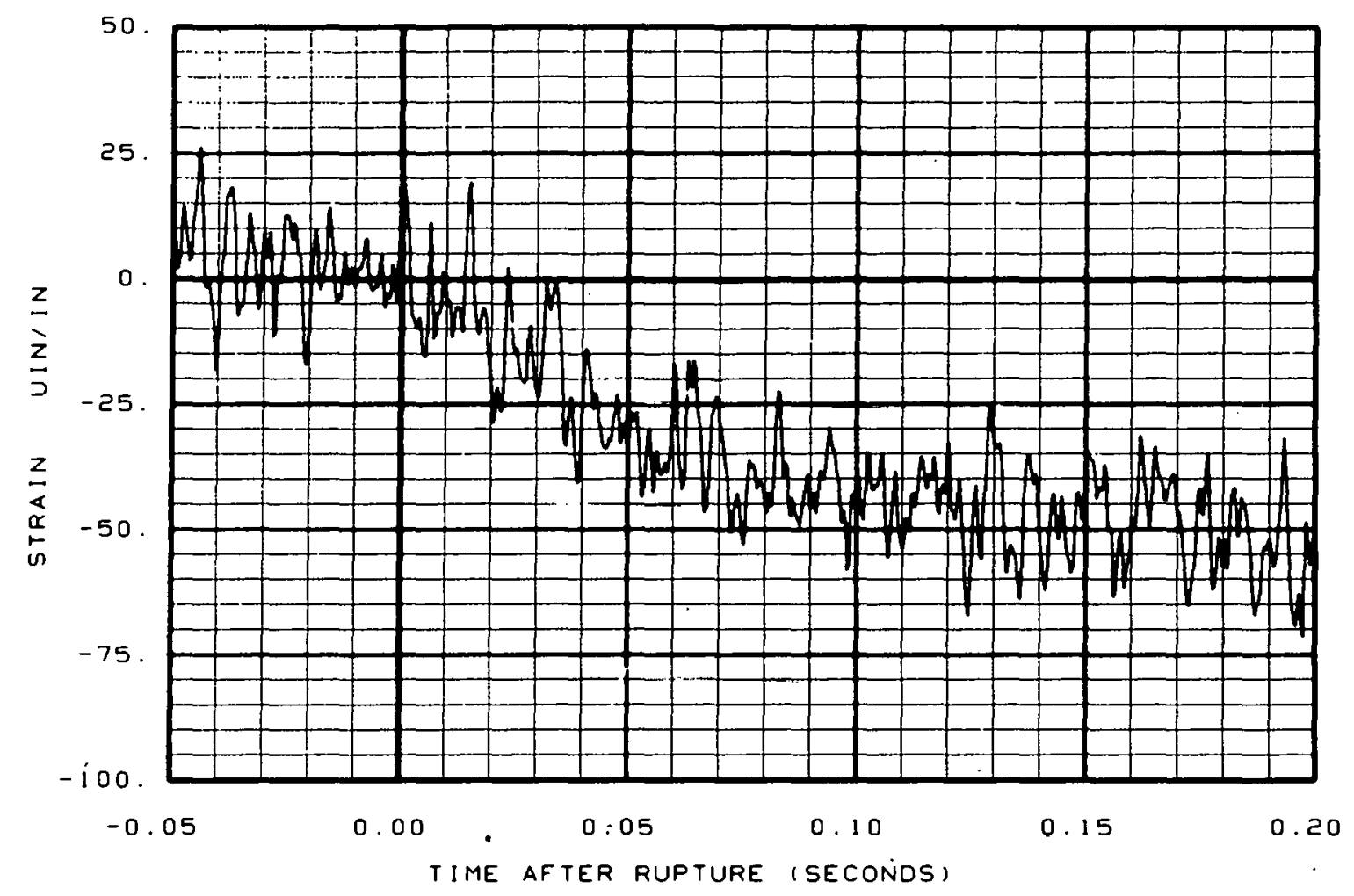

Fig. 98 Strain at primary coolant pump outlet (SE-PC18-19).

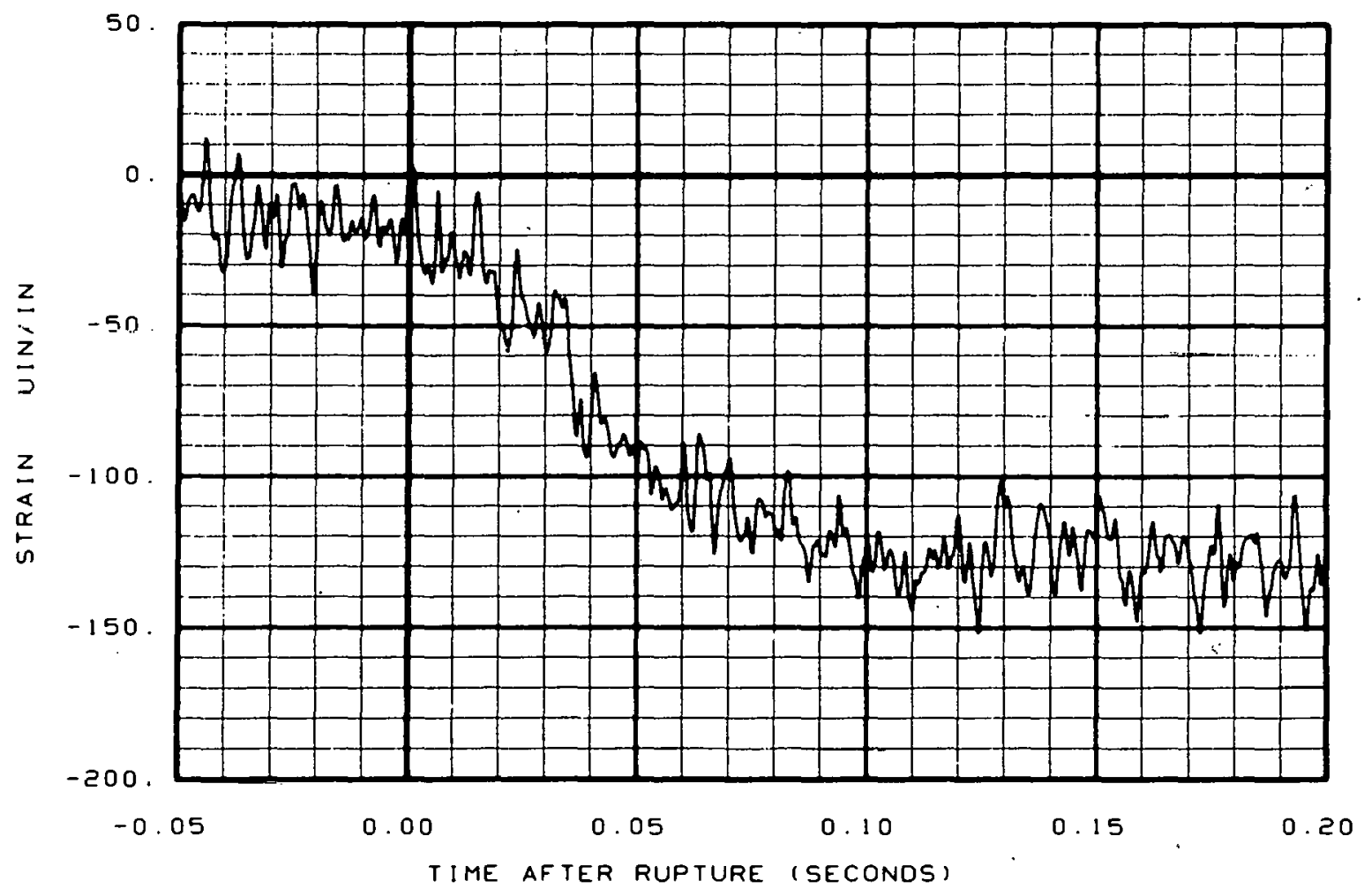

Fig. 99 Strain at primary coolant pump outlet (SE-PC18-21). 


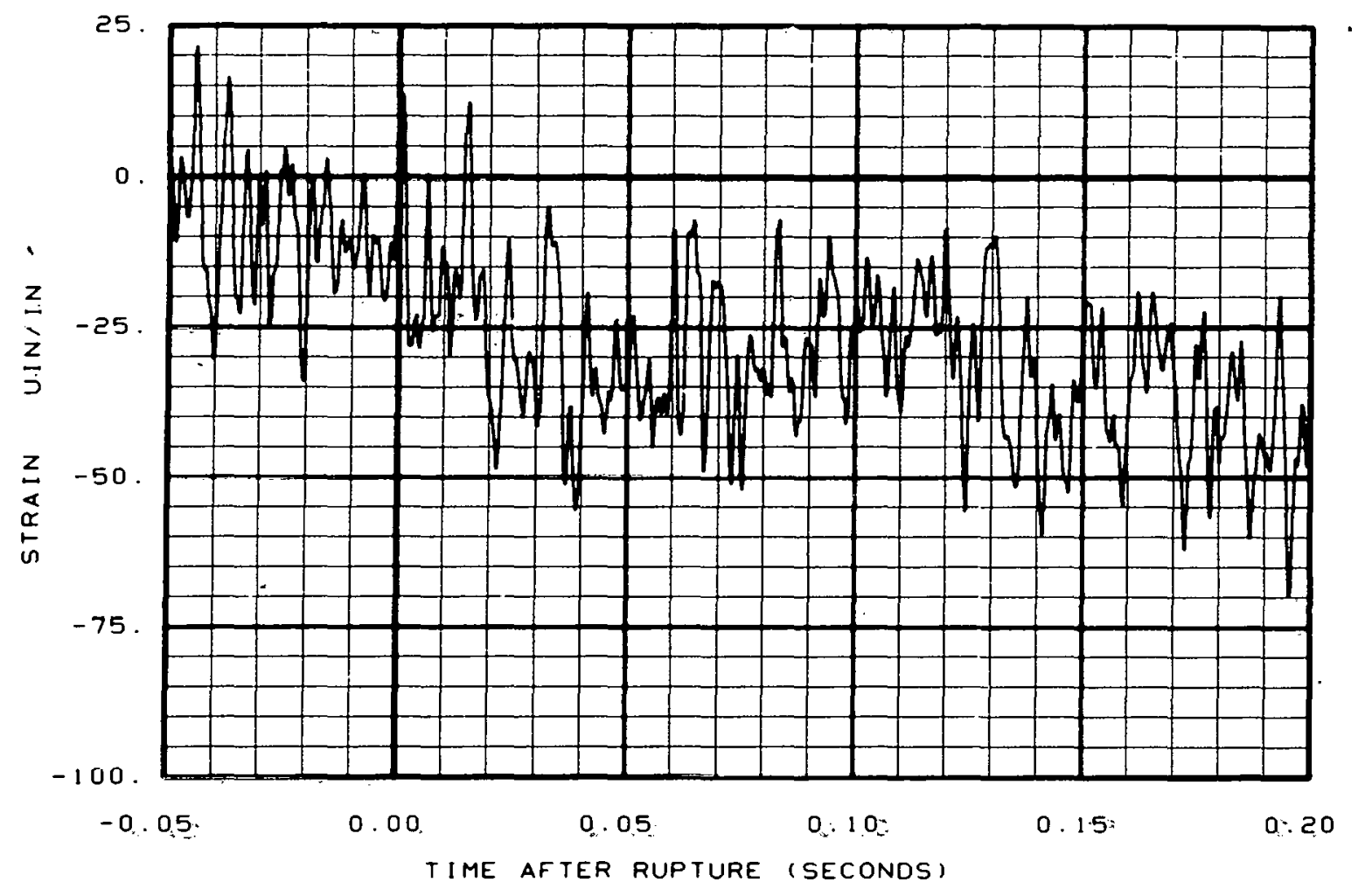

Fig. 100 Strain at primary coolant pump outlet (SE-PC18-22).

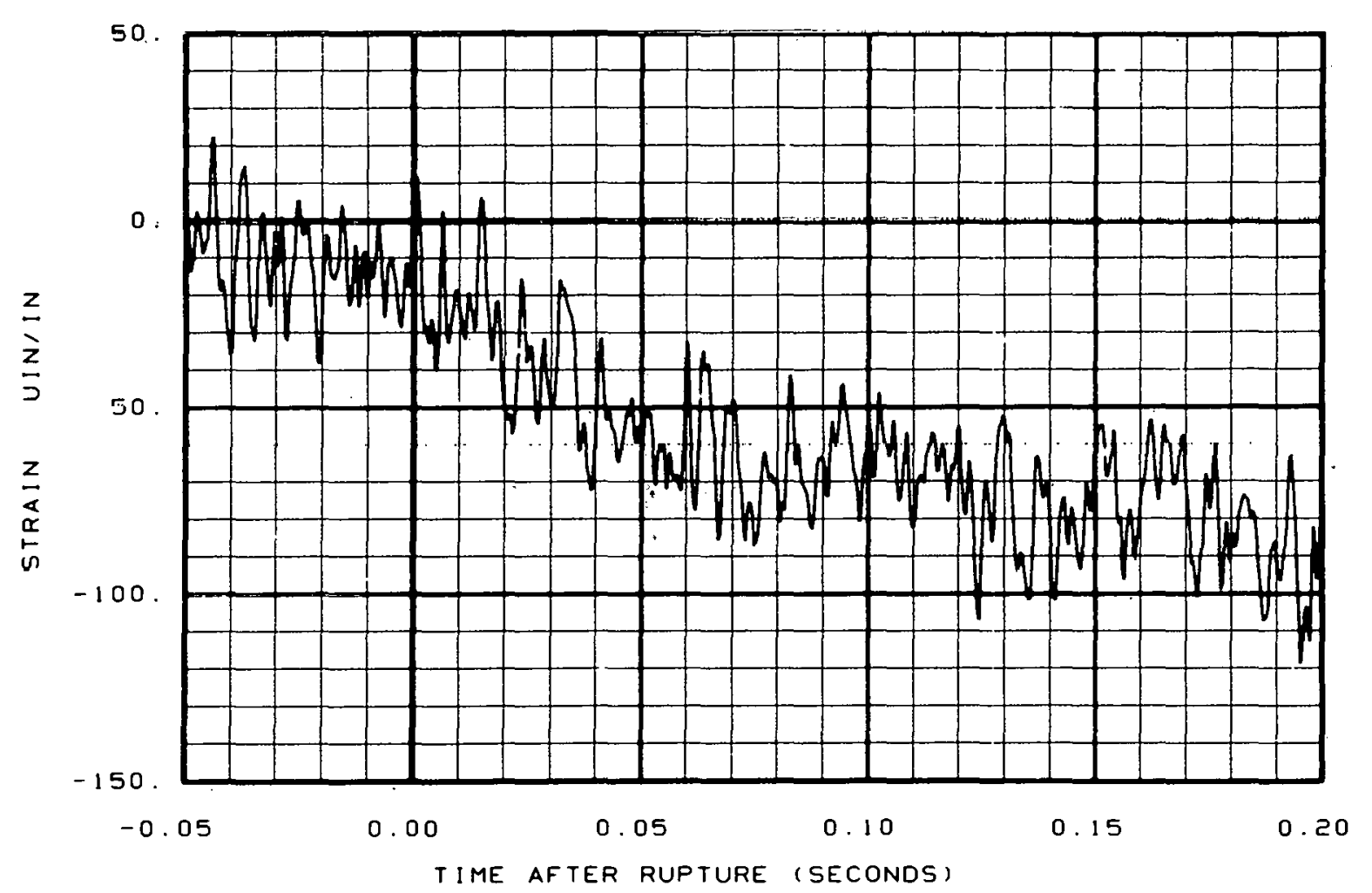

Fig. 101 Strain at primary coolant pump outlet (SE-PC18-23). 


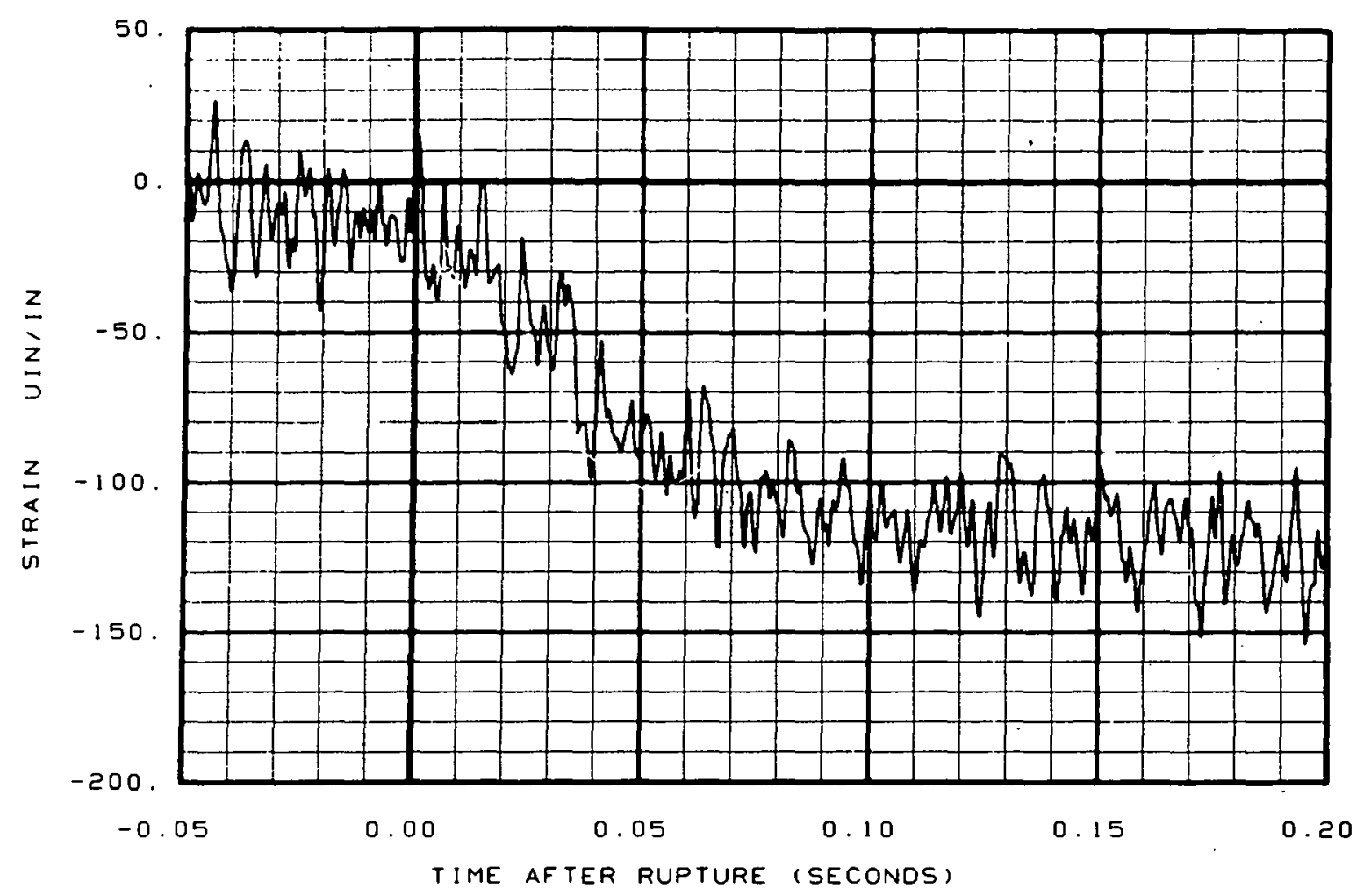

Fig. 102 Strain at primary coolant pump outlet (SE-PC18-24).

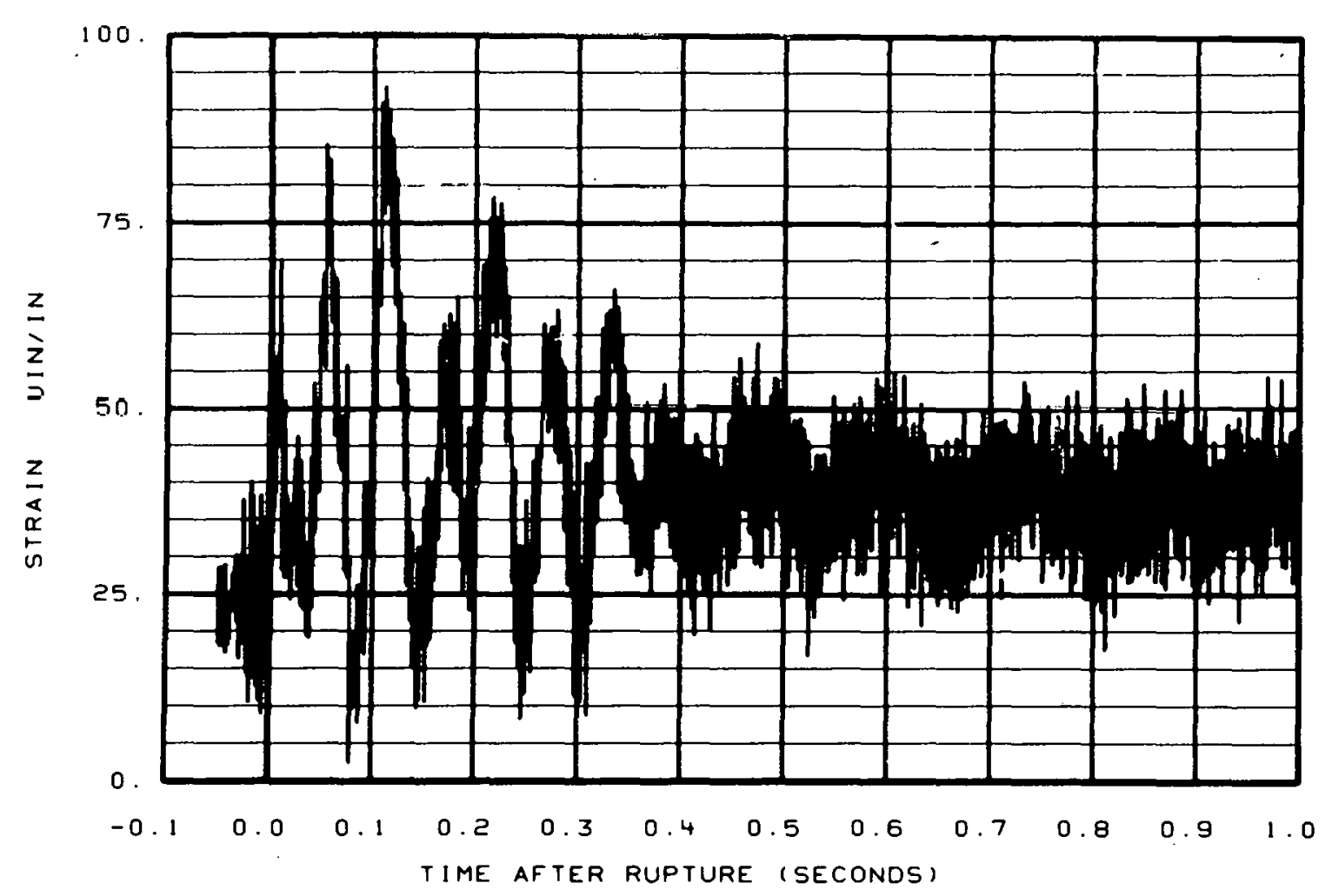

Fig. 103 Strain at reactor vessel broken loop cold leg nozzle (SE-BL8-1). 


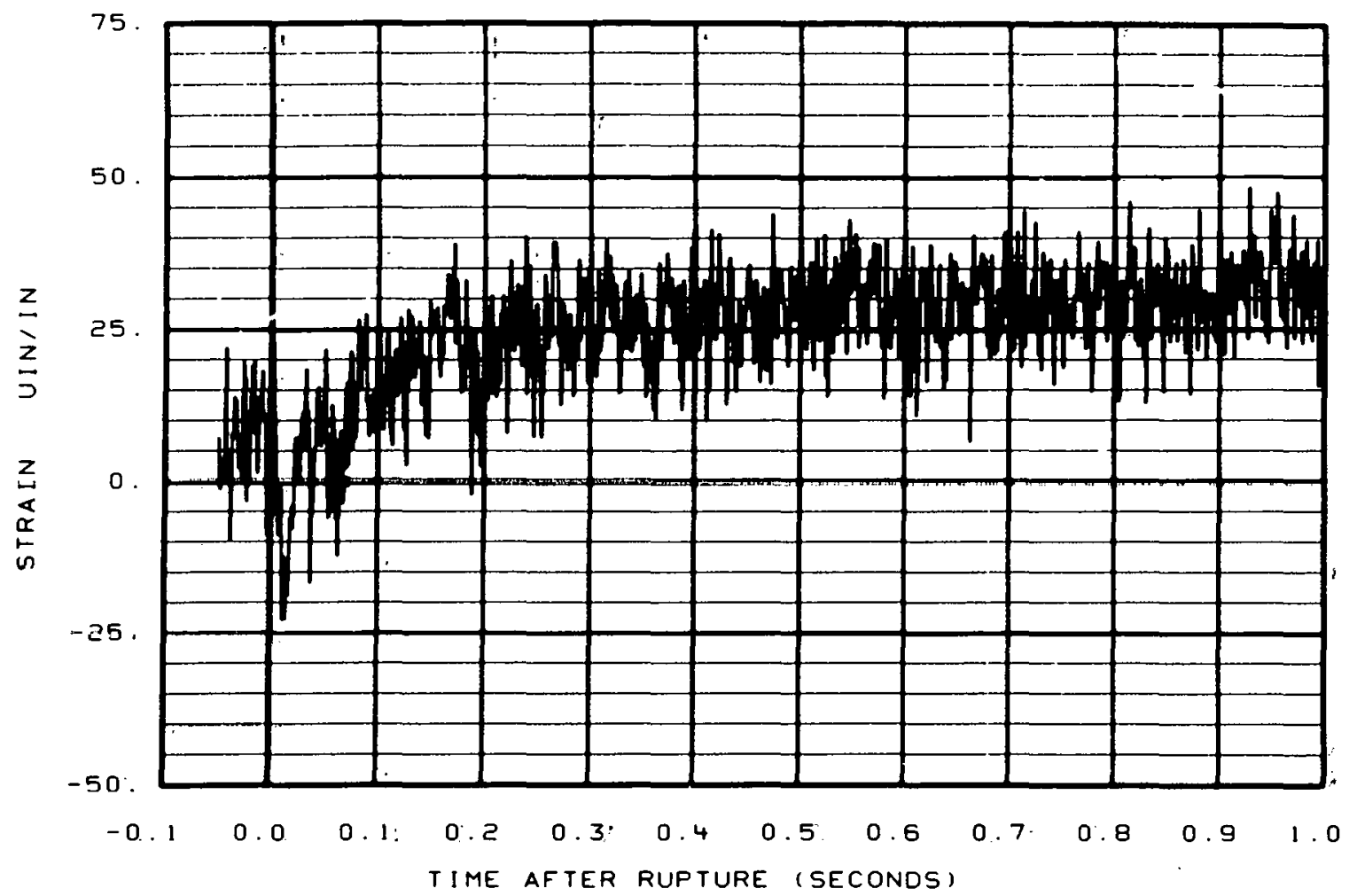

Fig. 104 Strain at reactor vessel broken loop cold leg nozzle (SE-BL8-2).

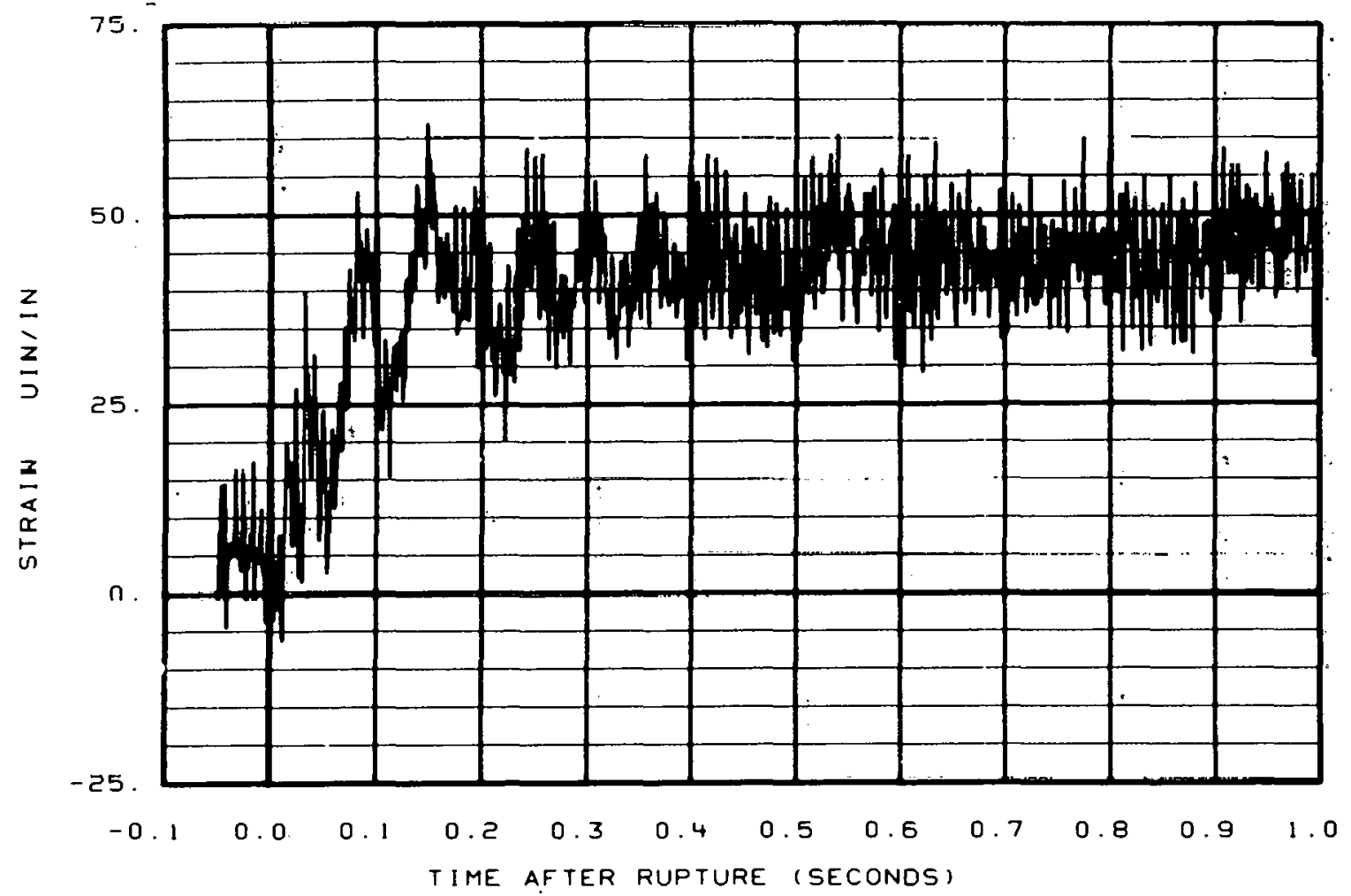

Fig. 105 Strain at reactor vessel broken loop cold leg nozzle (SE-BL.8-3). 


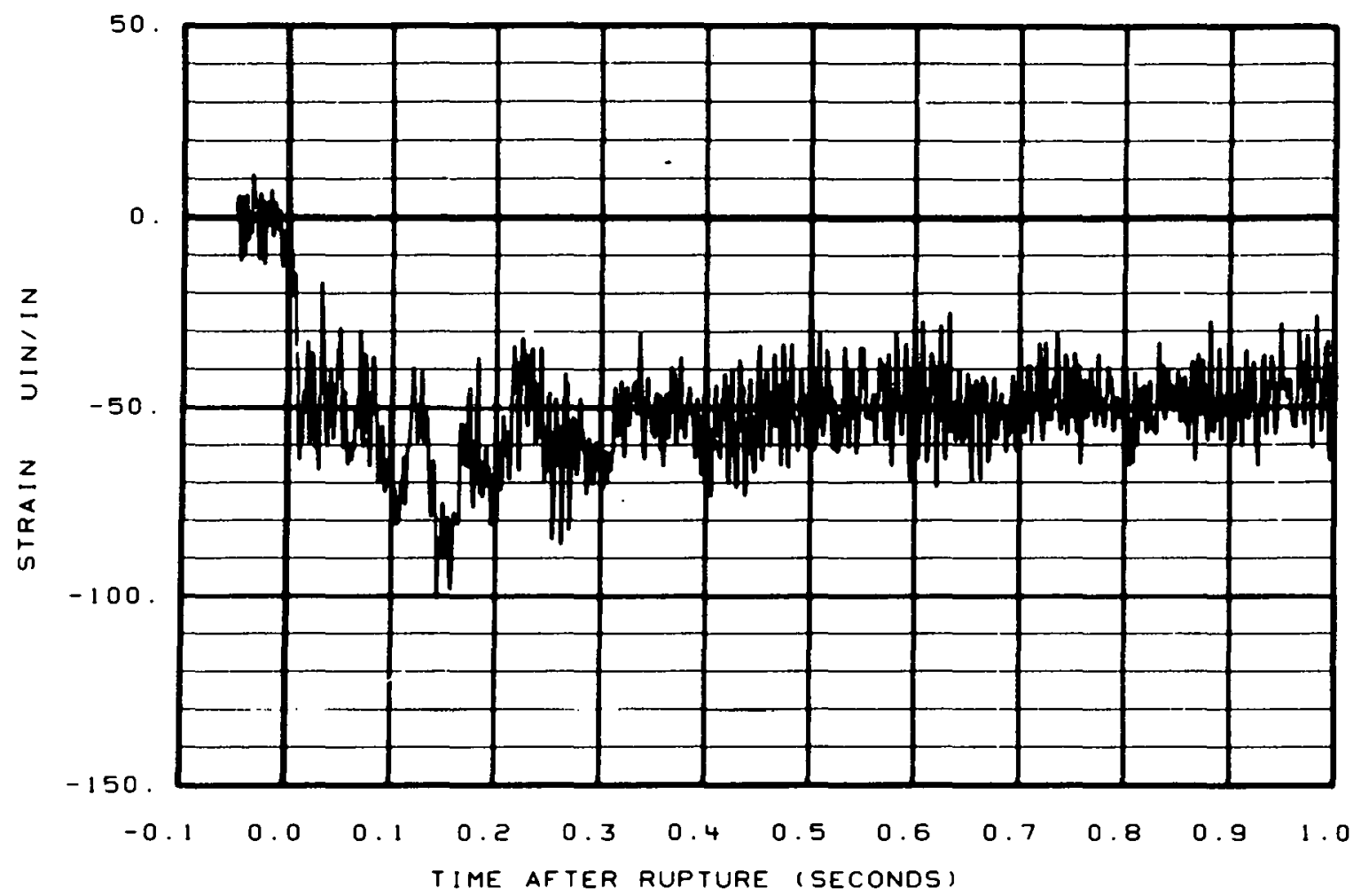

Fig. 106 Strain at reactor vessel broken loop cold leg nozzle (SE-BL8-4).

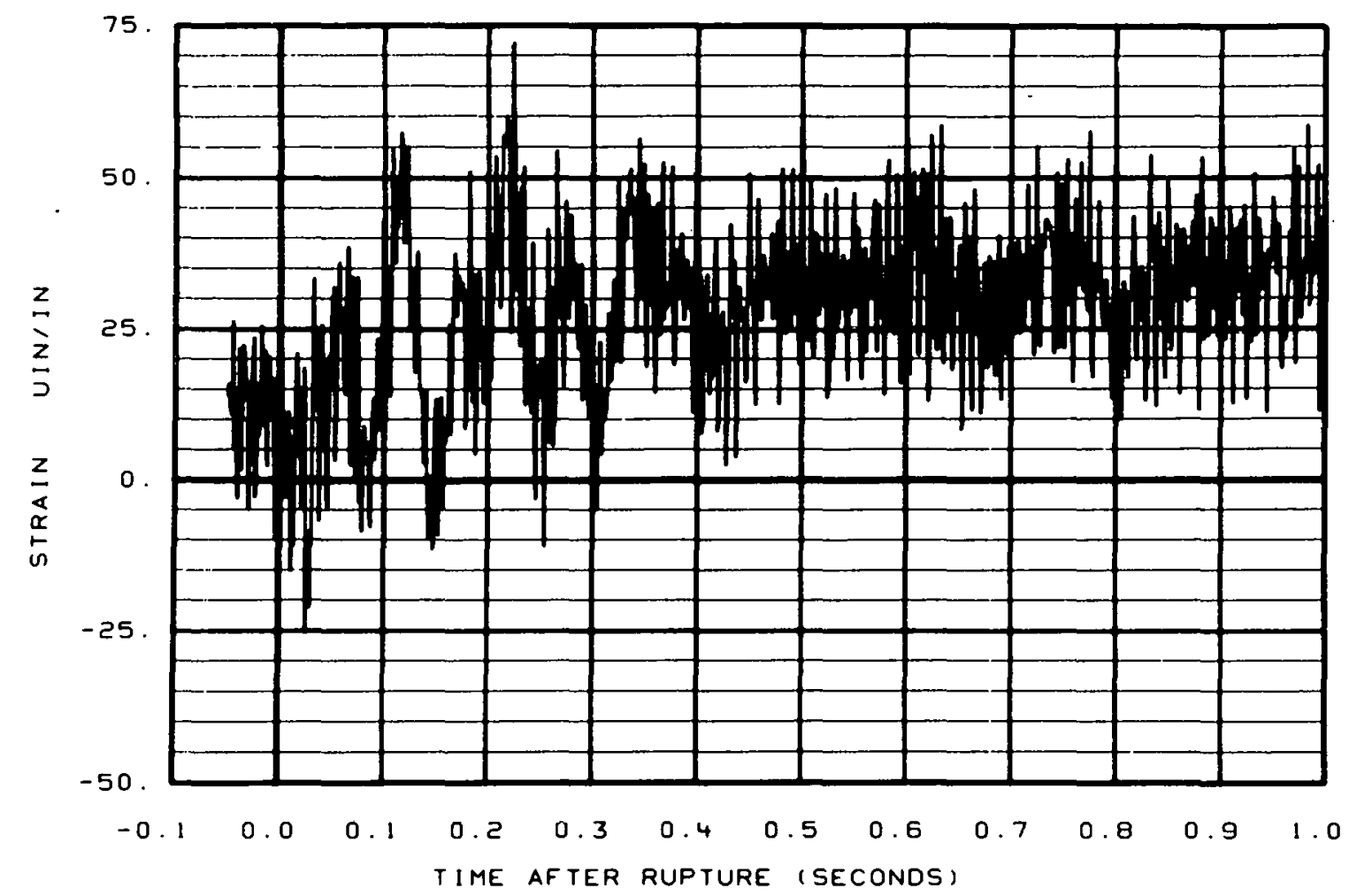

Fig. 107 Strain at reactor vessel broken loop cold leg nozzle (SE-BL8-5). 


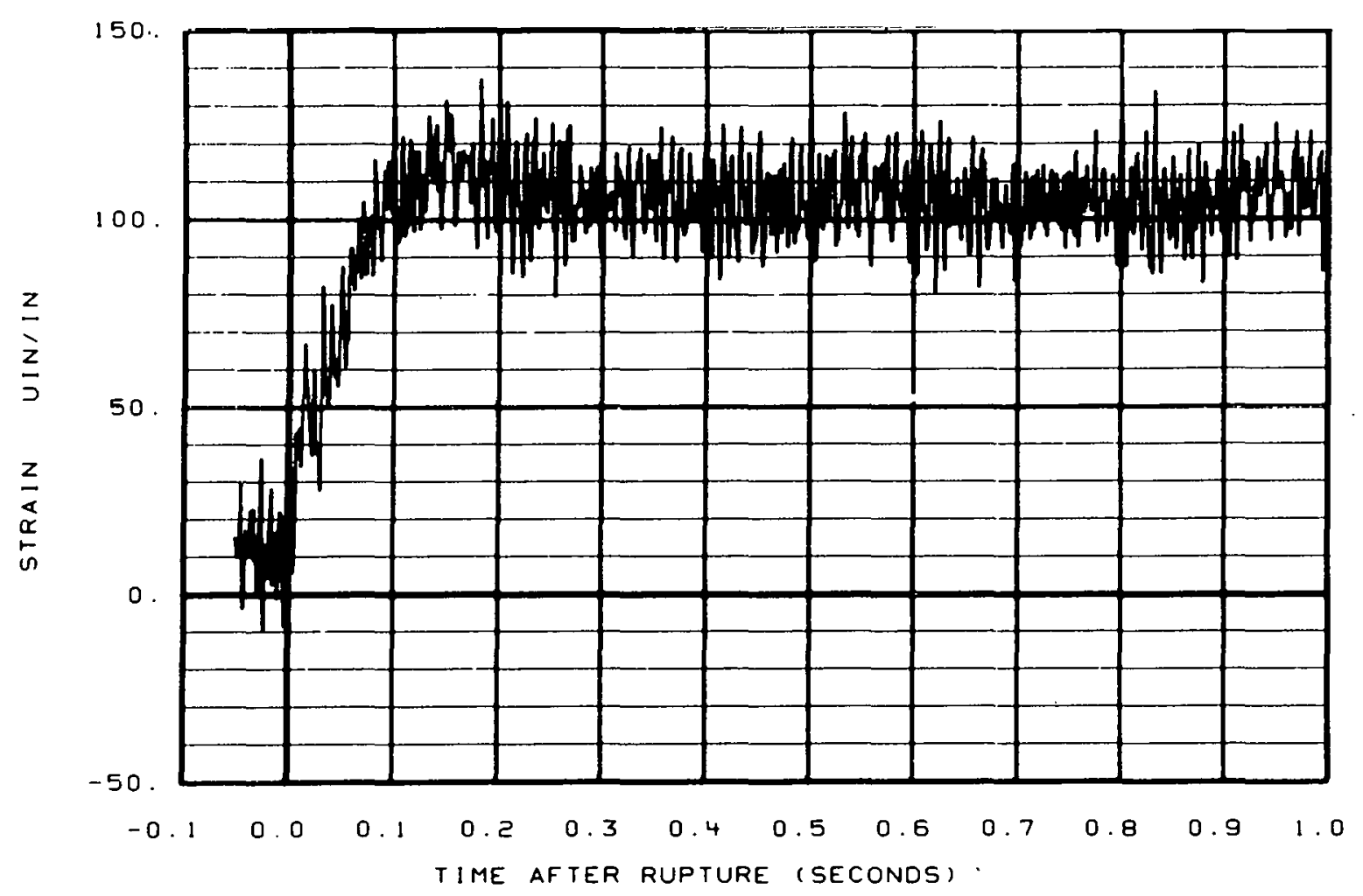

Fig. 108 Strain at reactor vessel broken loop cold leg nozzle (SE-BL8-6).

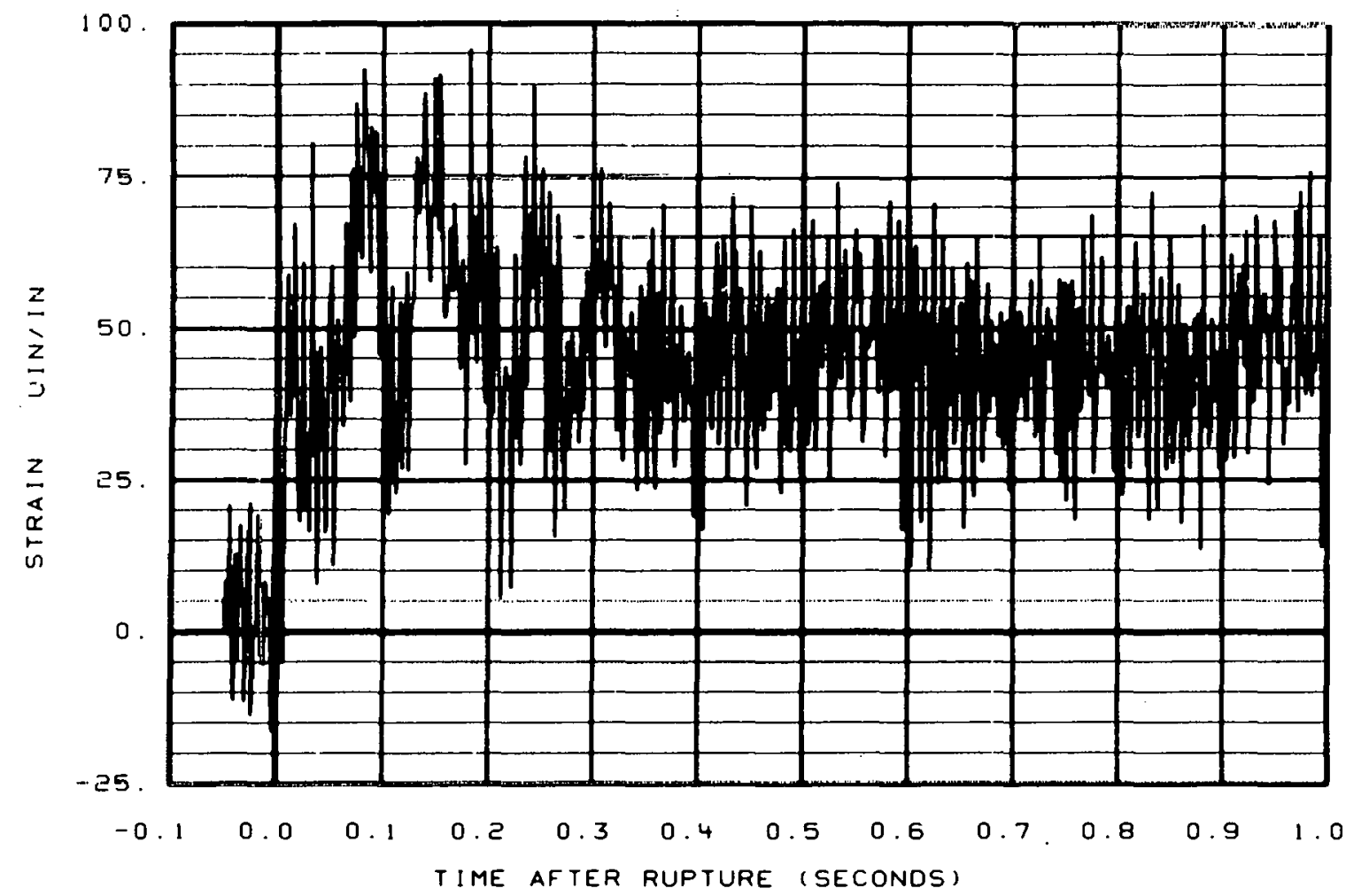

Fig. 109 Strain at reactor vessel broken loop cold leg nozzle (SE-BL8-8). 


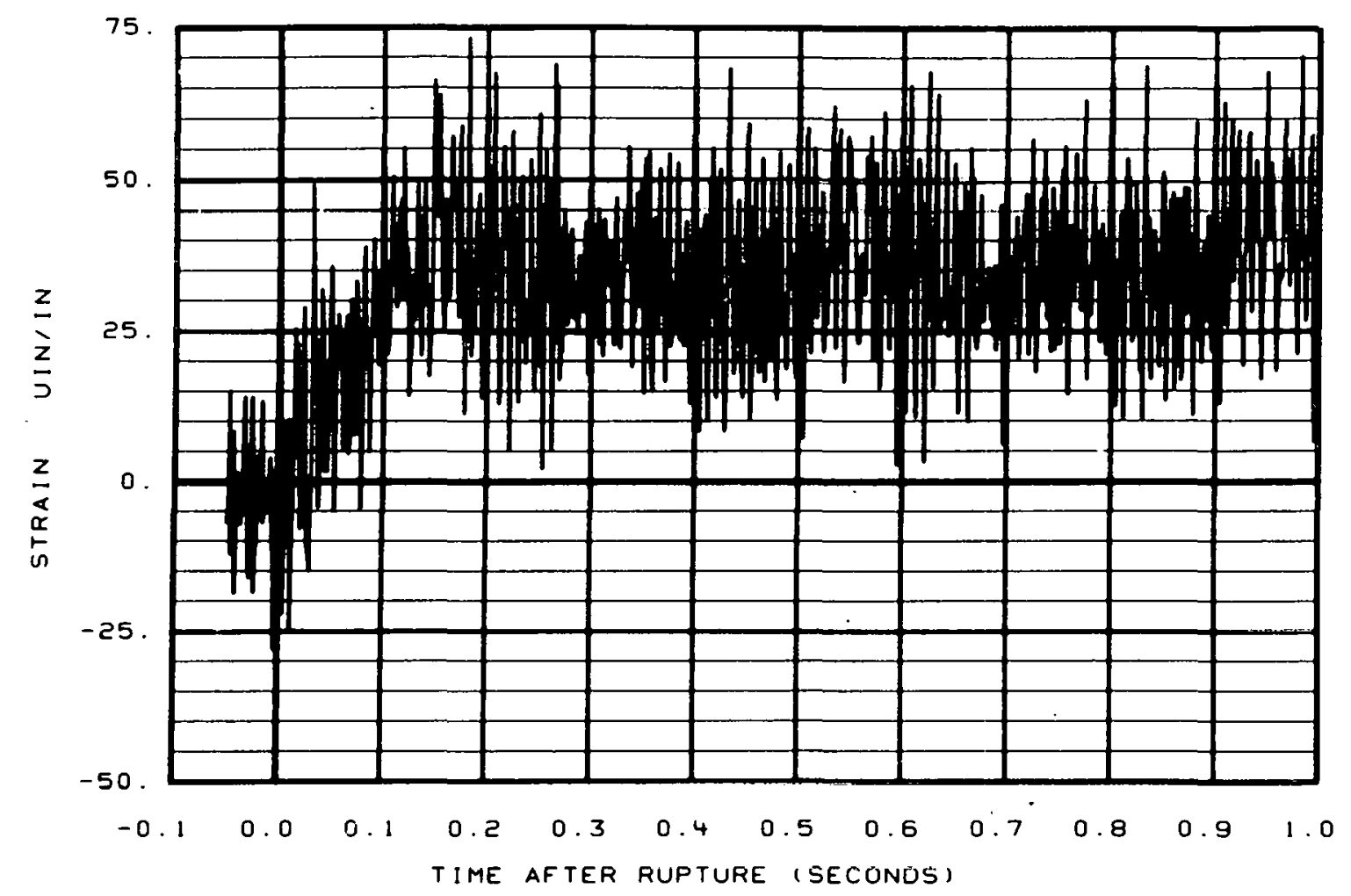

Fig. 110 Strain at reactor vessel broken loop cold leg nozzle (SE-BL8-9).

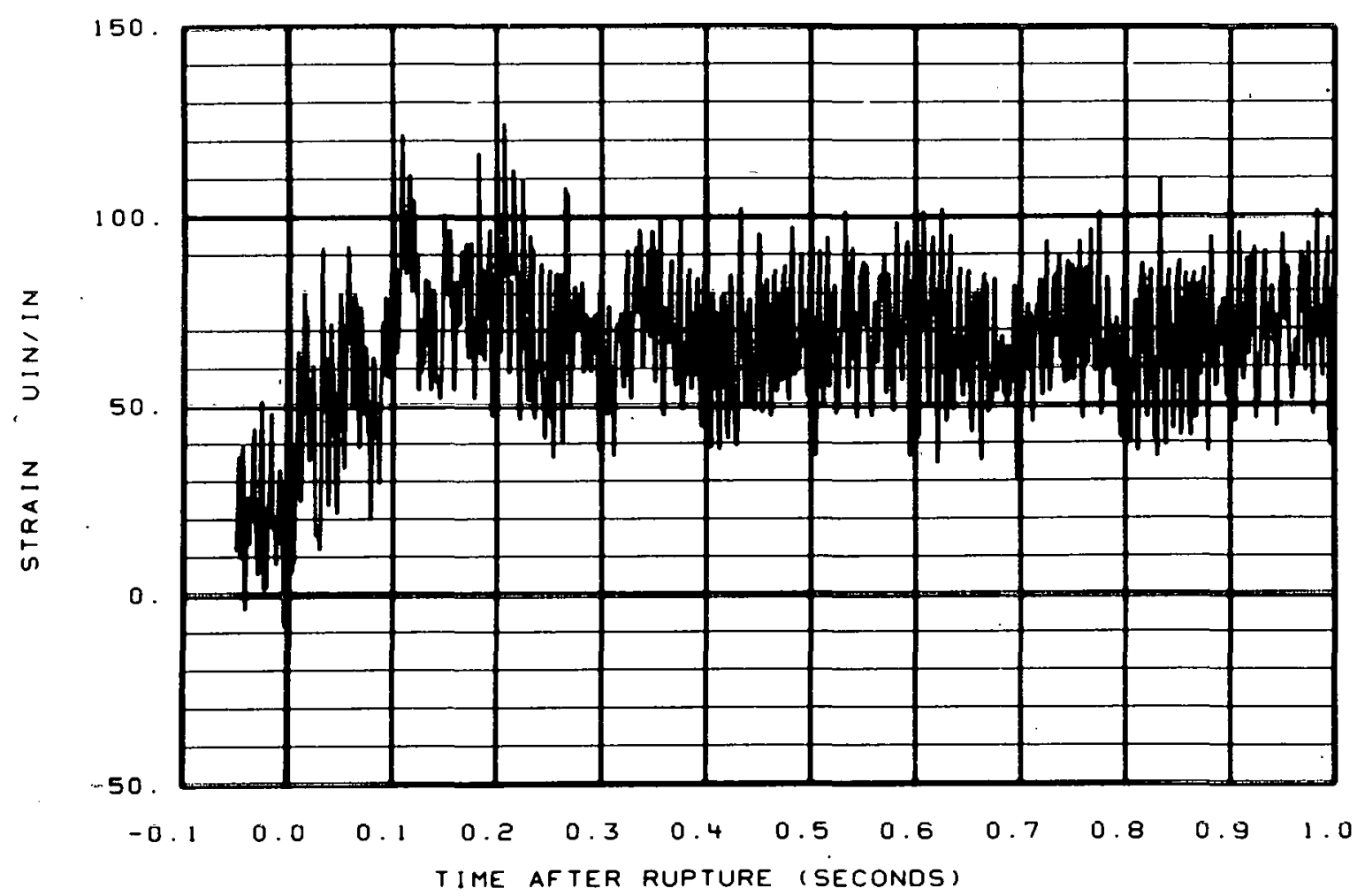

Fig. 111 Strain at reactor vessel broken loop cold leg nozzle (SË-BLC̈-11). 


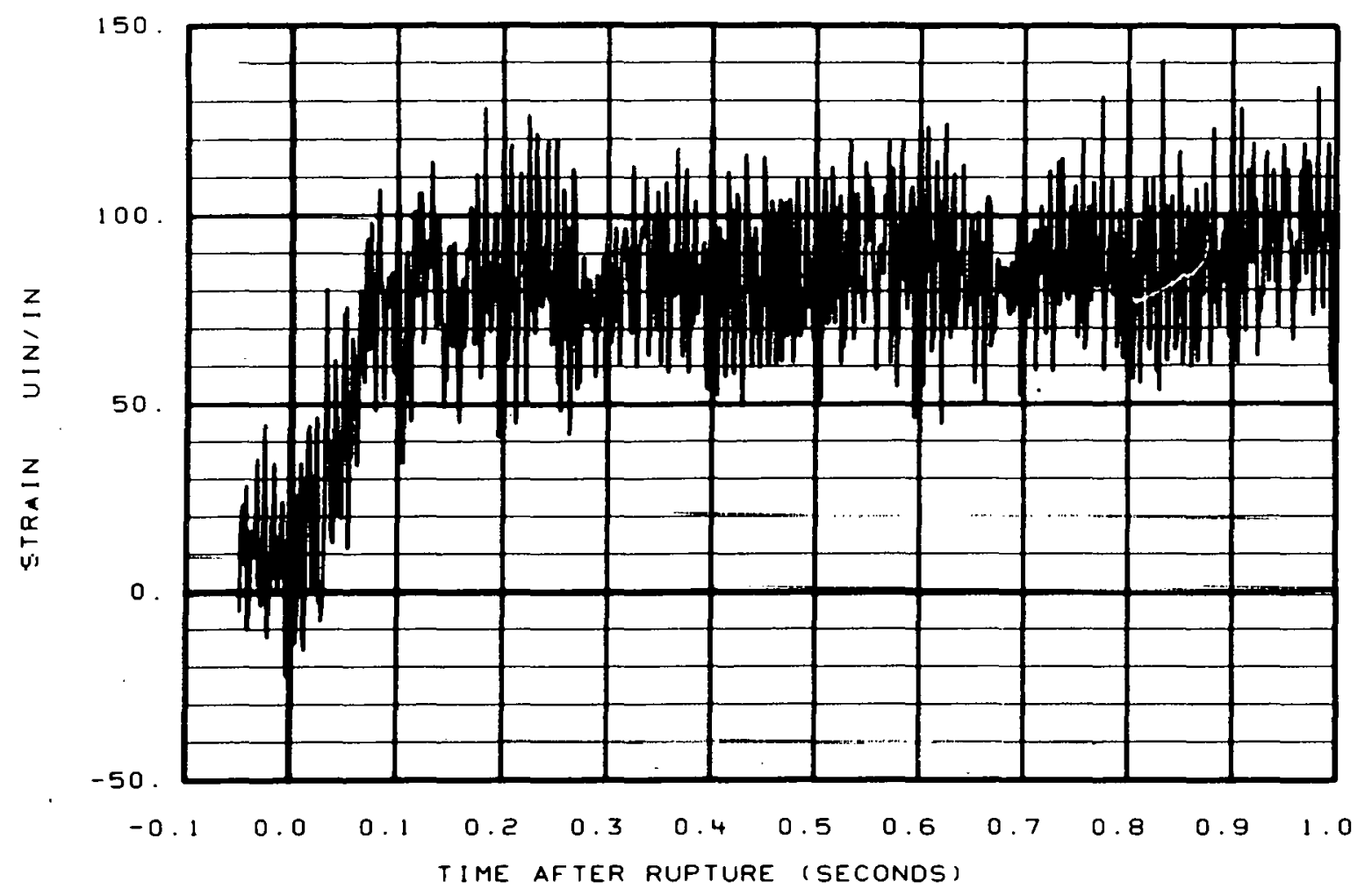

Fig. 112 Strain at reactor vessel broken loop cold leg nozzle (SE-BL8-12).

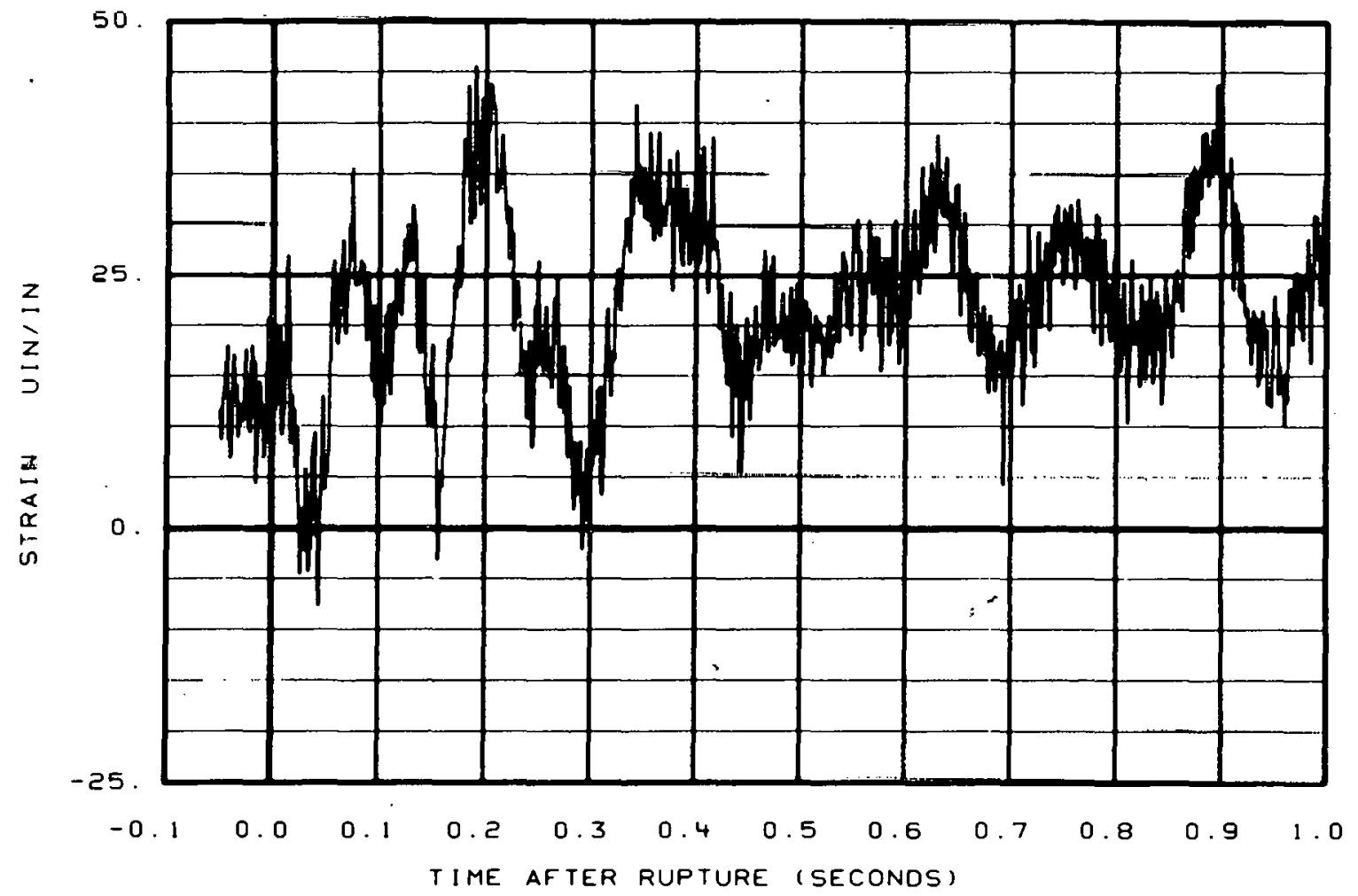

Fig. 113 Strain at reactor vessel broken loop hot leg nozzle (SE-BL9-1). 


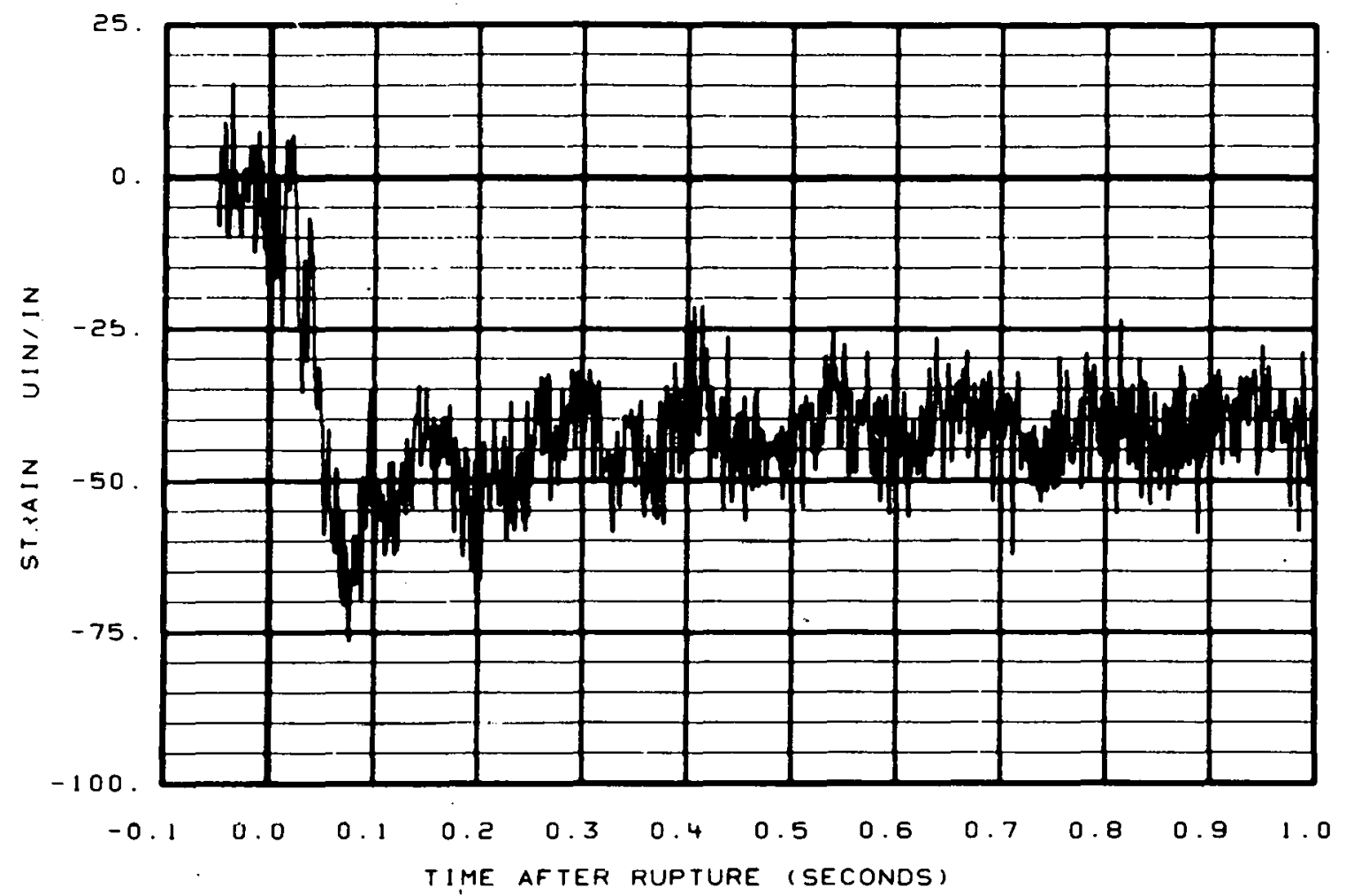

Fig. 114 Strain at reactor vessel broken loop hot leg nozzle (SE-BL9-2).

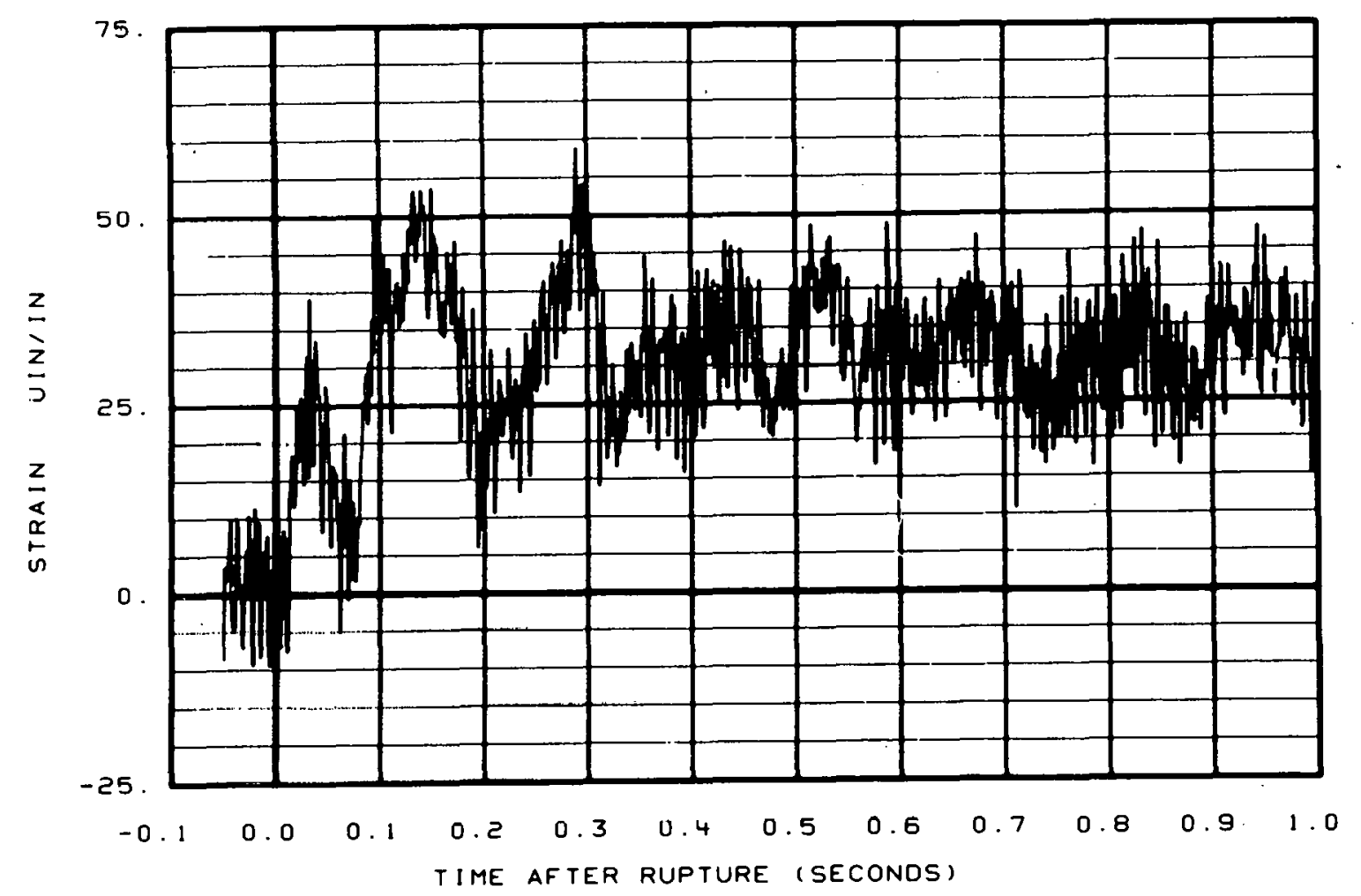

Fig. 115 Strain at ractor vessel broken loop hot leg nozzle (SE-BL9-3). 


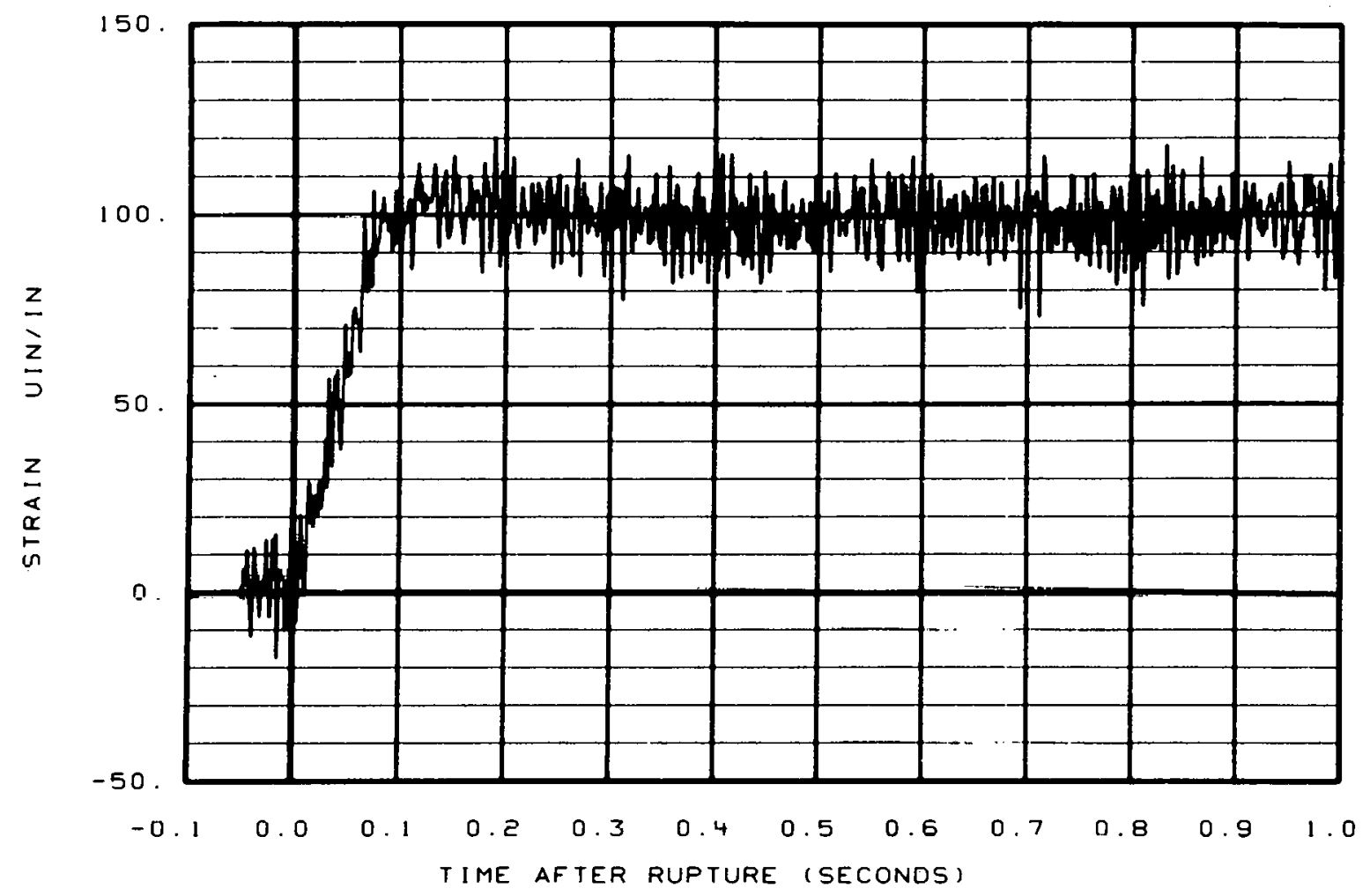

Fig. 116 Strain at reactor vessel broken loop hot leg nozzle (SE-BL9-4).

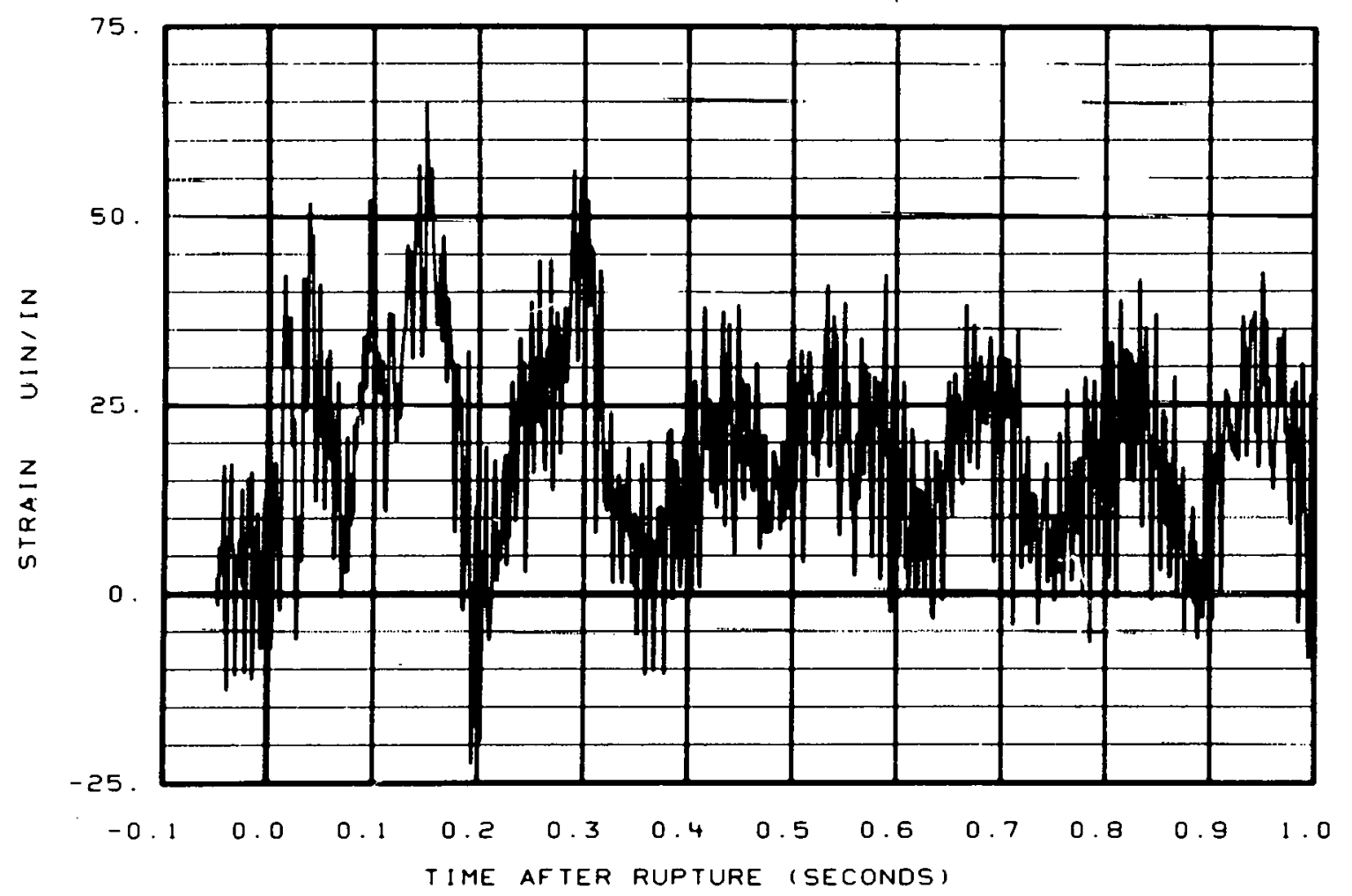

Fig. 117 Strain at reactor vessel broken loop hot leg nozzle (SE-BL9-5). 


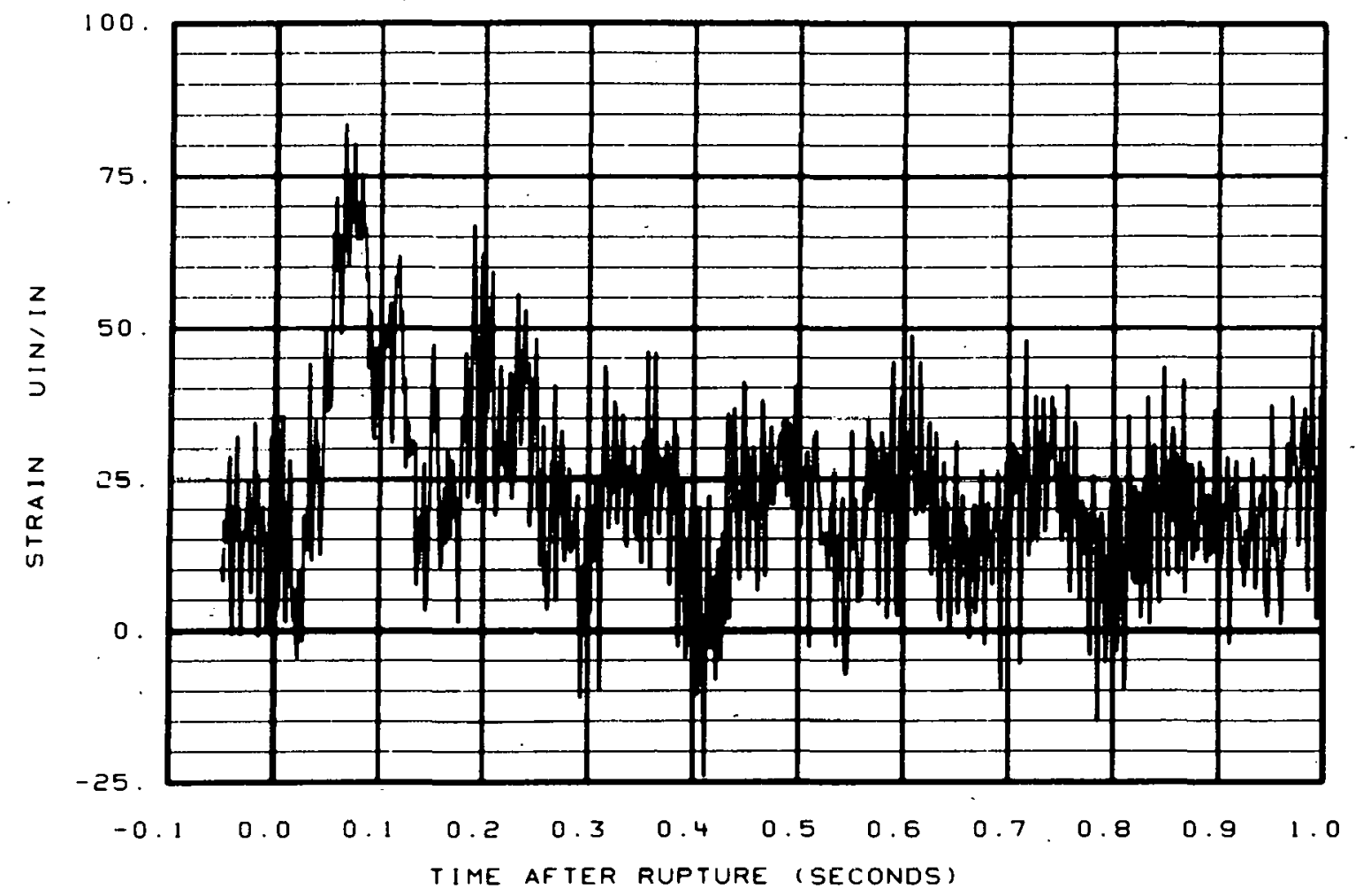

Fig. 118 Strain at reactor vessel broken loop hot leg nozzle (SE-BL9-6).

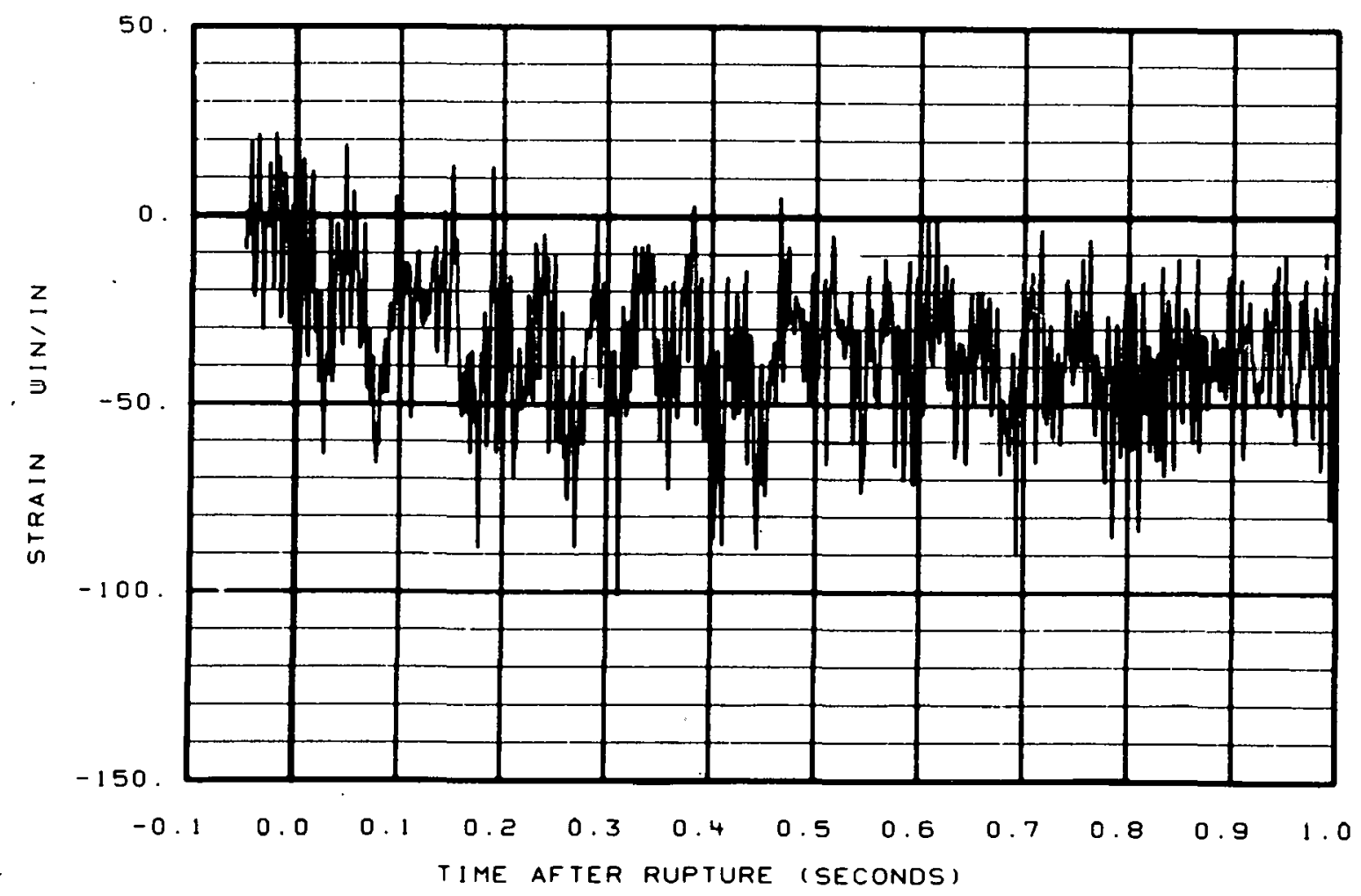

Fig. 119 Strain between pump and steam generator simulator (SE-BL27-2). 


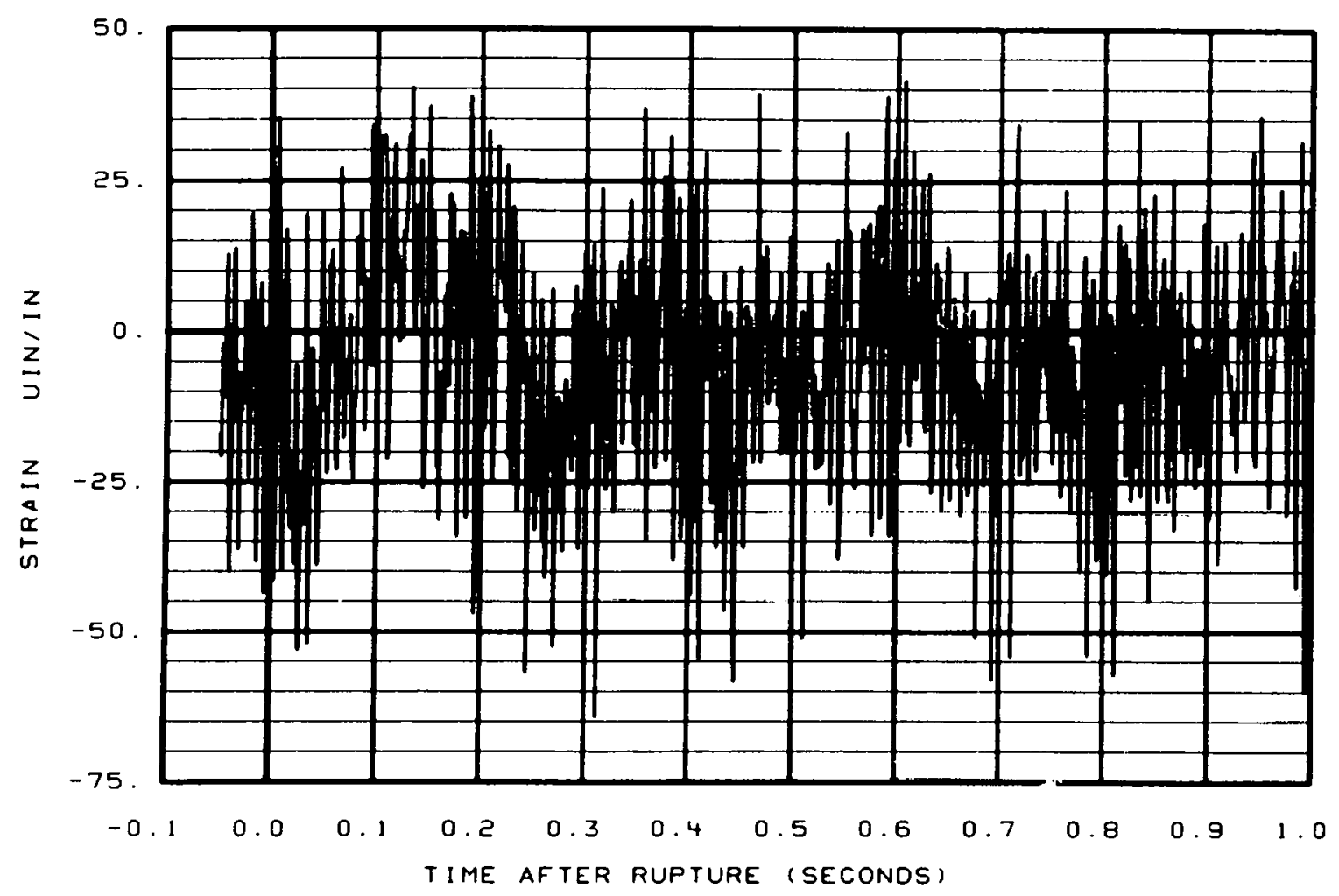

Fig. 120 Strain between pump and steam generator simulator (SE-BL27-4).

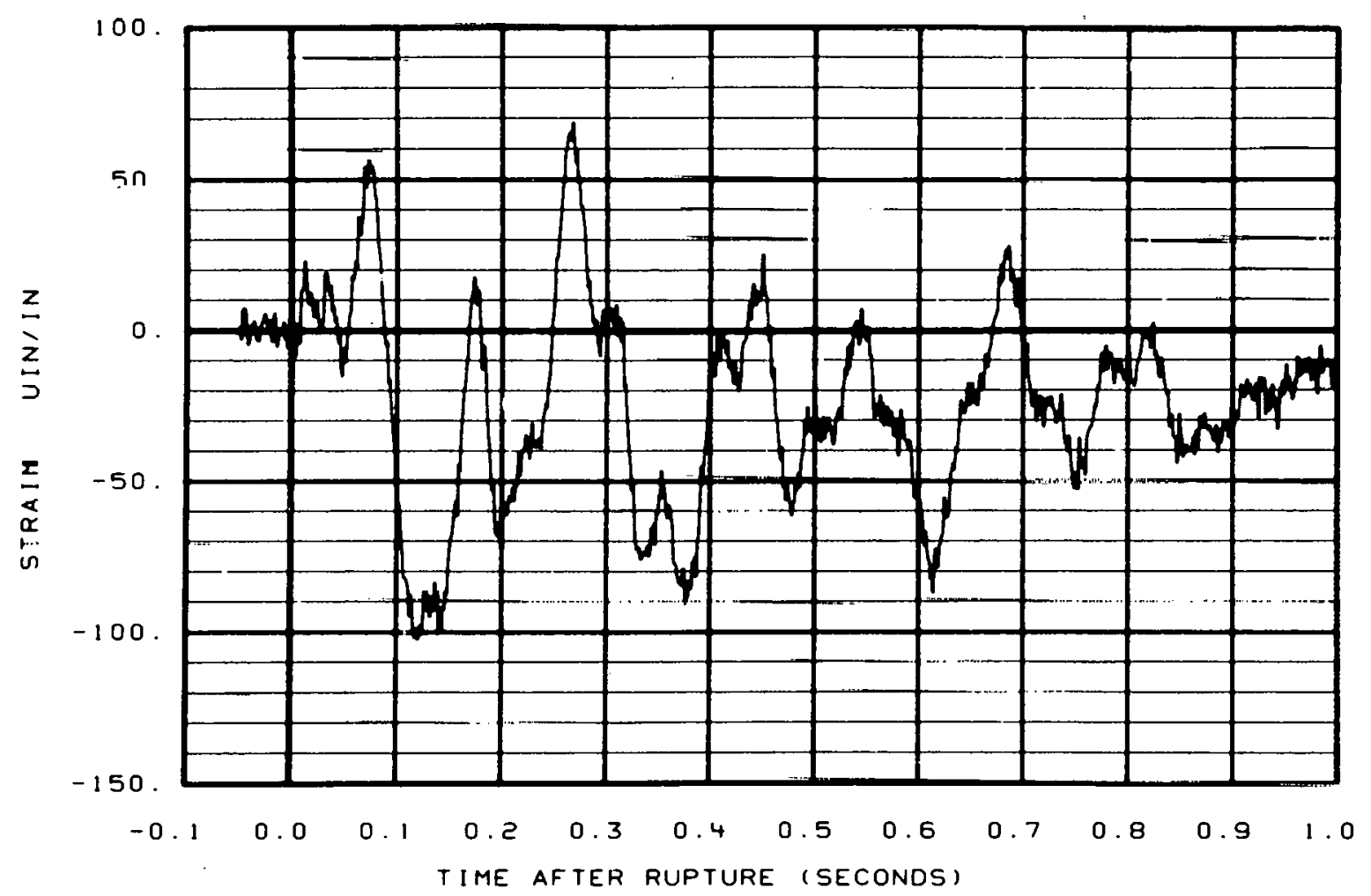

Fig. 121 Strain between pump and steam generator simulator (SE-BL27-5). 


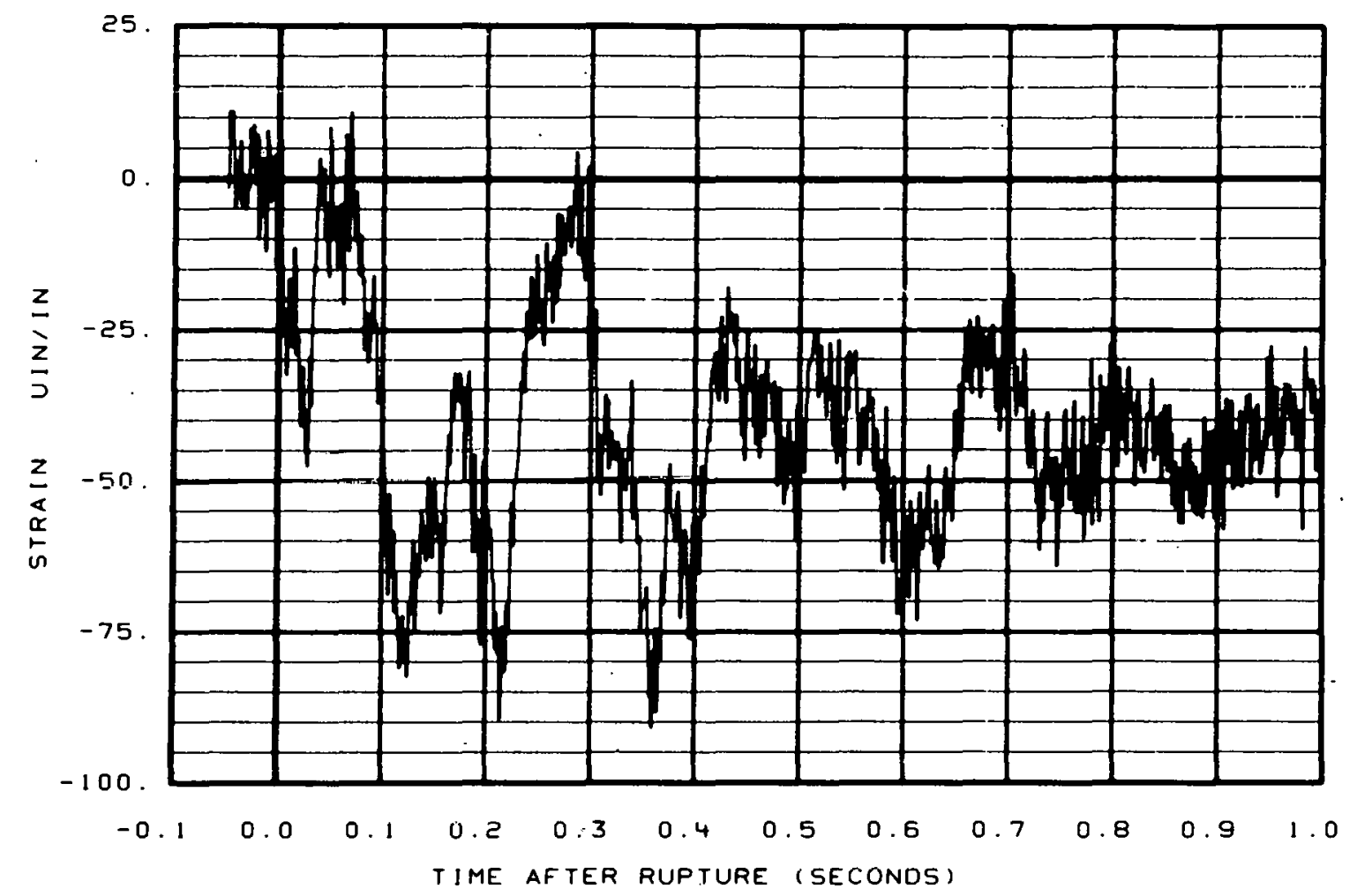

Fig. 122 Strain between pump and steam generator simulator (SE-BL27-6).

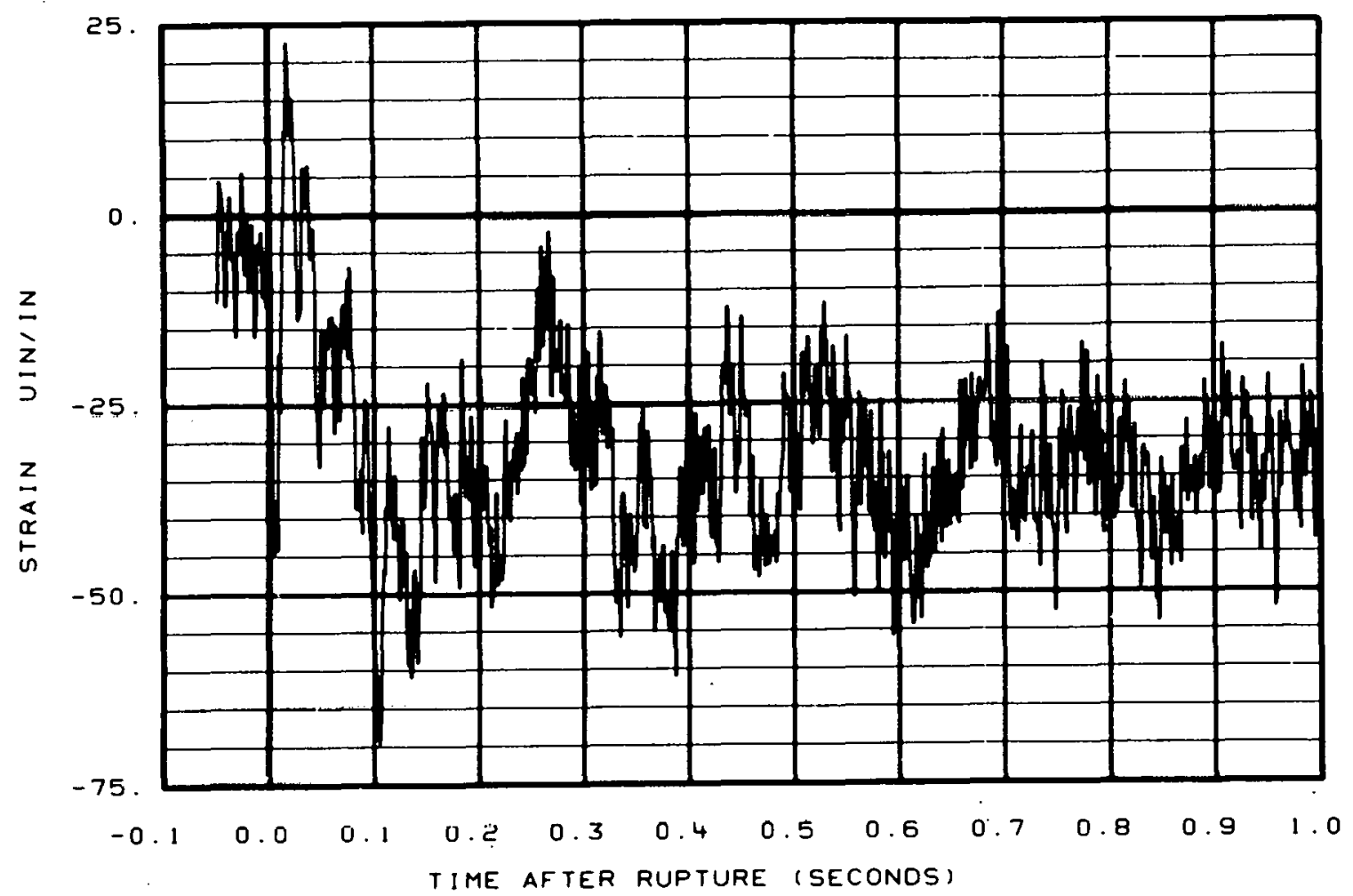

Fig. 123 SLrdin between pump and steam generator simulator (SE-BL27-8). 


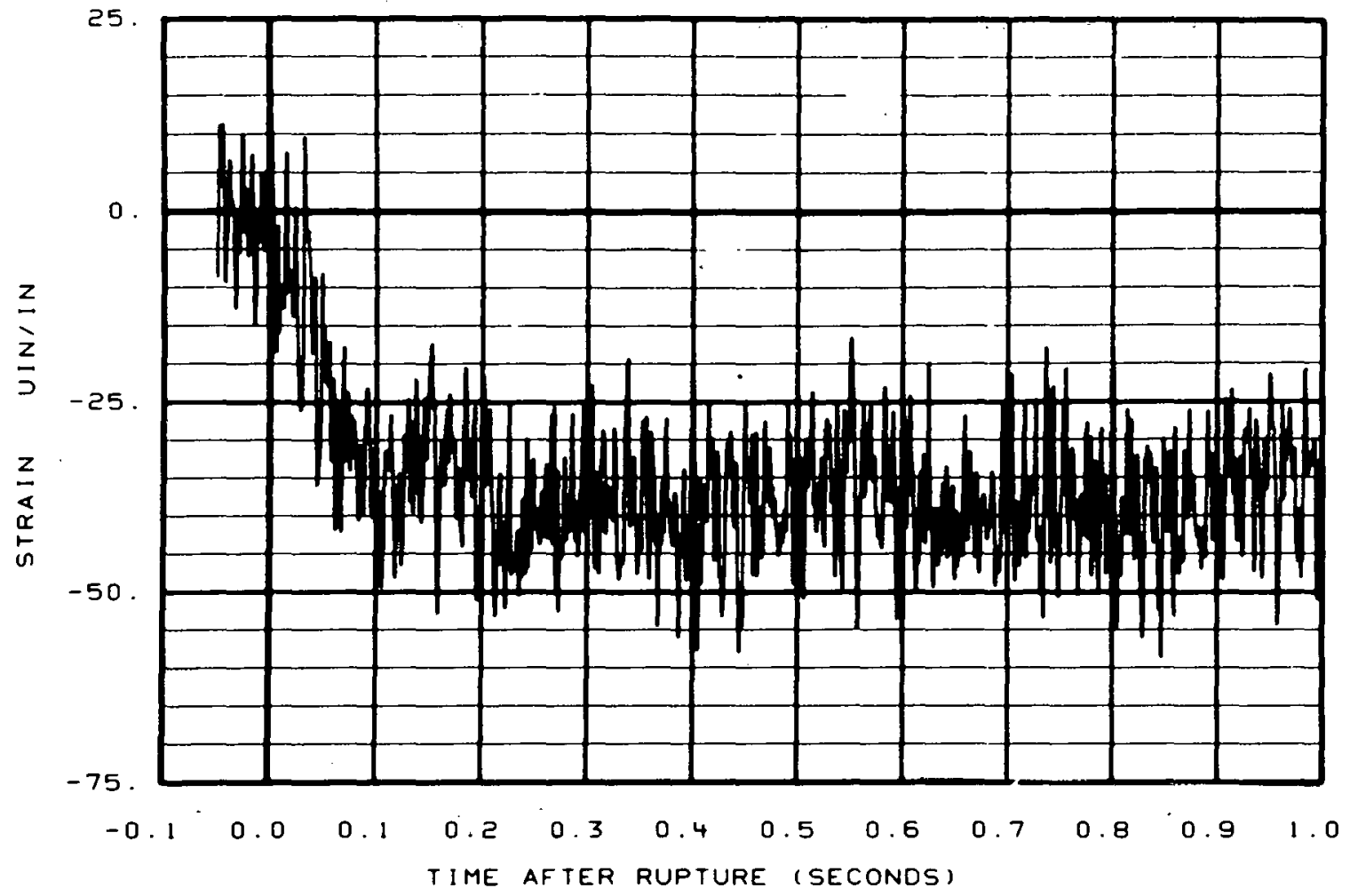

Fig. 124 Strain at reactor vessel intact loop cold leg nozzle (SE-PC4-1).

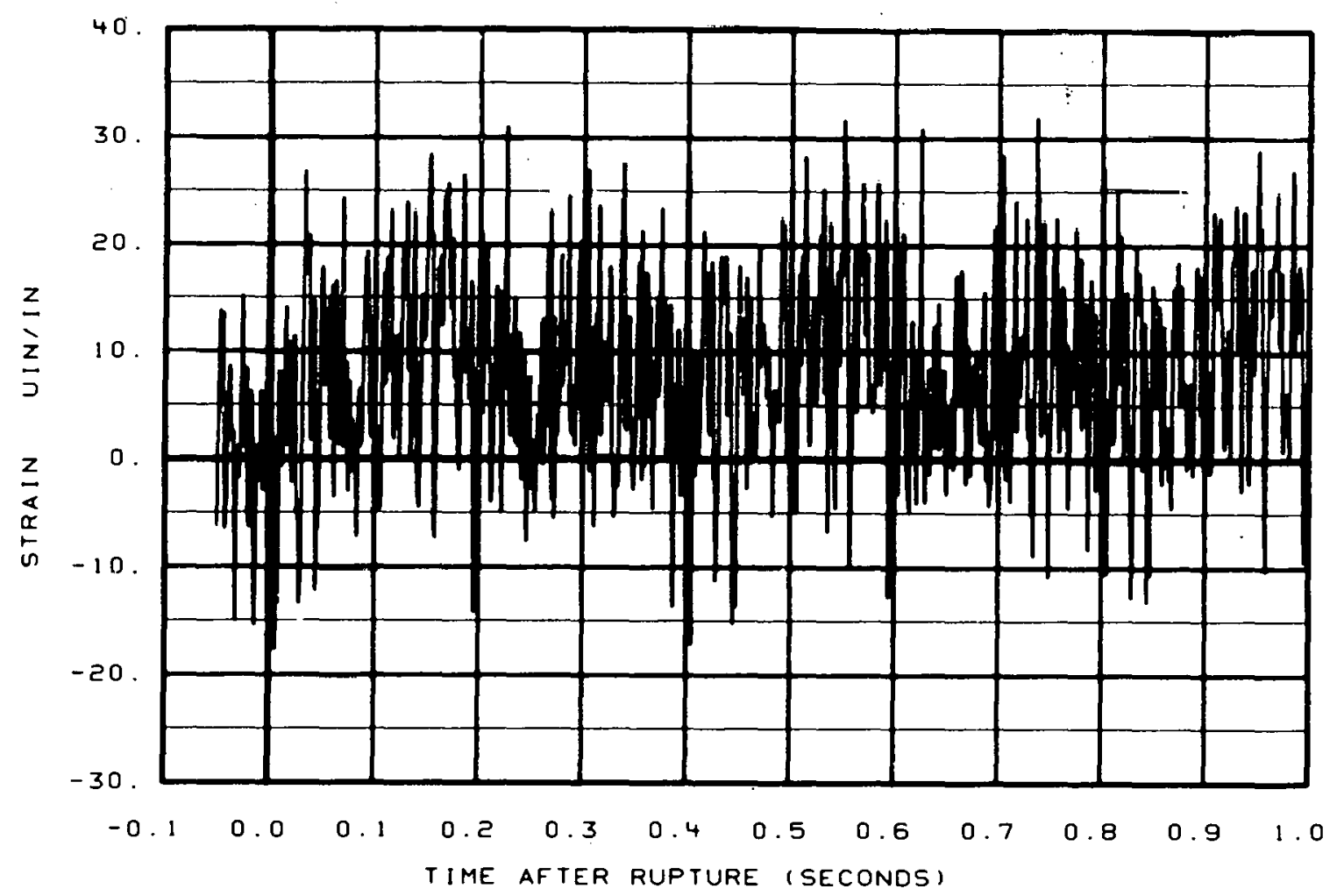

Fig. 125 Strain at reactor vessel intact loop cold leg nozzle (SE-PC4-2). 


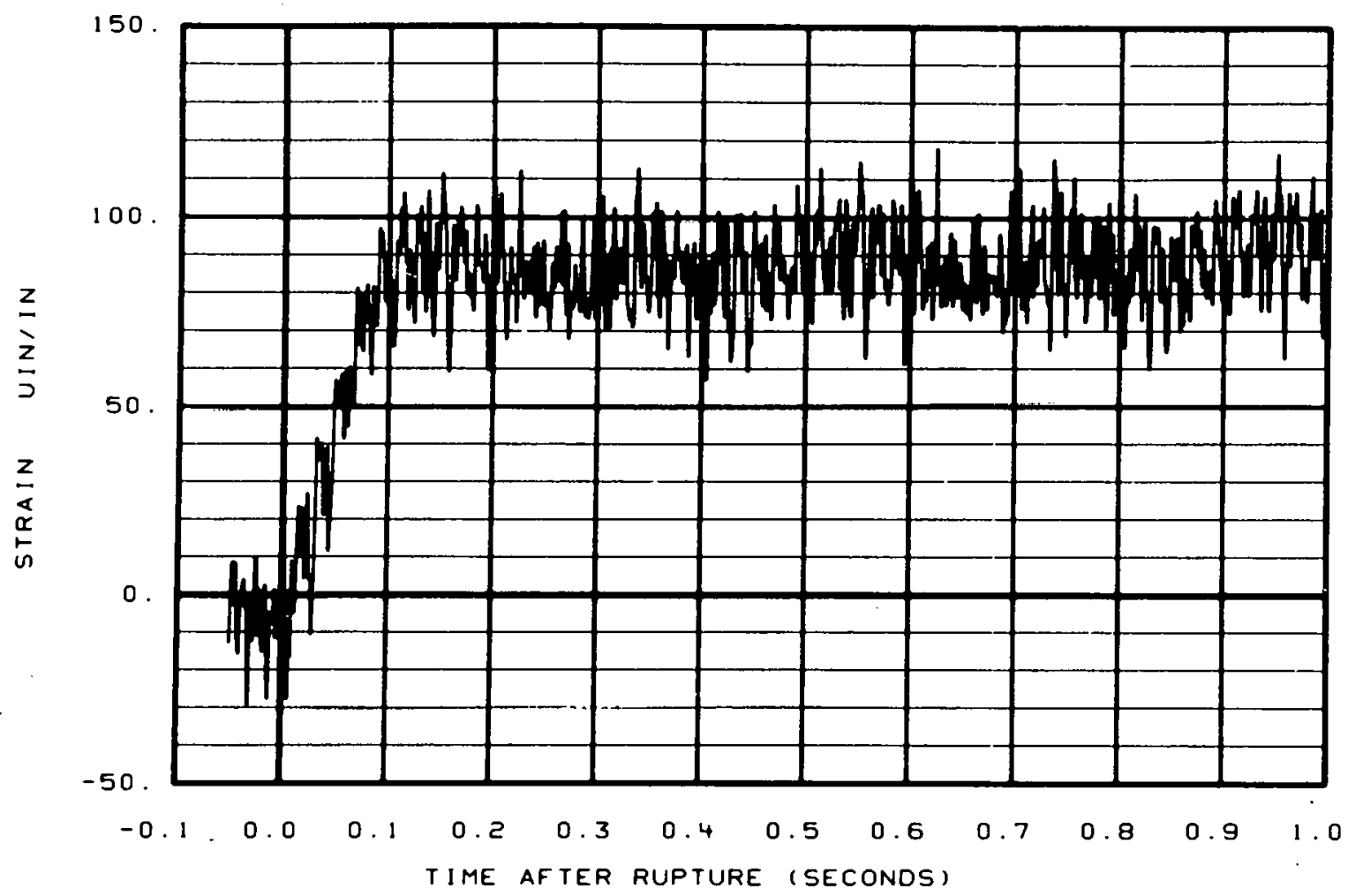

Fig. 126 Strain at reactor vessel intact loop cold leg nozzle (SE-PC4-4).

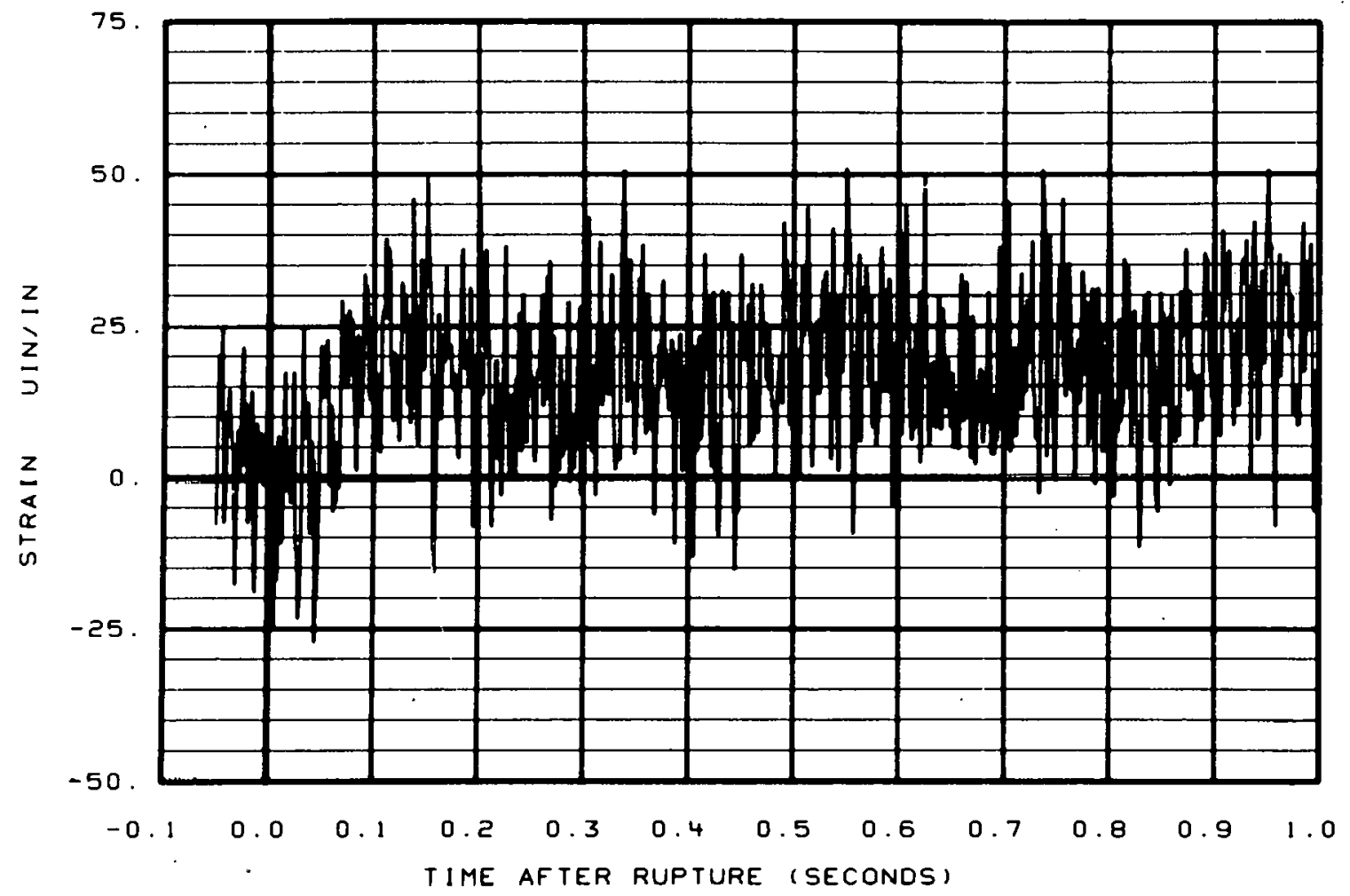

Fig. 127 Strain at reactor vessel intact loop cold leg nozzle (SE-PC4-5). 


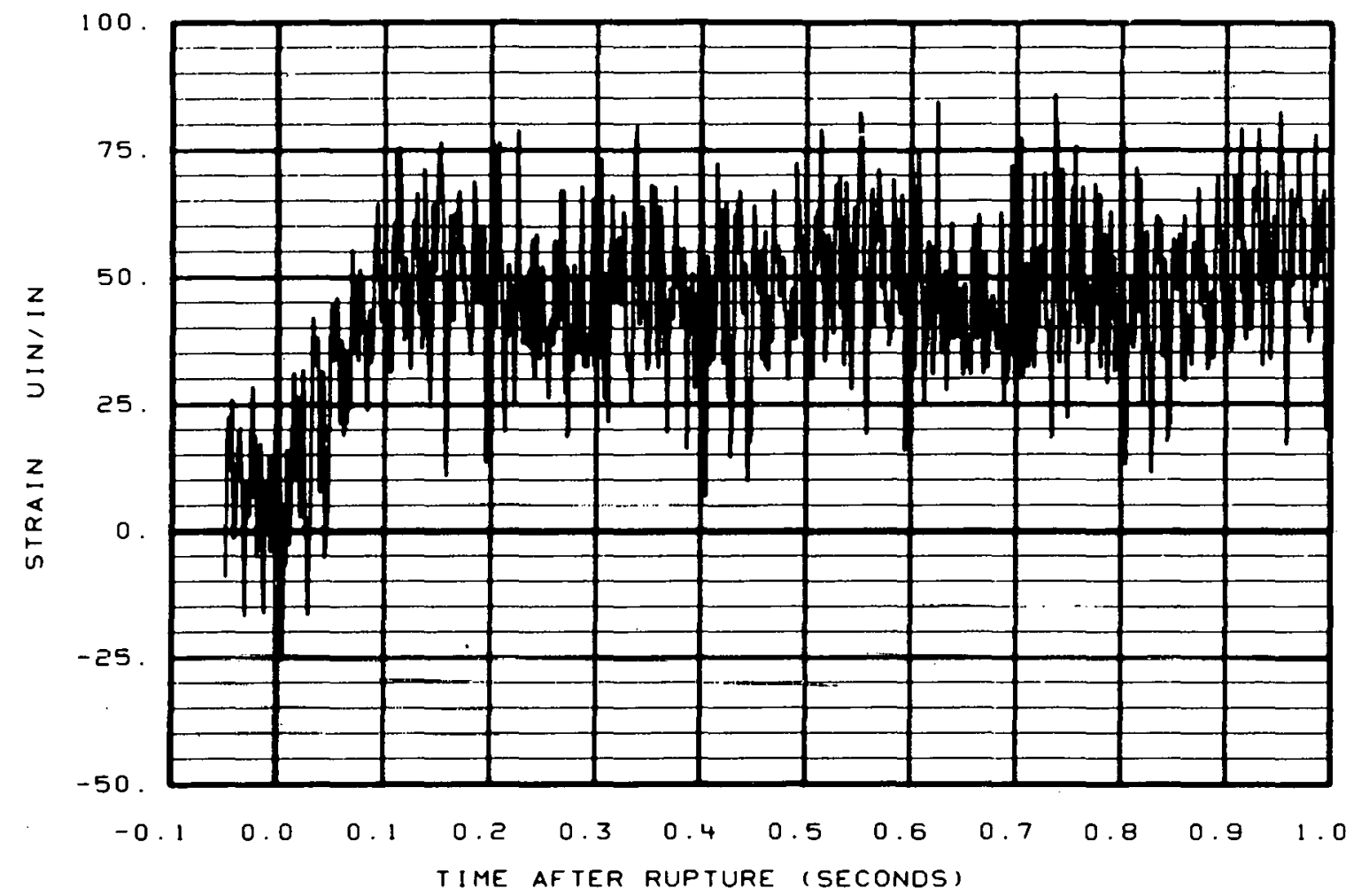

Fig. 128 Strain at reactor vessel intact loop cold leg nozzle (SE-PC4-7).

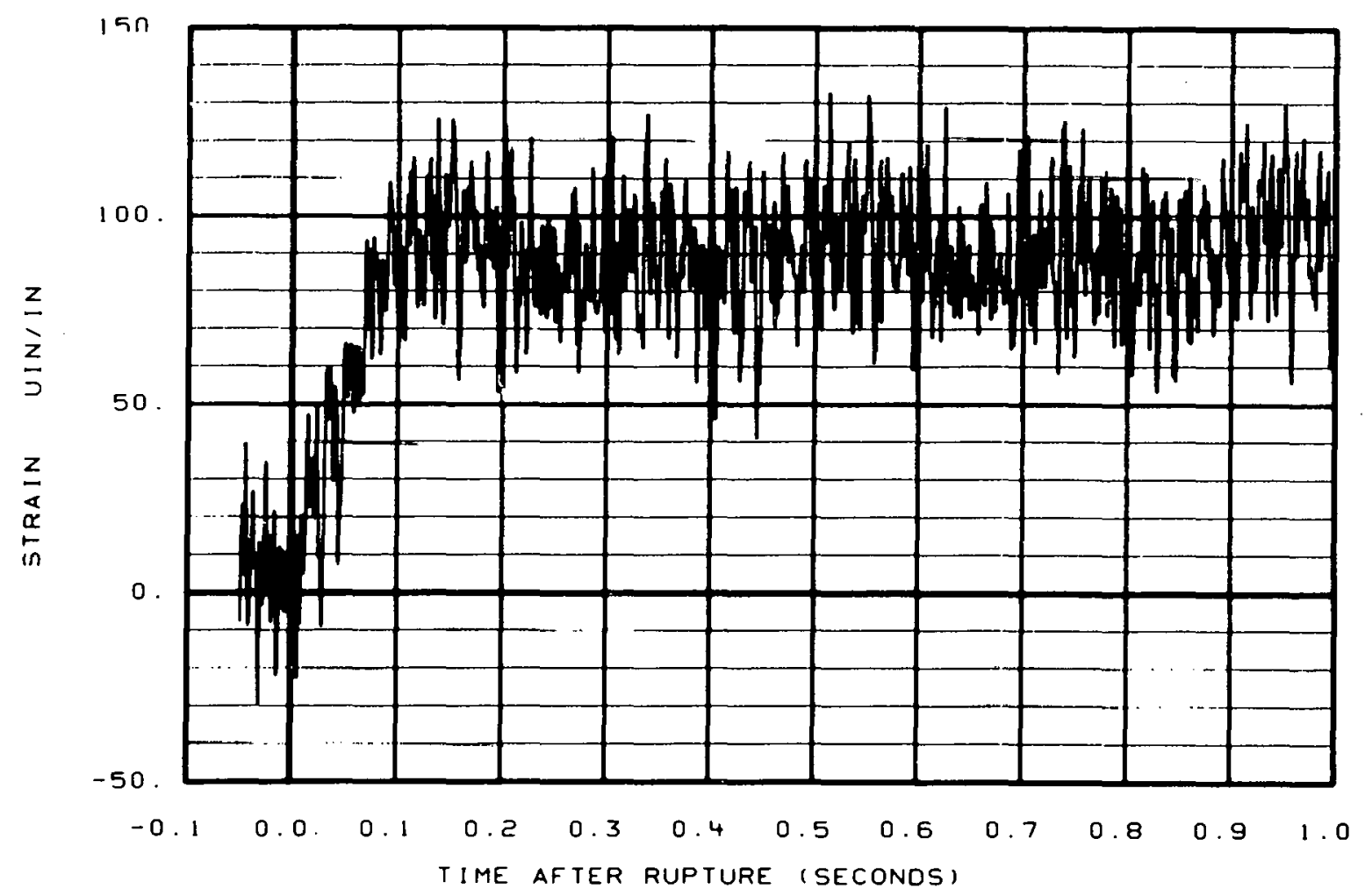

Fig. 129 Strain at reactor vessel intact loop cold leg nozzle (SE-PC4-8). 


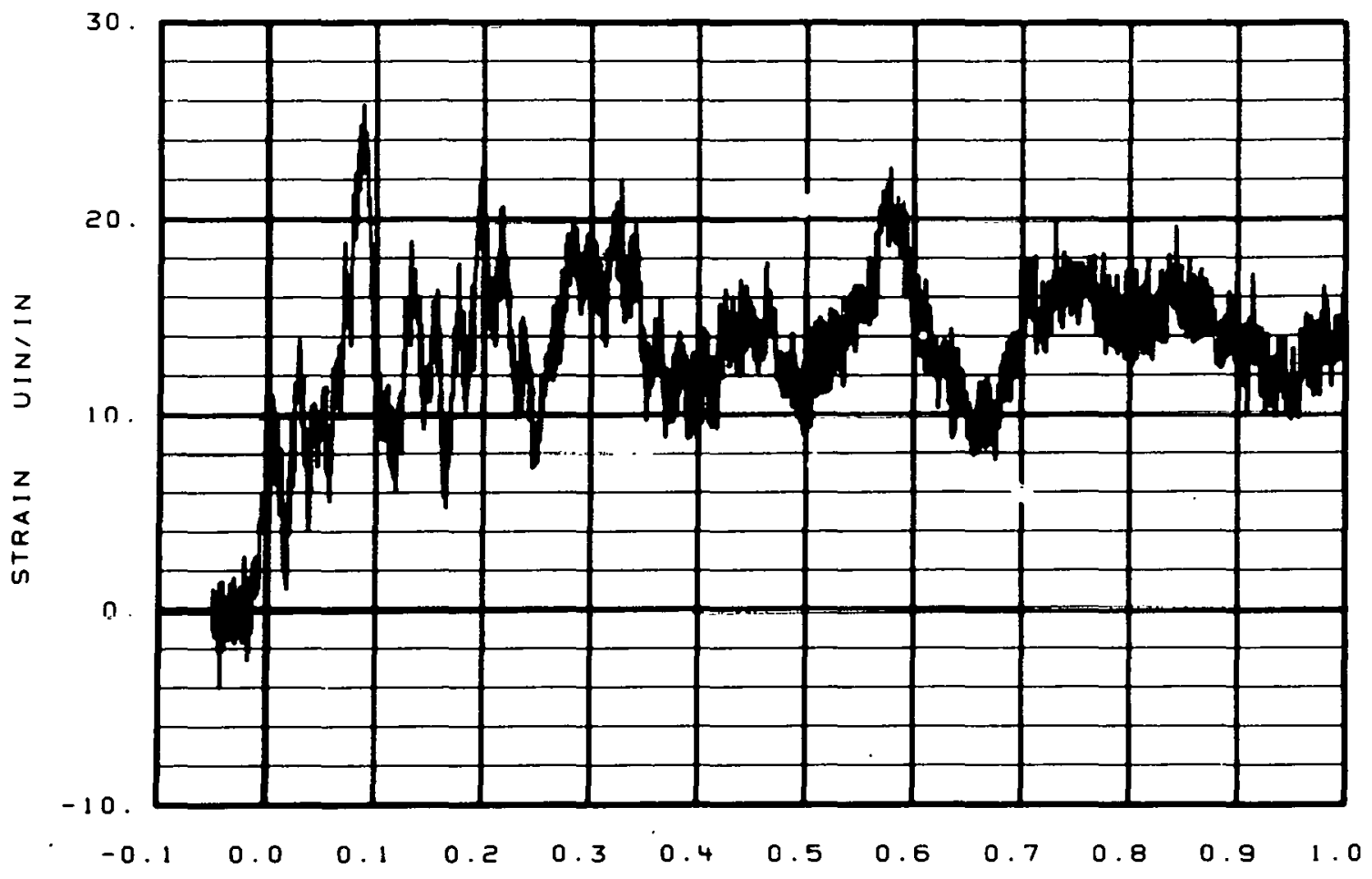

TIME AFTER RUPTURE (SECONDS)

Fig. 130 Strain at reactor vessel intact loop hot leg nozzle (SE-PC5-1).

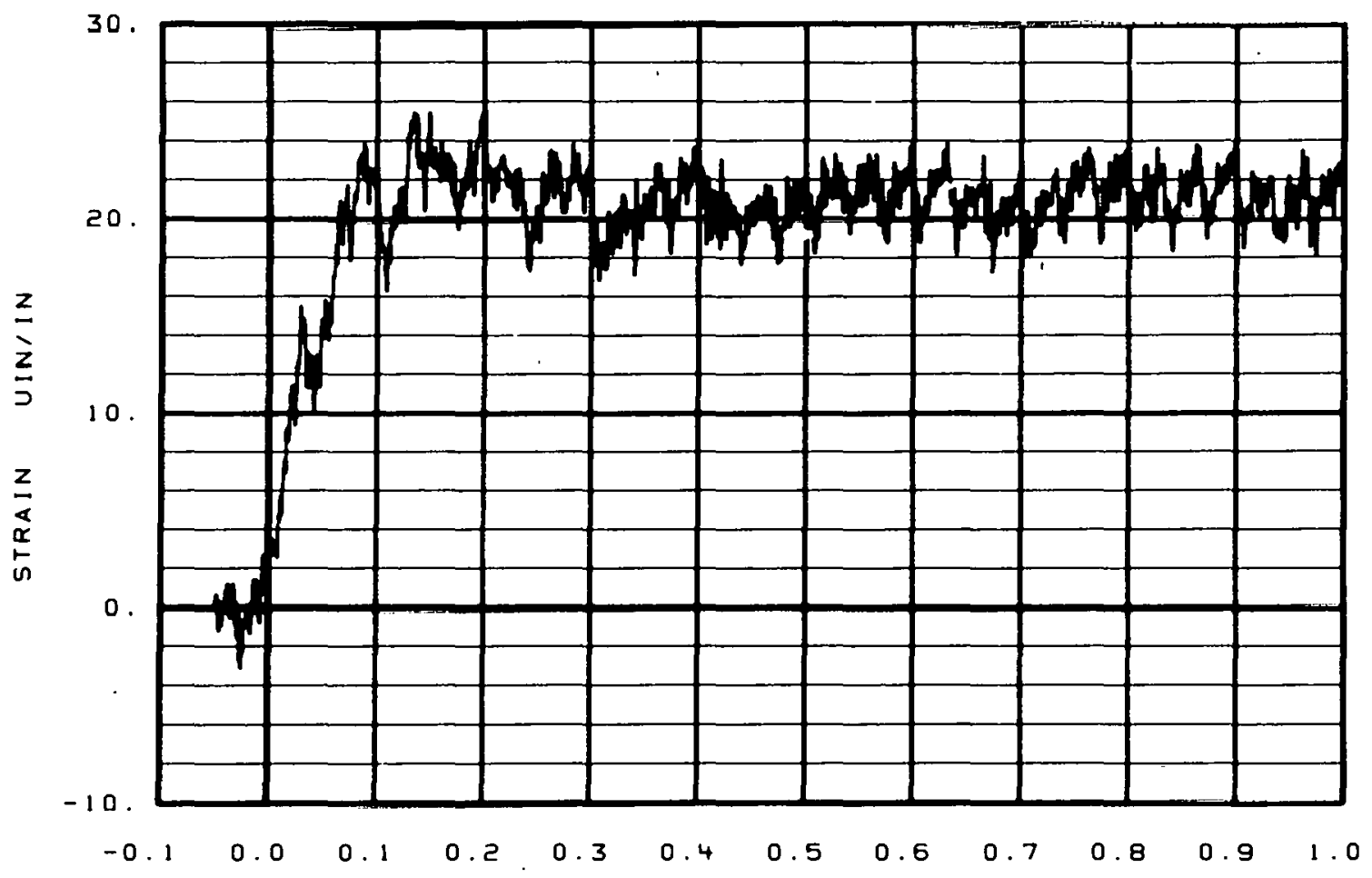

TIME AFTER RUPTURE (SECONDS)

Fig. 131 Strain at reactor vessel intact loop hot leg nozzle (SE-PC5-2).

85 


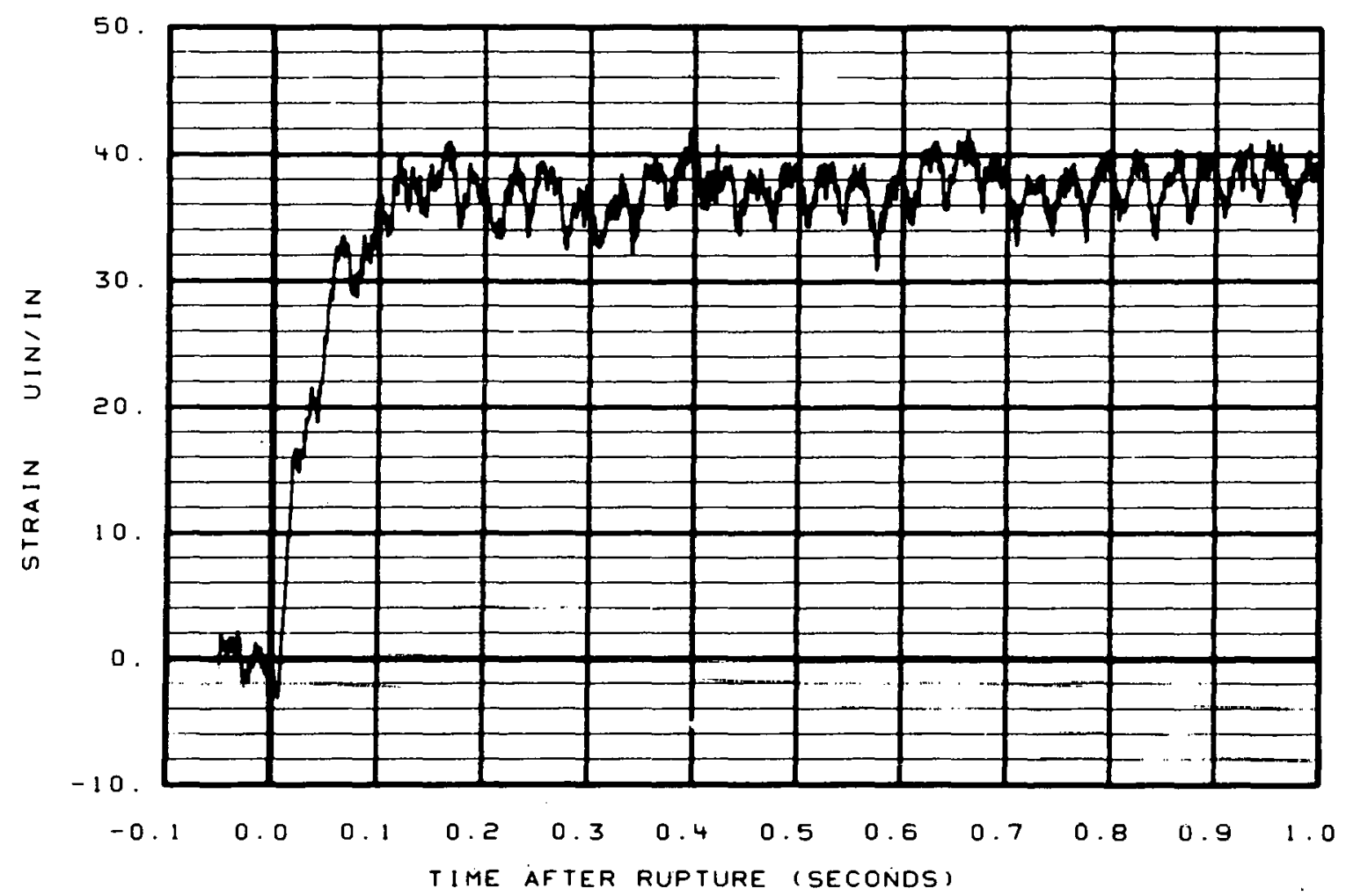

Fig. 132 Strain at reactor vessel intact loop hot leg nozzle (SE-PC5-3).

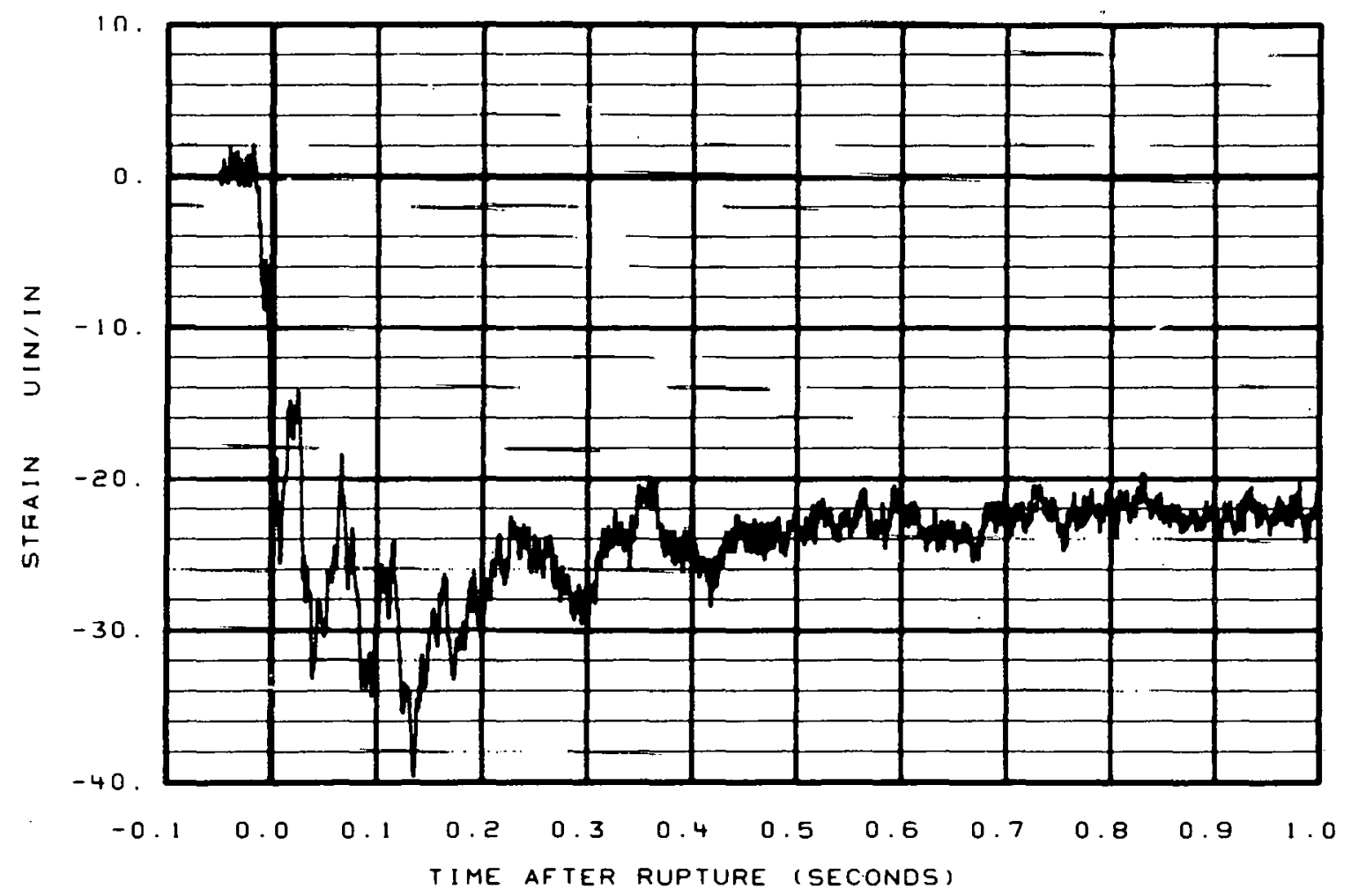

Fig. 133 Strain at reactor vessel intact loop hut leg nozzle (SE-PC5-4). 


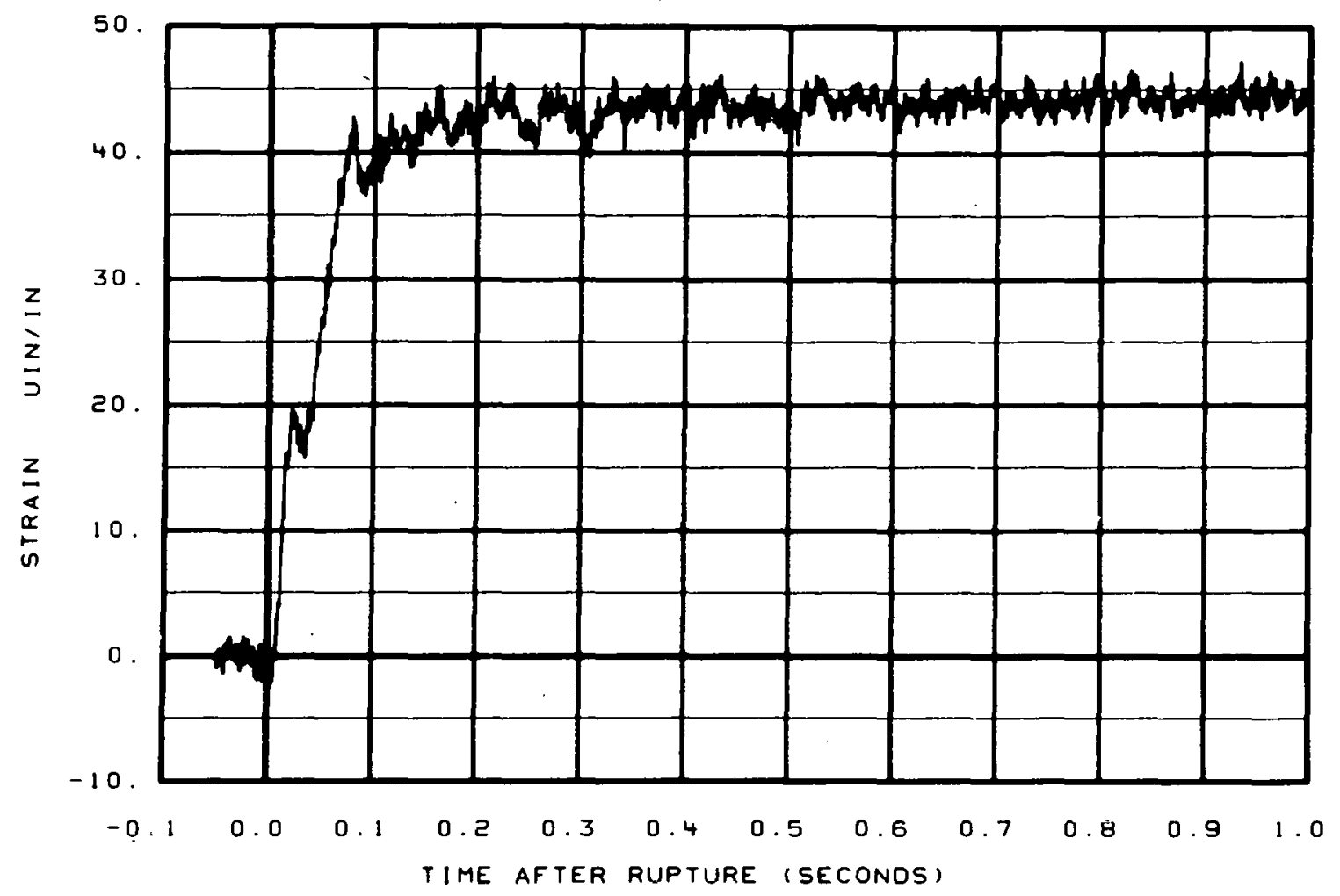

Fig. 134 Strain at reactor vessel intact loop hot leg nozzle (SE-PC5-5).

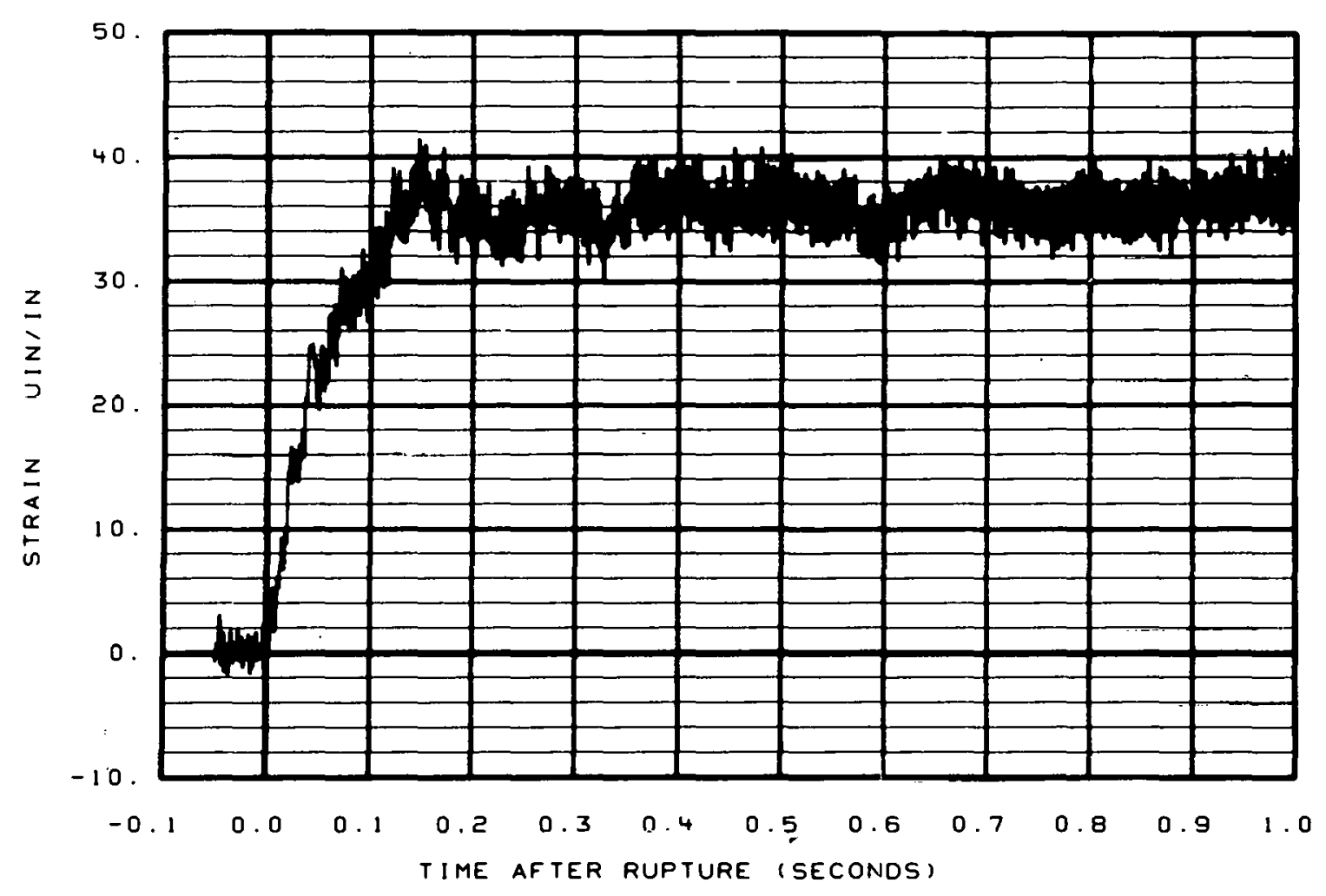

Fig. 135 Strain at reactor vessel intact loop hot leg nozzle (SE-PC5-8). 


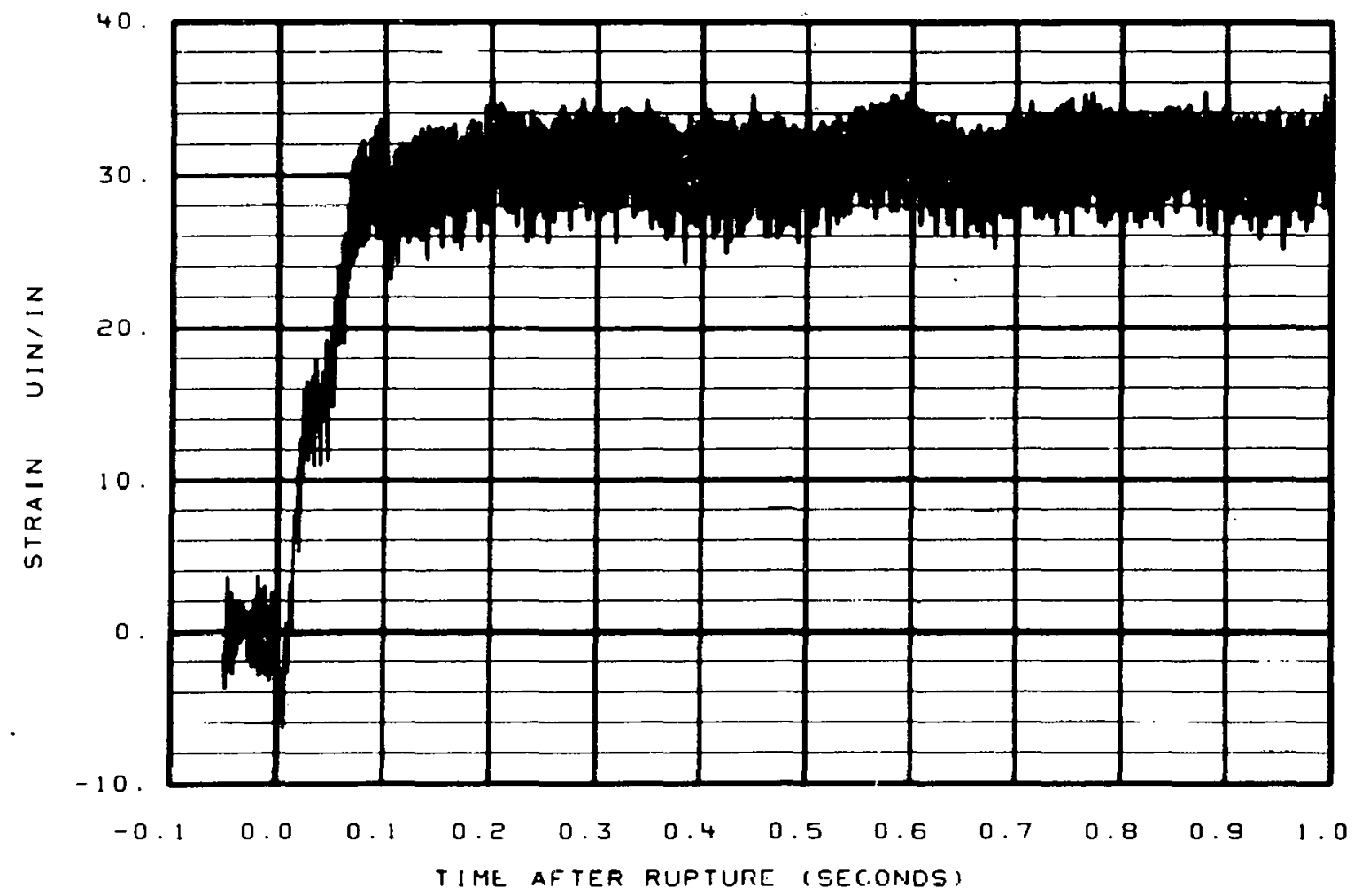

Fig. 136 Strain at reactor vessel intact loop hot leg nozzle (SE-PC5-9).

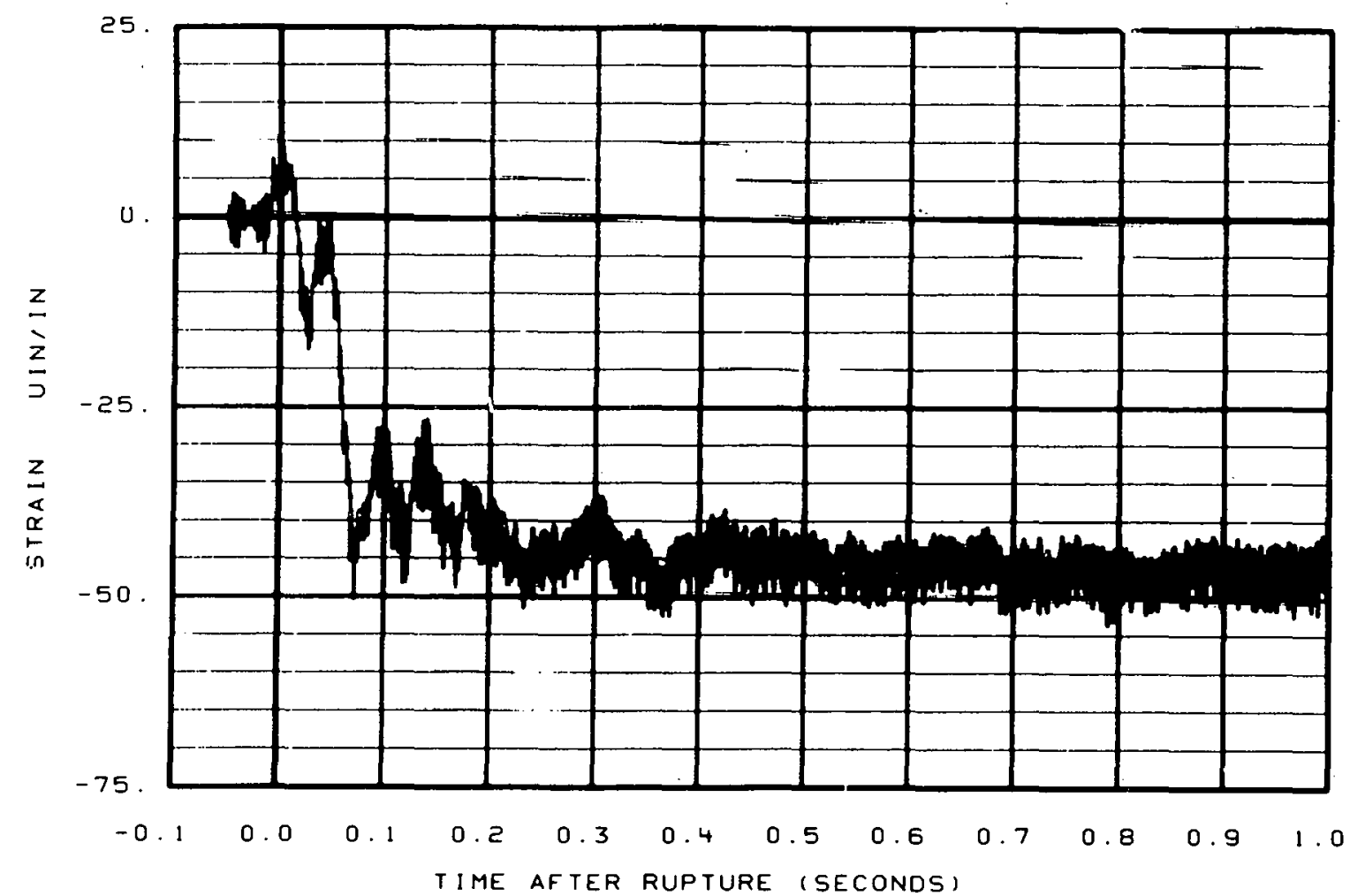

Fig. 137 Strain at reactor vessel intact loop hot leg nozzle (SE-PC5-10). 


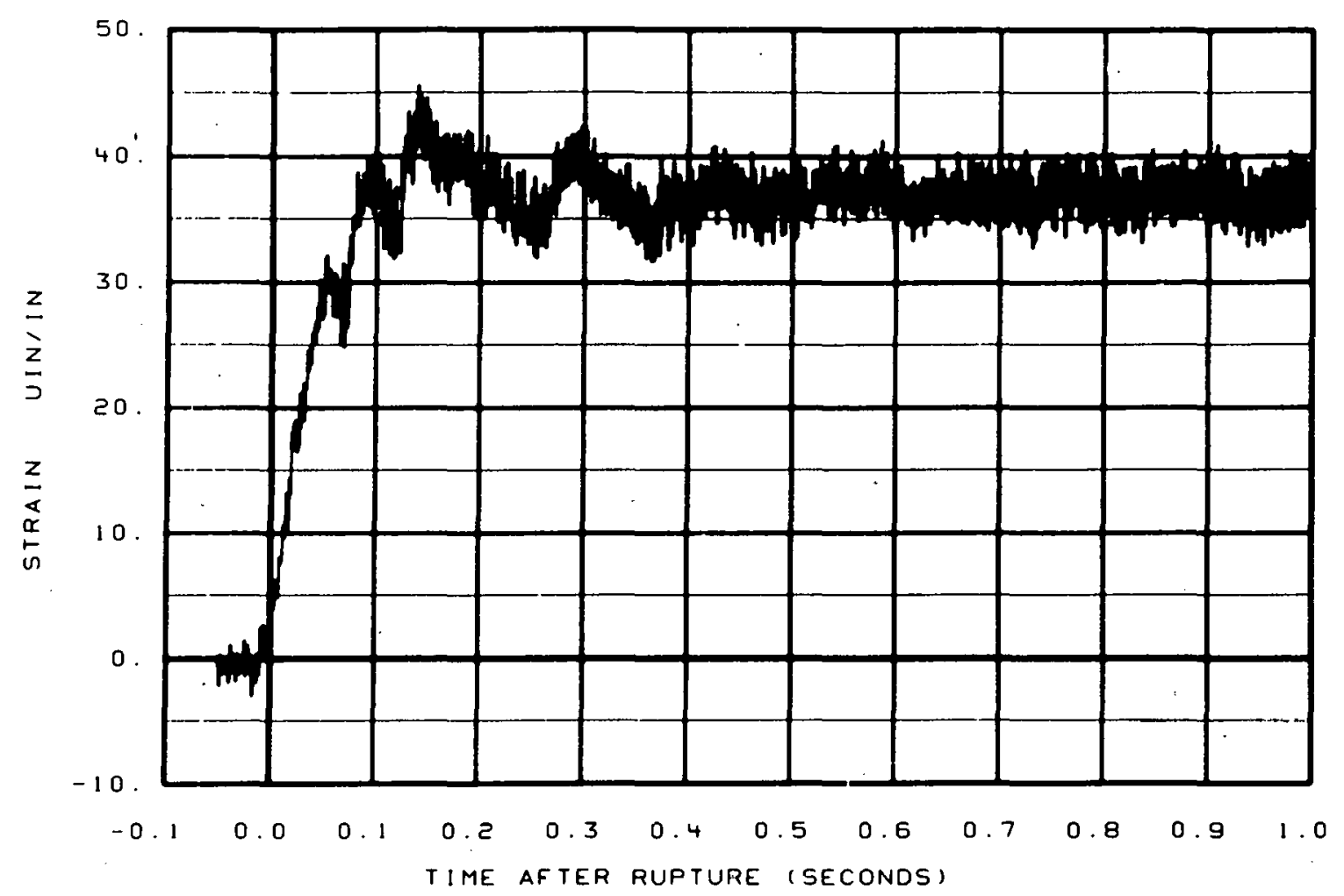

Fig. 138 Strain at reactor vessel intact loop hot leg nozzle (SE-PC5-11).

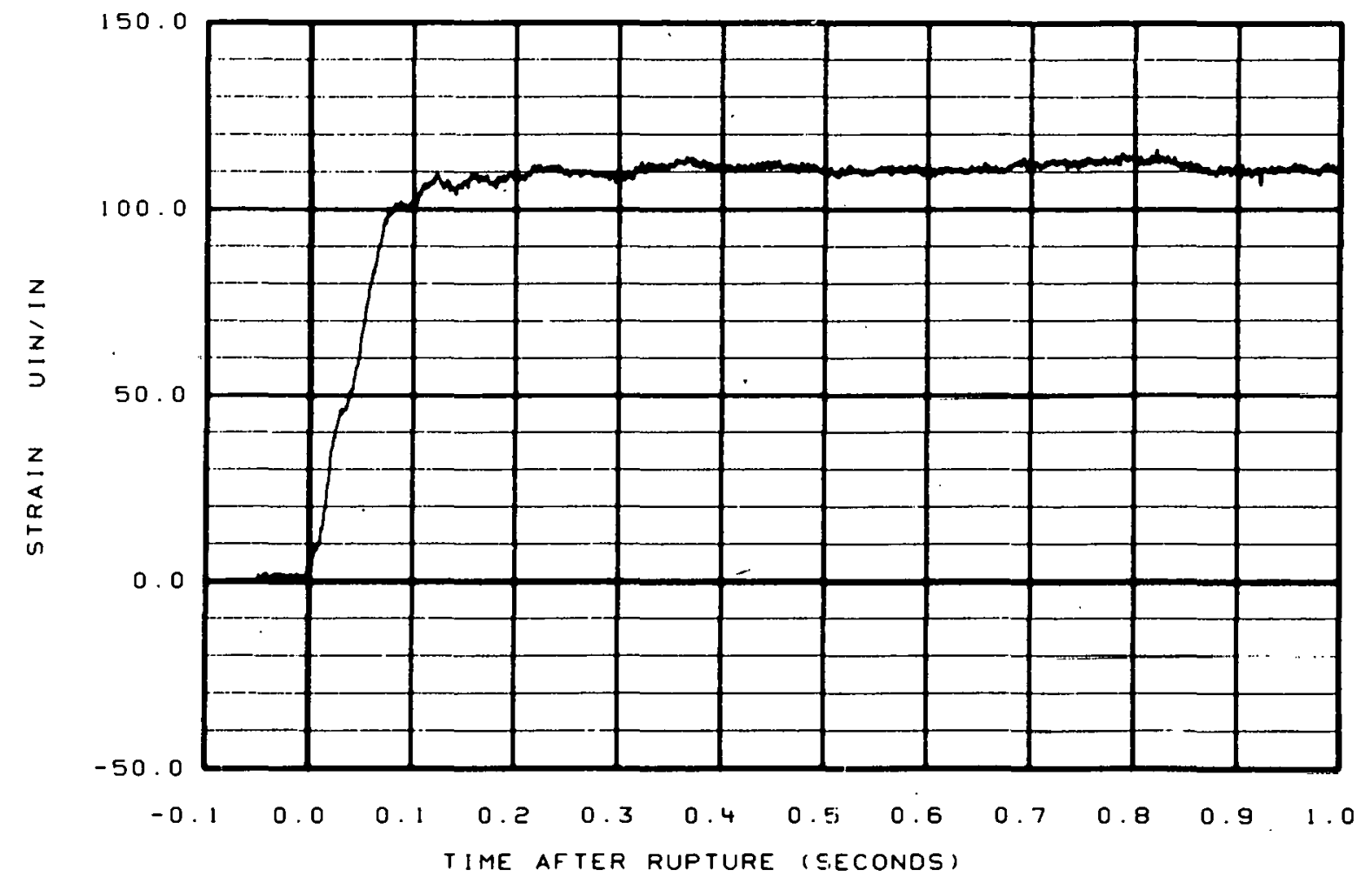

Fig. 139 Strain at reactor vessel intact loop hot leg nozzle (SE-PC5-12). 


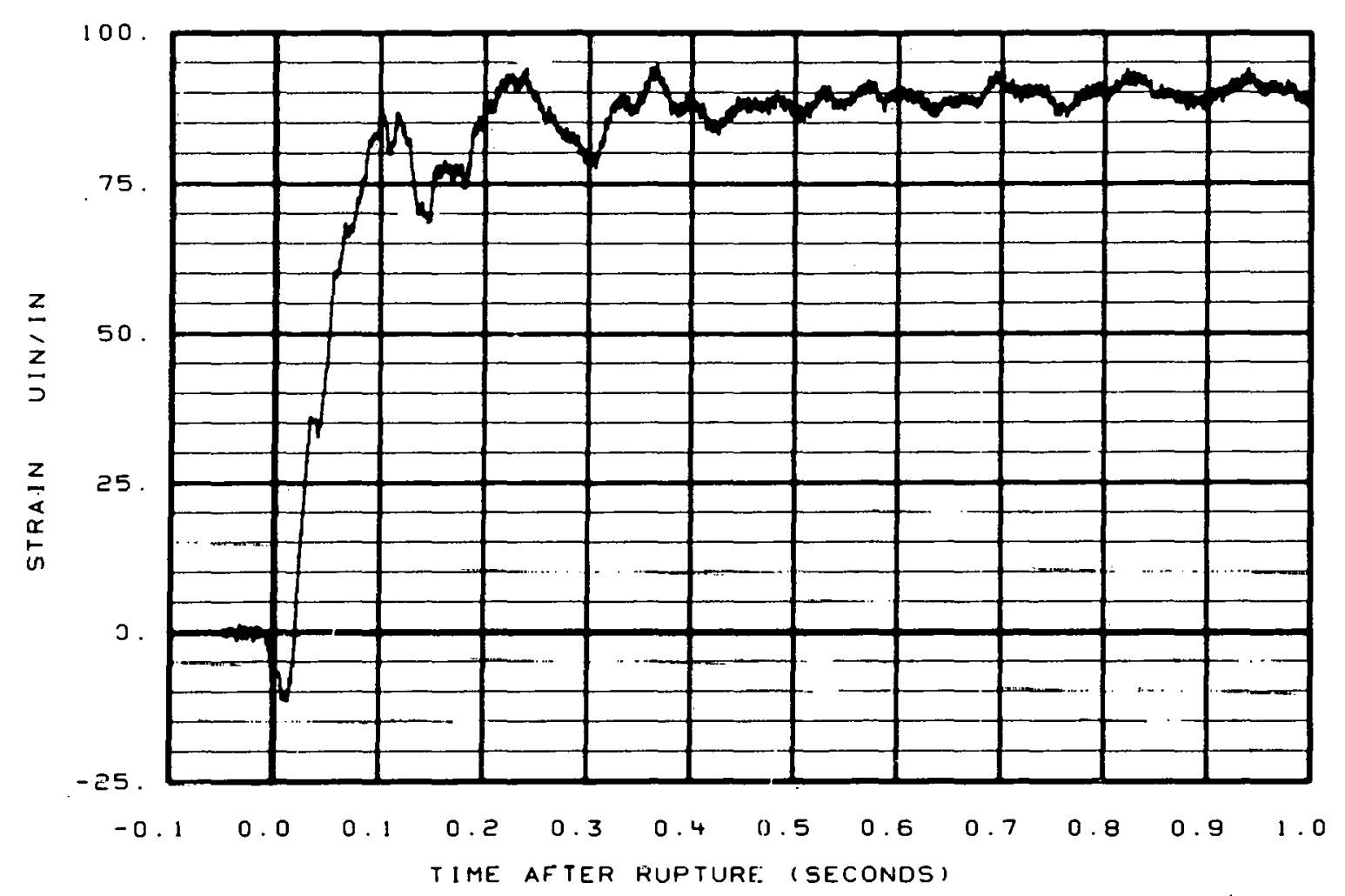

Fig. 140 Strain at steam generator inlet nozzle (SE-PC14-2).

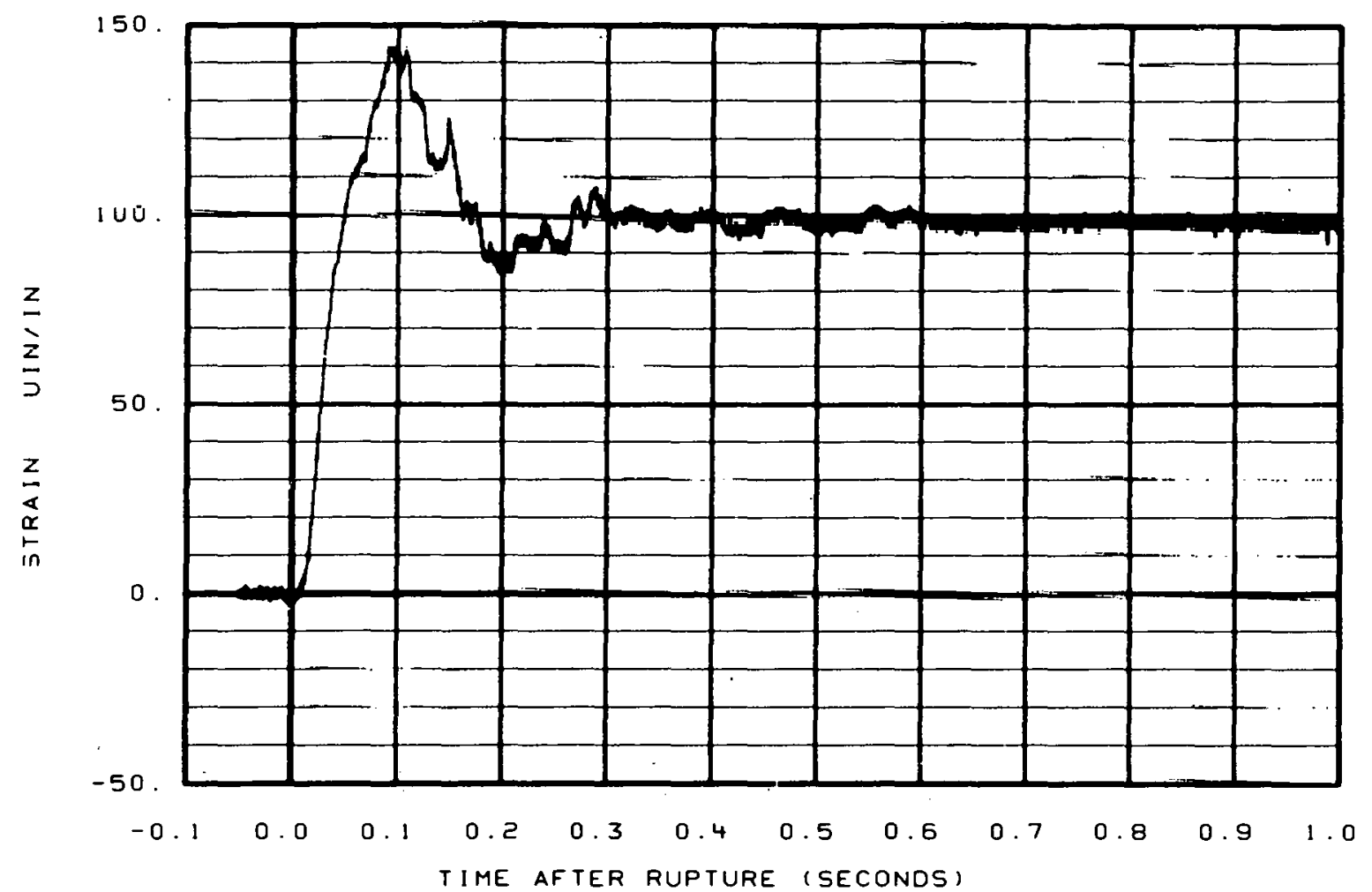

Fig. 141 Strain at steam generator inlet nozzle (SE-PC14-3). 


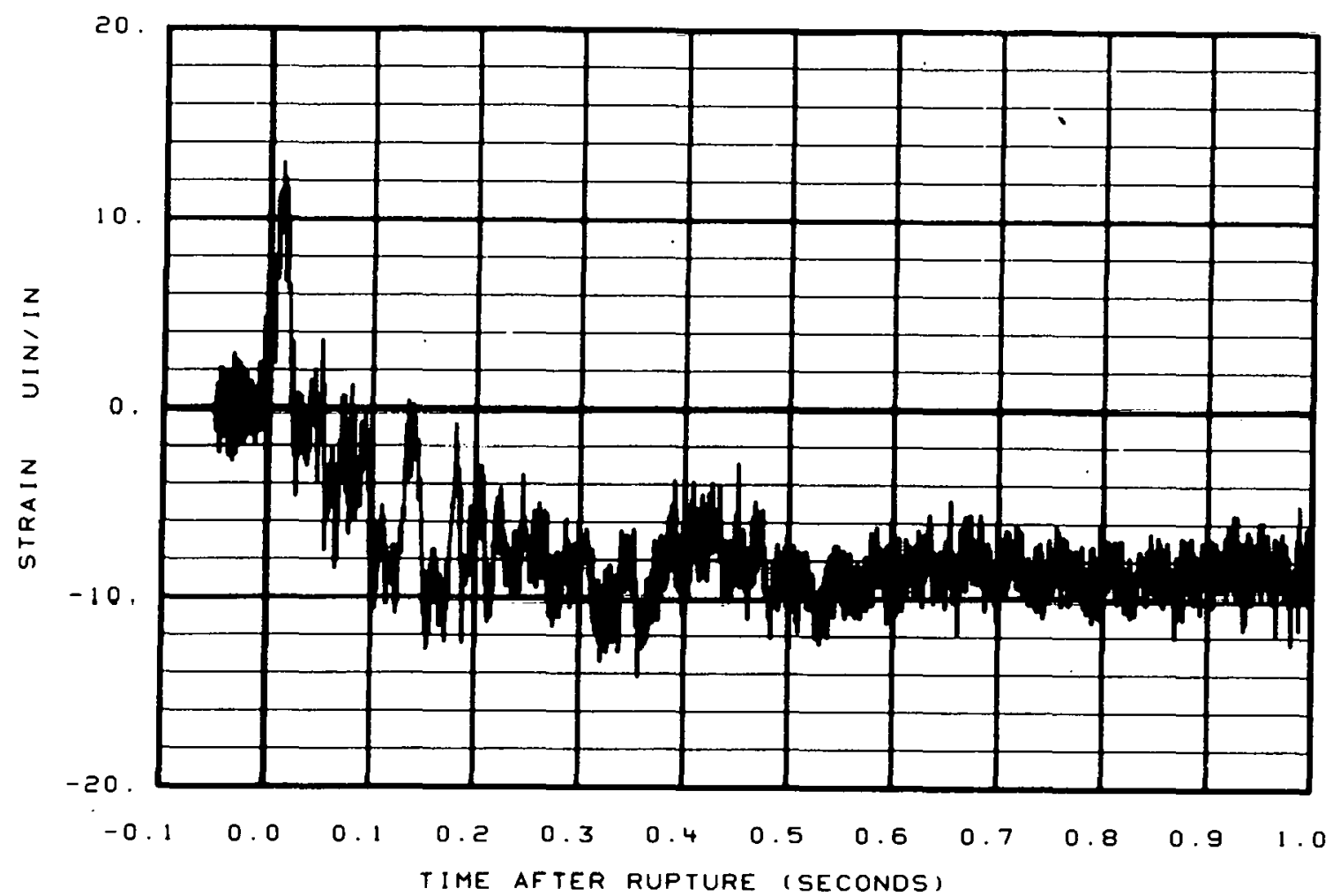

Fig. 142 Strain at steam generator inlet nozzle (SE-PC14-4).

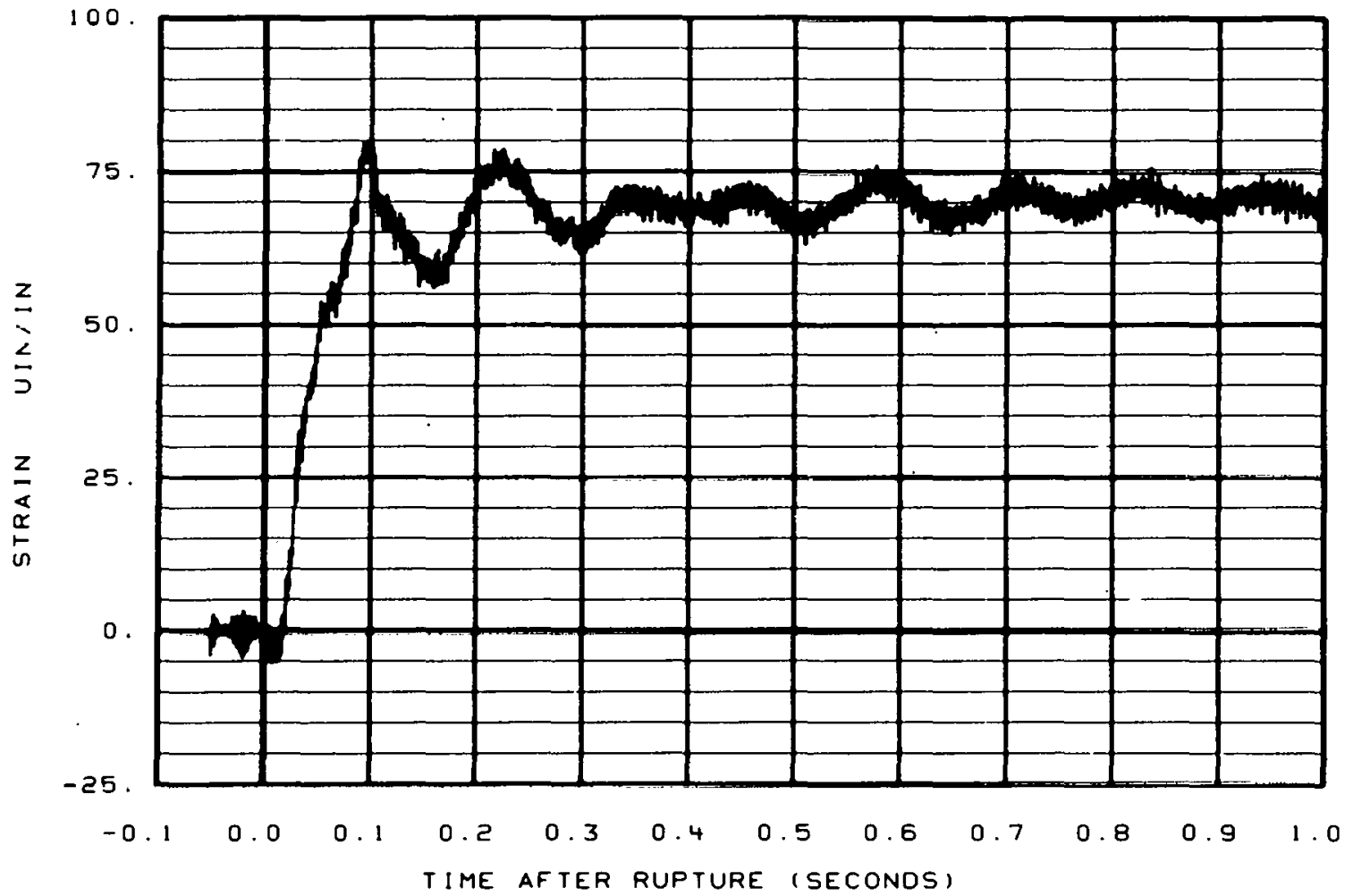

Fig. 143 Strain at steam generator inlet nozzle (SE-PC14-5). 


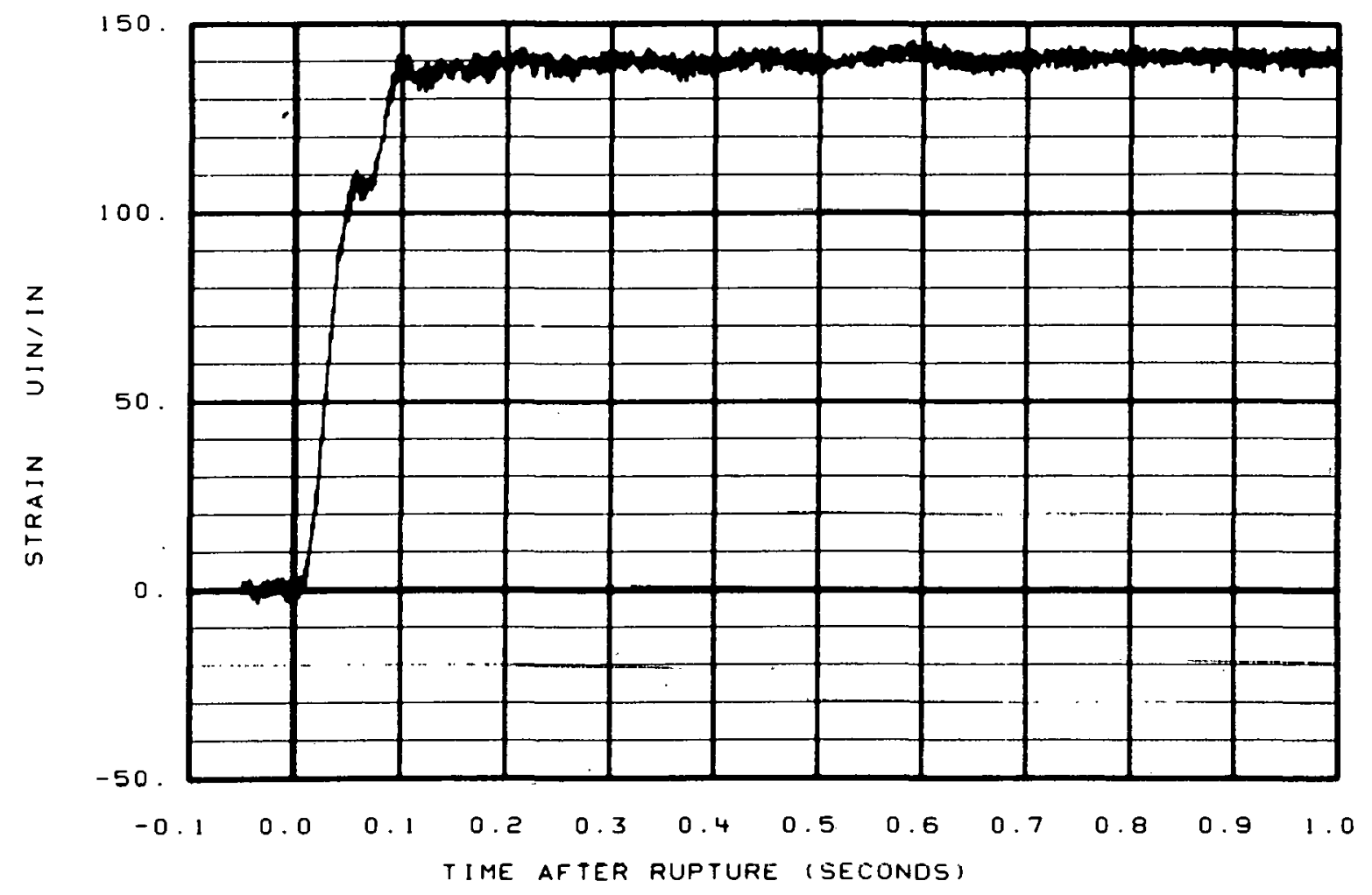

Fig. 144 Strain at steam generator inlet nozzle (SE-PC14-6).

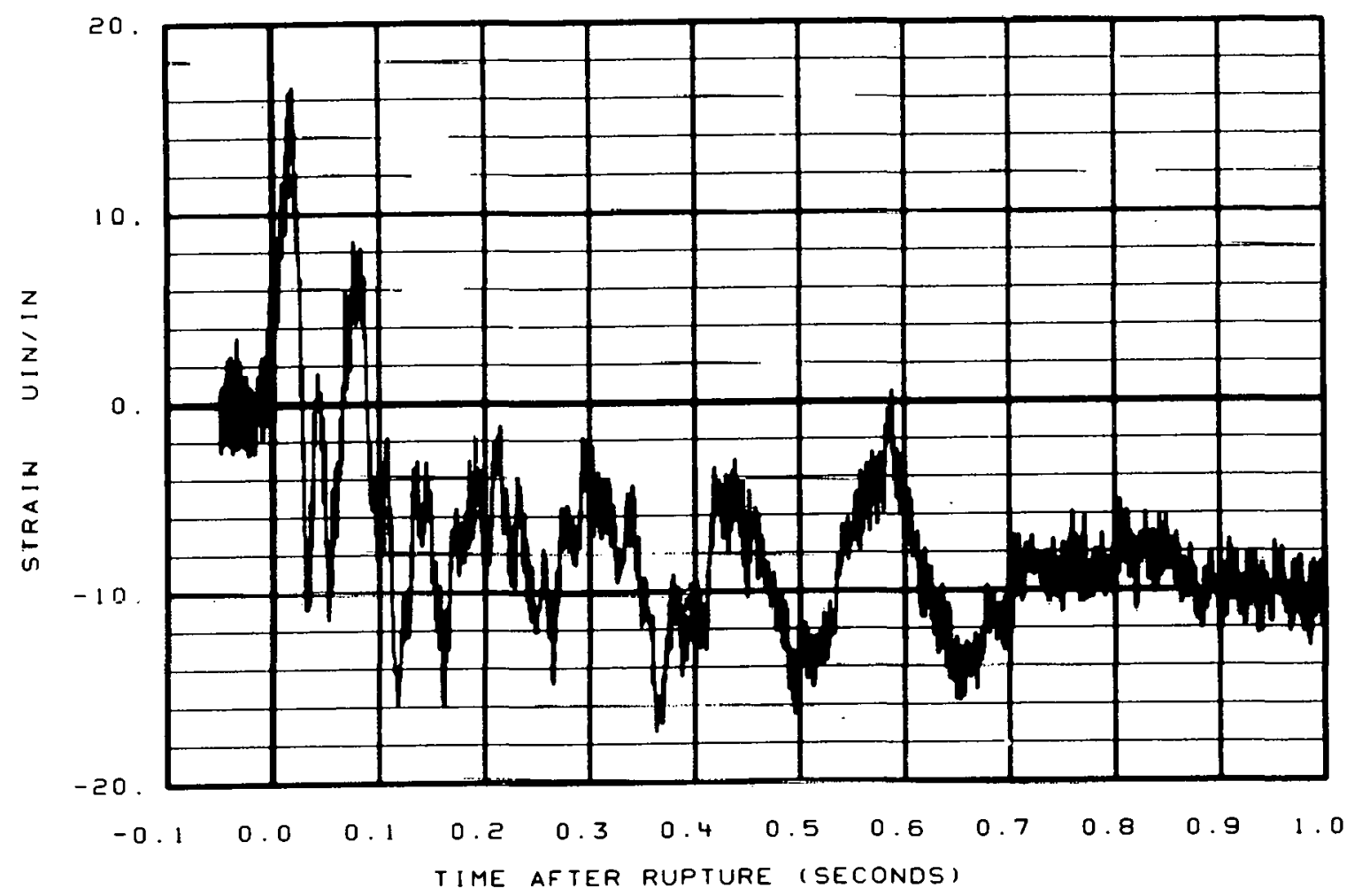

Fig. 145 Strain at steam generator inlet nozzle (SE-PC14-7). 


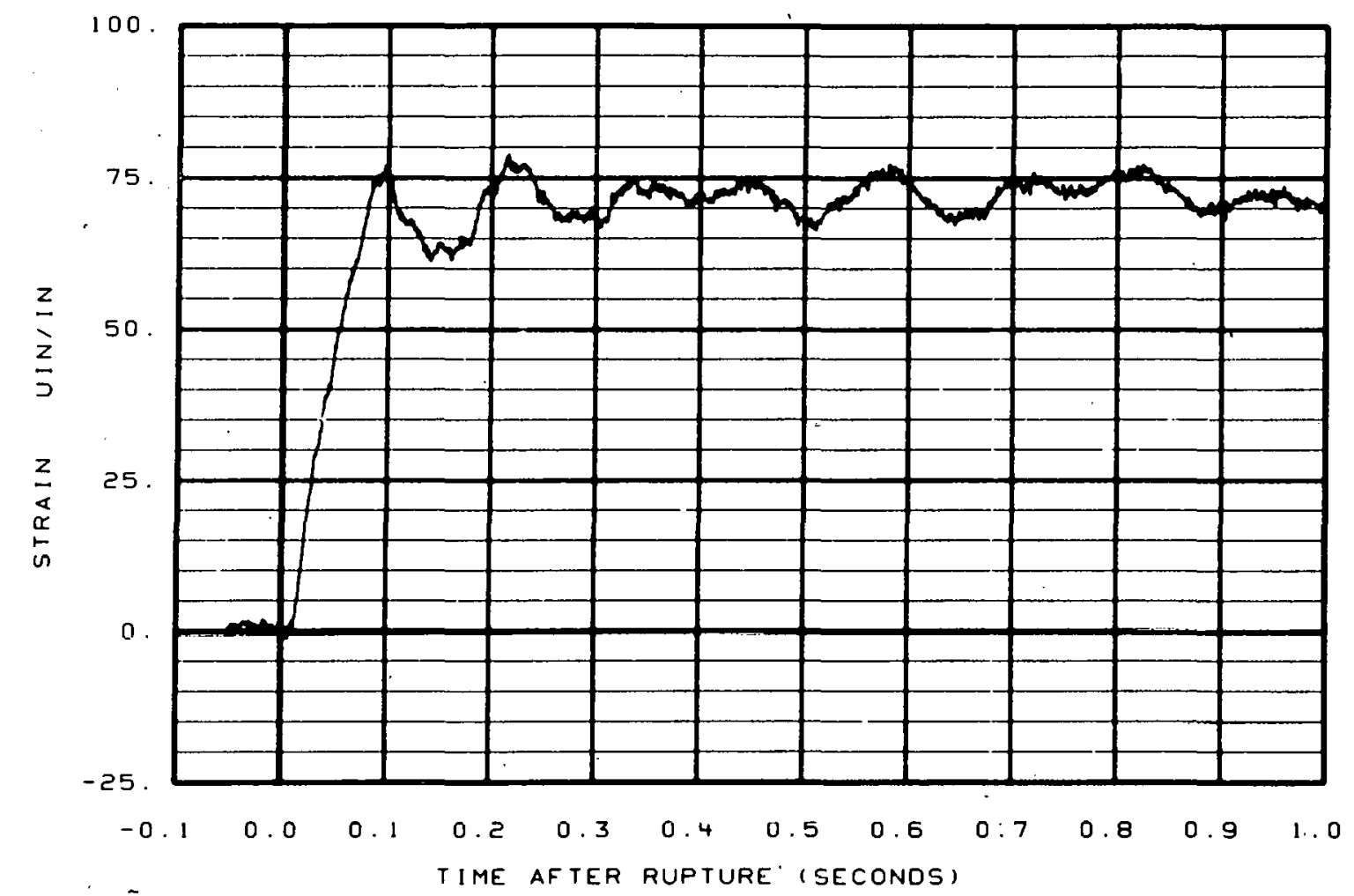

Fig. 146 Strain at steam generator inlet nozzle (SE-PC14-8).

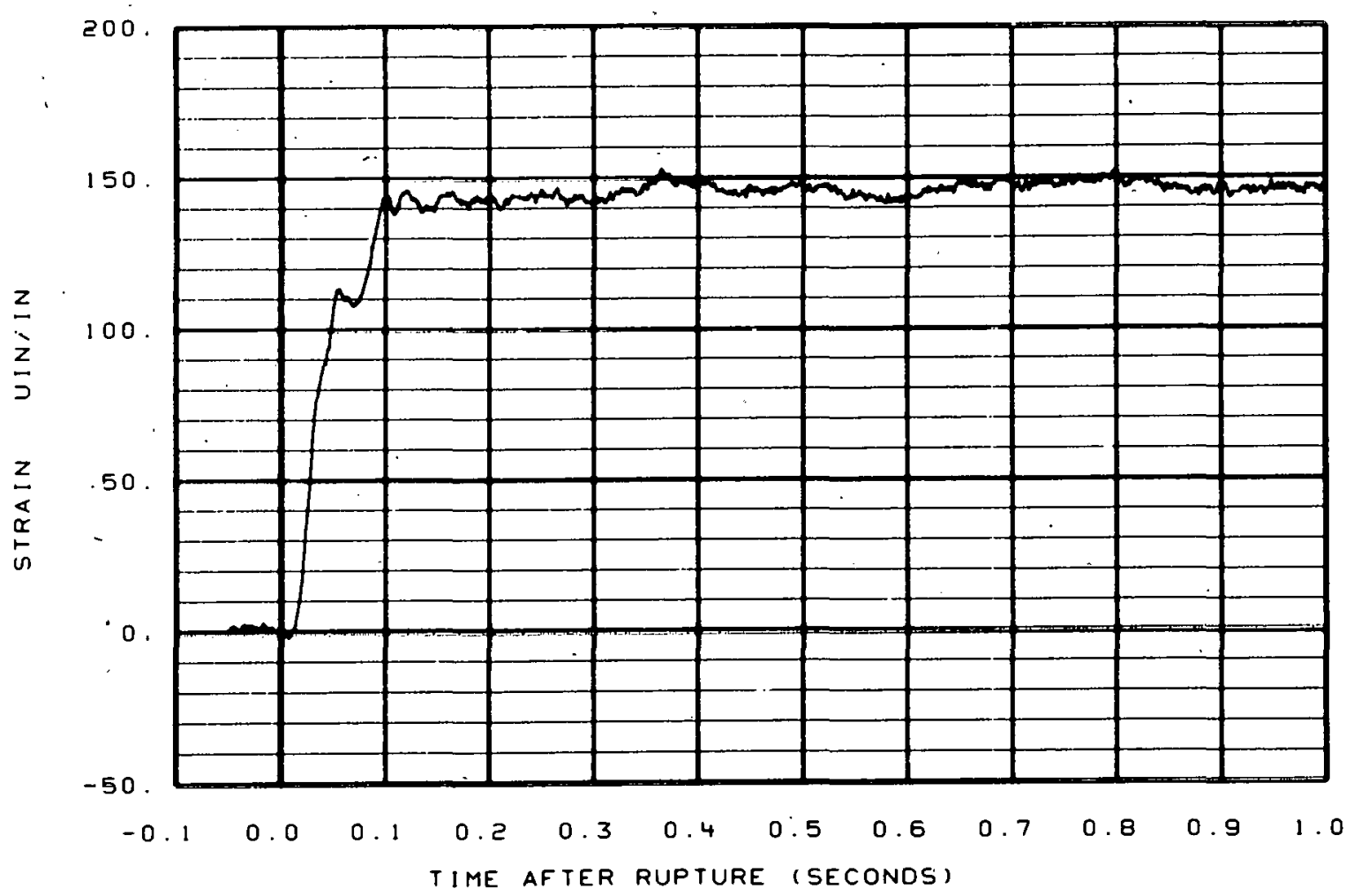

Fig. 147 Strain at steam generator inlet nozzle (SE-PC14-9). 


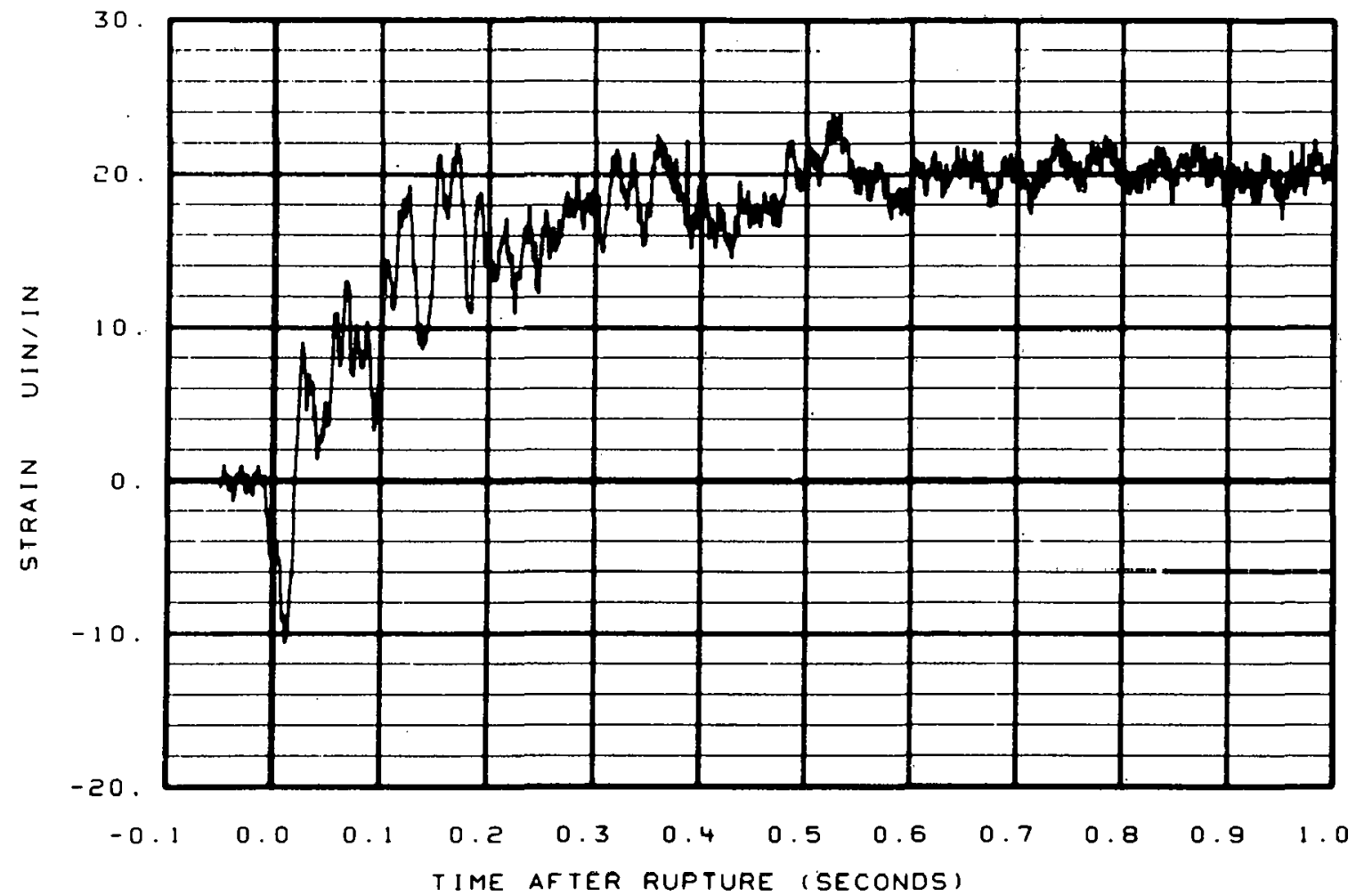

Fig. 148 Strain at steam generator inlet nozzle (SE-PC14-10).

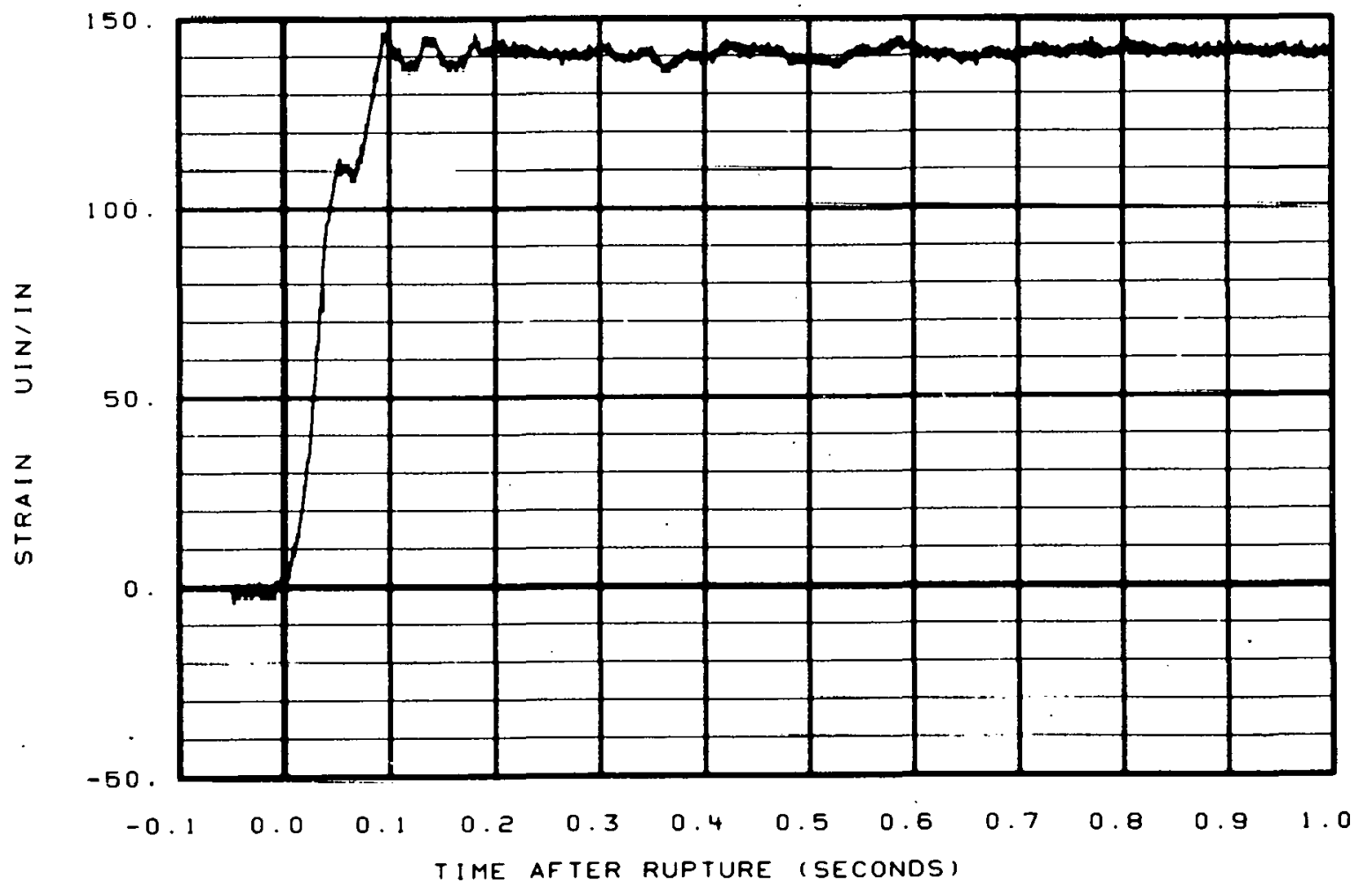

Fig. 149 Strain at steam generator inlet nozzle (SE-PC14-12). 


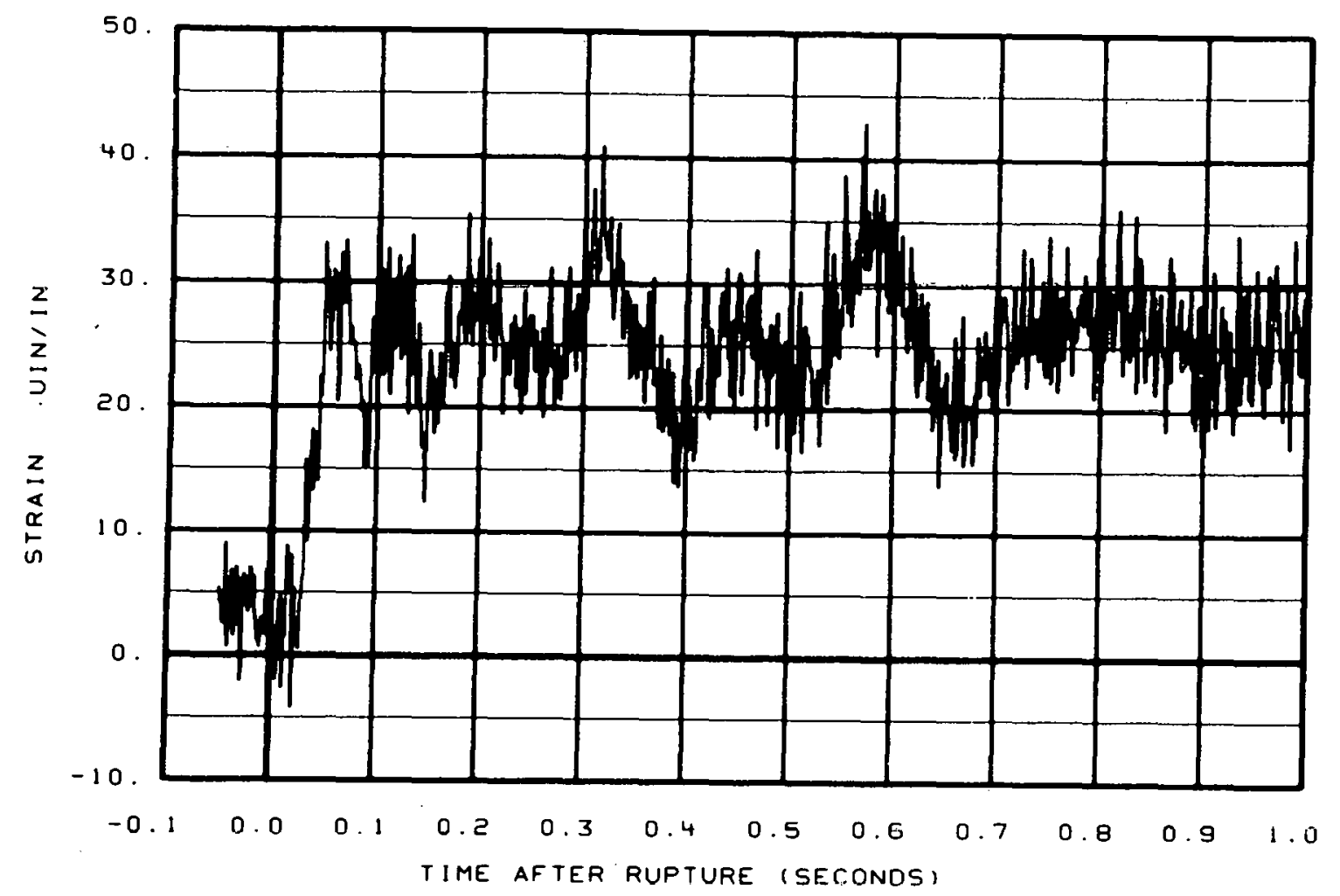

Fig. 150 Strain at steam generator outlet nozzle (SE-PC15-1).

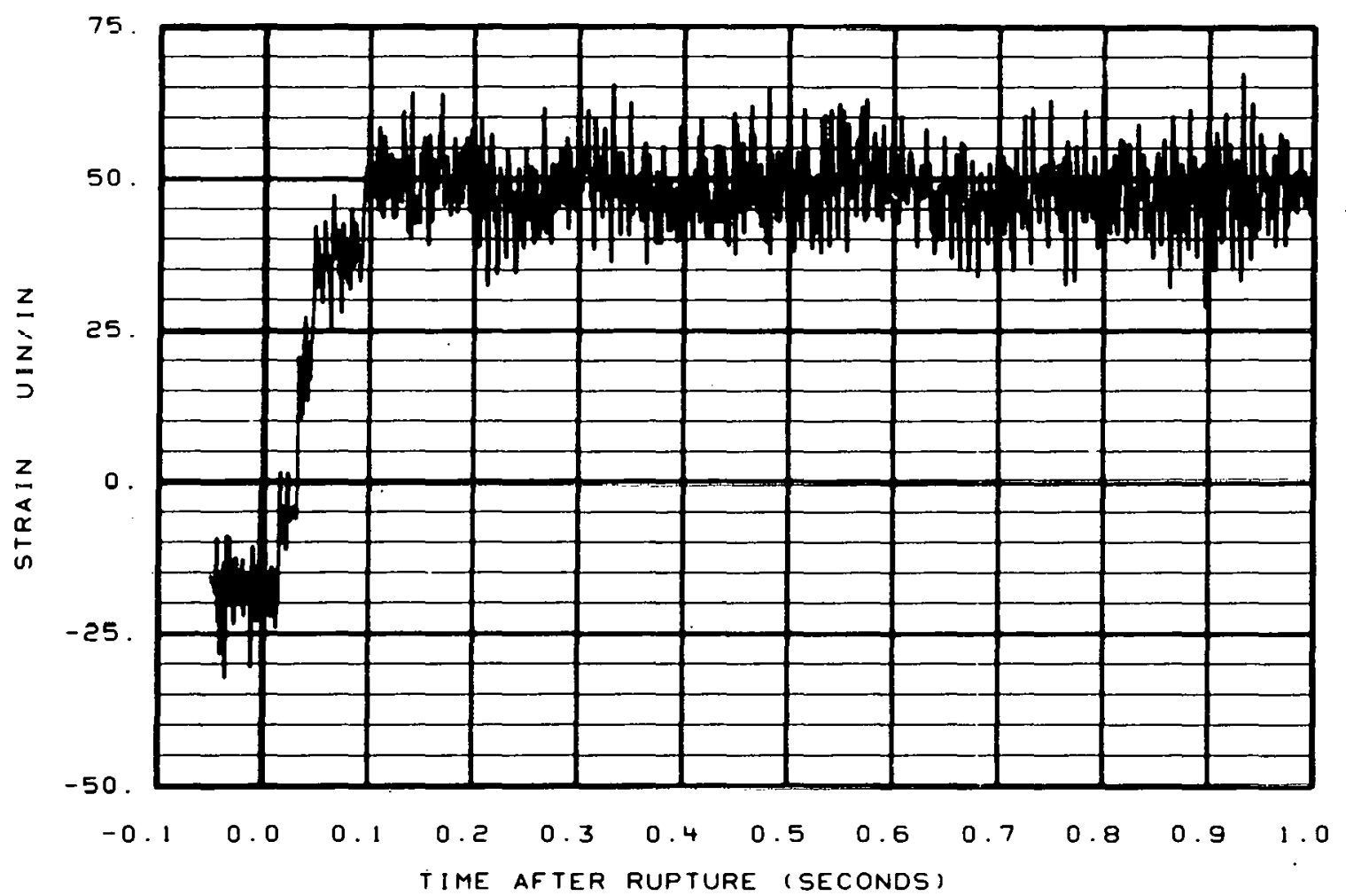

Fig. 151 Strain at steam generator outlet nozzle (SE-PC15-2). 


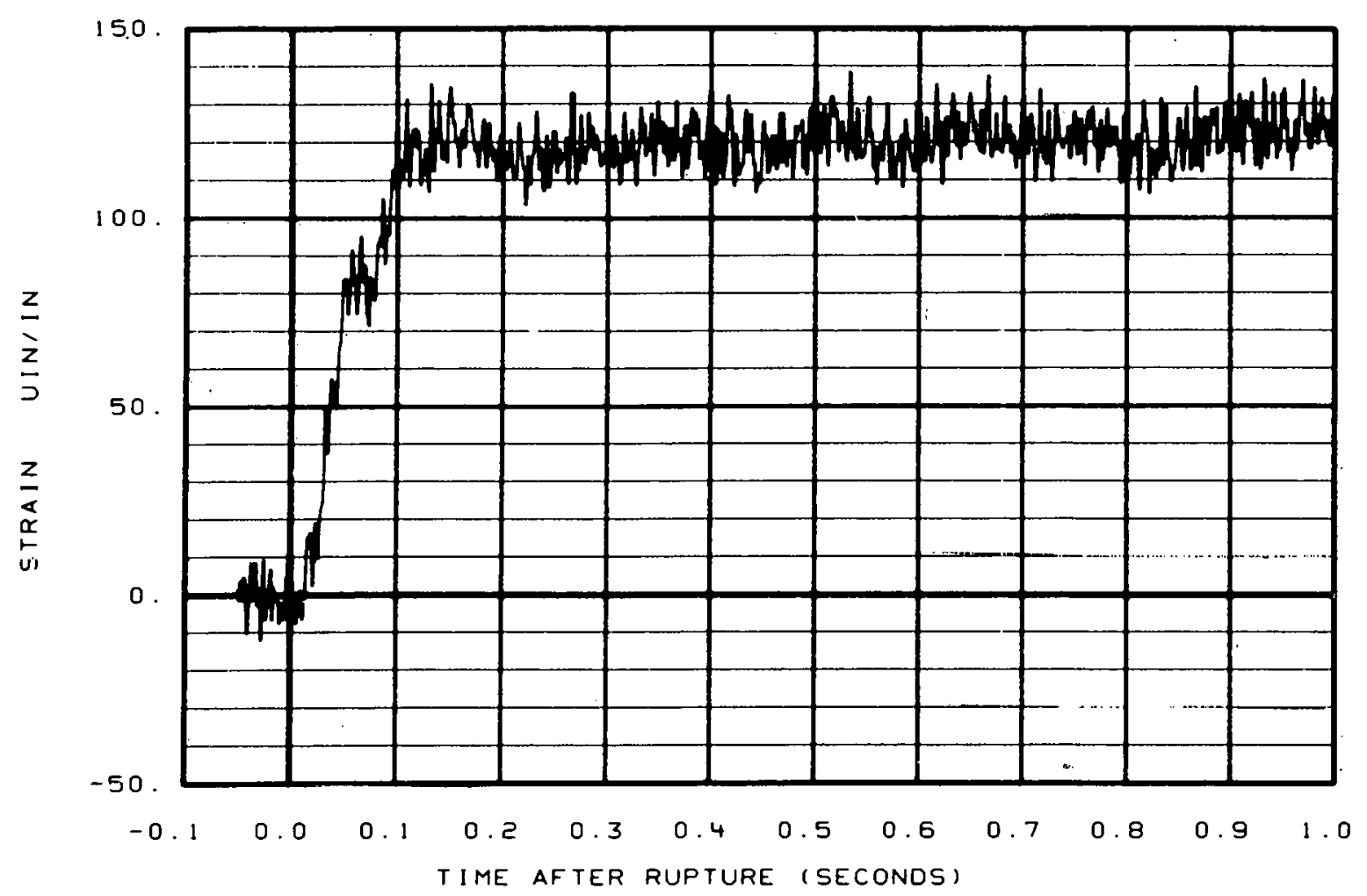

Fig. 152 Strain at steam generator outlet nozzle (SE-PC15-3).

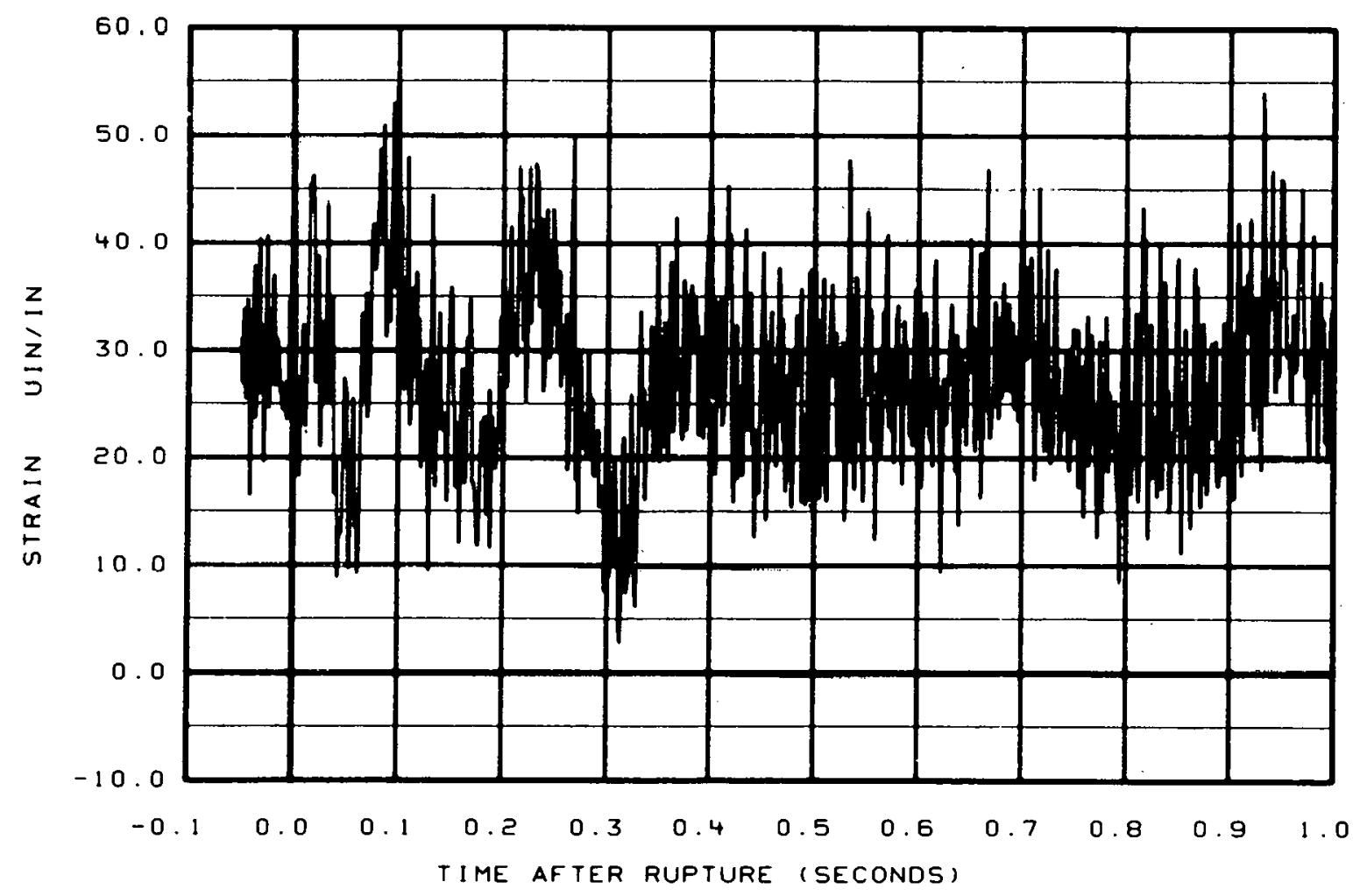

Fig. 153 Strain at steam generator outlet nozzle (SE-PC15-4). 


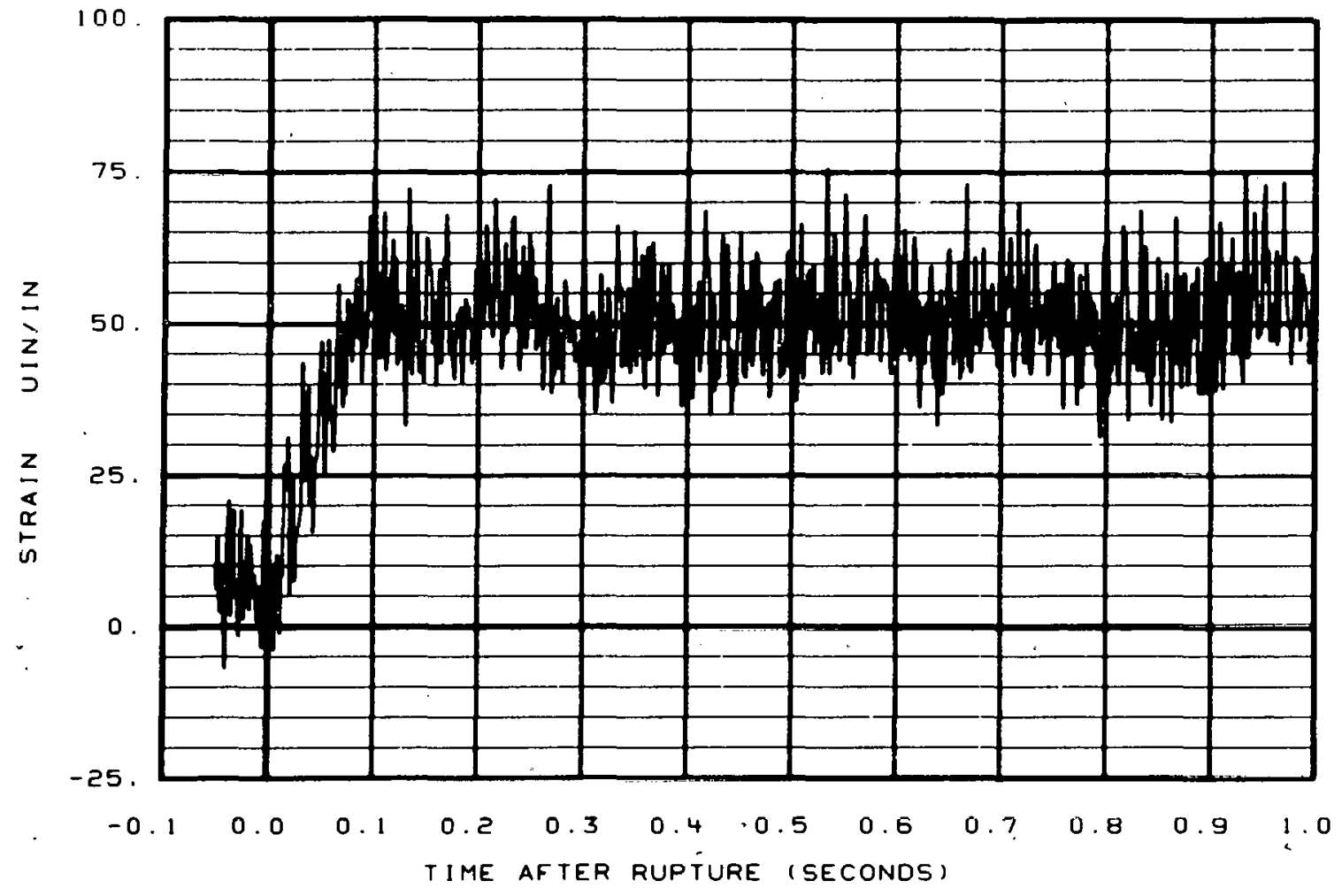

Fig. 154 Strain at steam generator outlet nozzle (SE-PC15-5).

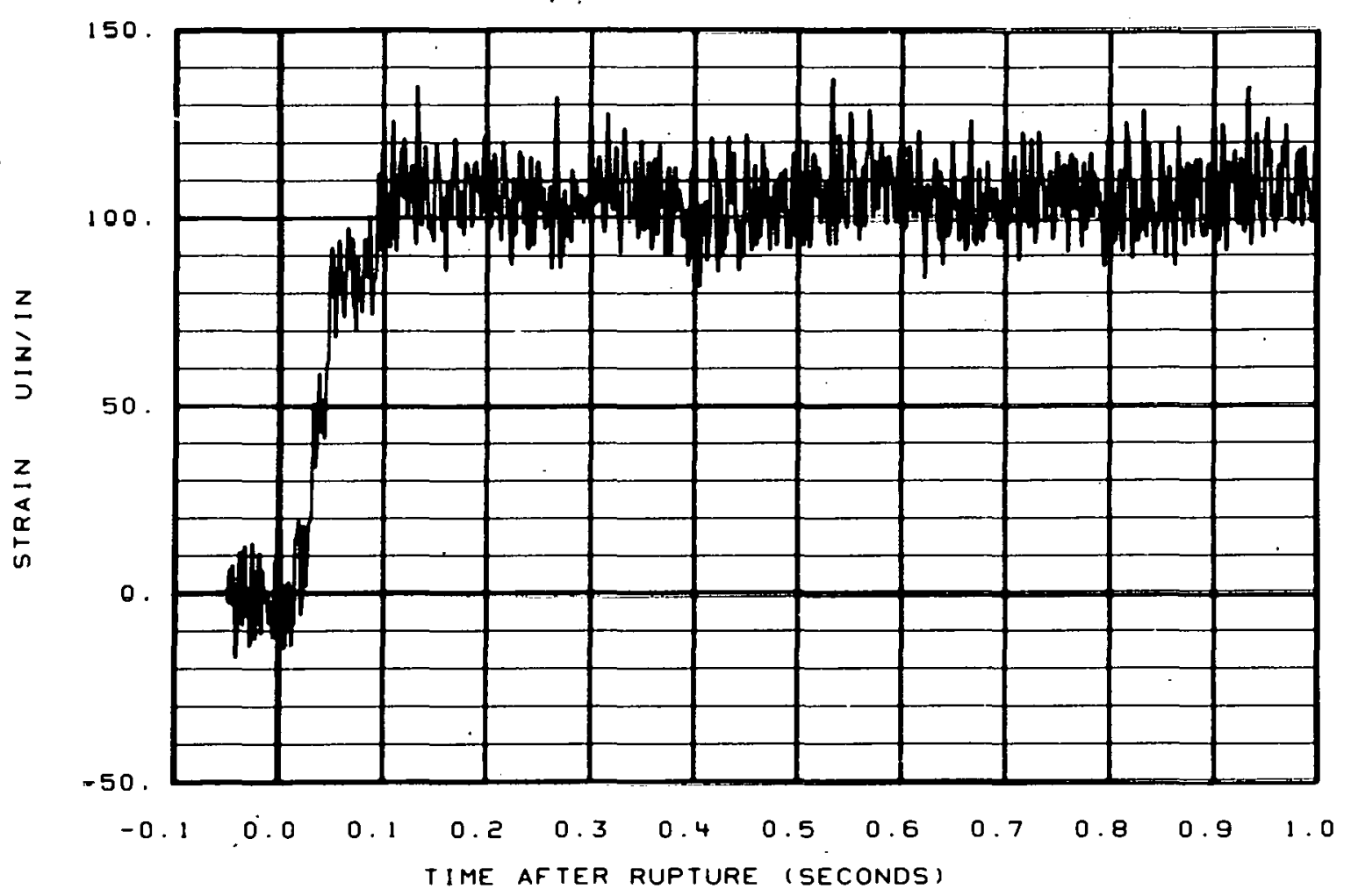

Fig. 155 Strain at steam generator outlet nozzle (SE-PC15-6). 


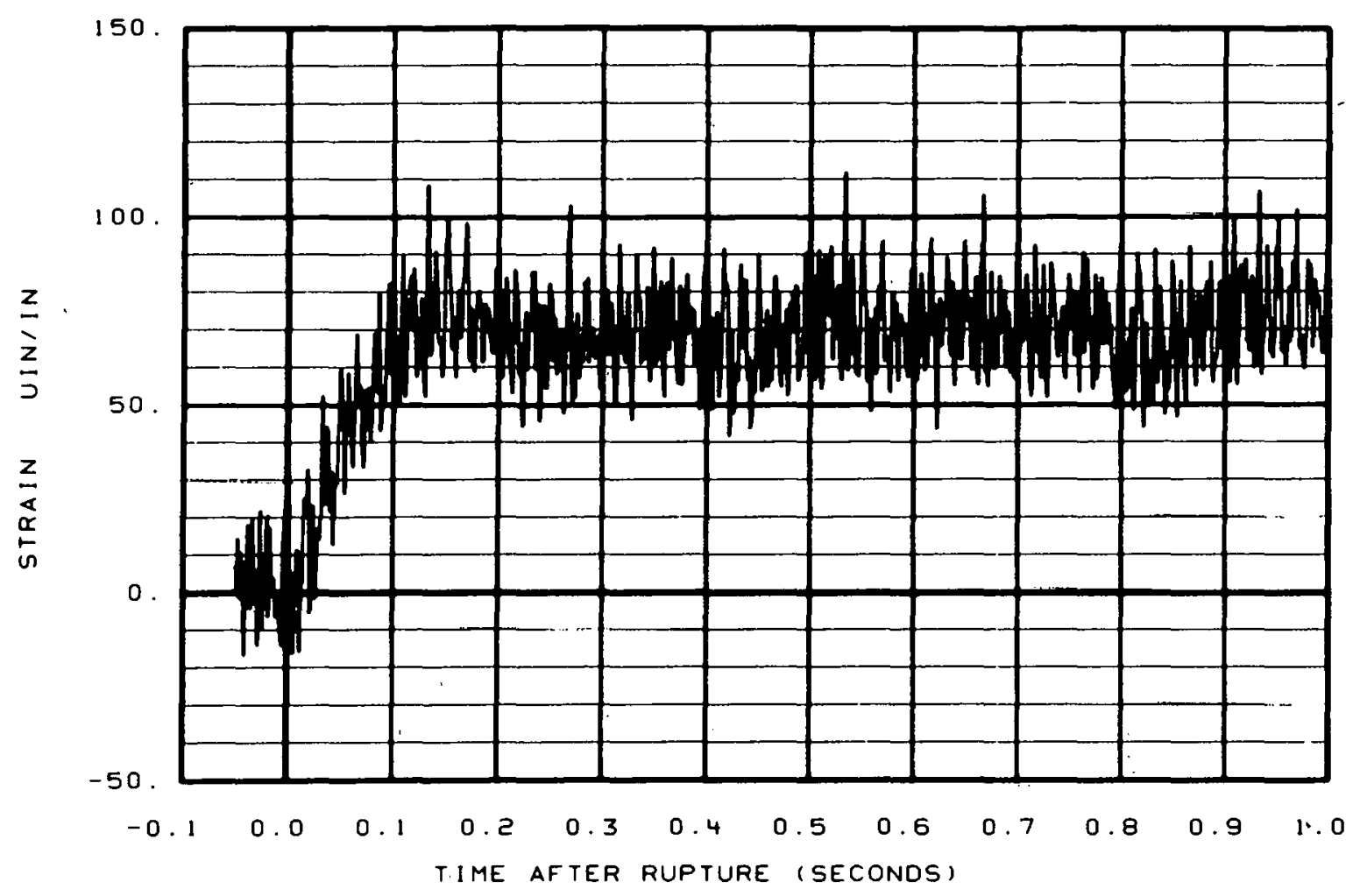

Fig. 156 Strain at steam generator outlet nozzle (SE-PC15-8).

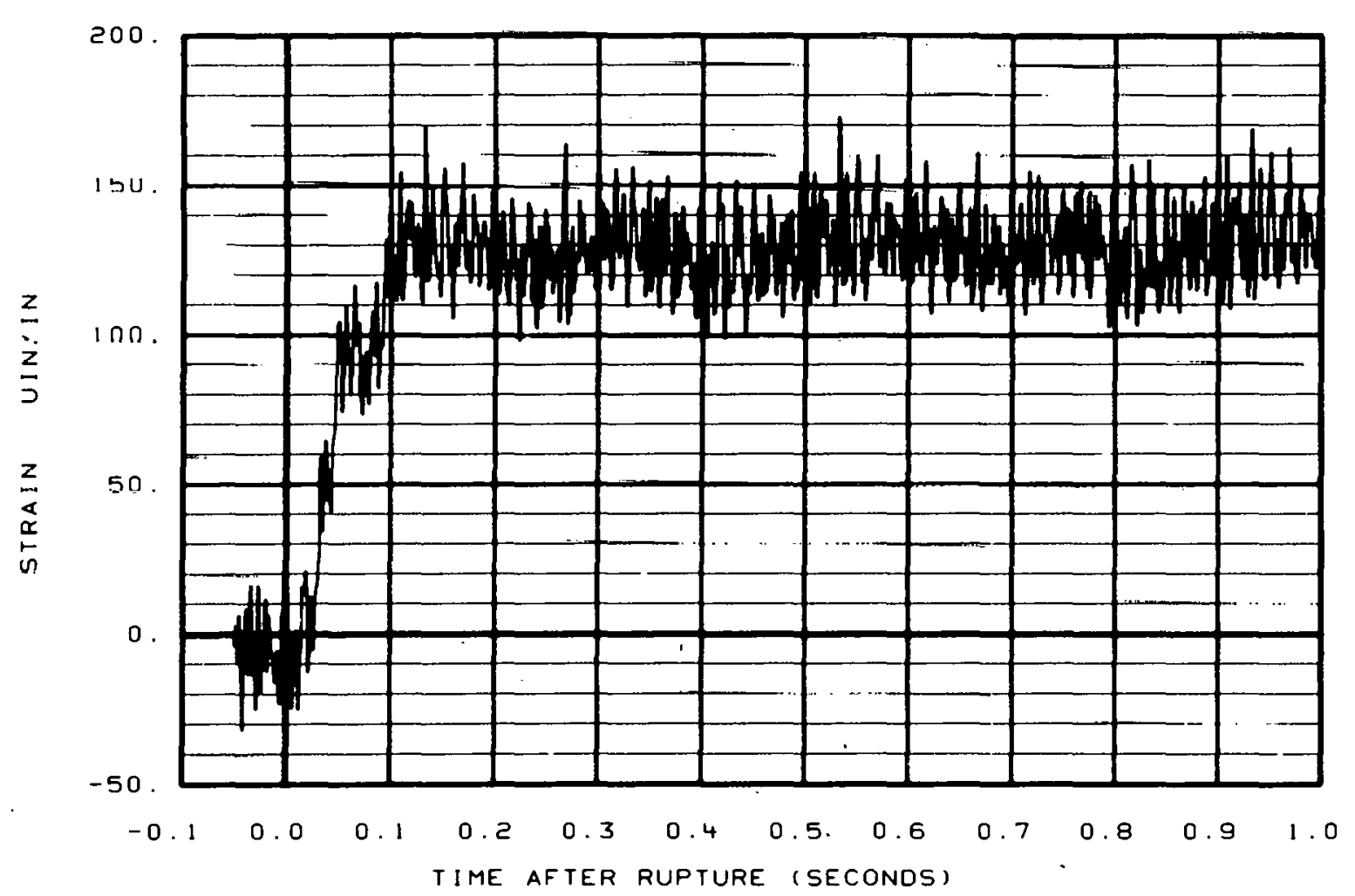

Fig. 157 Strain at steam generator outlet nozzle (SE-PC15-9). 


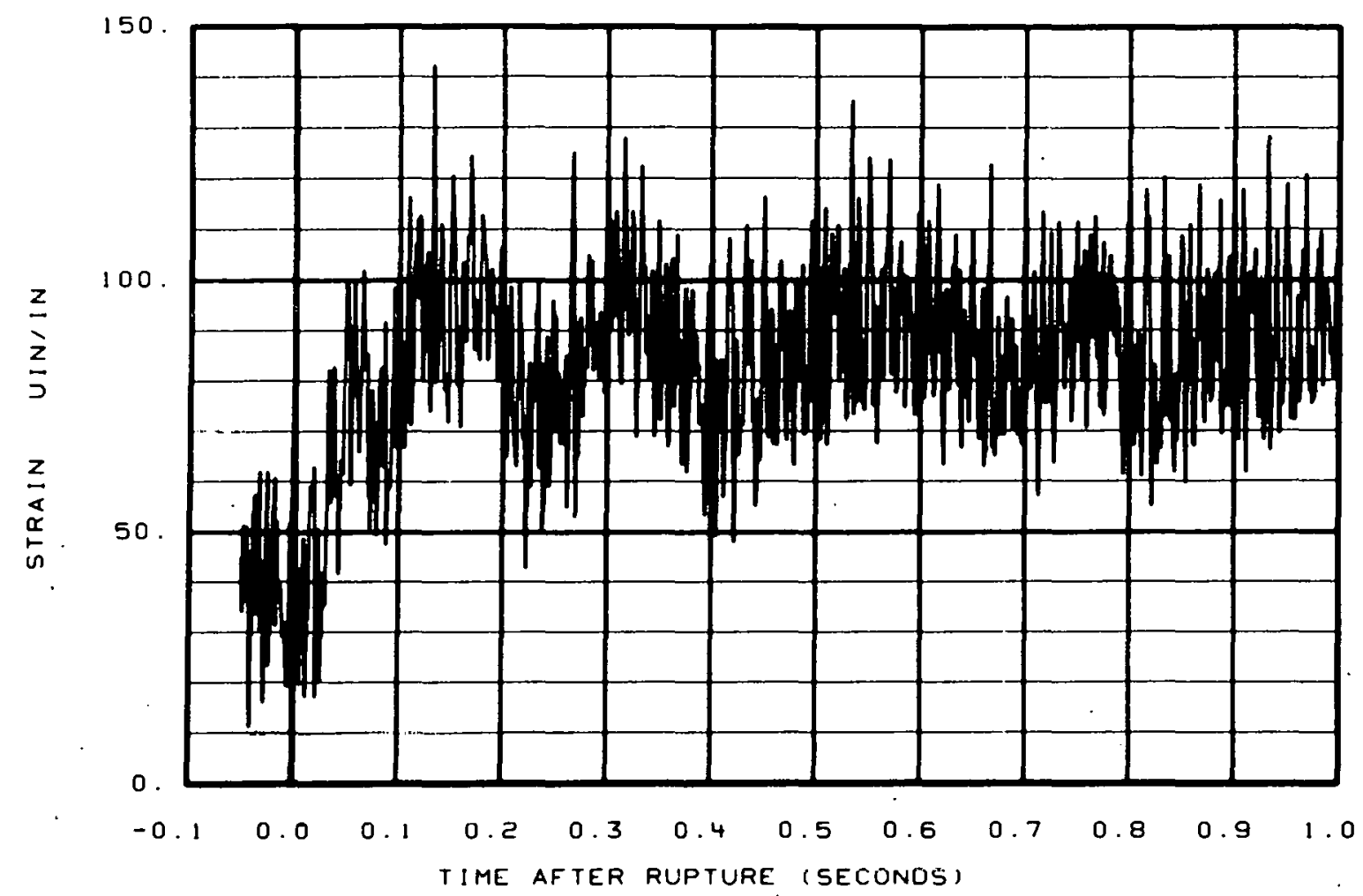

Fig. 158 Strain at steam generator outlet nozzle (SE-PC15-10).

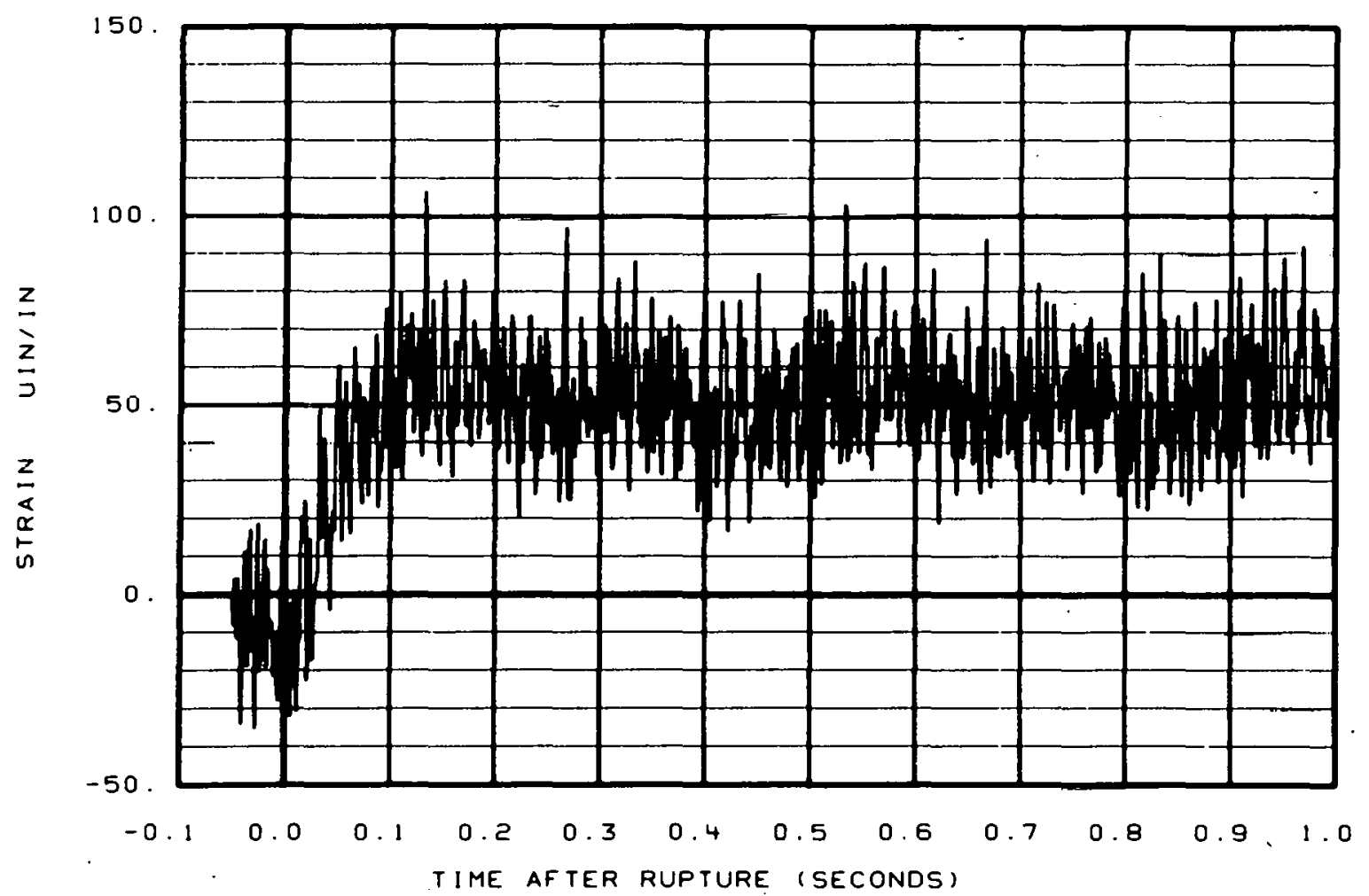

Fig. 159 Strain at stèam generator out.let nozzle (SE-PC15-11). 


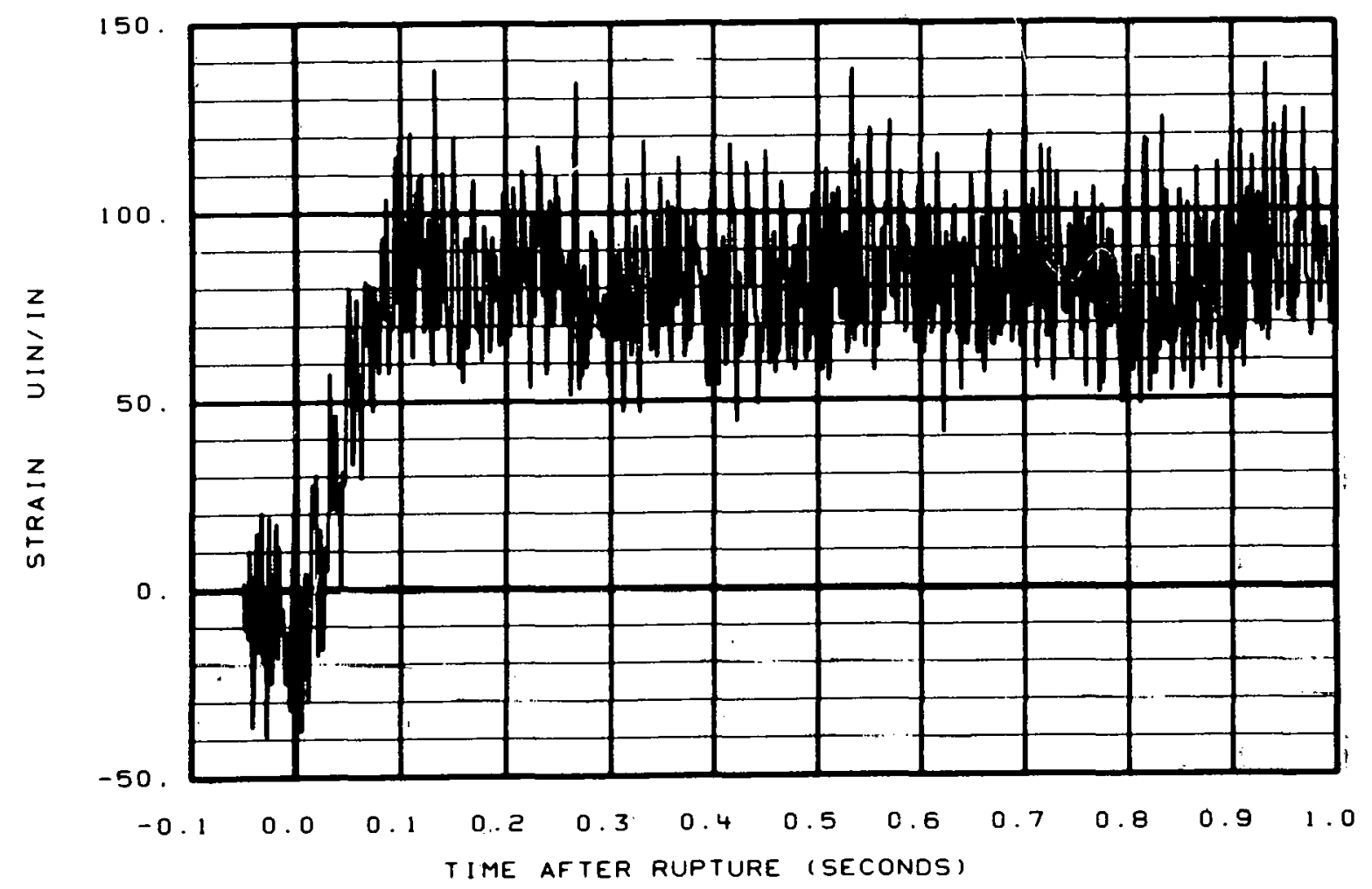

Fig. 160 Strain at steam generator outlet nozzle (SE-PC15-12).

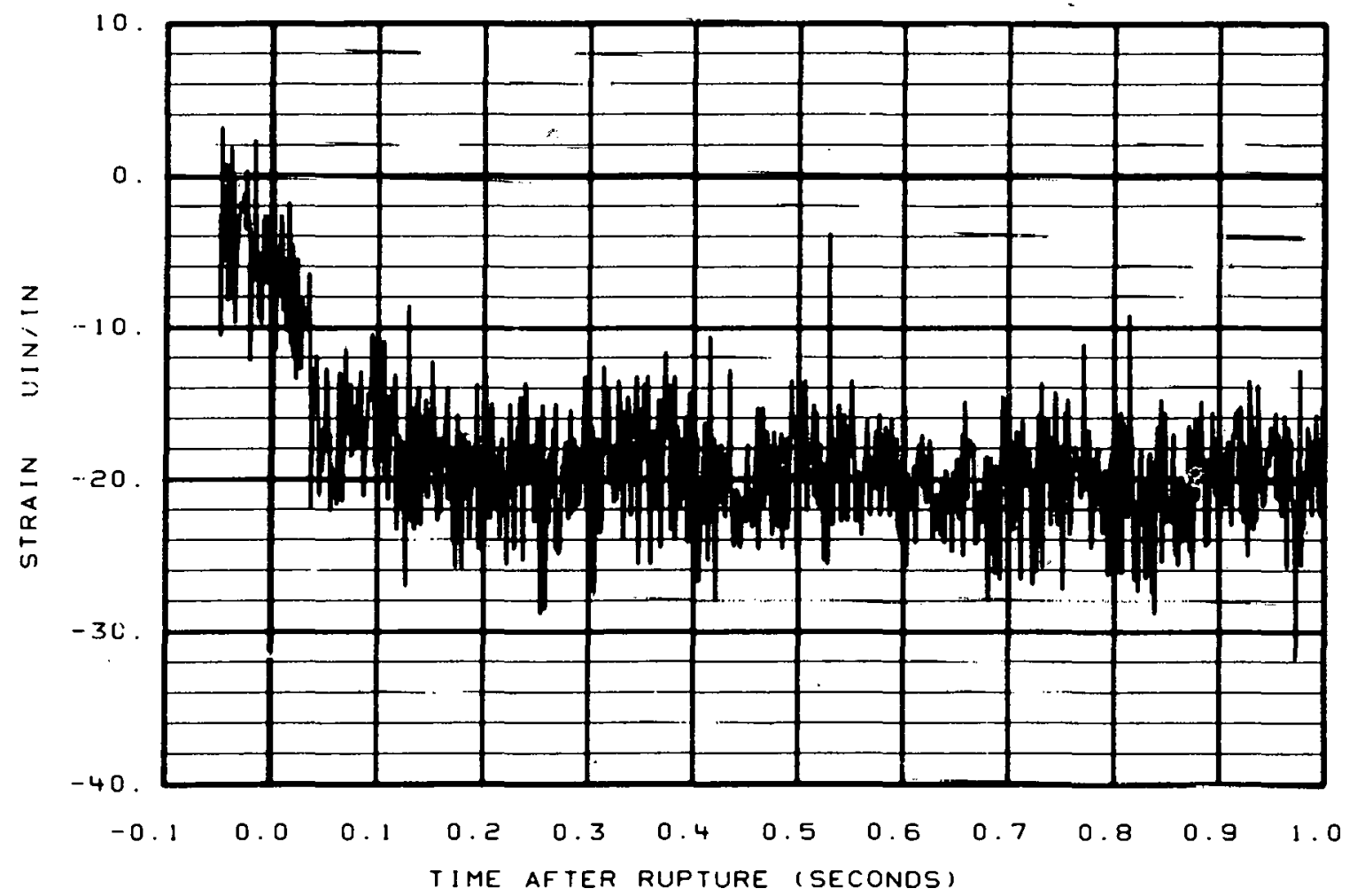

Fig. 161 Strain at primary coolant pumip. outlet (SE-PC18-13). 


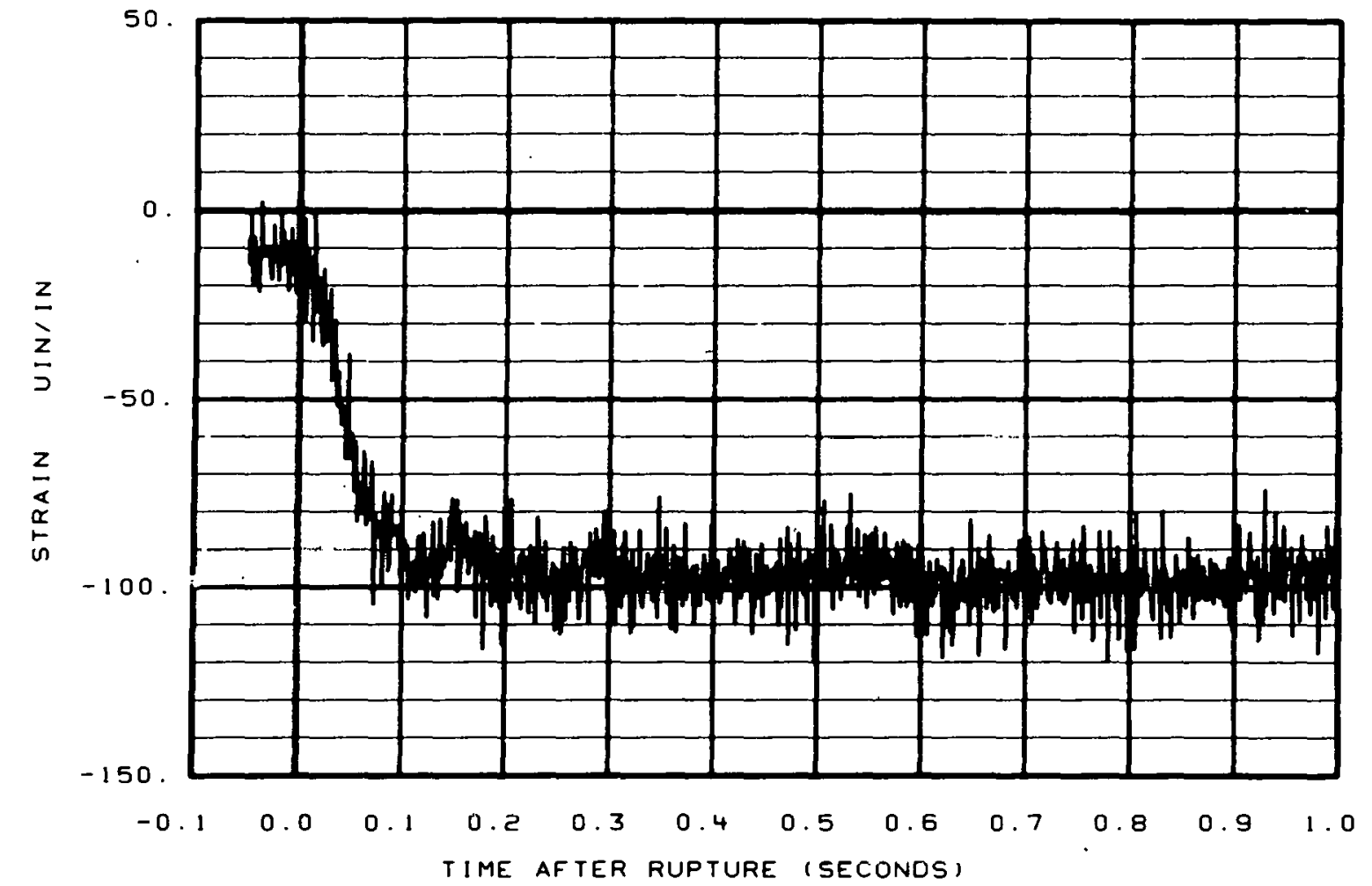

Fig. 162 Strain at primary coolant pump outlet (SE-PC18-14).

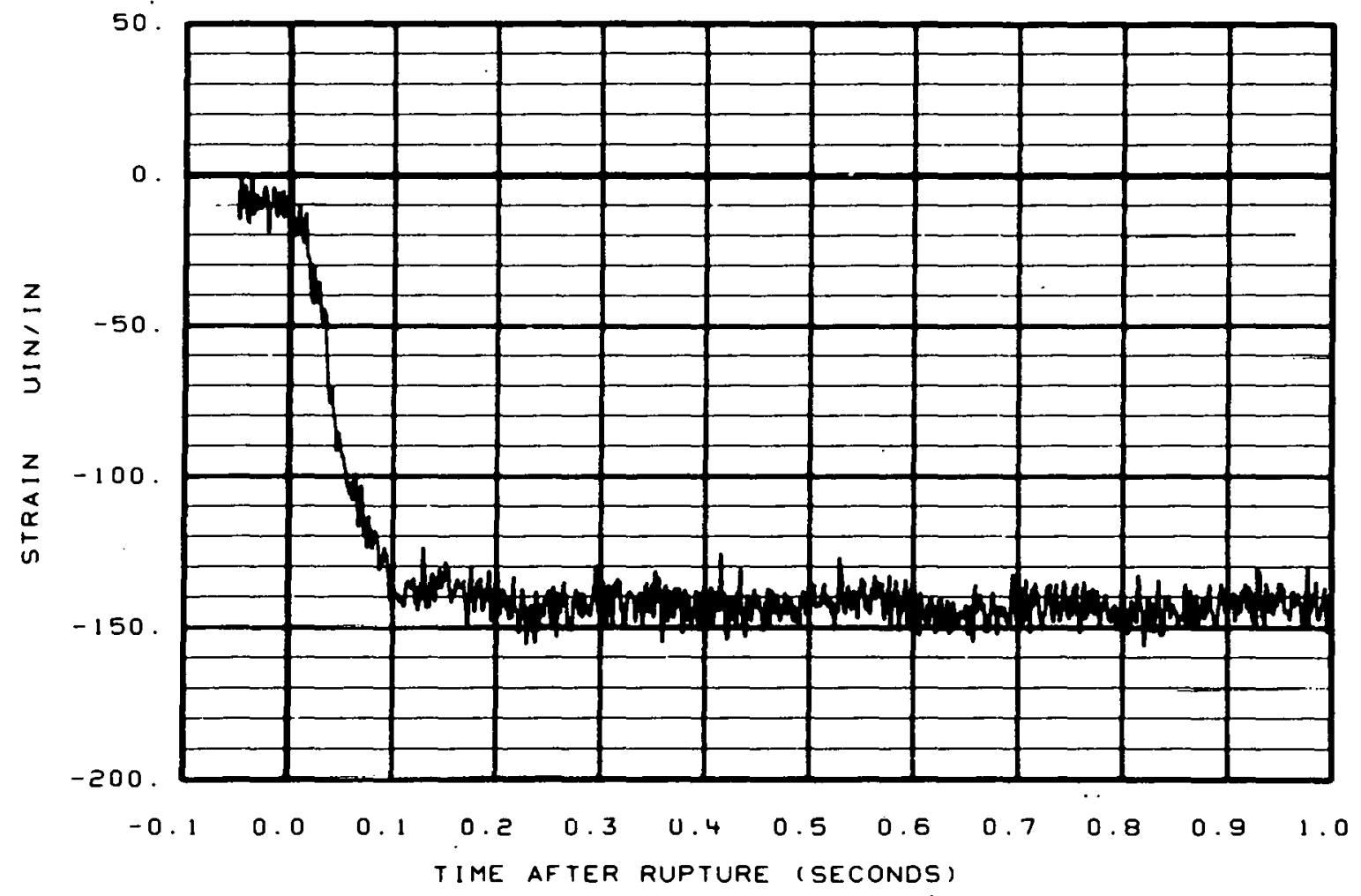

Fig. 163 Strain at primary coolant pump outlet (SE-PC18-15). 


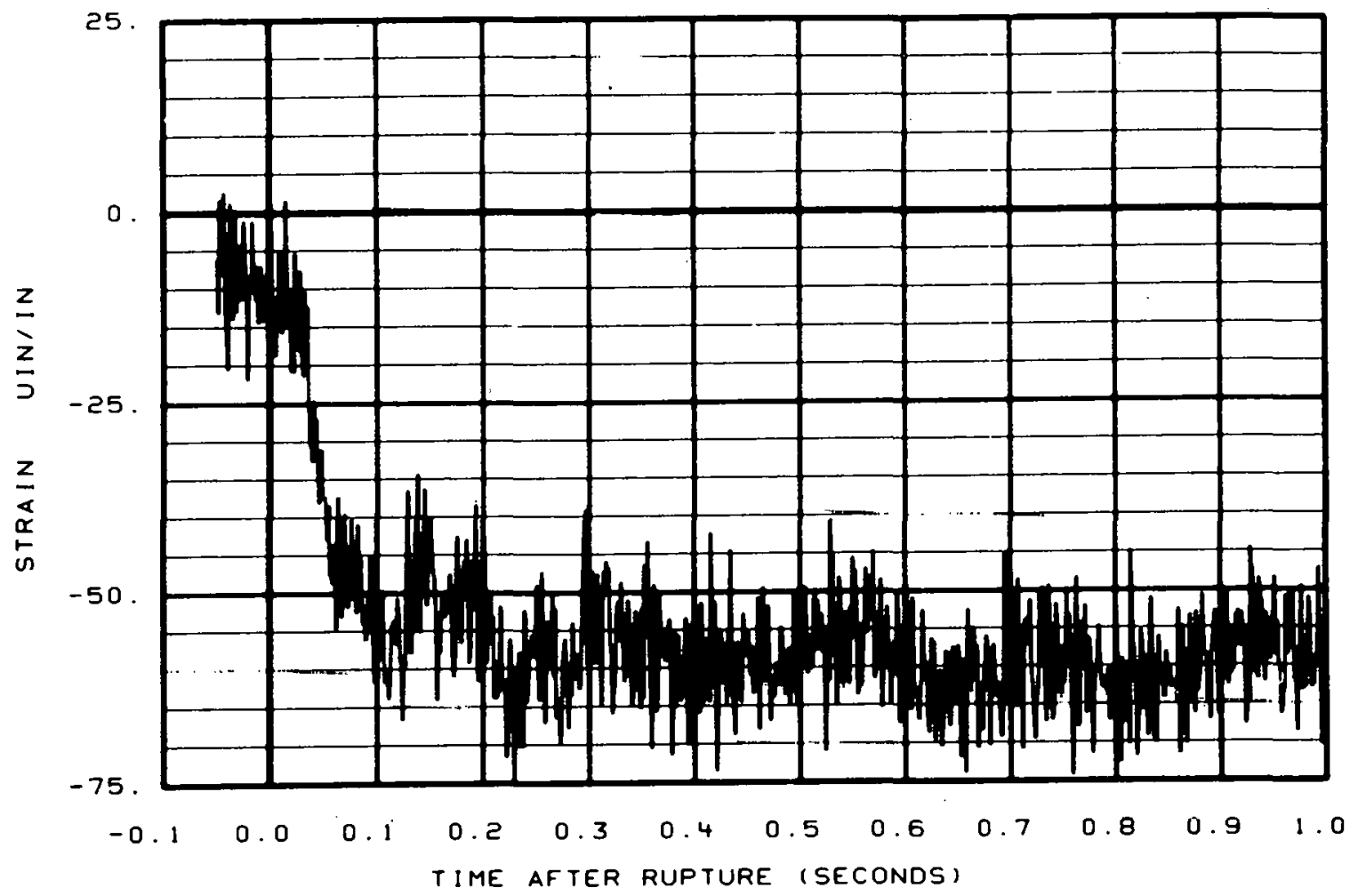

Fig. 164 Strain at primary coolant pump outlet (SE-PC18-16).

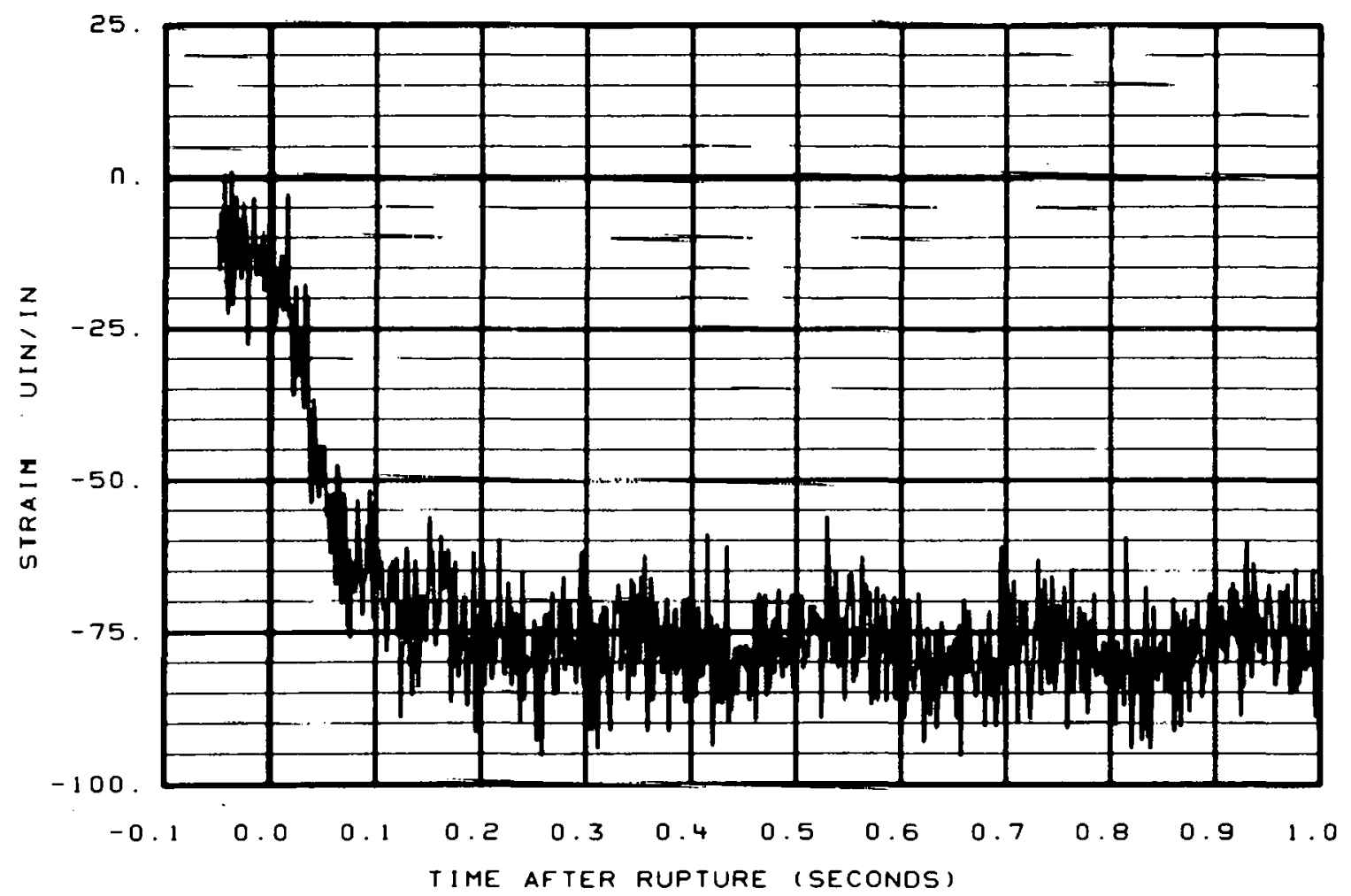

Fig. 165 Strain at primary coolant pump outlet (SE-PC.18-17). 


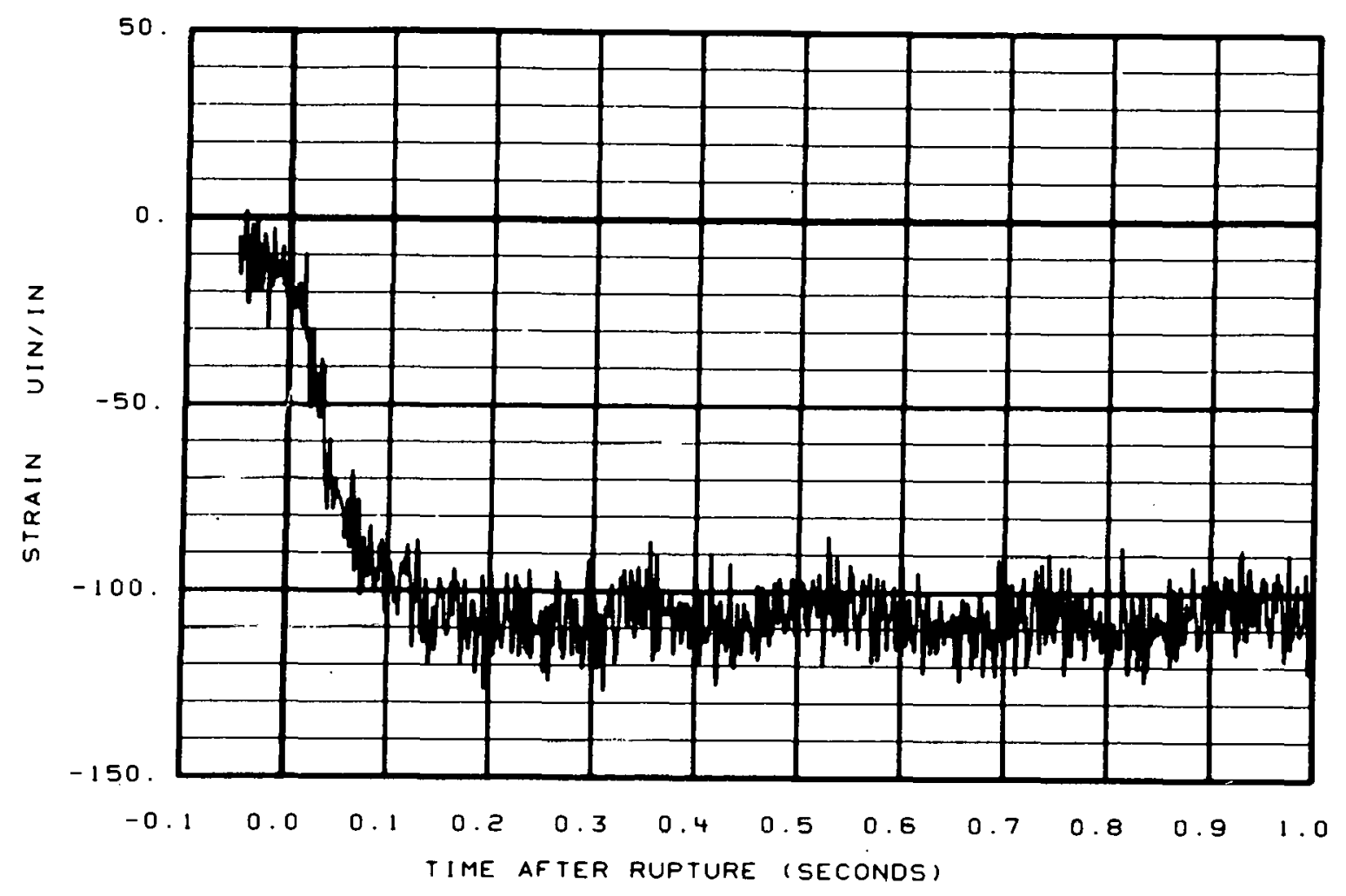

Fig. 166 Strain at primary coolant pump outlet (SE-PC18-18).

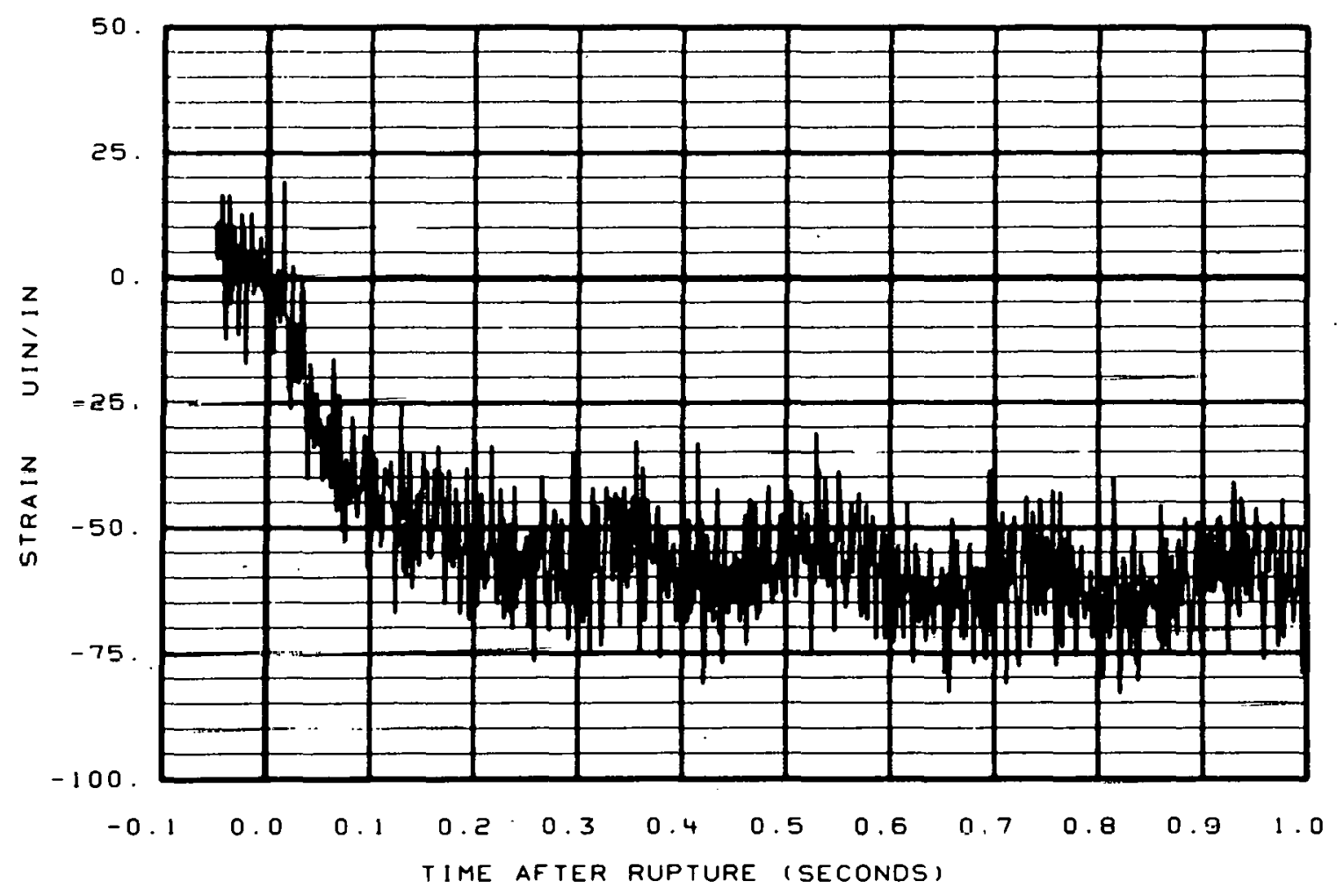

Fig. 167 Strain at primary conlant pump outlet (SE-PC18-19). 


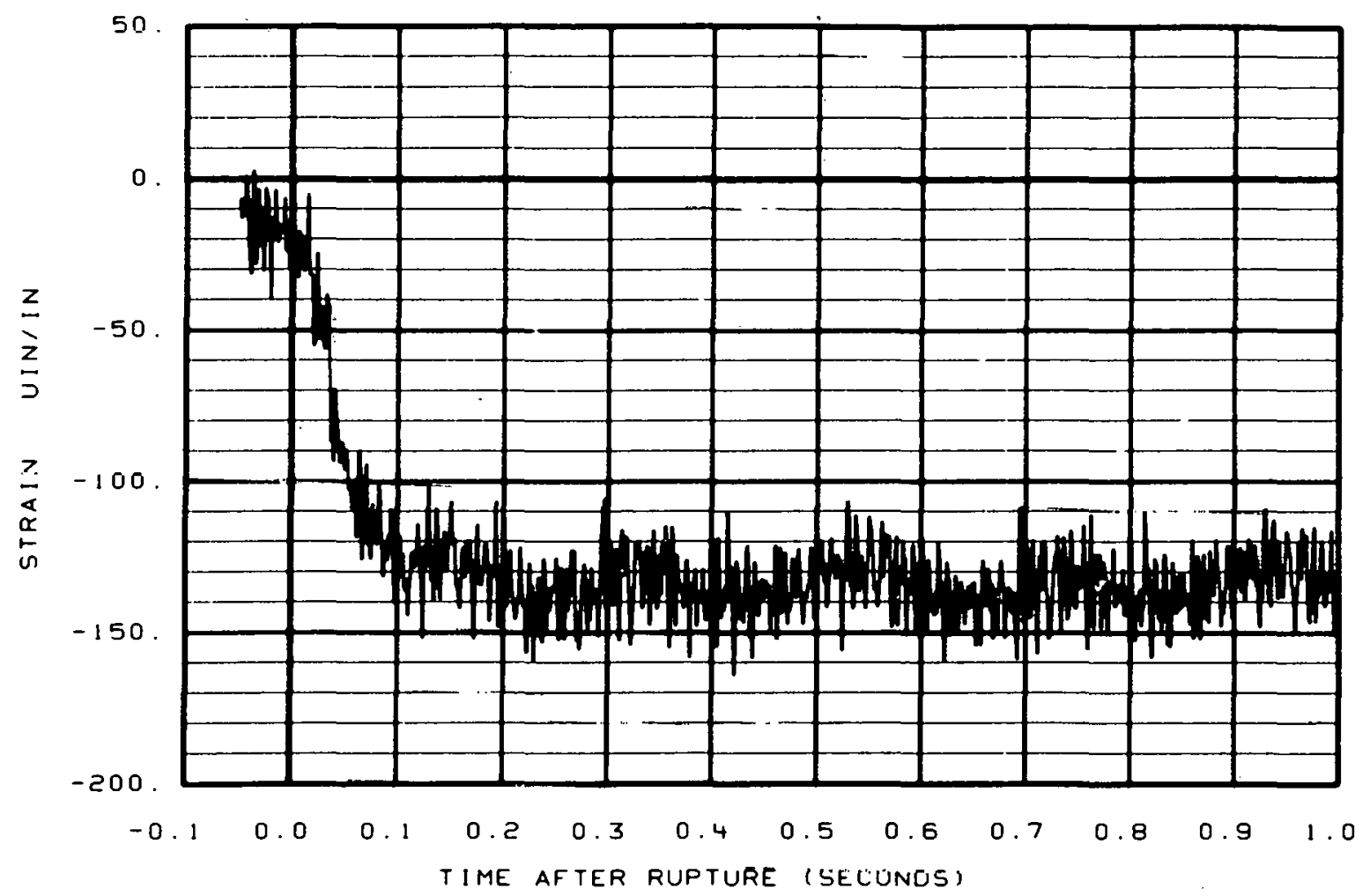

Fig. 168 Strain at primary coolant pump outlet (SE-PC18-21).

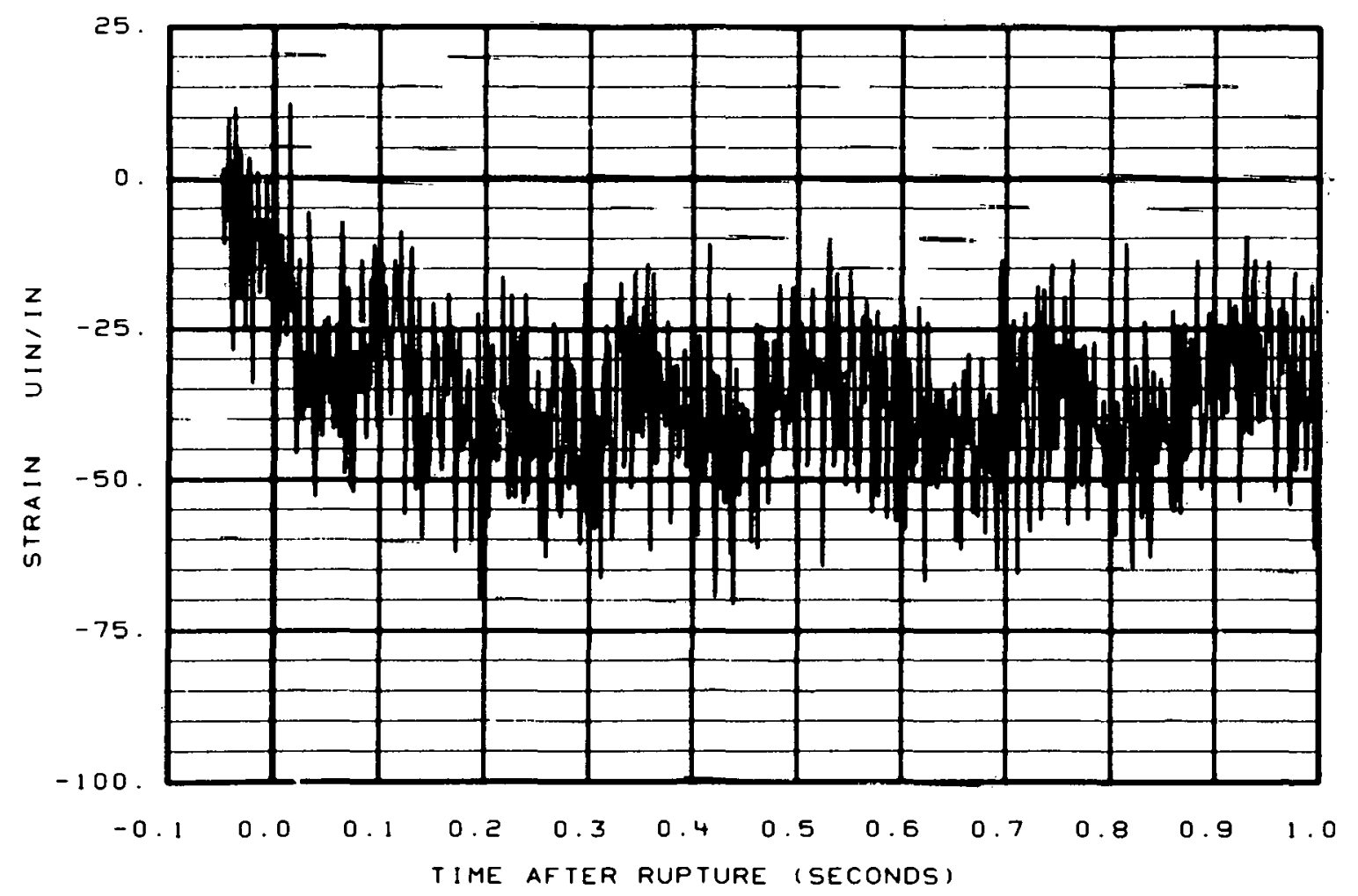

Fig. 169 Strain at primary coolant pump outlet (SE-PC18-22). 


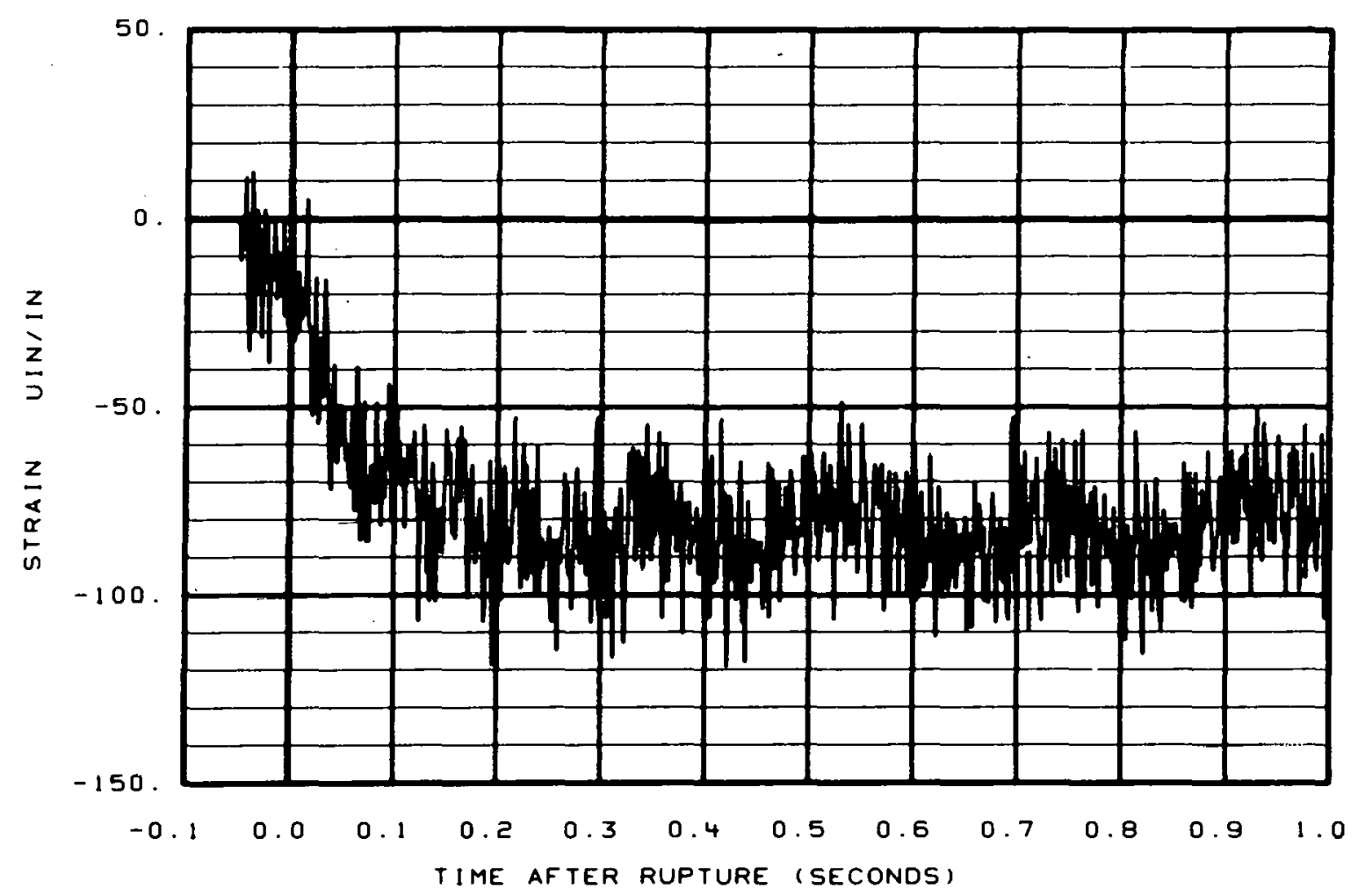

Fig. 170 Strain at primary coolant pump outlet (SE-PC18-23).

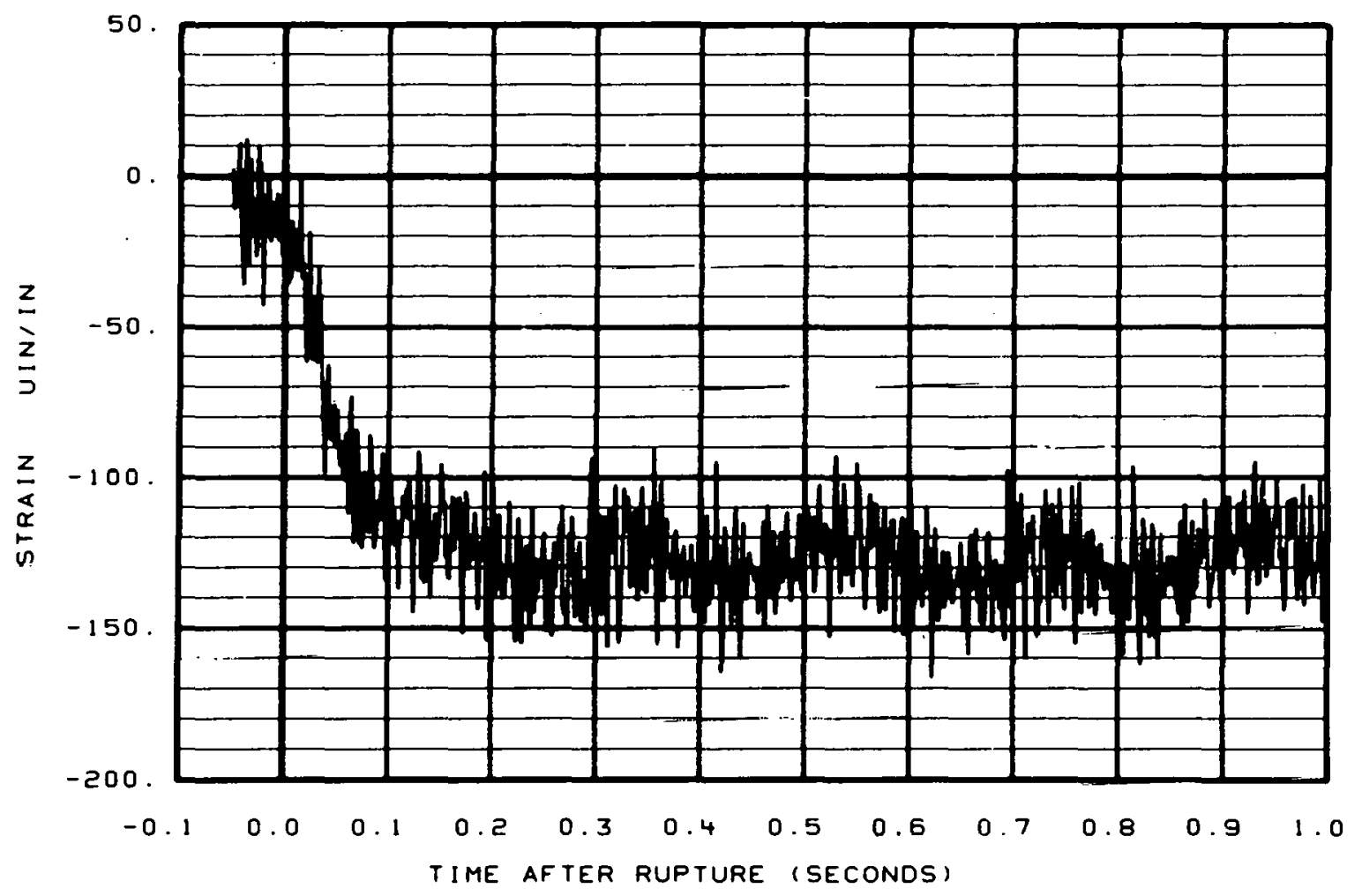

Fig. 171 Strain at primary coolant pump out.let. (SE-PC18-21). 
VI. REFERENCES

1. T. K. Samue1s, Conformed Copy of LOFT Experiment Operating Specification, Volume 2, Nonnuclear Test Series Ll Experiment 2, NNE Ll-2, Revision 1 (June 1976).

2. T. K. Samuels, Conformed Copy of LOFT Experiment Operating Specification, Volume 2, Nonnuclear Test Series LI. Experiment 3 and $3 A$, Aerojet Nuclear Cuimpany, EOS Volume 2, NNE LI-3 and $-3 A$, Revision 2 (September 1976).

3. H. C. Robinson, Experiment Datu Report for LOFT Nonnuclear. Test L1-2, TREE-NUREG-1026 (January 1977).

4. G. M. Millar, Experiment Data Report for LOFT Nonnuclear Test $L T-3$, TREE-NUREG-1065 (Apri1 1977).

5. G. M. Millar, Experiment Data Report for LOFT Nonnuclear Test L]-3A, TREE-NUREG-10?7 (December 1976).

6. H. C. Robinson, LOFT system and Test Description (!nss-of-Coolant Expertmenls Using a Core Simulator), IREE-NUREG-1019 (November 1976).

7. G. L. Biladeau et al, LOFT Experimental Measurements Uncertainty Analysis, Aerojet Nuclear Company, LTR 141-39, REG-76-560 (September 1975). 
DISTRIBUTION RECORD FOR TREE-NUREG-1136

Internal Distribution

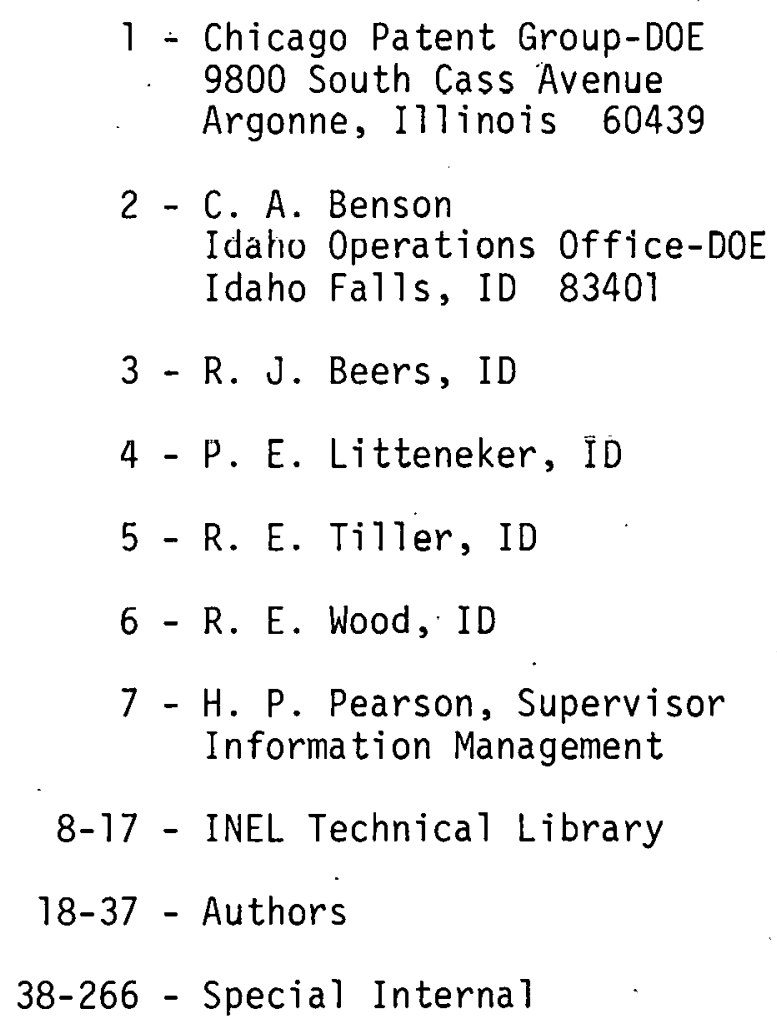

External Distribution

267-268 - Saul Levine, Director Office of Nuclear Regulatory Research, NRC Washington, D. C. 20555

269-315 - Special External

316-619 - Distribuiton under NRC-2, Water Reactor Safety Research Sys tems Engineering 